EDMILSON RENATO DE CASTRO

CONTRIBUIÇÃO AO DESENVOLVIMENTO DA REDUÇÃO CARBOTÉRMICA DE ÓXIDOS METÁLICOS EMPREGANDO ENERGIA DE MICROONDAS 
EDMILSON RENATO DE CASTRO

\section{CONTRIBUIÇÃO AO DESENVOLVIMENTO DA REDUÇÃO CARBOTÉRMICA DE ÓXIDOS METÁLICOS EMPREGANDO ENERGIA DE MICROONDAS}

Dissertação apresentada à Escola Politécnica da Universidade de São Paulo para obtenção do título de Mestre em Engenharia

Área de Concentração:

Engenharia Metalúrgica e de Materiais

Orientador: Prof. Dr. Marcelo Breda Mourão 


\section{DEDICATÓRIA}

Aos meus pais (in memorian) pelo empenho e incentivo em meus estudos. 


\section{AGRADECIMENTOS}

Agradeço ao Instituto Mauá de Tecnologia e a Escola Politécnica da Universidade de São Paulo, por propiciar condições para a realização deste trabalho.

Agradeço a FAPESP, pelo apoio e ajuda financeira.

Agradeço ao professor Dr. Marcelo Breda Mourão, pela sua relevante contribuição na orientação da elaboração desta dissertação.

Agradeço aos professores Dr. José Thomaz Senise e Dr. Luiz Alberto Jermolovicius, pela sabedoria, amizade e confiança, essenciais para a realização deste trabalho.

Agradeço aos funcionários do laboratório de microondas do Instituto Mauá de Tecnologia, Renata Borges do Nascimento, Luis Fernando Baccan, Lauro Ferreira, Luciano de Souza e Patrícia Azzi pelo suporte sempre eficiente.

Agradeço as bibliotecárias do Instituto Mauá de Tecnologia pela ajuda na realização das pesquisas em especial a Cleide Maria Maeda Hirata e Durcelina Francisco de Araújo.

Agradeço também aos bibliotecários da Universidade de São Paulo Departamento de Metalurgia e Materiais.

Agradeço a minha esposa Samantha Adamian Leal pelo incentivo e compreensão.

Agradeço a Deus pela minha saúde. 


\section{RESUMO}

O presente trabalho apresenta um equipamento para o processamento de reduções carbotérmicas sob campo de micro-ondas, permitindo pleno controle da potência fornecida e da medida da energia de micro-ondas efetivamente aplicada à carga em processo de redução podendo assim realizar balanços de energia e determinação de taxa de reação com altos níveis de confiança. O equipamento permite, sobretudo, a medida simultânea de temperatura e de massa do material sob redução, e a fácil reprodutibilidade das condições de ensaio.

O protótipo opera com um gerador de micro-ondas de $2.45 \mathrm{GHz}$ e potência variável até $3000 \mathrm{~W}$. A amostra é mantida sob atmosfera de argônio. Nos testes operacionais do protótipo procedeu-se à redução carbotérmica de minério de ferro de Carajás, utilizando coque de petróleo como redutor através de pelotas esféricas com massa de $3,5 \mathrm{~g}$ e diâmetro de $15 \mathrm{~mm}$. Obtiveram-se curvas cinéticas de redução de minério de ferro e de consumo de energia durante o processo. Os dados colhidos com este protótipo permitiram realizar uma análise da energia de micro-ondas efetivamente consumida na redução do minério.

Palavras-chave: Redução carbotérmica. Micro-ondas. Minério de ferro. 
This work presents of a device for microwave enhanced carbothermic reductions which permits the full control of microwave power irradiated, the measurement of effectively applied microwave power to the charge in process thus performing a high confidence determination of rate of reaction and energy balance. In particular, the simultaneous records of its temperature and mass loss, and good reproducibility of operation parameters, are obtainable.

This prototype works with a $2.45 \mathrm{GHz}$ microwave generator with variable power up to $3000 \mathrm{~W}$. Samples are processes under argon gas atmosphere. Operational tests for Carajás iron ore reduction with petroleum coke were performed using spherical pellets with weight of $3,5 \mathrm{~g}$ and diameter of $15 \mathrm{~mm}$. Kinetic curves of iron ore reduction and effective consumption of microwave power curves were determined. These results made possible to perform an analysis of actual energy consumption for enhanced microwave iron ore carbothermic reduction.

Key words: Carbothermic reduction. Microwaves. Iron ore. 


\section{LISTA DE FIGURAS}

Figura 1- Localização da região de micro-ondas no espectro eletromagnético ${ }^{21}$

Figura 2 - Ilustração de uma onda eletromagnética polarizada propagando-se num plano perpendicular a esta folha ( $\lambda=$ comprimento de onda, $E=$ campo elétrico, $H=$ campo magnético e $C=$ velocidade da luz ${ }^{22}$ 28

Figura 3 - Componentes de geração de micro-ondas 1) Potência de $60 \mathrm{~Hz}$ (corrente alternada); 2) Fonte de corrente contínua; 3) Gerador de micro-ondas; 4) Ondas eletromagnéticas; 5) Aplicador; 6) Sistema de controle de potência de micro-ondas 30

Figura 4 - Magnetron para aquecimento em processos industriais ${ }^{25}$. 31

Figura 5 - Interação das micro-ondas com os materiais ${ }^{26,27}$. 32

Figura 6 - Rotação do dipolo devido a mudança de campo elétrico ${ }^{29}$ 33

Figura 7 - Indução do campo eletromagnético em moléculas de água ${ }^{30}$.......... 33 Figura 8 - Comparação do comportamento da sinterização do molibdênio em forno convencional e em forno de micro-ondas ambos a $1400^{\circ} \mathrm{C}^{37}$ 39

Figura 9 - Comparação da taxa de aquecimento para o ferro puro compactado nos campos de micro-ondas magnético e elétrico ${ }^{40}$

Figura 10 - Comparação da redução carbotérmica convencional e por microondas $^{54}$

Figura 11 - Efeito do método de aquecimento na redução da magnetita ${ }^{17} \ldots . . .46$ Figura 12 - Representação esquemática da posição no interior de uma cavidade doméstica aonde possui maior densidade energética incidida no cadinho com amostra ${ }^{47}$

Figura 13 - Taxa de redução versus tempo para processamento com microondas a $800 \mathrm{~W}$, e aquecimento convencional a $1100^{\circ} \mathrm{C}^{47}$

Figura 14 - Ilustração esquemática de um forno de micro-ondas com cavidade doméstica ${ }^{48}$

Figura 15 - llustração esquemática de um forno de micro-ondas com cavidade doméstica ${ }^{49}$ 50

Figura 16 - llustração esquemática de um forno de micro-ondas com cavidade pentagonal ${ }^{50}$ 
Figura 17 - Efeito do nível de potência de micro-ondas na redução do óxido de zinco ${ }^{51}$

Figura 18 - Taxa de redução vs tempo de radiação de micro-ondas (redução em forno elétrico a $\left.1100^{\circ} \mathrm{C}\right)^{51}$

Figura 19 - Porcentagem de reação em função do tempo e tipo de pelota quando as pelotas são submetidas ao aquecimento por micro-ondas ${ }^{16,46} \ldots \ldots .54$ Figura 20 - Mudança de concentração dos metais zinco e chumbo com $1000 \mathrm{~W}$ de energia de micro-ondas ${ }^{52}$ 55

Figura 21 - llustração esquemática de um forno de micro-ondas com cavidade doméstica para recuperação de zinco e ferro metálico de resíduo do forno elétrico a $\operatorname{arco}^{53}$

Figura 22 - a) Pelota sem isolação térmica; b) pelota isolada termicamente; c) pelota no interior do cadinho de carbeto de silício 59

Figura 23 - Dimensões ( $\mathrm{mm}$ ) do a) tarugo de fibra cerâmica; b) do cadinho de fibra cerâmica e/ou carbeto de silício; c) do eixo de teflon 59

Figura 24 - Forno para redução carbotérmica e aquecimento de materiais por irradiação de micro-ondas

Figura 25 - Diagrama esquemático do forno para redução carbotérmica e aquecimento de materiais por irradiação de micro-ondas.

Figura 26 - Representação do campo elétrico em um guia retangular em curto 62

Figura 27 - Representação de um guia retangular envolvido por trocador de calor

Figura 28 - Esquema diagramático para aferição das perdas para o sistema. 65 Figura 29 - Misturador tipo $V$ utilizado para a homogeneização da mistura a ser pelotizada. 66

Figura 30 - Posição da pelota respeitando a faixa de movimentação (tracejado vermelho) do eixo da balança semi-analítica no interior da câmara de reação. a) Vista frontal. b) Vista lateral 70

Figura 31 - Esquema do forno de resistência utilizado nos ensaios termogravimétricos.

Figura 32 - llustração do forno de resistência utilizado nos ensaios termogravimétricos. 72

Figura 33 - Pelota após a formação de arco voltaico em sua superfície 83 
Figura 34 - Circulador trincado devido à formação de arco voltaico na pelota 83 Figura 35 - Cadinho de fibra cerâmica fundido............................................. 88 Figura 36 - Vista superior do interior da câmara de reação com o cadinho de carbeto de silício com tampa e sem pelota sob os três níveis de irradiação de micro-ondas

Figura 37 - Pelota sob irradiação a $1500 \mathrm{~W}$ de micro-ondas sem isolação térmica; a) durante o ensaio; b) após o ensaio.

Figura 38 - Pelota reduzida com 1500W de irradiação de micro-ondas com isolação térmica; a) após o ensaio; b) seção transversal 108 Figura 39 - Gota de ferro gusa produzido nos ensaios com cadinho de carbeto de silício a 1000W e 1500W de irradiação de micro-ondas 109 


\section{LISTA DE GRÁFICOS}

Gráfico 1 - Perfil da evolução da energia de micro-ondas absorvida pelo equipamento sem amostra e com cadinho ou tarugo de fibra cerâmica (W) ... 73 Gráfico 2 - Perfil da evolução da energia de micro-ondas absorvida pelo equipamento sem amostra e com cadinho de carbeto de silício (W) 75

Gráfico 3 - Temperatura da superfície do cadinho de SiC em função do tempo de exposição a três níveis de potências às micro-ondas

Gráfico 4 - Taxa de redução em função do tempo de exposição a três níveis de potências às micro-ondas para uma pelota na proporção estequiométrica entre minério de ferro de Carajás e coque de petróleo sem isolação térmica 78 Gráfico 5 - Temperatura da superfície da pelota em função do tempo de exposição a três níveis de potências às micro-ondas para uma pelota na proporção estequiométrica entre minério de ferro de Carajás e coque de petróleo sem isolação térmica 79 Gráfico 6 - Perfil da evolução da energia de micro-ondas refletida (W) na redução carbotérmica de uma pelota sem isolação térmica 79 Gráfico 7 - Perfil da evolução da energia de micro-ondas efetiva (W) na redução carbotérmica de uma pelota sem isolação térmica 80 Gráfico 8 - Taxa de redução em função do tempo de exposição a três níveis de potências às micro-ondas para uma pelota na proporção estequiométrica entre minério de ferro de Carajás e coque de petróleo com isolação térmica 84 Gráfico 9 - Perfil da evolução de energia de micro-ondas refletida (W) na redução carbotérmica de uma pelota com isolação térmica 85 Gráfico 10 - Perfil da evolução da energia de micro-ondas efetiva (W) na redução carbotérmica de uma pelota com isolação térmica 85 Gráfico 11 - Taxa de redução em função do tempo de exposição a três níveis de potências às micro-ondas para uma pelota na proporção estequiométrica entre minério de ferro de Carajás e coque de petróleo em um cadinho de carbeto de silício 89

Gráfico 12 - Perfil da evolução de energia de micro-ondas refletida (W) na redução carbotérmica de uma pelota com cadinho de carbeto de silício 90 
Gráfico 13 - Taxa de redução em função do tempo de exposição a 1000 W de micro-ondas para uma pelota na proporção estequiométrica entre minério de ferro de Carajás e coque de petróleo sem isolação térmica no máximo campo magnético.

Gráfico 14 - Perfil da evolução da energia de micro-ondas refletida (W) na redução carbotérmica de uma pelota sem isolação térmica no máximo campo magnético 92

Gráfico 15 - Perfil da evolução da energia de micro-ondas efetiva (W) na redução carbotérmica de uma pelota sem isolação térmica no máximo campo magnético

Gráfico 16 - Taxa de redução em função do tempo de exposição a $1000 \mathrm{~W}$ de micro-ondas para duas pelotas na proporção estequiométrica entre minério de ferro de Carajás e coque de petróleo com isolação térmica 95 Gráfico 17 - Perfil da evolução da energia de micro-ondas refletida (W) na redução carbotérmica de duas pelotas com isolação térmica 95 Gráfico 18 - Perfil da evolução da energia de micro-ondas efetiva (W) na redução carbotérmica de duas pelotas com isolação térmica 96 Gráfico 19 - Taxa de redução em função do tempo para uma pelota na proporção estequiométrica entre minério de ferro de Carajás e coque de petróleo, a $1150^{\circ} \mathrm{C}$ em forno de resistência elétrica 98 Gráfico 20 - Taxa de redução em função do tempo de exposição a $500 \mathrm{~W}$ de potência irradiada de micro-ondas para uma pelota na proporção estequiométrica entre minério de ferro de Carajás e coque de petróleo 99 Gráfico 21 - Taxa de redução em função do tempo de exposição a $1000 \mathrm{~W}$ de potência irradiada de micro-ondas para uma pelota na proporção estequiométrica entre minério de ferro de Carajás e coque de petróleo ........ 100 Gráfico 22 - Taxa de redução em função do tempo de exposição a $1500 \mathrm{~W}$ de potência irradiada de micro-ondas para uma pelota na proporção estequiométrica entre minério de ferro de Carajás e coque de petróleo 101 Gráfico 23 - Taxa de redução em função do tempo de exposição a 1000 W de potência irradiada de micro-ondas no máximo campo elétrico e no máximo campo magnético para uma pelota na proporção estequiométrica entre minério de ferro de Carajás e coque de petróleo 102 
Gráfico 24 - Perfil da evolução da energia de micro-ondas refletida (W) em função do tempo de exposição a $1000 \mathrm{~W}$ de potência de micro-ondas no máximo campo elétrico e no máximo campo magnético na redução carbotérmica de uma pelota sem isolação térmica 103 Gráfico 25 - Taxa de redução em função do tempo de exposição a $1000 \mathrm{~W}$ de potência irradiada de micro-ondas no máximo campo elétrico para uma e duas pelotas na proporção estequiométrica entre minério de ferro de Carajás e coque de petróleo. 104

Gráfico 26 - Perfil da evolução da energia de micro-ondas refletida (W) em função do tempo de exposição a $1000 \mathrm{~W}$ de potência de micro-ondas no máximo campo elétrico na redução carbotérmica de uma e duas pelotas com isolação térmica 105 Gráfico 27 - Relação watts/grama em função do tempo de exposição a $1000 \mathrm{~W}$ de potência irradiada de micro-ondas no máximo campo elétrico para uma e duas pelotas na proporção estequiométrica entre minério de ferro de Carajás e coque de petróleo. 105

Gráfico 28 - Comparação de resultados de taxa de reação de uma pelota em função do tempo obtidos com aquecimento por micro-ondas e com forno de resistência elétrica 


\section{LISTA DE TABELAS}

Tabela 1 - Constante dielétrica $\left(\varepsilon^{\prime}\right)$, fator de perdas dielétrica $\left(\varepsilon^{\prime \prime}\right)$ e fator de dissipação de algumas substâncias $\left(25^{\circ} \mathrm{C} \text { e } 3 \mathrm{GHz}\right)^{34}$ 34

Tabela 2 - Composição química do minério de ferro de Carajás (\% em peso). 57 Tabela 3 - Análise granulométrica do minério de ferro de Carajás. 57

Tabela 4 - Análise imediata do coque de petróleo (\% em peso)...................... 58

Tabela 5 - Propriedades típicas do hidroxietil celulose. 58

Tabela 6 - Energia média de micro-ondas irradiada, refletida e absorvida pelo equipamento sem amostra e com a presença do tarugo ou cadinho de fibra cerâmica.

Tabela 7 - Balanço de energia absorvida pelo equipamento sem amostra e com a presença do tarugo ou cadinho de fibra cerâmica

Tabela 8 - Energia média de micro-ondas irradiada, refletida e absorvida pelo equipamento sem amostra e com a presença do cadinho de carbeto de silício

Tabela 9 - Balanço de energia absorvida pelo equipamento sem amostra e com a presença do cadinho de carbeto de silício.

Tabela 10 - Balanço de energia para ensaios de redução carbotérmica com 500 $W$ de energia de micro-ondas irradiada em uma pelota sem isolação térmica 81 Tabela 11 - Balanço de energia para ensaios de redução carbotérmica com $1000 \mathrm{~W}$ de energia de micro-ondas irradiada em uma pelota sem isolação térmica

Tabela 12 - Balanço de energia para ensaios de redução carbotérmica com $1500 \mathrm{~W}$ de energia de micro-ondas irradiada em uma pelota sem isolação térmica 82

Tabela 13 - Balanço de energia para ensaios de redução carbotérmica com 500 $W$ de energia de micro-ondas irradiada em uma pelota com isolação térmica 86 Tabela 14 - Balanço de energia para ensaios de redução carbotérmica com $1000 \mathrm{~W}$ de energia de micro-ondas irradiada em uma pelota com isolação térmica 
Tabela 15 - Balanço de energia para ensaios de redução carbotérmica com $1500 \mathrm{~W}$ de energia de micro-ondas irradiada em uma pelota com isolação térmica

Tabela 16 - Balanço de energia para ensaios de redução carbotérmica com $1000 \mathrm{~W}$ de energia de micro-ondas no máximo campo magnético irradiada em uma pelota sem isolação térmica 94

Tabela 17 - Balanço de energia para ensaios de redução carbotérmica com $1000 \mathrm{~W}$ de energia de micro-ondas no máximo campo elétrico irradiada em duas pelotas com isolação térmica

Tabela 18 - Relação watts/grama (W/g) para ensaios de redução carbotérmica com $1000 \mathrm{~W}$ de energia de micro-ondas irradiada em uma e duas pelotas com isolação térmica 106 Tabela 19 - Calor absorvido pelos trocadores de calor 1 e 2 com $500 \mathrm{~W}$ de energia de micro-ondas irradiada após o período de estabilização térmica sem pelota e com cadinho ou tarugo de fibra cerâmica 119 Tabela 20 - Calor absorvido pelos trocadores de calor 1 e 2 com $1000 \mathrm{~W}$ de energia de micro-ondas irradiada após o período de estabilização térmica sem pelota e com cadinho ou tarugo de fibra cerâmica 120 Tabela 21 - Calor absorvido pelos trocadores de calor 1 e 2 com $1500 \mathrm{~W}$ de energia de micro-ondas irradiada após o período de estabilização térmica sem pelota e com cadinho ou tarugo de fibra cerâmica........................................ 120 Tabela 22 - Calor absorvido pelo argônio com 500 W de energia de microondas irradiada após o período de estabilização térmica sem pelota e com cadinho ou tarugo de fibra cerâmica

Tabela 23 - Calor absorvido pelo argônio com 1000 W de energia de microondas irradiada após o período de estabilização térmica sem pelota e com cadinho ou tarugo de fibra cerâmica 121

Tabela 24 - Calor absorvido pelo argônio com 1500 W de energia de microondas irradiada após o período de estabilização térmica sem pelota e com cadinho ou tarugo de fibra cerâmica 122 Tabela 25 - Calor absorvido pela câmara de reação com $500 \mathrm{~W}$ de energia de micro-ondas irradiada após o período de estabilização térmica sem pelota e com cadinho ou tarugo de fibra cerâmica 122 
Tabela 26 - Calor absorvido pela câmara de reação com 1000 W de energia de micro-ondas irradiada após o período de estabilização térmica sem pelota e com cadinho ou tarugo de fibra cerâmica

Tabela 27 - Calor absorvido pela câmara de reação com 1500 W de energia de micro-ondas irradiada após o período de estabilização térmica sem pelota e com cadinho ou tarugo de fibra cerâmica 123

Tabela 28 - Calor absorvido pelo circulador com $500 \mathrm{~W}$ de energia de microondas irradiada após o período de estabilização térmica sem pelota e com cadinho ou tarugo de fibra cerâmica

Tabela 29 - Calor absorvido pelo circulador com $1000 \mathrm{~W}$ de energia de microondas irradiada após o período de estabilização térmica sem pelota e com cadinho ou tarugo de fibra cerâmica

Tabela 30 - Calor absorvido pelo circulador com 1500 W de energia de microondas irradiada após o período de estabilização térmica sem pelota e com cadinho ou tarugo de fibra cerâmica

Tabela 31 - Calor absorvido pelo cadinho ou tarugo de isolante cerâmico com $500 \mathrm{~W}$ de energia de micro-ondas irradiada após o período de estabilização térmica sem pelota.

Tabela 32 - Calor absorvido pelo cadinho ou tarugo de isolante cerâmico com $1000 \mathrm{~W}$ de energia de micro-ondas irradiada após o período de estabilização térmica sem pelota

Tabela 33 - Calor absorvido pelo cadinho ou tarugo de isolante cerâmico com $1500 \mathrm{~W}$ de energia de micro-ondas irradiada após o período de estabilização térmica sem pelota.

Tabela 34 - Calor absorvido pelos trocadores de calor 1 e 2 com 500 W de energia de micro-ondas irradiada após o período de estabilização térmica sem pelota e com o cadinho de carbeto de silício. 127

Tabela 35 - Calor absorvido pelos trocadores de calor 1 e 2 com 1000 W de energia de micro-ondas irradiada após o período de estabilização térmica sem pelota e com o cadinho de carbeto de silício

Tabela 36 - Calor absorvido pelos trocadores de calor 1 e 2 com 1500 W de energia de micro-ondas irradiada após o período de estabilização térmica sem pelota e com o cadinho de carbeto de silício. 128 
Tabela 37 - Calor absorvido pelo argônio com 500 W de energia de microondas irradiada após o período de estabilização térmica sem pelota e com 0 cadinho de carbeto de silício

Tabela 38 - Calor absorvido pelo argônio com 1000 W de energia de microondas irradiada após o período de estabilização térmica sem pelota e com o cadinho de carbeto de silício

Tabela 39 - Calor absorvido pelo argônio com 1500 W de energia de microondas irradiada após o período de estabilização térmica sem pelota e com 0 cadinho de carbeto de silício

Tabela 40 - Calor absorvido pela câmara de reação com $500 \mathrm{~W}$ de energia de micro-ondas irradiada após o período de estabilização térmica sem pelota e com o cadinho de carbeto de silício

Tabela 41 - Calor absorvido pela câmara de reação com 1000 W de energia de micro-ondas irradiada após o período de estabilização térmica sem pelota e com o cadinho de carbeto de silício 130

Tabela 42 - Calor absorvido pela câmara de reação com 1500 W de energia de micro-ondas irradiada após o período de estabilização térmica sem pelota e com o cadinho de carbeto de silício

Tabela 43 - Calor absorvido pelo circulador com 500 W de energia de microondas irradiada após o período de estabilização térmica sem pelota e com o cadinho de carbeto de silício 132

Tabela 44 - Calor absorvido pelo circulador com 1000 W de energia de microondas irradiada após o período de estabilização térmica sem pelota e com 0 cadinho de carbeto de silício

Tabela 45 - Calor absorvido pelo circulador com $1500 \mathrm{~W}$ de energia de microondas irradiada após o período de estabilização térmica sem pelota e com 0 cadinho de carbeto de silício 132

Tabela 46 - Calores de formação 134

Tabela 47 - Capacidade térmica 134

Tabela 48 - Entalpias de transformação. 134 


\section{LISTA DE ABREVIATURAS E SIGLAS}

$\begin{array}{ll}\text { DC } & \text { Fonte de corrente contínua } \\ \text { UIT } & \text { União Internacional de Telecomunicações } \\ \text { ISM } & \text { Industrial, scientific and medical } \\ \text { TE }_{103} & \text { Transverse electric mode } \\ \text { RDF } & \text { Refuse Derived Fuel } \\ \text { XRD } & \text { X-ray diffractometer } \\ \text { ABNT } & \text { Associação Brasileira de Normas Técnicas } \\ \text { ASTM } & \text { American Society for Testing Materials } \\ \text { isol } & \text { Isolante }\end{array}$




\section{LISTA DE SIMBOLOS}

\begin{tabular}{|c|c|}
\hline E & Campo elétrico \\
\hline$H$ & Campo magnético \\
\hline$\lambda$ & Comprimento de onda \\
\hline$C$ & Velocidade da luz \\
\hline$f$ & Freqüência \\
\hline$v$ & Velocidade da onda \\
\hline$h$ & Constante de Plank \\
\hline$\varepsilon^{\prime}$ & Constante dielétrica \\
\hline$\varepsilon_{r}^{\prime}$ & Constante dielétrica relativa \\
\hline$\varepsilon_{0}$ & Constante dielétrica do vácuo \\
\hline$\varepsilon^{\prime \prime}$ & Fator ou constante de perdas \\
\hline$\varepsilon_{r}^{\prime \prime}$ & Fator de perdas relativas \\
\hline$\varepsilon_{e f}^{\prime \prime}$ & Perdas efetivas \\
\hline $\tan \delta$ & Tangente de perdas \\
\hline$P v$ & Potência dissipada por unidade de volume \\
\hline$E_{(Z)}$ & Campo elétrico no interior do material, à distância $Z$ da superfície \\
\hline$E_{0}$ & $\begin{array}{l}\text { Intensidade do campo elétrico num ponto na superfície do } \\
\text { material }\end{array}$ \\
\hline$\alpha$ & Constante de atenuação \\
\hline$\rho$ & Massa específica \\
\hline$C p$ & Calor específico \\
\hline$d$ & Profundidade de penetração \\
\hline$E_{\operatorname{máx}}$ & Campo elétrico máximo \\
\hline$E_{\text {equip }}$ & $\begin{array}{l}\text { Energia de micro-ondas absorvida pelo equipamento durante } \\
\text { ensaio com o equipamento sem amostra }\end{array}$ \\
\hline$E_{i r r s a}$ & $\begin{array}{l}\text { Energia de micro-ondas irradiada durante ensaio com o } \\
\text { equipamento sem amostra }\end{array}$ \\
\hline$E_{\text {refssa }}$ & $\begin{array}{l}\text { Energia de micro-ondas refletida durante ensaio com o } \\
\text { equipamento sem amostra }\end{array}$ \\
\hline
\end{tabular}




$\begin{array}{ll}E_{r e f l} & \text { Energia de micro-ondas refletida pelo equipamento durante o } \\ & \text { processo de redução carbotérmica } \\ E_{i r r} & \text { Energia de micro-ondas irradiada durante o processo de redução } \\ & \text { carbotérmica } \\ E_{e f} & \text { Energia de micro-ondas efetivamente utilizada no processo de } \\ E_{p p r} & \text { redução carbotérmica } \\ \text { C } & \text { Energia de micro-ondas perdida por radiação térmica da pelota } \\ \text { TC } & \text { Circulador } \\ \mathrm{T} & \text { Trocador de calor } \\ T R & \text { Temperatura } \\ M & \text { Taxa de redução } \\ M M_{i} & \text { Porcentagem máxima de perda de peso } \\ M M_{t} & \text { Peso inicial da amostra } \\ \Delta H & \text { Peso no instante } t \\ Q & \text { Entalpia de reação }\end{array}$




\section{SUMÁRIO}

RESUMO

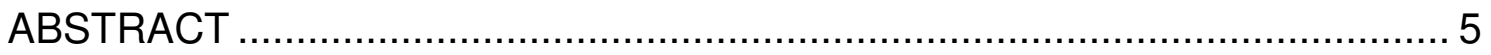

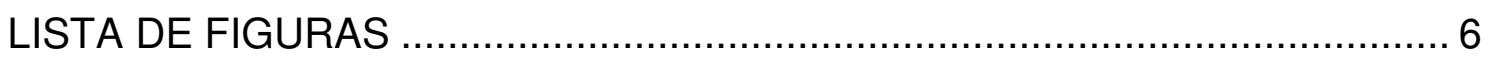

LISTA DE GRÁFICOS................................................................... 9

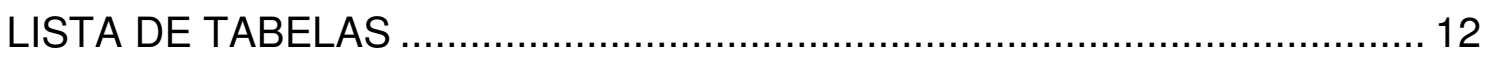

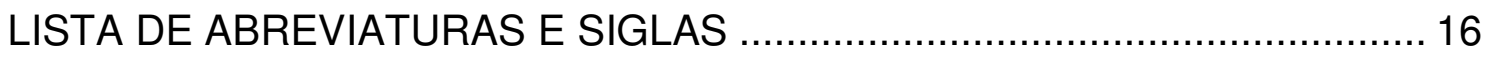

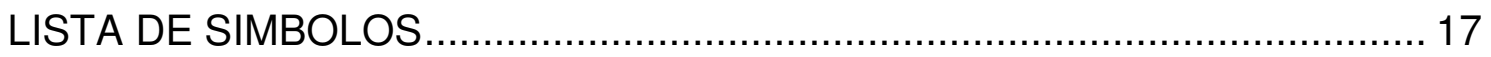

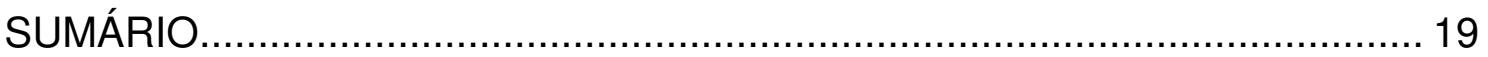

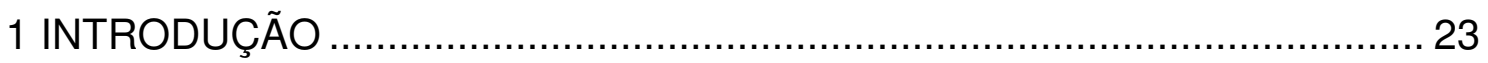

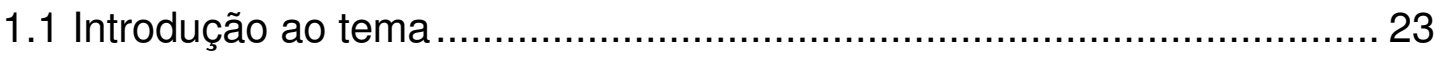

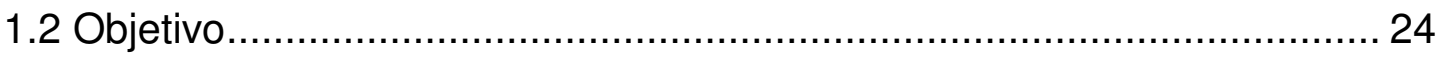

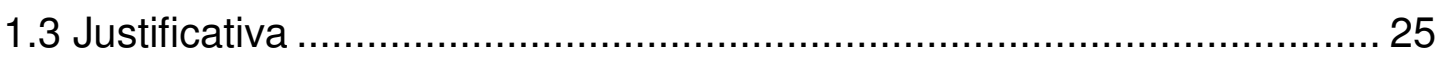

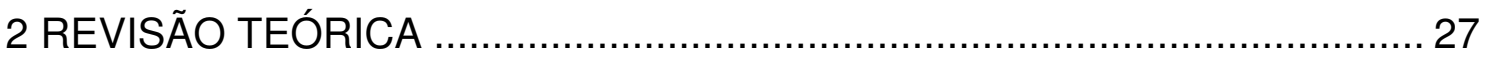

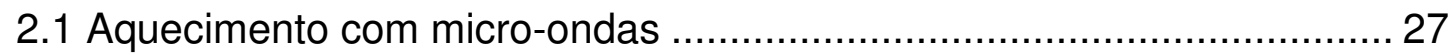

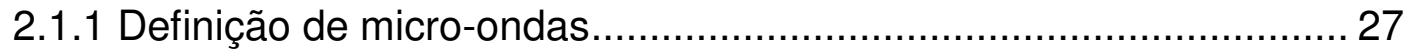

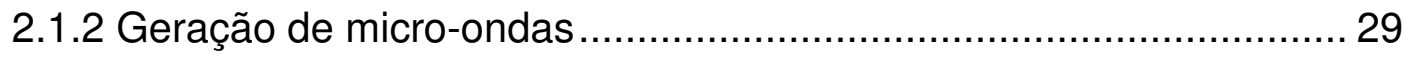

2.1.3 Interação da energia de micro-ondas com os materiais .................... 31

2.1.4 Quantificação da energia de micro-ondas..................................... 34

2.2 Aplicação das micro-ondas em engenharia metalúrgica e materiais ...... 37

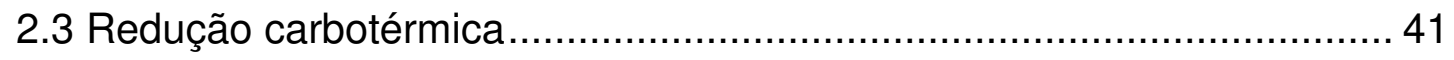

2.4 Redução carbotérmica com micro-ondas …………........................... 43

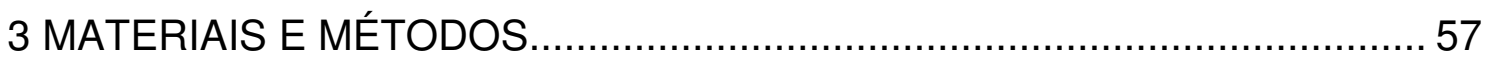

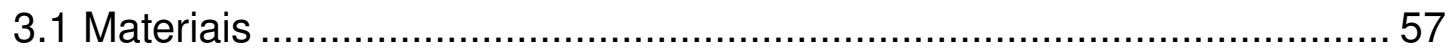

3.1.1 Material a ser reduzido por micro-ondas ............................... 57

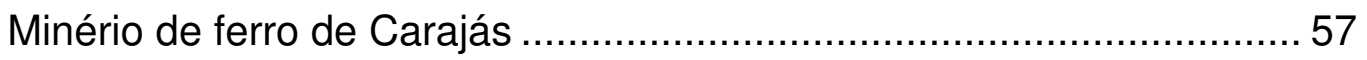

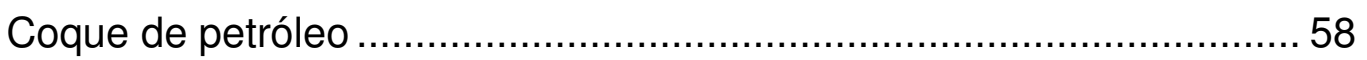

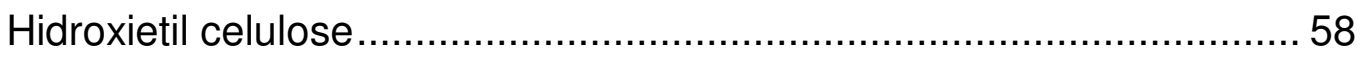

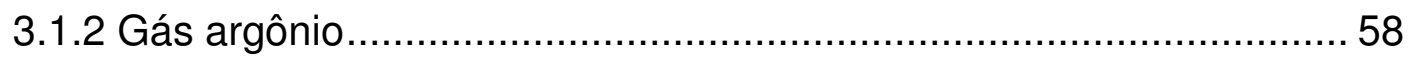

3.1.3 Base cerâmica/eixo de teflon e cadinho cerâmica/eixo de teflon ..... 58

3.2 Forno de redução carbotérmica de óxidos metálicos com aquecimento

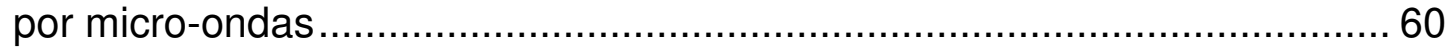

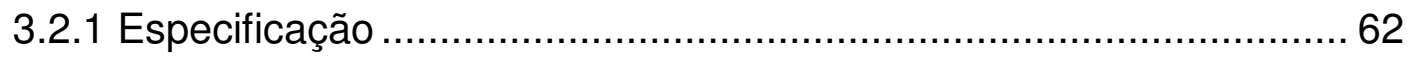

3.2.2 Determinação das perdas de energia para o equipamento sem amostra 
3.2.3 Teste de uso do forno para redução carbotérmica de óxidos metálicos.

3.2.3.1 Pelotização

3.2.3.2 Procedimento operacional para redução carbotérmica de óxidos metálicos com e sem isolação e com cadinho de carbeto de silício

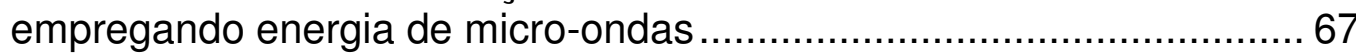

3.2.3.2.1 Ensaios com uma pelota no máximo campo elétrico ........... 67

3.2.3.2.2 Ensaios com uma pelota no máximo campo magnético ..... 70

3.2.3.2.3 Ensaios com duas pelotas no máximo campo elétrico......... 70

3.3 Forno de redução carbotérmica de óxidos metálicos com aquecimento

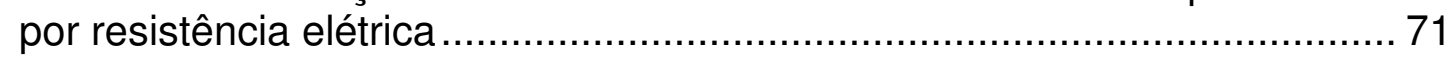

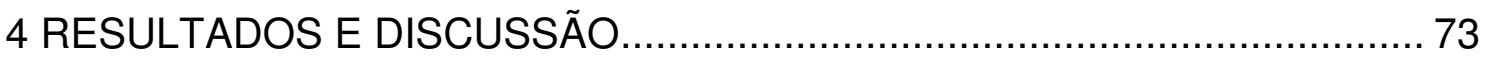

4.1 Quantificação da energia absorvida pelo equipamento sem amostra .... 73

4.1.1 Com tarugo ou cadinho de fibra cerâmica...................................... 73

4.1.2 Com cadinho de carbeto de silício ............................................. 75

4.2 Redução carbotérmica com micro-ondas ............................................... 77

4.2.1 Ensaios com uma pelota no máximo campo elétrico ....................... 77

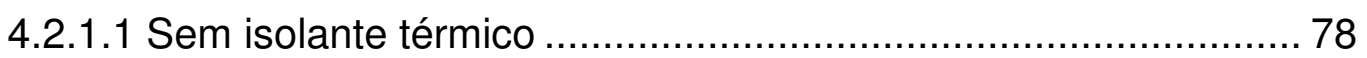

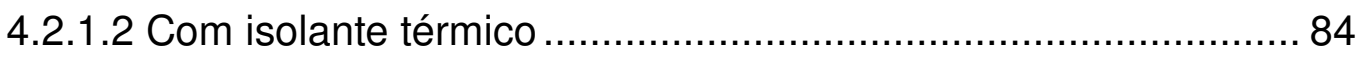

4.2.1.3 Com cadinho de carbeto de silício ........................................... 88

4.2.2 Ensaios com uma pelota no máximo campo magnético .................. 91

4.2.3 Ensaios com duas pelotas no máximo campo elétrico ...................... 94

4.3 Redução carbotérmica em forno de resistência elétrica ......................... 97

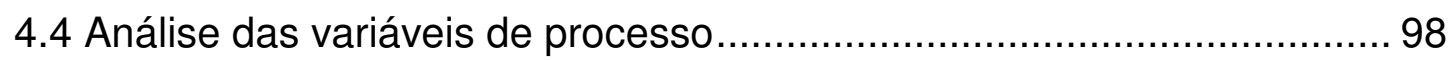

4.4.1 Influência na taxa de redução variando os níveis de energia de microondas irradiadas na pelota no máximo campo elétrico .............................. 98

4.4.2 Influência do máximo campo elétrico comparado com o máximo

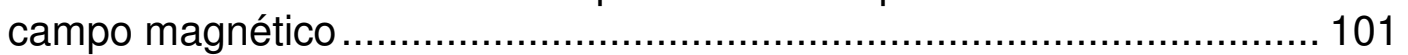

4.4.3 Influência da variação da quantidade de pelotas .......................... 103

4.5 Comparação dos resultados entre aquecimento convencional e por micro-ondas.

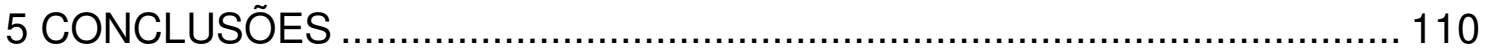

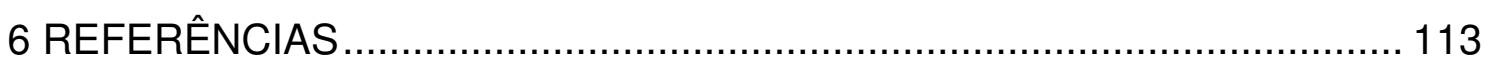

APÊNDICE A - Memorial de cálculo para as perdas para o equipamento após o período de estabilização térmica sem pelota e com cadinho ou tarugo de fibra cerâmica.

APÊNDICE B - Memorial de cálculo para perdas para o equipamento após o período de estabilização térmica sem pelota e com cadinho de carbeto de silício 
APÊNDICE C - Determinação do máximo campo elétrico ou do máximo campo magnético no interior da câmara de reação.

ANEXO A - Balanço térmico para aquecer até $1000^{\circ} \mathrm{C}$ e reduzir uma pelota de $3,5 \mathrm{~g} \mathrm{com} 80,1 \%$ de $\mathrm{Fe}_{2} \mathrm{O}_{3}$ e $19,9 \%$ de redutor 134 


\section{INTRODUÇÃO}

\subsection{Introdução ao tema}

Diversas aplicações da tecnologia de micro-ondas têm sido experimentadas em várias áreas, como no processamento de alimentos, de materiais, de produtos químicos e metalúrgicos ${ }^{1-3}$.

A utilização das micro-ondas em processos metalúrgicos tem gerado uma grande quantidade de pesquisas ${ }^{4-15}$. Porém, o uso da energia de microondas na redução carbotérmica é o que tem atraído os pesquisadores pelo mundo. Muitos trabalhos focaram na comparação entre a taxa de redução de óxidos metálicos através dos processos convencionais e com micro-ondas ${ }^{16-20}$, em especial os benefícios de um tempo de processamento menor.

As características do uso da energia de micro-ondas são as seguintes:

1) $O$ aquecimento por micro-ondas é fundamentalmente diferente dos métodos de aquecimento convencionais, nos quais transporte de calor como condução, convecção e radiação, pois a energia de micro-ondas rapidamente penetra e deposita-se dentro do material, devido à absorção ocorrer a nível molecular e atômico. Deste modo, não há dependência da condutividade térmica para transportar calor da superfície para o interior da amostra. Também, a temperatura no interior da amostra é maior que a temperatura na superfície, resultando em um gradiente de temperatura invertido comparado com o aquecimento convencional. Isto pode resultar em taxas de aquecimento muito maiores para materiais com baixa condutividade térmica.

2) Um aquecimento seletivo de componentes individuais em uma mistura pode ser alcançado sob algumas condições, desde que diferentes minerais tenham diferentes características de absorção da energia de micro-ondas. Em alguns minérios, o aquecimento seletivo dos minerais presentes nos minérios pode conduzir ao estresse térmico, o qual proporciona a fratura das partículas deste minério. 
3) Como a energia de micro-ondas é gerada a partir de energia elétrica, a fonte de energia é relativamente limpa. Micro-ondas não geram gases de combustão, ficando é claro, apenas os gases gerados através das reações entre os materiais que estão sendo processados sob o campo de micro-ondas para serem tratados. Deste modo, o meio ambiente é preservado.

O estado da arte mostra que os equipamentos utilizados para estudos de reduções carbotérmicas são basicamente fornos de micro-ondas domésticos adaptados para este propósito. Esta improvisação foi boa em trabalhos exploratórios, ou seja, com o objetivo de descobrir novas tendências e provar a possibilidade do uso das micro-ondas na redução de óxidos metálicos. Nos dias atuais, uma maior precisão de dados coletados, como por exemplo, a efetiva potência absorvida pelos materiais reagentes, a diminuição real da massa durante o tempo de redução não são possíveis de se obter através de um forno doméstico adaptado. Com o intuito de auxiliar no entendimento da redução carbotérmica de óxidos metálicos com energia de micro-ondas foi desenvolvido um equipamento ora descrito. Este equipamento possibilita obter curvas de redução carbotérmica de óxidos metálicos em níveis de potência variáveis bem como a efetiva energia necessária para promover a reação. $O$ equipamento também possibilita obter curvas de aquecimento de materiais puros com o tempo.

\subsection{Objetivo}

Estudar redução carbotérmica de óxidos metálicos promovida por energia de micro-ondas em equipamento projetado de modo a determinar quantitativamente parâmetros do processo. 


\subsection{Justificativa}

O estado da arte reporta muitos experimentos de redução carbotérmica de óxidos metálicos por micro-ondas, nos quais se utilizam cavidades multimodais para a aplicação de micro-ondas, mais especificamente forno doméstico (uma caixa paralelepipedal) e/ou fornos constituídos por uma caixa com perfil pentagonal ${ }^{20}$.

Apesar de sua relevância, esses experimentos geralmente apresentam limitações que decorrem do próprio tipo de forno utilizado a saber:

a) Não há como medir a potência transmitida do gerador (magnetron) para o interior da cavidade do forno nem a potência refletida de volta. A potência efetivamente aplicada na amostra de material irradiada é dada pela diferença entre as duas, menos as perdas nas paredes do próprio forno. Em outras palavras, não há como determinar a energia específica $(\mathrm{J} / \mathrm{kg})$ consumida para obter o efeito observado na amostra, dado esse essencial para o cálculo da eficiência do processo e para um possível aumento de escala.

b) Não possuem homogeneidade na distribuição do campo de microondas em seu interior, conseqüentemente apresentando regiões com maiores e menores densidades de energia, fato que justifica a muito relatada busca de um local de concentração energética ótima. Esta busca, no entanto, é infrutífera, pois pequenas alterações físicas do sistema ocasionam grandes alterações da distribuição do campo eletromagnético. Conseqüentemente a reprodutibilidade das reduções carbotérmicas incentivadas por micro-ondas é baixa.

c) Um recurso raramente utilizado é a adaptação de uma balança ao forno, podendo acompanhar de maneira contínua a variação da massa da amostra durante o aquecimento.

Visando a melhoria deste tipo de experimento iniciou-se 0 trabalho descrito nesta dissertação. O objetivo é alcançar alta reprodutibilidade nos experimentos de redução carbotérmica de óxidos metálicos incentivada por micro-ondas. 
Na engenharia de micro-ondas, a configuração da parte eletrônica dada ao forno descrito neste trabalho é comum e faz parte de catálogos industriais de fabricantes de equipamentos para micro-ondas. Entretanto, não foi localizada a aplicação desta configuração na área de engenharia metalúrgica. 


\section{REVISÃO TEÓRICA}

\subsection{Aquecimento com micro-ondas}

\subsubsection{Definição de micro-ondas}

Micro-ondas são radiações eletromagnéticas que têm uma faixa de freqüência no espectro de energia de 0,3 a $300 \mathrm{GHz}$, com o correspondente intervalo de comprimento de onda de $1 \mathrm{~m}$ a $1 \mathrm{~mm}$ conforme figura 1.

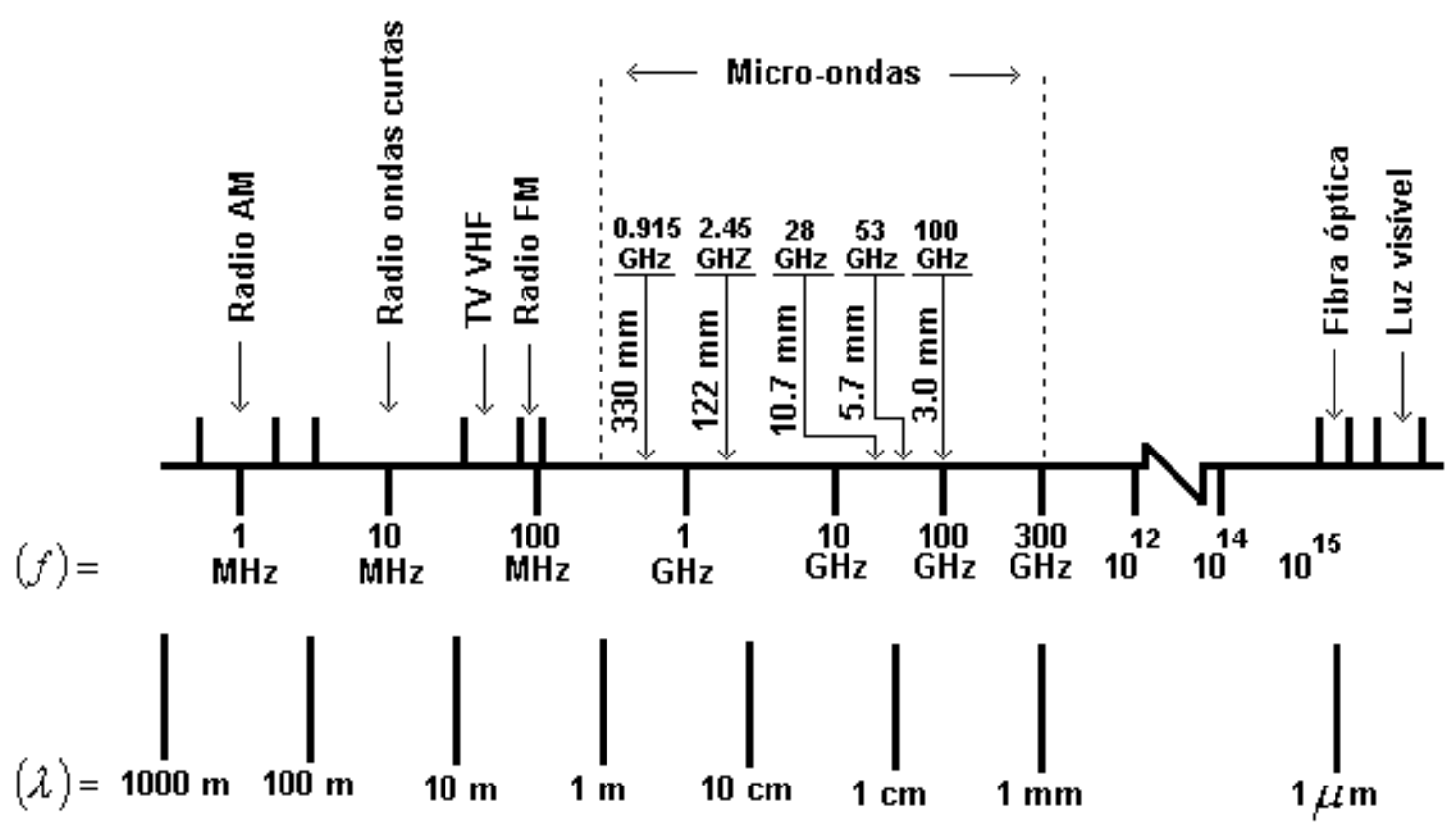

Figura 1 - Localização da região de micro-ondas no espectro eletromagnético ${ }^{21}$

Radiação eletromagnética tem 0 mesmo significado que onda eletromagnética. A onda eletromagnética é um campo elétrico $(E)$ conjugado com um campo magnético $(H)$, caracterizado por um comprimento de onda $(\lambda)$ e movendo-se na velocidade da luz $(C)$, conforme representado na figura 2. 


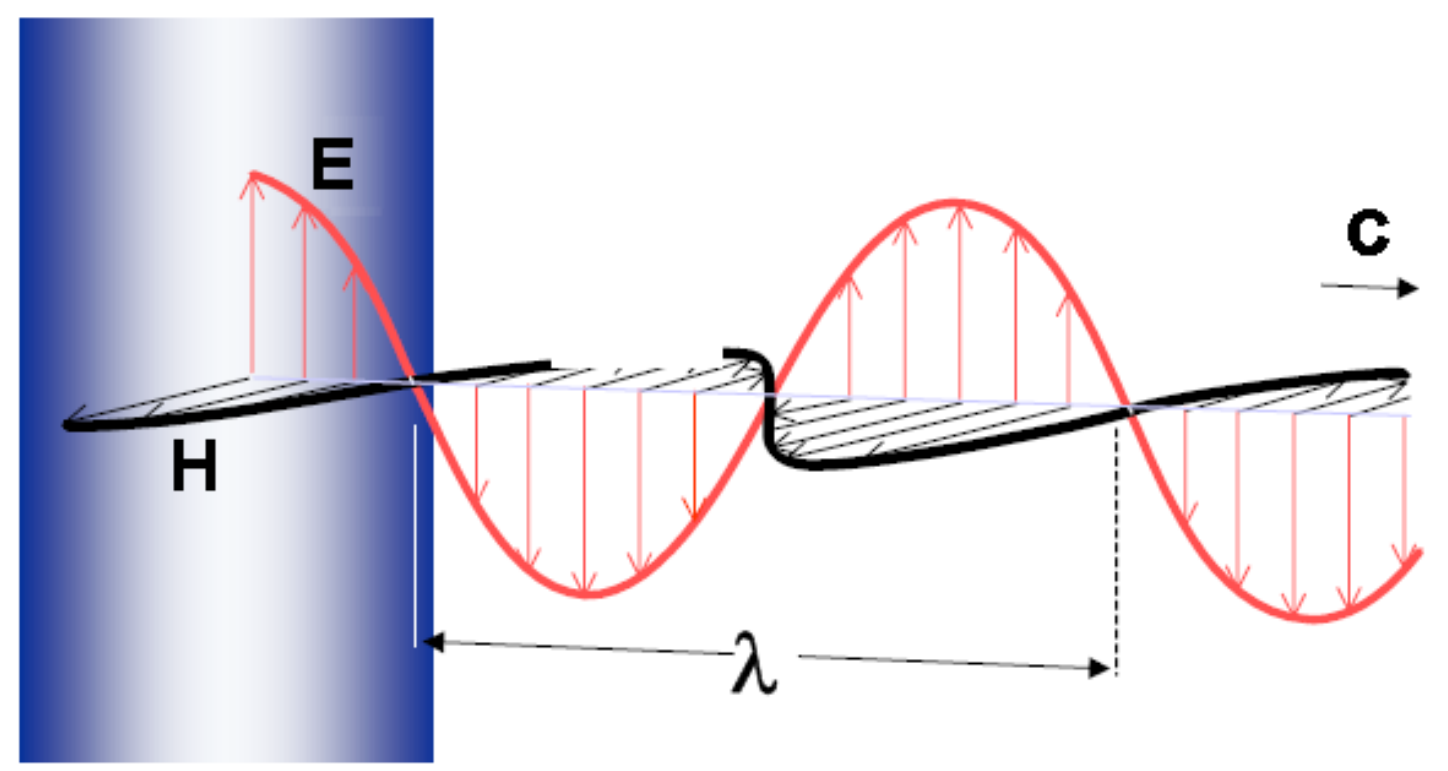

Figura 2 - llustração de uma onda eletromagnética polarizada propagando-se num plano perpendicular a esta folha ( $\lambda=$ comprimento de onda, $E=$ campo elétrico, $H=$ campo magnético e $C$ = velocidade da luz $)^{22}$

A onda eletromagnética é caracterizada pela freqüência $(f)$, sendo ela uma propriedade invariante, não se alterando por nenhum processo linear. A velocidade da onda $(v)$ muda em função do meio em que a onda está propagando. A velocidade de propagação das ondas eletromagnéticas no vácuo é de aproximadamente $3 \times 10^{8} \mathrm{~m} / \mathrm{s}$. O comprimento de onda é a relação entre a velocidade da onda e a freqüência: $\lambda=v / f$.

A quantidade de energia $(E)$ contida em uma onda eletromagnética, medida em Joules $(J)$, é definida por: $E=h f$, onde $h$ é a constante de Plank $\left(6,63 \times 10^{-34} \mathrm{~J} / \mathrm{Hz}\right)$, e $f$ é a freqüência $(\mathrm{Hz})$. As radiações são classificadas em função do seu conteúdo energético entre radiações ionizantes e não ionizantes. As radiações classificadas como ionizantes possuem freqüências maiores que as radiações que caracterizam a luz visível, mais especificamente, o ultravioleta curto, raios $\mathrm{X}$ e raios gama, possuem energia suficiente para quebrar as ligações moleculares dos materiais sobre as quais incidem, por exemplo, material biológico, com possíveis conseqüências graves às pessoas expostas. As micro-ondas por possuírem freqüências inferiores às radiações ionizantes, não trazem este tipo de perigo, pois não tem a capacidade de quebrar as ligações moleculares, sendo classificadas como radiações não ionizantes. 
A utilização efetiva das micro-ondas iniciou-se durante a segunda guerra mundial, em sistemas de radar. A grande necessidade do desenvolvimento de sistemas para detectar aeronaves inimigas contribuiu para o acumulo de muitos conhecimentos sobre micro-ondas ${ }^{23}$.

A sua utilidade para o aquecimento de materiais foi descoberta em 1945. Um engenheiro chamado Percy Spencer notou que uma barra de um doce em seu bolso começou a derreter quando ele ficou em frente a um tubo de magnetron que estava ligado, e intrigado por este fato ele conduziu alguns experimentos simples, como preparar pipoca espalhando alguns grãos de milho em frente ao tubo. Pouco tempo depois, no ano seguinte, a Raytheon, uma empresa americana responsável por cerca de $80 \%$ de todos os magnetrons produzidos no mundo, solicitou a primeira patente sobre a utilização de micro-ondas para o aquecimento de alimentos e apresentou 0 primeiro forno de micro-ondas chamado "Radarange" sendo popularizado nas décadas de 70 e 80 como forno de micro-ondas doméstico ${ }^{23}$.

\subsubsection{Geração de micro-ondas}

De uma maneira simplificada, o sistema necessário para se obter o campo de micro-ondas é composto por uma fonte DC (fonte de corrente contínua), por um gerador de micro-ondas, um aplicador e um sistema de controle mostrado pela figura 3. A fonte de corrente contínua é composta por um transformador e um retificador de corrente. $O$ transformador possui função de aumentar a tensão elétrica. Em alguns casos esta tensão poderá chegar à faixa de $30 \mathrm{kV}$. Em seguida, o retificador de corrente transforma a corrente alternada em corrente contínua que irá alimentar o gerador de micro-ondas. Este gerador é composto por uma válvula, que transforma a corrente contínua em ondas eletromagnéticas de alta frequência ${ }^{24}$ que são direcionadas ao aplicador. Dependendo do nível de potência e design do equipamento, um controle da potência de micro-ondas pode ser usado para regular de acordo com o produto presente no aplicador. 


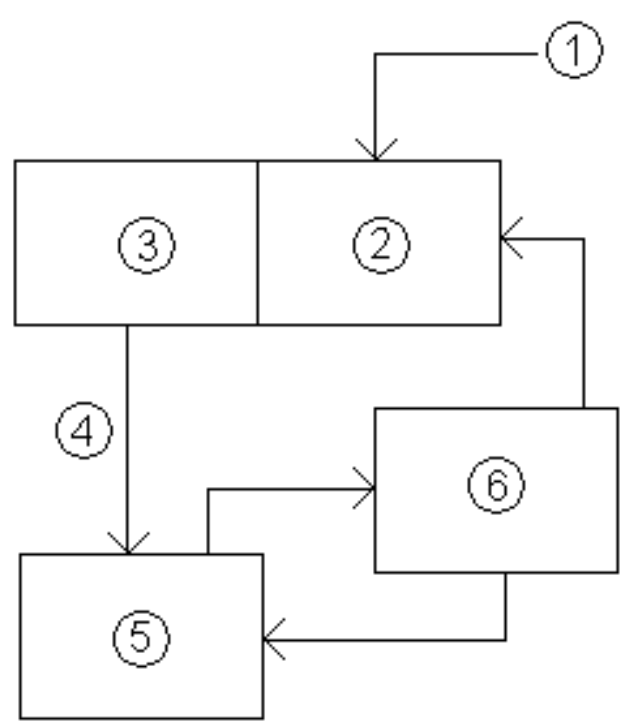

Figura 3 - Componentes de geração de micro-ondas 1) Potência de $60 \mathrm{~Hz}$ (corrente alternada); 2) Fonte de corrente contínua; 3) Gerador de micro-ondas; 4) Ondas eletromagnéticas; 5) Aplicador; 6) Sistema de controle de potência de micro-ondas.

Os geradores de micro-ondas mais conhecidos são o magnetron, klystron, power grid, e gyrotron.

O magnetron é o gerador de micro-ondas mais utilizado para aquecimento. Este gerador é utilizado para gerar micro-ondas em fornos domésticos, com potência aproximada de $1 \mathrm{~kW}$ e freqüência variando entre $2 \mathrm{e}$ $3 \mathrm{GHz}$. São muito utilizados em radares e na indústria. Em exemplar de um magnetron de uso industrial pode ser visto na figura 4. Devido à grande quantidade fabricada, possui um custo menor em relação a outros geradores de alta potência. Suas principais vantagens são: o preço, o peso, o tamanho e a eficiência. Sua eficiência pode chegar a $90 \%$, sendo mais comum eficiências entre $70 \%$ e $80 \%$.

O gerador tipo klystron é utilizado quando se necessita de ondas contínuas de grande potência. São utilizados em radares civis e militares, processos industriais especiais, em pesquisas científicas, em aceleradores lineares, em medicina e em terapias contra o câncer. Sua eficiência é de 50\% a $60 \%{ }^{25}$.

O power grid é um tipo de gerador de micro-ondas de baixo custo, utilizado em baixas freqüências. Este gerador é semelhante aos geradores de ondas de transmissão de rádio $\mathrm{AM}, \mathrm{FM}$ e de televisão ${ }^{25}$. 


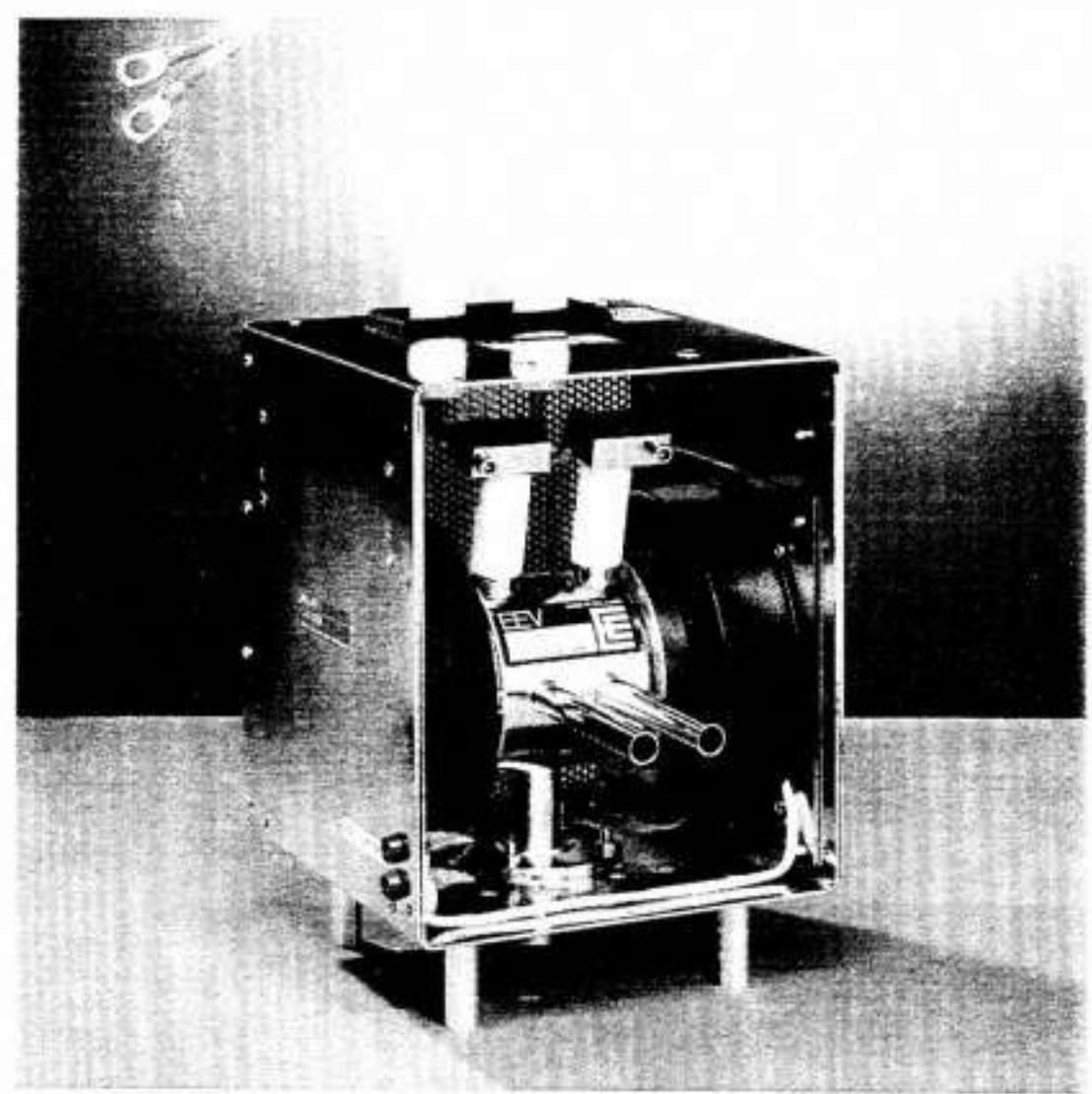

Figura 4 - Magnetron para aquecimento em processos industriais ${ }^{25}$.

Quando se necessita de um gerador que emita ondas de grande potência e altas freqüências, utiliza-se o gyrotron. Muito caro, grande e pesado, é utilizado em processos de fusão através de plasma. Sua eficiência é de 50\% a $60 \%{ }^{25}$.

\subsubsection{Interação da energia de micro-ondas com os materiais}

As ondas de micro-ondas, tal como as ondas visíveis, obedecem às leis da óptica e podem ser transmitidas, absorvidas ou refletidas dependendo do tipo de material. A figura 5 ilustra os tipos de interação das micro-ondas com os materiais e observa-se que existem basicamente três tipos de materiais, com relação à forma de interação com as micro-ondas. Os materiais transparentes às micro-ondas permitem a total passagem das ondas através de si, sem perdas significativas de energia. Os materiais opacos refletem as ondas 
eletromagnéticas enquanto que os materiais com altas perdas dielétricas, ou seja, materiais que absorvam irradiação de micro-ondas, também chamados de dielétricos interagem com as micro-ondas absorvendo-as eficientemente, o que provoca o seu rápido aquecimento ${ }^{26,27}$.

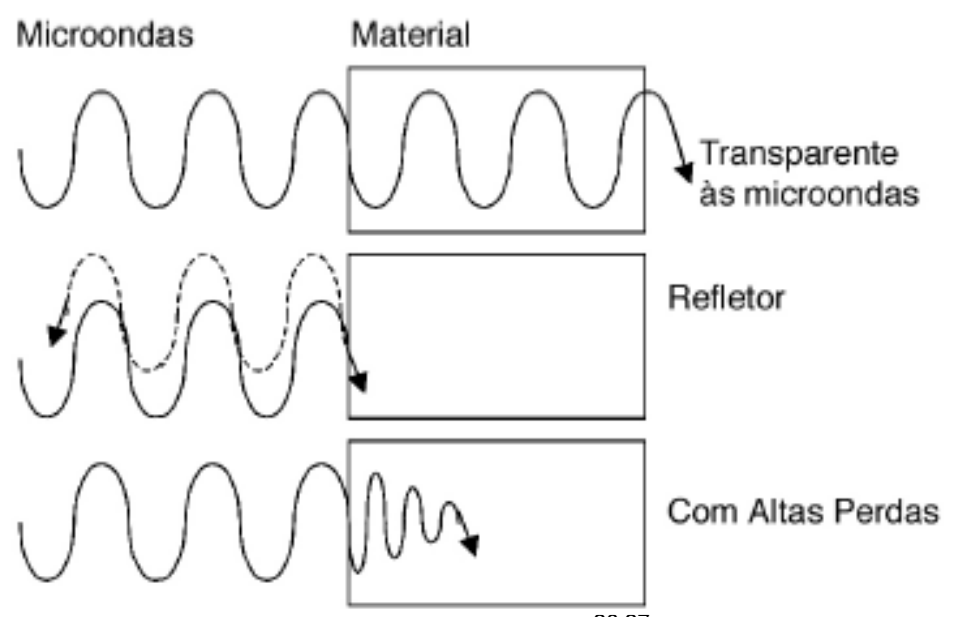

Figura 5 - Interação das micro-ondas com os materiais ${ }^{26,27}$.

A freqüência de micro-ondas mais utilizada para aquecimento é 2.45 $\mathrm{GHz}$ por apresentar a melhor relação custo-benefício entre todas as freqüências alocadas para aplicações industriais, científicas e médicas (ISM) pela união internacional de telecomunicações (UIT). Esta freqüência corresponde ao comprimento de onda no espaço livre de $12,25 \mathrm{~cm}$.

Quando as micro-ondas penetram e se propagam através de um material dielétrico, o campo elétrico interno, gerado dentro do volume afetado, induz ao movimento translacional das cargas livres e ligadas, como íons ou elétrons, e a rotação de cargas complexas, como os dipolos conforme figura 6 . A resistência a esses movimentos induzidos, devido à inércia elástica e forças de atrito, causa perdas e atenua o campo elétrico. Como conseqüência dessas perdas, ocorre o aquecimento do material ${ }^{28,31,32}$. 


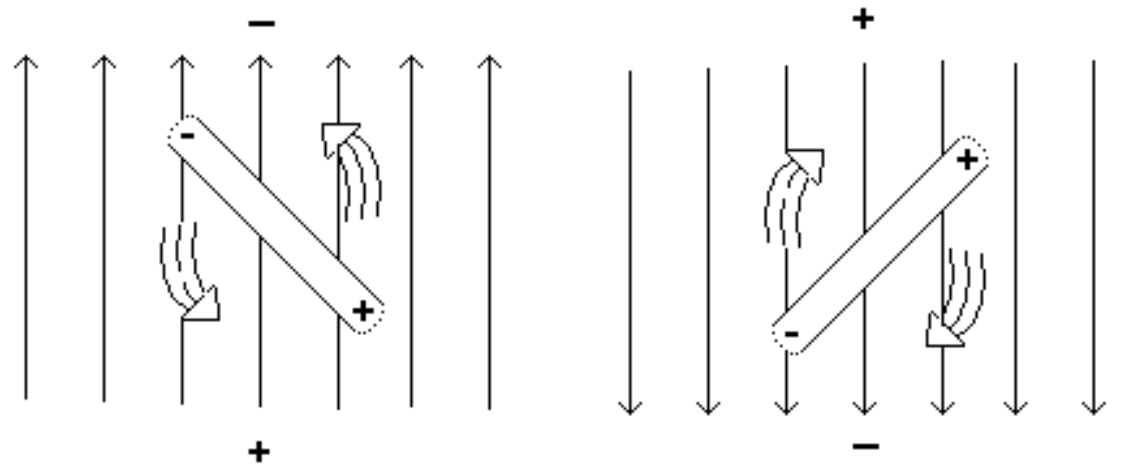

Figura 6 - Rotação do dipolo devido a mudança de campo elétrico ${ }^{29}$

Assim, de forma geral, destaca-se ainda dentre as várias teorias para explicar os mecanismos pelo quais as micro-ondas aquecem um material, os processos de aquecimento por polarização iônica como mostrado na figura 7. A polarização ocorre quando os íons na solução se movem em resposta ao campo eletromagnético e o calor é gerado através das perdas por fricção e pela migração (movimento) dos íons dissolvidos ${ }^{30}$.

\section{Sem o campo eletromagnético Com o campo eletromagnético}

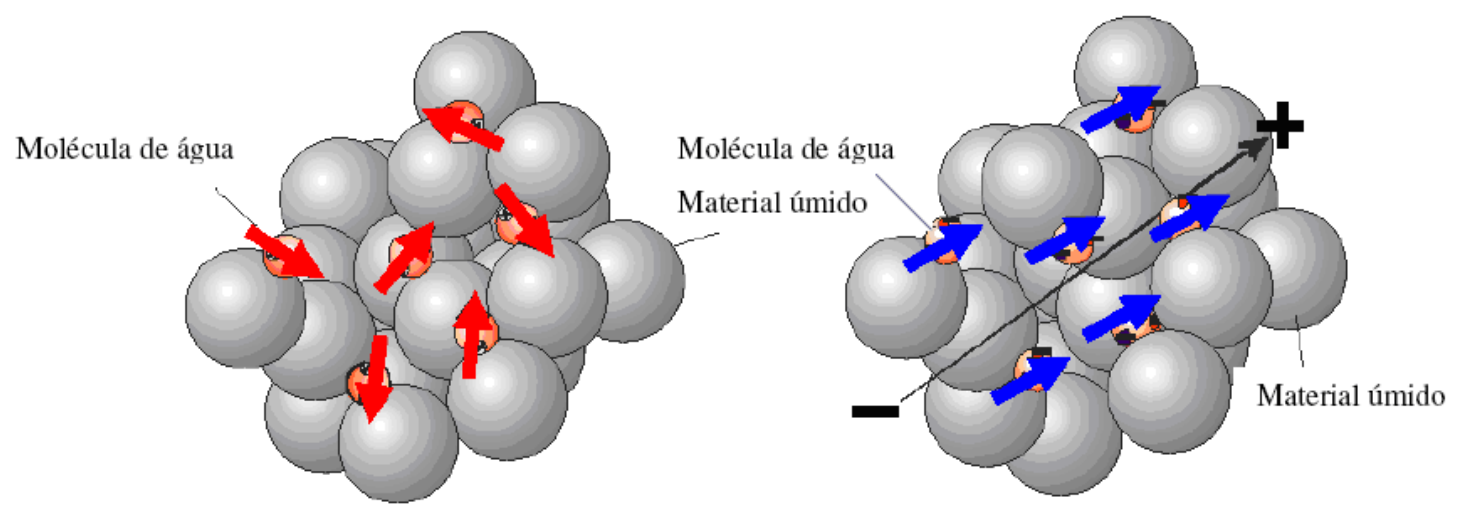

Figura 7 - Indução do campo eletromagnético em moléculas de água ${ }^{30}$

Ambos os processos propiciam perdas em determinadas freqüências, e não é geralmente fácil diferenciar experimentalmente entre os dois mecanismos. Conseqüentemente, as perdas são tipicamente reportadas como perdas efetivas $\left(\varepsilon_{e f}^{\prime \prime}\right)$, quando os mecanismos de perdas são desconhecidos ou não podem ser claramente separados ${ }^{26}$.

O comportamento de materiais diante de micro-ondas pode ser caracterizado por sua permissividade elétrica (constante dielétrica, $\varepsilon^{\prime}$ ), fator de 
perdas (constante de perdas, $\varepsilon^{\prime \prime}$ ) e tangente de perdas $(\tan \delta)$. A permissividade elétrica é uma medida da quantidade de energia armazenada no material na forma de campo elétrico, enquanto que o fator de perdas é uma medida da energia dissipada na forma de calor dentro do material. A tangente de perdas é a relação entre o fator de perdas e a permissividade, ou seja, relaciona a energia dissipada com a armazenada e é muito usado para expressar a resposta dielétrica de um material para com as micro-ondas.

\subsubsection{Quantificação da energia de micro-ondas}

O fator de perda dielétrica $(\varepsilon ")$ mede a eficiência da conversão de energia eletromagnética em calor. A constante dielétrica $\left(\varepsilon^{\prime}\right)$ da substância é uma medida que indica sua polaridade. Já a razão $\varepsilon^{\prime \prime} / \varepsilon^{\prime}$, é numericamente igual a $\left(\tan \delta=\varepsilon^{\prime \prime} / \varepsilon^{\prime}\right)$, sendo chamada de fator de dissipação, que significa a habilidade de uma amostra converter radiação eletromagnética em calor (quanto maior este valor mais a substância é aquecida por micro-ondas). A tabela 1 mostra várias substâncias e estes parâmetros mencionados.

Tabela 1 - Constante dielétrica $\left(\varepsilon^{\prime}\right)$, fator de perdas dielétrica $\left(\varepsilon^{\prime \prime}\right)$ e fator de dissipação de algumas substâncias $\left(25^{\circ} \mathrm{C} \text { e } 3 \mathrm{GHz}\right)^{34}$

\begin{tabular}{|c|c|c|c|}
\hline Material & $\begin{array}{c}\varepsilon^{\prime} \\
\text { (constante dielétrica) }\end{array}$ & $\begin{array}{c}\varepsilon^{\prime \prime} \\
\text { (perda dielétrica) }\end{array}$ & $\begin{array}{c}\tan \delta \times 10^{4} \\
\text { (fator de dissipação) }\end{array}$ \\
\hline Gelo & 3.2 & 0.00288 & 9 \\
\hline Água $\left(25^{\circ} \mathrm{C}\right)$ & 76.7 & 12.0419 & 1570 \\
\hline $\mathrm{NaCl}$ aq. $0,1 \mathrm{M}$ & 75.5 & 18.12 & 2400 \\
\hline $\mathrm{NaCl}$ aq. $0,5 \mathrm{M}$ & 67.0 & 41.875 & 6250 \\
\hline Propanol & 3.7 & 2.479 & 6700 \\
\hline Etilenoglicol & 12.0 & 12 & 10000 \\
\hline Heptano & 1.9 & 0.00019 & 1 \\
\hline $\begin{array}{l}\text { Tetracloreto de } \\
\text { carbono }\end{array}$ & 2.2 & 0.00088 & 4 \\
\hline
\end{tabular}


Pode-se deduzir que a potência dissipada numa amostra de material dielétrico, por unidade de volume, é dada por:

$$
P v=2 \pi \times f \times \mathcal{E}^{\prime \prime} \times E^{2}
$$

Costuma-se referir $\varepsilon^{\prime}$ e $\varepsilon^{\prime \prime}$ à constante dielétrica do vácuo, $\varepsilon_{0}=8,85 \times 10^{-12} \frac{F}{m}$, definindo-se assim a constante dielétrica relativa $=$ $\mathcal{E}_{r}^{\prime}=\frac{\varepsilon^{\prime}}{\varepsilon_{0}} \therefore \varepsilon^{\prime}=\varepsilon^{\prime} \times \varepsilon_{0}$, e o fator de perdas relativas $=\varepsilon^{\prime \prime}{ }_{r}=\frac{\varepsilon^{\prime \prime}}{\varepsilon_{0}} \therefore \varepsilon^{\prime \prime}=\varepsilon^{\prime \prime}{ }_{r} \times \varepsilon_{0}$ e substituindo na equação (1), temos:

$$
P v=2 \pi \times f \times \varepsilon^{\prime \prime}{ }_{r} \times \varepsilon_{0} \times E^{2}
$$

Sendo $\varepsilon_{0}=8,85 \times 10^{-12} \frac{F}{m}$ e substituindo na equação (2), temos:

$$
P v=5,56 \times 10^{-11} \times f \times \mathcal{E}^{\prime \prime}, E^{2} \quad\left(W / m^{3}\right)
$$

Também pode ser a equação apresentada de outra forma, pois como $\tan \delta=\frac{\varepsilon^{\prime \prime}{ }_{r}}{\mathcal{E}_{r}^{\prime}} \therefore \mathcal{E}^{\prime \prime}{ }_{r}=\tan \delta \times \mathcal{E}_{r}^{\prime}$, temos:

$$
P v=5,56 \times 10^{-11} \times f \times \mathcal{E}^{\prime}{ }_{r} \times \tan \delta \times E^{2} \quad\left(W / m^{3}\right)
$$

$P v$ = potência dissipada por unidade de volume $\left(\mathrm{W} / \mathrm{m}^{3}\right)$;

$f=$ freqüência do campo elétrico $(\mathrm{Hz})$;

$E=$ intensidade do campo elétrico num ponto no interior do material $(\mathrm{V} / \mathrm{m})$;

$\varepsilon^{\prime}=$ constante dielétrica relativa

$\tan \delta=$ tangente de perda e/ou fator de dissipação

Na fórmula (4), $E$, é a intensidade do campo elétrico, de freqüência $f$, num ponto no interior do material. Este valor é fortemente menor do que o valor do campo sobre a superfície, pois houve dissipação de energia pelo percurso, da superfície até o ponto considerado. Portanto, a intensidade do campo elétrico dentro do dielétrico decai exponencialmente. Em primeira aproximação, suposto que uma onda eletromagnética plana incida perpendicularmente sobre 
a superfície plana do dielétrico, o campo elétrico no interior do material, à distância $z$ da superfície, é dado por:

$$
E_{(z)}=E_{0} \exp ^{-\alpha . z}
$$

$E_{(z)}=$ campo elétrico no interior do material, à distância $z$ da superfície;

$E_{0}=$ intensidade do campo elétrico num ponto na superfície do material $(\mathrm{V} / \mathrm{m})$; $\alpha=$ constante de atenuação e mostrado pela equação 6.

$$
\alpha=1,48 \times 10^{-8} \times f \times\left\{\varepsilon^{\prime} \times\left[\sqrt{\left(1+\tan ^{2} \delta\right)}-1\right]\right\}^{1 / 2}
$$

Destas equações tem-se que a potência dissipada na cota $z$ é:

$$
P v_{(z)}=5,56 \times 10^{-11} \times f \times \mathcal{E}_{r}^{\prime} \times \tan \delta \times E_{0}^{2} \times \exp ^{(-2 . \alpha . z)} \quad\left(W / m^{3}\right)
$$

Em conseqüência desta potência dissipada $P v_{(z)}$, a temperatura, em função da penetração, é representada em ${ }^{\circ} \mathrm{C} / s$, por:

$$
\frac{\partial T_{(z)}}{\partial t}=\frac{P v_{(z)}}{\rho \times C p} \quad\left({ }^{\circ} C / s\right)
$$

$\rho=$ massa específica $\left(\mathrm{kg} / \mathrm{m}^{3}\right)$;

$\mathrm{Cp}=$ calor específico $\left(\mathrm{J} / \mathrm{kg} .{ }^{\circ} \mathrm{C}\right)$.

A profundidade de penetração das micro-ondas em um dielétrico é representada pela equação:

$$
\left.d=\frac{c}{2 \times \pi \times f} \times\left\{\frac{2}{\varepsilon_{r} \times\left[\sqrt{\left(1+\tan ^{2} \delta\right)}-1\right.}\right]\right\}^{1 / 2} \quad(\mathrm{~cm})
$$

Onde $\frac{c}{f}=\lambda_{0}$ é o comprimento de onda da radiação incidente. 


\subsection{Aplicação das micro-ondas em engenharia metalúrgica e materiais}

Com o passar dos anos, a energia de micro-ondas tem sido aplicada em vários campos, incluindo alimentos, materiais, químicos e processos metalúrgicos, sendo este de grande interesse recentemente como mostrado a seguir:

Milhões de toneladas de escórias são gerados como subproduto da produção de outros milhões de toneladas de aço todo ano. A escória de alto forno é classificada como escória resfriada bruscamente com água e escória resfriada lentamente. A escória resfriada bruscamente com água existe no estado quase vítreo e é usada como componente do cimento de alto forno ou como agregado fino, ao passo que a escória resfriada lentamente existe no estado bem cristalizado e é usada como agregado grosso. Escória de alto forno é convenientemente reciclada desta maneira; porém usos adicionais da escória estão sendo pesquisados. As propriedades físicas e químicas da escória como resistência, dureza, propriedades hidráulicas, etc são consideravelmente influenciadas pela composição, morfologia, grau de cristalização, etc

Kuroki $^{35}$ et al. (2007) apresentaram os efeitos da irradiação por microondas (28 GHz/2.45 GHz) na cristalização da escória $40 \% \mathrm{CaO}-40 \% \mathrm{SiO}_{2}$ $20 \% \mathrm{Al}_{2} \mathrm{O}_{3}$ produzida sinteticamente e por altos-fornos industriais. Os autores descobriram que a irradiação por micro-ondas a $28 \mathrm{GHz}$ é capaz de cristalizar a escória, acelerando sua velocidade de cristalização, especialmente em temperaturas mais baixas, ou seja, em torno de $800^{\circ} \mathrm{C}$, ao passo que uma fonte de calor auxiliar, grânulos de carbeto de silício, foi necessária nos experimentos com $2.45 \mathrm{GHz}$. Os resultados foram comparados com os do forno de resistência elétrica e mostrou uma pequena diferença na fase cristalina e na fração de cristalização entre a irradiação por micro-ondas a 2.45 $\mathrm{GHz}$ e o forno de resistência elétrica, ao passo que uma alta fração de cristalização foi observada em temperaturas menores de $800^{\circ} \mathrm{C}$ aplicando a irradiação de micro-ondas a $28 \mathrm{GHz}$, efeito este não encontrado em aquecimentos convencionais. Portanto se as micro-ondas podem acelerar a cristalização das escórias, pode-se não somente encontrar um efetivo 
tratamento de calor para as escórias, mas também a possibilidade de novos processos para a produção de escórias cristalizadas.

Aproximadamente 5 milhões de toneladas de pigmento dióxido de titânio, conhecido como rutila, têm sido produzidos por ano no mundo. Porém existem problemas com a grande quantidade de resíduos gerados, com o grande consumo de energia e com o impacto ambiental.

O trabalho de Itoh $^{36}$ et al. (2007) além de propor uma nova rota para a extração do rutilo, propiciando um período menor de oxidação e tamanhos de grãos maiores nas fases precipitadas, fatores que resultam em uma separação mais fácil, mostrou a necessidade de um aquecimento mais eficiente para a oxidação do minério de ilmenita. Deste modo, o aquecimento por micro-ondas tornou-se viável devido à ilmenita e a fase pseudobrookita absorverem fortemente as micro-ondas na freqüência de $28 \mathrm{GHz}$, aquecendo rapidamente acima de $1000^{\circ} \mathrm{C}$. Como resultado, duas fases em equilíbrio do rutilo e pseudobrookita foram facilmente formadas com uma potência de micro-ondas de $1.5 \mathrm{~kW}$. Como a fase pseudobrookita possui grande permissividade bem como a fase ilmenita, o minério ilmenítico pode ser aquecido com micro-ondas não somente em seu estágio inicial, mas também depois de ocorrer à reação de oxidação. A taxa de crescimento da fase pseudobrookita com a irradiação por micro-ondas é mais rápida que a fase rutila comparado ao aquecimento convencional. A diferença do tamanho dos grãos entre estas fases é considerada favorável para o processo de separação.

Molibdênio sinterizado apresentando fina microestrutura é desejado, pois melhora suas propriedades mecânicas. Porém, não é fácil sua sinterização através dos processos convencionais, podendo variar de 10 a 40 horas para obtê-lo. Chhillar, Agrawal e Adair ${ }^{37}$ (2008) pesquisaram a utilização da energia de micro-ondas como fonte de aquecimento na sinterização do molibdênio e os resultados mostraram redução da temperatura e do tempo comparados à sinterização convencional.

Como exemplo, amostras sinterizadas a $1400^{\circ} \mathrm{C}$ por 10 horas em processo convencional obtêm uma densidade de $98 \%$ sobre a densidade teórica. Porém, usando energia de micro-ondas a $1400^{\circ} \mathrm{C}$ obteve-se uma densidade de $99 \%$ sobre a densidade teórica em 30 minutos, mostrando que a 
sinterização por micro-ondas é muito mais rápida do que a convencional como mostrado pela figura 8 .

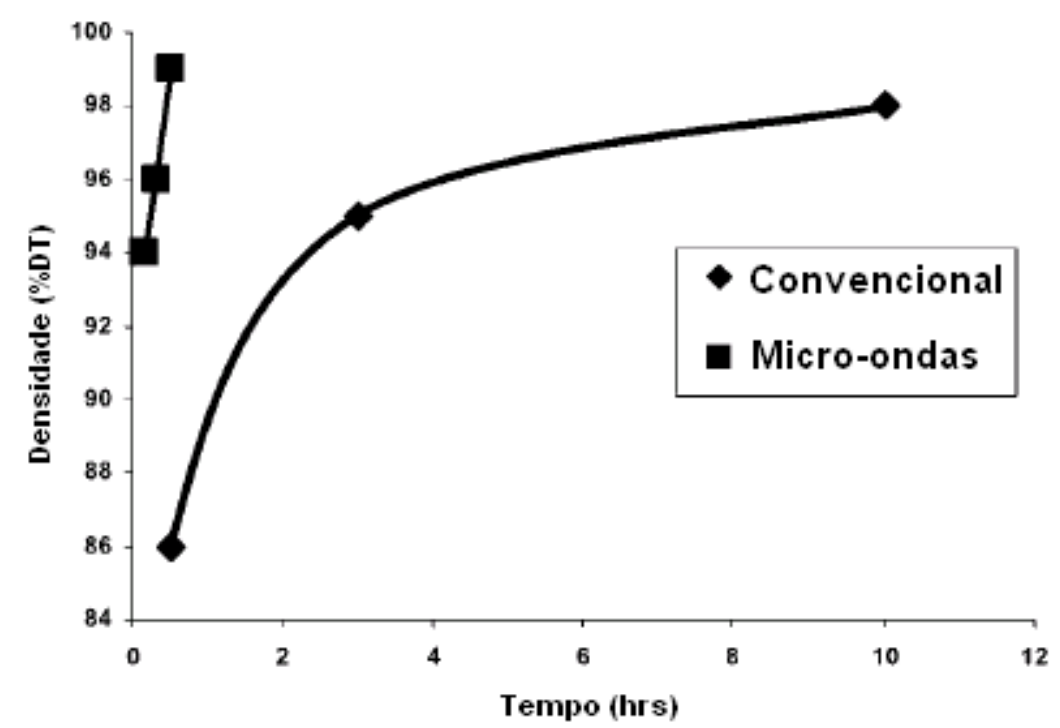

Figura 8 - Comparação do comportamento da sinterização do molibdênio em forno convencional e em forno de micro-ondas ambos a $1400^{\circ} \mathrm{C}^{37}$

As escórias provenientes de um alto forno são utilizadas na sua maioria na fabricação de cimento. Quando em uma redução carbotérmica utiliza-se de minério de ferro com grandes quantidades de titânio, a escória produzida neste caso contém uma alta quantidade de $\mathrm{TiO}_{2}$ que impossibilita sua utilização na confecção do cimento devido possuir baixa afinidade com a água gerando assim um passivo ambiental.

Neste tipo de escória, o titânio está presente na forma de $\mathrm{CaTiO}_{3}$, que sendo extraído pode ser utilizado em pigmentos e o resíduo pode então ser utilizado na fabricação do cimento. Porém, não é fácil separar a fase $\mathrm{CaTiO}_{3}$ da escória sólida através de processos convencionais. Em vista disto, $\mathrm{Chen}^{38}$, et al. (2007) pesquisaram sobre a diminuição da resistência a compressão da escória com a energia de micro-ondas. Neste estudo, o comportamento do aquecimento por micro-ondas na escória com titânio, em uma escória sem titânio e numa fase perovskita $\left(\mathrm{CaTiO}_{3}\right)$ sintética foram examinadas. Sob as mesmas condições de aquecimento, a escória com titânio absorveu mais energia de micro-ondas que a escória comum, ficando entre elas a fase peroyskita. Isto se deve a escória com titânio ter uma permissividade alta. A resistência a compressão da escória diminuiu com o aumento do tempo de 
exposição e com uma aplicação cíclica das micro-ondas sendo este último mais efetivo. Os resultados mostraram uma diminuição na resistência em torno de $35 \%$ depois de 10 ciclos de aquecimento pelo período de 5 minutos.

Sano ${ }^{39}$ et al. (2007) estudaram o comportamento da absorção de microondas em pó de ferro em temperaturas elevadas especialmente em torno da temperatura de Curie, ou seja, $780^{\circ} \mathrm{C}$. Para este propósito, o comportamento da absorção das micro-ondas em pó de ferro puro e na mistura com $50 \%$ de pó de ferro e $50 \%$ de alumina foi medido através de um guia de onda circular acoplado a um analisador vetorial de rede. O pó de ferro puro ao atingir $700^{\circ} \mathrm{C}$ tornou-se refletor, logo qualquer mudança na absorção de micro-ondas em torno da temperatura de Curie não foi obtida. Uma drástica mudança ocorreu na absorção das micro-ondas em torno da temperatura de Curie para a mistura de $50 \%$ de ferro e $50 \%$ de alumina, estimando $72 \%$ de perda magnética e $28 \%$ de perda dielétrica. Esta técnica, portanto tornou-se muito importante na validação da absorção de micro-ondas em pós metálicos. A partir destes resultados, é considerado que o comportamento de absorção da energia de micro-ondas no ferro em pó, utilizando a mistura ferro e alumina ambos pulverizados, pode ser determinado separadamente através de perdas magnéticas e perdas dielétricas.

O trabalho realizado por Cheng, Roy e Agrawal $^{40}$ (2002) mostrou que a interação do campo magnético com alguns materiais contribui muito na taxa de aquecimento comparado aos materiais expostos ao campo elétrico. Foram preparadas amostras compactadas de vários materiais entre eles de ferro puro, em forma cilíndrica ( $5 \mathrm{~mm}$ de diâmetro e $5 \mathrm{~mm}$ de altura) e inseridas no interior de um tubo de quartzo e este tubo por sua vez inserido no interior de uma cavidade "single" modal $\mathrm{TE}_{103}$. A localização das amostras no interior na cavidade obedeceu à distribuição do campo de micro-ondas, ou seja, para ensaios com o máximo campo magnético (onde o campo elétrico é aproximadamente zero) eram colocadas próximas a parede e para ensaios com o máximo campo magnético (onde 0 campo magnético é aproximadamente zero) eram colocadas no centro. A freqüência utilizada nos ensaios foi a $2.45 \mathrm{GHz}$ e a potência irradiada de $500 \mathrm{~W}$.

A figura 9 mostra a comparação entre a taxa de aquecimento do ferro puro compactado nos campos de micro-ondas elétrico ou magnético. 


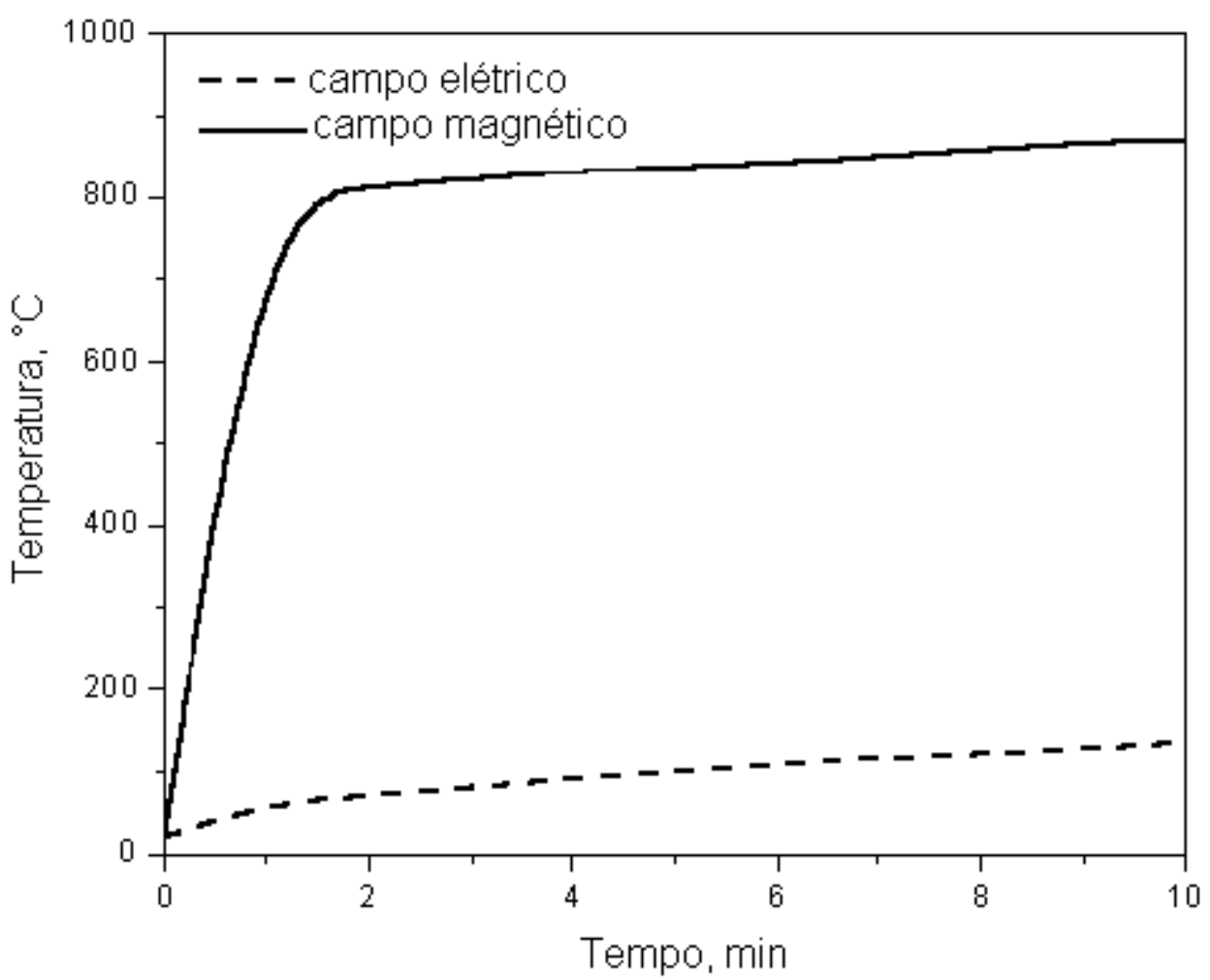

Figura 9 - Comparação da taxa de aquecimento para o ferro puro compactado nos campos de micro-ondas magnético e elétrico ${ }^{40}$

Os resultados deste trabalho demonstraram uma notável diferença no comportamento da taxa de aquecimento para vários materiais principalmente para o ferro puro, pois sendo um material condutivo, aquece com mais eficiência no campo magnético das micro-ondas.

\subsection{Redução carbotérmica}

A metalurgia do ferro consiste, basicamente, na redução de seus óxidos por meio de um redutor, o qual, em geral é um combustível carbonoso. Se aceita que a maior parte do mecanismo do processo consiste na redução dos óxidos do ferro pelo monóxido de carbono gerado pela combustão do material carbonáceo com ar ou pela reação de gaseificação do redutor ${ }^{41-42}$. 
O ferro na natureza se apresenta principalmente combinado com o oxigênio na forma de óxidos: hematita $\left(\mathrm{Fe}_{2} \mathrm{O}_{3}\right)$, magnetita $\left(\mathrm{Fe}_{3} \mathrm{O}_{4}\right)$, limonita $\left(\mathrm{Fe}_{2} \mathrm{O}_{3} \mathrm{nH}_{2} \mathrm{O}\right)$, ou siderita $\left(\mathrm{FeCO}_{3}\right)^{43}$.

Quando um óxido de ferro e carbono sólido são misturados e aquecidos numa temperatura de redução, do ponto de vista termodinâmico, a reação pode ocorrer por dois mecanismos ${ }^{44}$.

a) Reação sólido-sólido;

$$
\mathrm{Fe}_{2} \mathrm{O}_{3(s)}+3 \mathrm{C}_{(s)} \rightarrow 2 \mathrm{Fe}_{(s)}+3 \mathrm{CO}_{(g)}
$$

b) Reação gás-sólido com intermediários gasosos;

$$
\begin{gathered}
3 \mathrm{Fe}_{2} \mathrm{O}_{3}+\mathrm{CO}_{(s)} \rightarrow 2 \mathrm{Fe}_{3} \mathrm{O}_{4(s)}+\mathrm{CO}_{2(g)} \\
\mathrm{Fe}_{3} \mathrm{O}_{4(s)}+\mathrm{CO}_{(g)} \rightarrow 3 " \mathrm{FeO}{ }_{(s)}+\mathrm{CO}_{2(g)} \\
" \mathrm{FeO}{ }_{(s)}+\mathrm{CO}_{(g)} \rightarrow \mathrm{Fe}_{(s)}+\mathrm{CO}_{2(g)} \\
\mathrm{CO}_{2(g)}+\mathrm{C}_{(s)} \rightarrow 2 \mathrm{CO}_{(g)}
\end{gathered}
$$

Como se pode notar através das reações 11 a 14, a redução de óxidos de ferro por carbono ocorre principalmente através de intermediários gasosos. Porém, a reação global que ocorre no sistema pode ser representada por ${ }^{45}$ :

$$
\mathrm{Fe}_{2} \mathrm{O}_{3(s)}+p \mathrm{C}_{(s)} \rightarrow 2 \mathrm{Fe}_{(s)}+u C \mathrm{O}_{(g)}+v \mathrm{CO}_{2(g)}
$$

Os valores dos coeficientes $p, u$ e $v$ dependem não apenas das condições de equilíbrio da temperatura do processo, mas também das velocidades relativas das reações de redução de óxidos de ferro por $C O$ e 
gaseificação de carbono por $\mathrm{CO}_{2}$, demonstrando assim que a reação global não possui estequiometria fixa ${ }^{45}$.

O desenvolvimento do processo de redução entre o sistema óxido de ferro e carbono foi acompanhado, em sua maior parte, pela técnica de termogravimetria. Para obter certeza experimental sobre o estado do sistema em um determinado instante, devido à perda de peso ocasionada pela geração e liberação dos gases $\mathrm{CO}$ e $\mathrm{CO}_{2}$, e devido à estequiometria do sistema não ser definida, só é possível com uma análise simultânea da composição do gás de saída.

Informações a respeito de estudos cinéticos sobre a redução de óxidos de ferro por carbono têm sido acumuladas com o passar do tempo e as principais características desta reação são mostradas a seguir ${ }^{46}$ :

a) a reação global entre óxidos de ferro e material carbonoso ocorre através de intermediários gasosos $\mathrm{CO}$ e $\mathrm{CO}_{2}$, isto é, a reação global ocorre por meio de duas reações gás-sólido, quais seja a redução do óxido por $C O$ e a gaseificação do carbono por $\mathrm{CO}_{2}$ (reação de Boudouard).

b) dentre estas duas reações, a mais lenta é a reação de gaseificação do carbono (até a temperatura de $1150^{\circ} \mathrm{C}$ ); isto implica que as propriedades relativas à reatividade do redutor (tipo, granulometria, teor de impurezas) são importantes na determinação da cinética global.

c) ainda como conseqüência do controle químico ser devido à reação de Boudouard, que possui alta energia de ativação, a velocidade global é muito sensível a variações de temperatura.

d) a reação é fortemente endotérmica; transporte de calor para as regiões internas da pelota é um dos fatores determinantes da velocidade do processo.

\subsection{Redução carbotérmica com micro-ondas}

Standish e Wormer ${ }^{54}$ (1990) compararam a redução carbotérmica da hematita e magnetita com coque e óxido de cálcio em aquecimento 
convencional e por micro-ondas. Amostras idênticas foram aquecidas em forno elétrico mantendo uma temperatura constante de $1000^{\circ} \mathrm{C}$, e em forno de microondas doméstico com potência de $1300 \mathrm{~W}$ e $2.45 \mathrm{GHz}$ de freqüência. As temperaturas foram medidas através de um termopar inserido na amostra, e no caso dos ensaios com micro-ondas especificamente aterrado na carcaça do forno para não falsear as leituras. Para ambas as situações de aquecimento, os testes terminaram quando a temperatura atingia $1000^{\circ} \mathrm{C}$. A figura 10 mostra os resultados e indica que a taxa de aquecimento por micro-ondas foi muito maior que a taxa de aquecimento convencional. Isto, segundo os autores, está diretamente ligado ao aquecimento volumétrico provocado pelas micro-ondas, de modo que as pelotas aquecem do interior para a superfície resolvendo um problema de transferência de calor encontrado em processos convencionais e ainda uma possível diminuição da energia de ativação significando assim um aumento da taxa de redução.

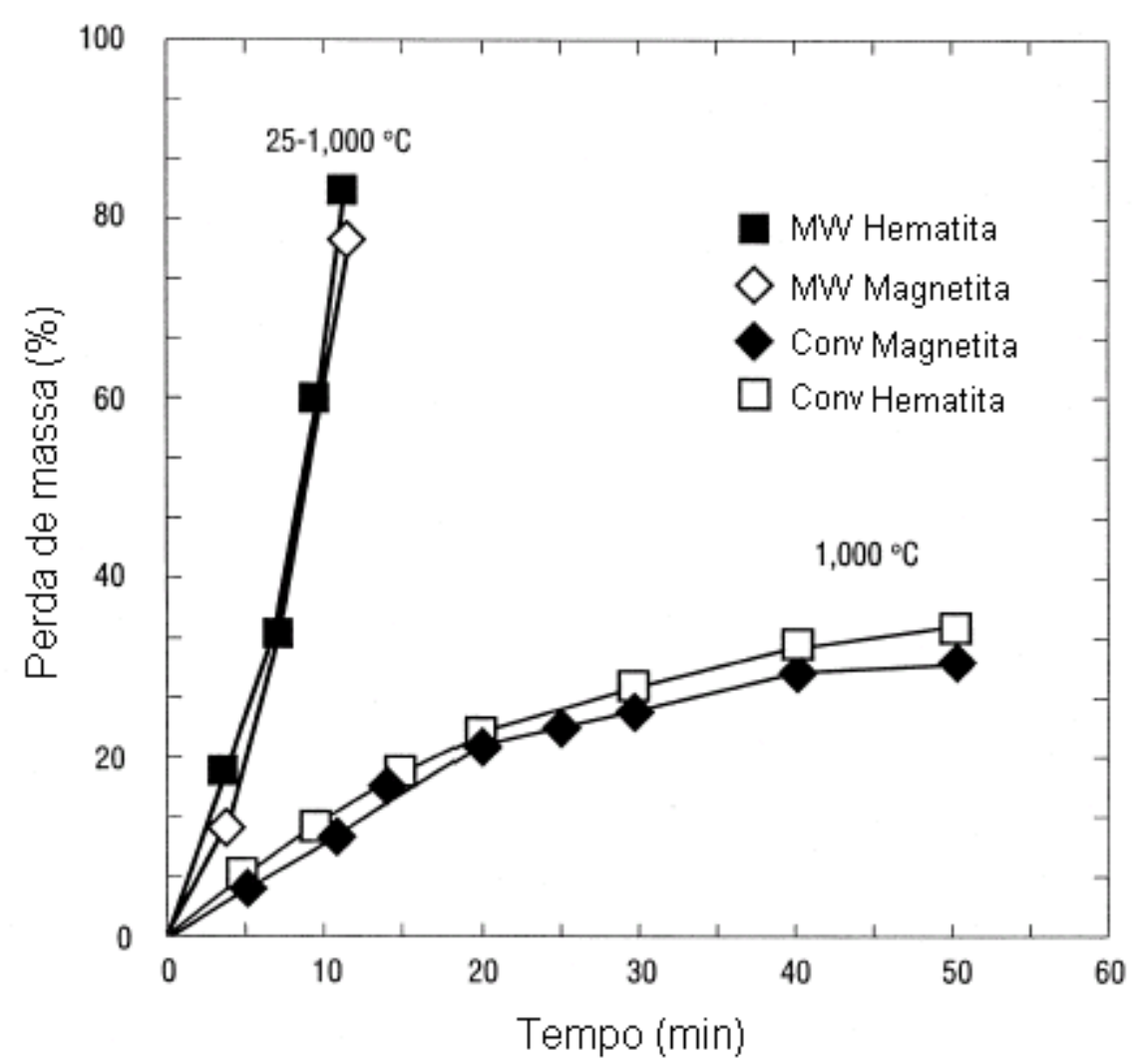

Figura 10 - Comparação da redução carbotérmica convencional e por micro-ondas ${ }^{54}$ 
Os autores baseados em uma suposição racional para o capital e custos de operação, concluíram que o processo de redução por micro-ondas poderá ser mais econômico do que a operação convencional em torno de 15 a 50\%.

$O$ estudo de Standish e Pramasanto ${ }^{55}$ (1991) demonstrou que irradiando micro-ondas antes da redução carbotérmica de minério de ferro aumenta a taxa de redução, como também demonstraram Saidi e Azari ${ }^{51}$ (2005) com óxido de zinco. O equipamento de micro-ondas utilizado para a pré-irradiação foi um forno doméstico, com magnetron de potência variável de 700 a $1300 \mathrm{~W}$ e freqüência de $2.45 \mathrm{GHz}$. A temperatura foi medida através de um termopar aterrado na cavidade para evitar erros de leitura devido ao campo eletromagnético. Foram feitas várias experiências variando a potência irradiada de micro-ondas e o tempo de exposição. Após esta etapa as amostras eram reduzidas em forno elétrico convencional e os resultados apresentaram que as maiores taxas de redução aconteciam para o minério tratado durante 6 minutos a $1300 \mathrm{~W}$, ou seja, em torno de $96 \%$ de conversão versus $84 \%$ de redução para um minério sem a pré-irradiação. Segundo os autores isto ocorreu, após análises microscópicas, pela maior porosidade encontrada no minério tratado, e essa maior porosidade ocasionada pelo trincamento das partículas do minério, que ocorreu devido ao aquecimento seletivo que as micro-ondas proporcionam.

Foi estudado por Zhong, Geotzman e Bleifuss ${ }^{17}$ (1996) o uso do aquecimento do minério de ferro através das micro-ondas como sendo uma alternativa para resolver o problema da lenta transferência de calor encontrado em processos convencionais de redução de óxidos metálicos. Testes de redução e aquecimento com micro-ondas foram realizadas em pelotas ou em pó da mistura entre um minério rico em magnetita, o qual apresentava baixo teor de sílica e outro com alto teor de sílica. Foram utilizados como redutores carvão e coque. O forno de micro-ondas utilizado possuía uma potência máxima de $15000 \mathrm{~W}$ e freqüência de $2.45 \mathrm{GHz}$.

Os resultados mostraram um significante aumento na taxa de redução sob o aquecimento através das micro-ondas, comparado com o sistema de aquecimento convencional conforme mostrado na figura 11. 


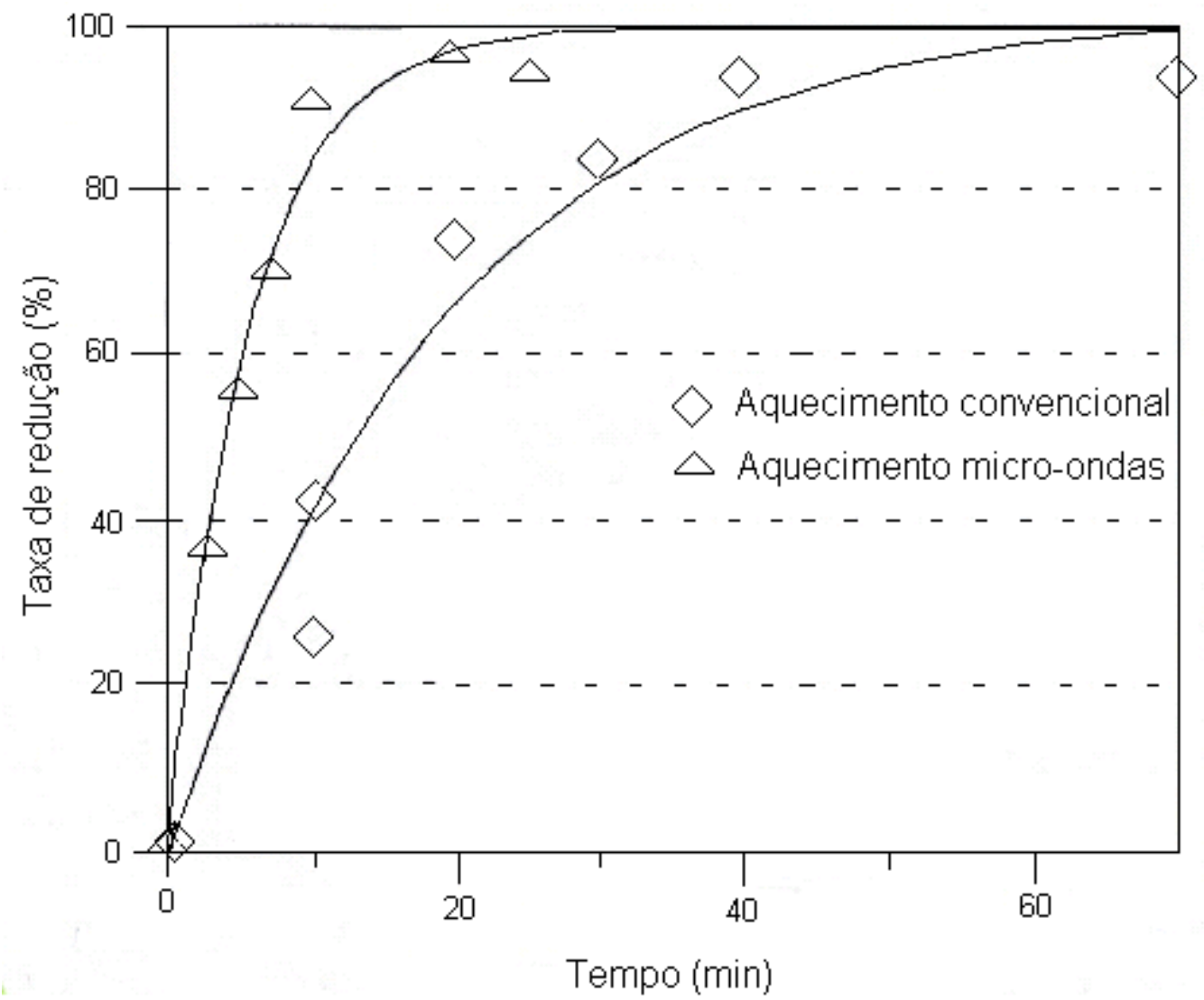

Figura 11 - Efeito do método de aquecimento na redução da magnetita"

Uma redução de $90 \%$ do minério de ferro com alto teor de sílica e com carvão pode facilmente ser alcançada em 10 minutos com uma temperatura de aproximadamente $1000^{\circ} \mathrm{C}$. O uso da energia de micro-ondas para aquecer e reduzir pelotas compostas de minérios ricos em magnetita e carvão tem várias vantagens. A energia de micro-ondas fornece calor para o mineral específico que controla a reação, ou seja, a magnetita e o carbono. A penetração da energia de micro-ondas é instantânea e não é limitada pelos coeficientes de difusão térmica. A energia de micro-ondas pode imediatamente iniciar a redução no interior da pelota através do fornecimento de calor específico para iniciar a reação entre a mistura sólida óxido de ferro-carbono, e então, continuar a fornecer energia para governar a reação de Boudouard para melhorar a geração de $C O$ para a reação. Os autores concluíram que o processo não precisa de um grande volume de carga e temperaturas altas de ar para abastecer a energia térmica necessária para manter o processo. O gás de saída gerado por este processo de redução é essencialmente limpo, livre de pó e com alto poder calorífico e sendo assim mais fácil de utilizá-lo na geração de potência para outros processos. 
Aguilar e Gomes $^{47}$ (1997) apresentaram os resultados de testes de redução carbotérmica realizados com pelotas de minério de ferro e carbono em forno doméstico de micro-ondas com potência nominal de $800 \mathrm{~W}$ e compararam com taxas de redução em processo de aquecimento convencional a $1100^{\circ} \mathrm{C}$. Os autores realizaram vários testes de redução com micro-ondas para definir melhores condições de operação, como a melhor proporção de carbono na pelota, melhor posição do cadinho com amostra no interior da cavidade onde possua maior densidade energética e a influência do cadinho de sílica. Concluíram que a quantidade de carbono deve ser 3.5 vezes ao estequiométrico, que a melhor posição do cadinho no interior da cavidade é a mostrada pela figura 12 e que os testes realizados com e sem cadinho fornecem os mesmos resultados.

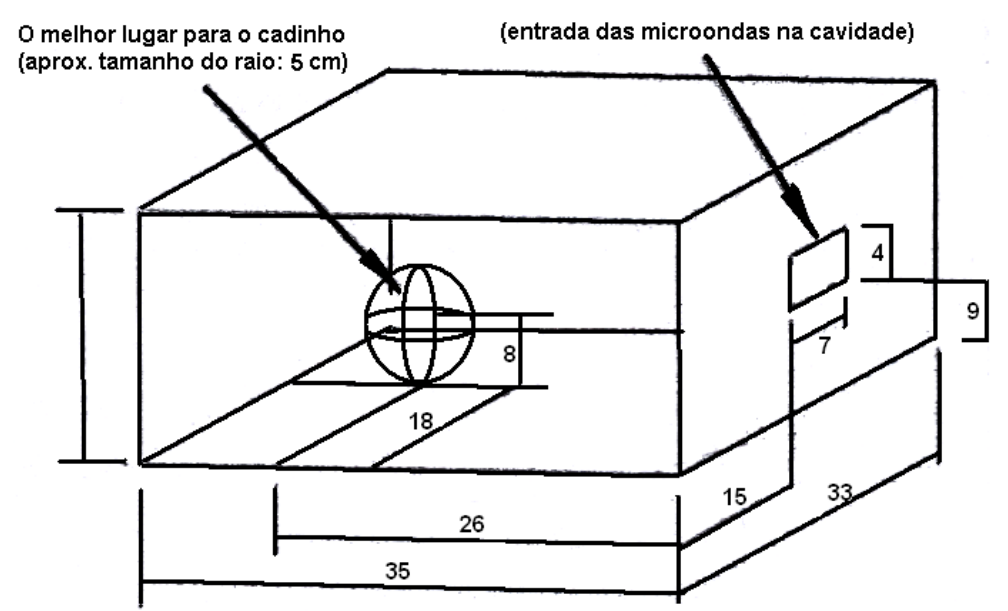

Figura 12 - Representação esquemática da posição no interior de uma cavidade doméstica aonde possui maior densidade energética incidida no cadinho com amostra ${ }^{47}$

Outras conclusões obtidas pelos autores é que a baixa taxa de redução obtida comparada ao aquecimento tradicional, mostrada através da figura 13, é que o processo neste caso é governado por difusão e, portanto quando na superfície da pelota um filme metálico se forma, o agente redutor perde a eficiência, ou seja, dificultando a difusão do $C O$, além da energia de microondas não penetrar na massa reagente. Outra observação obtida é a vantagem do aquecimento volumétrico na amostra proporcionado pela radiação de microondas, aonde pode ajudar na baixa transferência de calor encontrada pelos métodos convencionais de redução. 


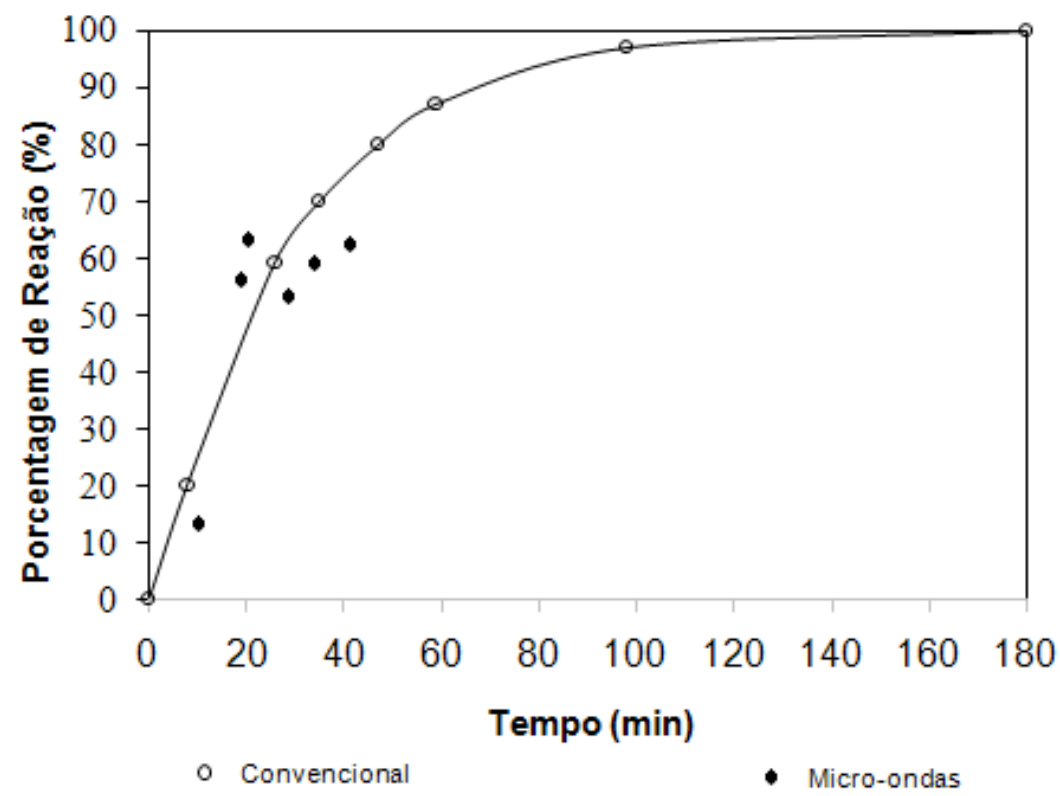

Figura 13 - Taxa de redução versus tempo para processamento com micro-ondas a $800 \mathrm{~W}$, e aquecimento convencional a $1100^{\circ} \mathrm{C}^{47}$

Nishioka ${ }^{48}$ et al. (2007) pesquisaram fundamentalmente a co-geração de hidrogênio e ferro metálico provenientes de redução carbotérmica da mistura entre pó de plásticos como agente redutor e de minério de ferro usando as micro-ondas como fonte de aquecimento. Os experimentos foram conduzidos com o equipamento mostrado pela figura 14. Os plásticos em pó utilizados foram o polipropileno, polietileno e borra de combustível (RDF). O comportamento da decomposição térmica destes plásticos em pó, o efeito do tipo de plástico e sua composição na geração de $\mathrm{H}_{2}, \mathrm{CH}_{4}, \mathrm{CO}$ e $\mathrm{CO}_{2}$ a partir das misturas ensaiadas também foram estudadas. Como resultado, $\mathrm{H}_{2}, \mathrm{CO}$ e ferro metálico foram produzidos a partir destas misturas em um mesmo tempo de irradiação por micro-ondas e uma faixa de $57-88 \%$ de hidrogênio na forma de $\mathrm{H}_{2}$ e $\mathrm{CH}_{4}$ foi recuperado nos ensaios. 


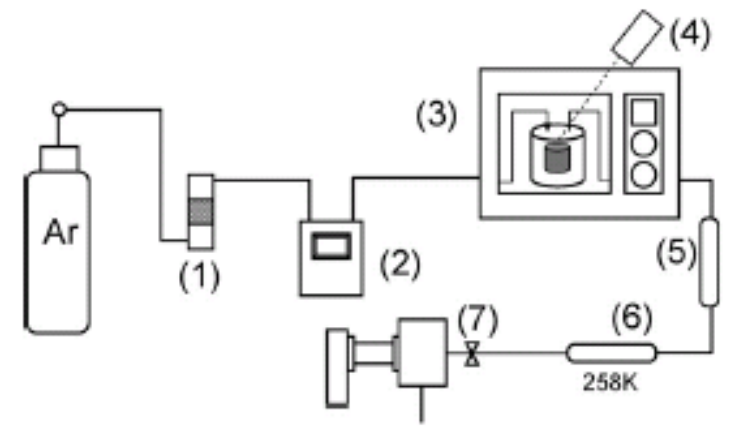

(1) Silica gel; (2) Rotâmetro; (3) Forno de micro-ondas doméstico

(4) Termômetro infravermelho $170-1700^{\circ} \mathrm{C}$ ou termopares;

(5) Filtro; (6) Trocador de calor; (7) Espectrometro de massa

Figura 14 - Ilustração esquemática de um forno de micro-ondas com cavidade doméstica ${ }^{48}$

O resíduo de laminação gerado na produção de aço inoxidável é um dos maiores tipos de passivo ambiental para a indústria do aço no mundo inteiro. Anualmente 13.5 milhões de toneladas deste resíduo são gerados pelo mundo e vários estudos realizados até agora não possuem apelo comercial, pois se consome muita energia para recuperar os componentes metálicos ${ }^{49}$. Quando um aquecimento convencional é aplicado, aproximadamente 180 minutos são necessários para obter $100 \%$ de metalização em uma faixa de temperatura de $1100^{\circ} \mathrm{C}$ a $1200^{\circ} \mathrm{C}$. Em adição, devido às características de o resíduo ser pulverulenta, um pré-tratamento como a pelotilização se faz necessário, no qual pode resultar em um aumento no nível das impurezas como o silício e na redução da metalização.

Cho e Lee ${ }^{49}$ (2008) pesquisaram a recuperação destes componentes metálicos provenientes do resíduo de laminação gerado na produção de aço inoxidável através da redução carbotérmica usando aquecimento por microondas. O equipamento utilizado pelos autores foi um forno de micro-ondas doméstico com uma câmara de material isolante revestida internamente com carbeto de silício. Um cadinho de alumina com tampa foi utilizado para a reação e a temperatura monitorada através de um termopar tipo-B. O aparato é mostrado pela figura 15. O estudo mostrou uma taxa de reação mais rápida do que a encontrada por métodos convencionais sem a necessidade de utilizar um pré-tratamento como a pelotilização. Além disso, gotas metálicas de $1 \mathrm{~mm}$ a 5 $\mathrm{mm}$ de diâmetro são produzidas em menos de 15 minutos facilitando a separação entre o metal e o pó restante não reagido. Ainda, devido a esta facilidade na separação, não encontrada em processos convencionais, o pó 
não reagido contendo grande quantidade de grafite pode retornar ao processo como agente redutor diminuindo o consumo de energia.

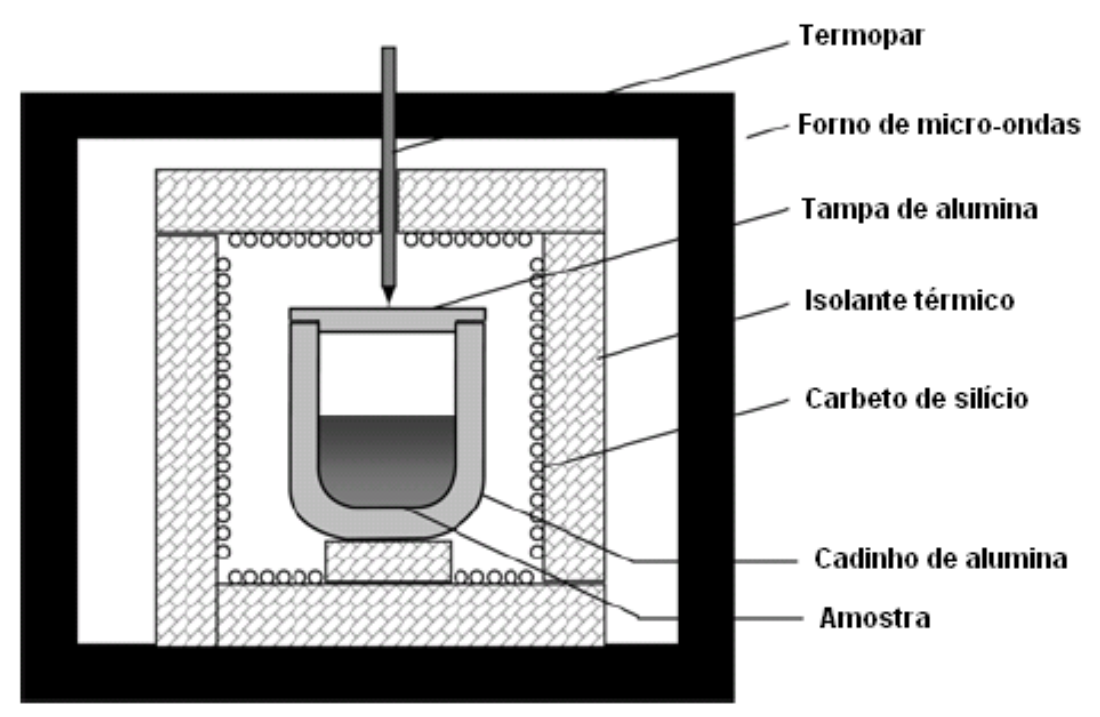

Figura 15 - Ilustração esquemática de um forno de micro-ondas com cavidade doméstica ${ }^{49}$

O estudo realizado por Ishizaki, Nagata e Hayashi ${ }^{50}$ (2006) mostrou a produção de ferro gusa a partir de pelotas compostas por magnetita e carvão com aproximadamente 10, 15 e 20 mm de diâmetro, usando o aquecimento por micro-ondas. O equipamento utilizado possui um gerador de micro-ondas com potência máxima de $5000 \mathrm{~W}$ e freqüência $2.45 \mathrm{GHz}$ mostrado na figura 16 . O formato da câmara de reação é pentagonal facilitando a homogeneização entre o campo elétrico e magnético não encontrado em cavidades retangulares. As potências de micro-ondas irradiadas foram de $1000 \mathrm{~W}, 2000 \mathrm{~W}$ e $3000 \mathrm{~W}$. De uma a quatro pelotas foram colocadas no meio da cavidade e cobertas por um isolante térmico de alumina revestido internamente com carbeto de silício para aquecer e compensar a perda de calor da amostra. O carbeto de silício é um material de alta perda dielétrica e possui uma elevada capacidade de absorver energia eletromagnética. A temperatura foi medida através de um pirômetro óptico localizado na parte superior do forno e a taxa de reação acompanhada visualmente por um visor localizado no lado externo da câmara. Através das análises XRD a redução iniciou a $820^{\circ} \mathrm{C}$ e completou-se a aproximadamente entre $1150^{\circ} \mathrm{C}$ a $1250^{\circ} \mathrm{C}$. Só não foi possível obter o ferro gusa nos ensaios com 
potência irradiada de micro-ondas de 1000 W. A escória foi facilmente separado do ferro gusa produzido e o conteúdo de impurezas foi muito baixo.

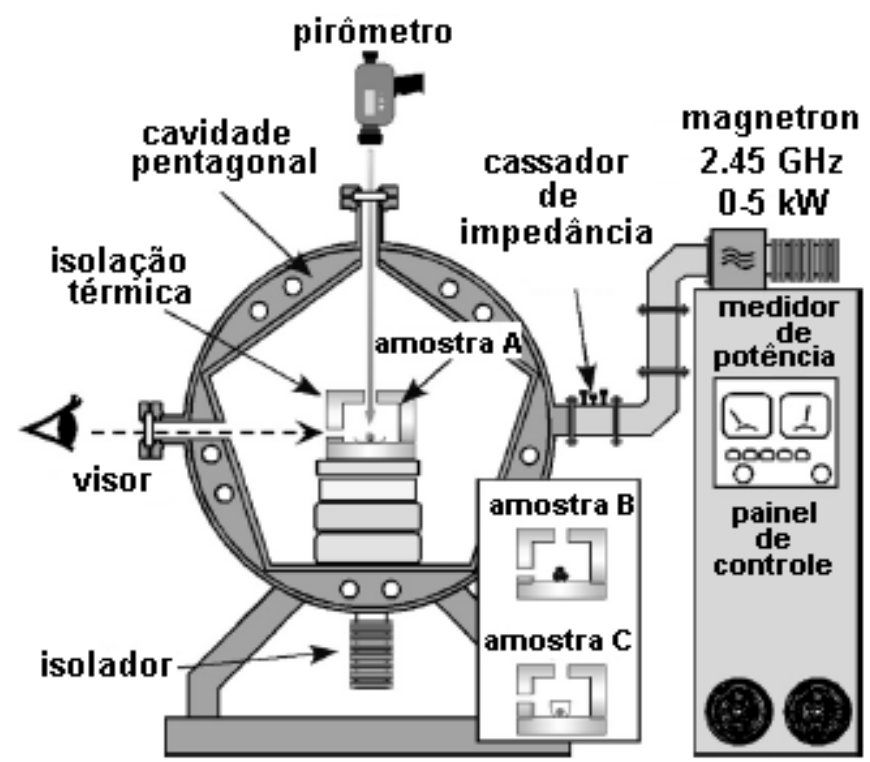

Figura 16 - Ilustração esquemática de um forno de micro-ondas com cavidade pentagonal ${ }^{50}$

Saidi e Azari $^{51}$ (2005) estudaram a possibilidade da redução carbotérmica do concentrado de óxido de zinco bem como os efeitos dos parâmetros de operação usando como fonte de aquecimento as micro-ondas. Diferentes fontes de carbono como o coque, grafite e carvão foram usados como agentes redutores. Os autores dividiram o trabalho em 3 etapas: Primeiro foi determinada a capacidade de absorção da energia de micro-ondas do óxido de zinco concentrado e puro e das diferentes fontes de carbono. Segundo, misturas entre concentrado de óxido de zinco e coque variando granulometria, quantidade de carbono e tamanho da pelota. E a última etapa o efeito de uma pré-radiação com micro-ondas no óxido de zinco puro na cinética de redução carbotérmica com aquecimento convencional através de um forno elétrico a $1100^{\circ} \mathrm{C}$.

Os estudos mostraram que tanto o óxido de zinco concentrado como 0 puro não absorvem energia de micro-ondas devido possuírem fator de perda dielétrica baixa. Todas as fontes de carbono absorveram bem as micro-ondas, mas o grafite e o coque apresentaram melhor resultado. Houve aumentos na porcentagem de redução carbotérmica com micro-ondas aumentando a quantidade de carbono presente na amostra, o tamanho das partículas do 
óxido de zinco e o tamanho da amostra. A figura 17 indica que a taxa de redução possui relação direta com a potência. Obviamente, aumentando 0 nível de potência diminui o tempo de radiação.

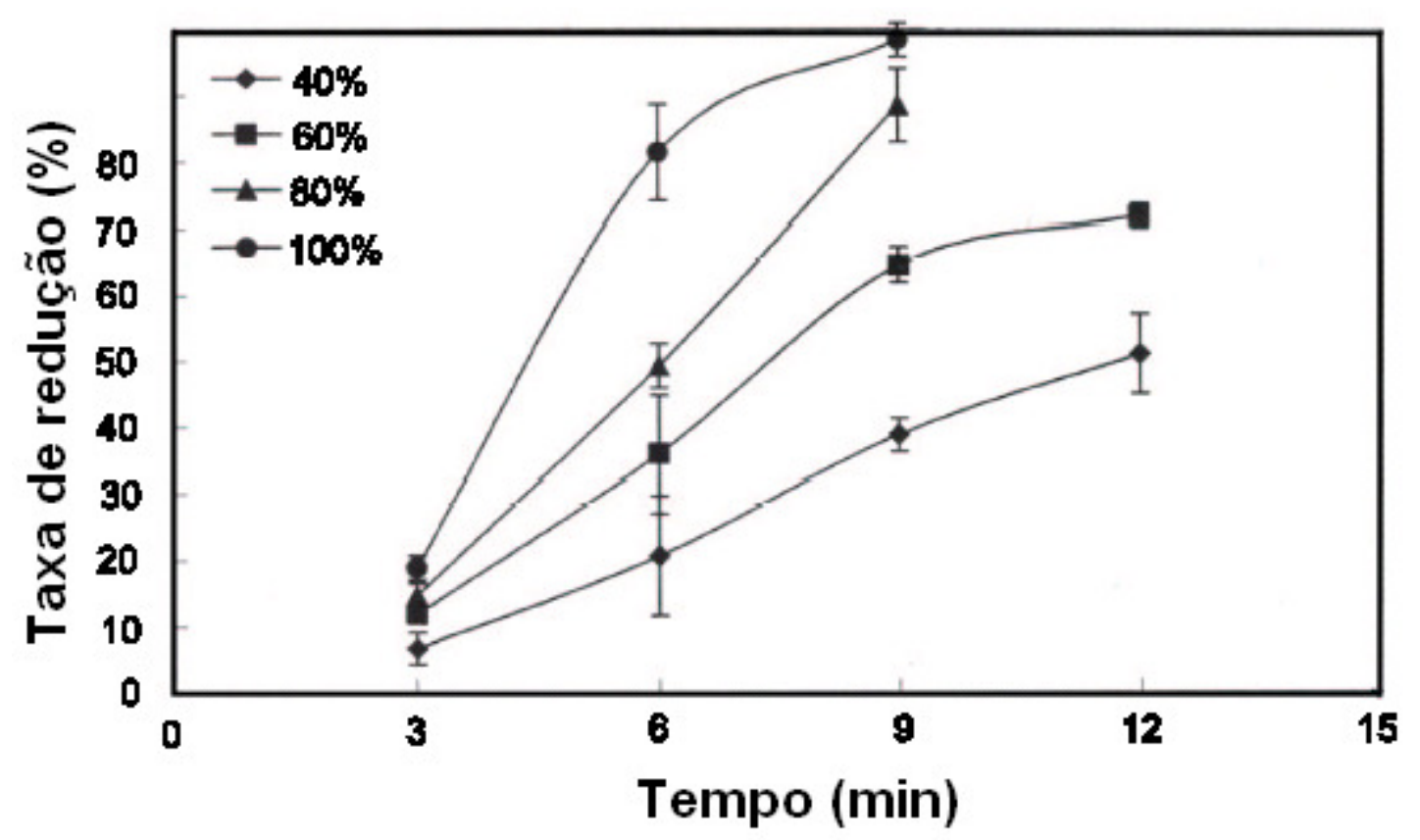

Figura 17 - Efeito do nível de potência de micro-ondas na redução do óxido de zinco ${ }^{\text {b1 }}$

Para todos os ensaios foram utilizados um forno doméstico com potência nominal de $1000 \mathrm{~W}$ e freqüência de $2.45 \mathrm{GHz}$. Uma pré-exposição às micro-ondas do óxido de zinco também aumenta a taxa de redução em métodos convencionais como mostra a figura 18. Os autores concluíram que todos estes efeitos positivos foram causados pelo efeito não térmico proporcionado pela energia das micro-ondas como uma alta taxa de aquecimento, mudança da energia de ativação, perfil de temperatura inversa, taxa constante de reação e melhor taxa de difusão. 


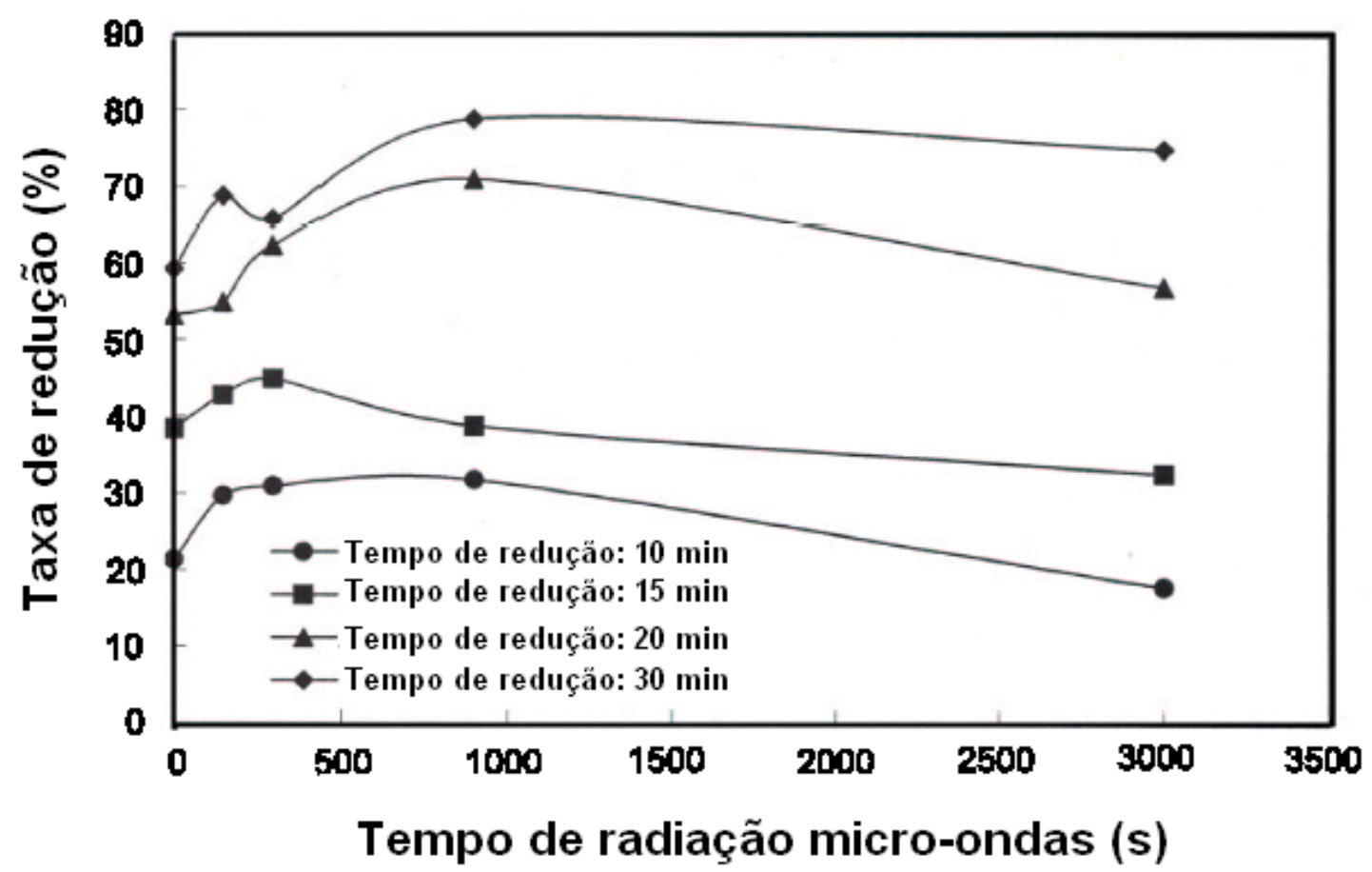

Figura 18 - Taxa de redução vs tempo de radiação de micro-ondas (redução em forno elétrico a $\left.1100^{\circ} \mathrm{C}\right)^{51}$

Mourão, Carvalho Jr. e Takano ${ }^{16,46}$ (2001) estudaram a redução da hematita com irradiação por micro-ondas através de um forno doméstico com $1100 \mathrm{~W}$ de potência nominal e freqüência de $2.45 \mathrm{GHz}$. A presença de aglomerante, a quantidade e tipo de agente redutor e o isolamento térmico da amostra foram às variáveis utilizadas pelos autores e mostraram de grande influência na cinética de redução.

A quantidade de material carbonáceo (coque ou carvão vegetal) adicionado à mistura foi calculada baseando-se na quantidade de oxigênio combinado com o minério de ferro. Foram usadas duas relações diferentes entre o material carbonáceo e oxigênio combinado: $C / O=1,0$ e $C / O=1,33$ (tanto para coque como para carvão vegetal), onde "C" representa a quantidade do material carbonáceo. Todas as composições das pelotas (de "A" a "F") possuíam diâmetros e pesos semelhantes, ou seja, de 15 a 18 mm e de 4 a $6 \mathrm{~g}$, respectivamente.

$\mathrm{Na}$ figura 19 são mostrados os resultados obtidos em vários experimentos em termos de porcentagem de reação em função do tempo para os vários tipos de pelotas testadas. 


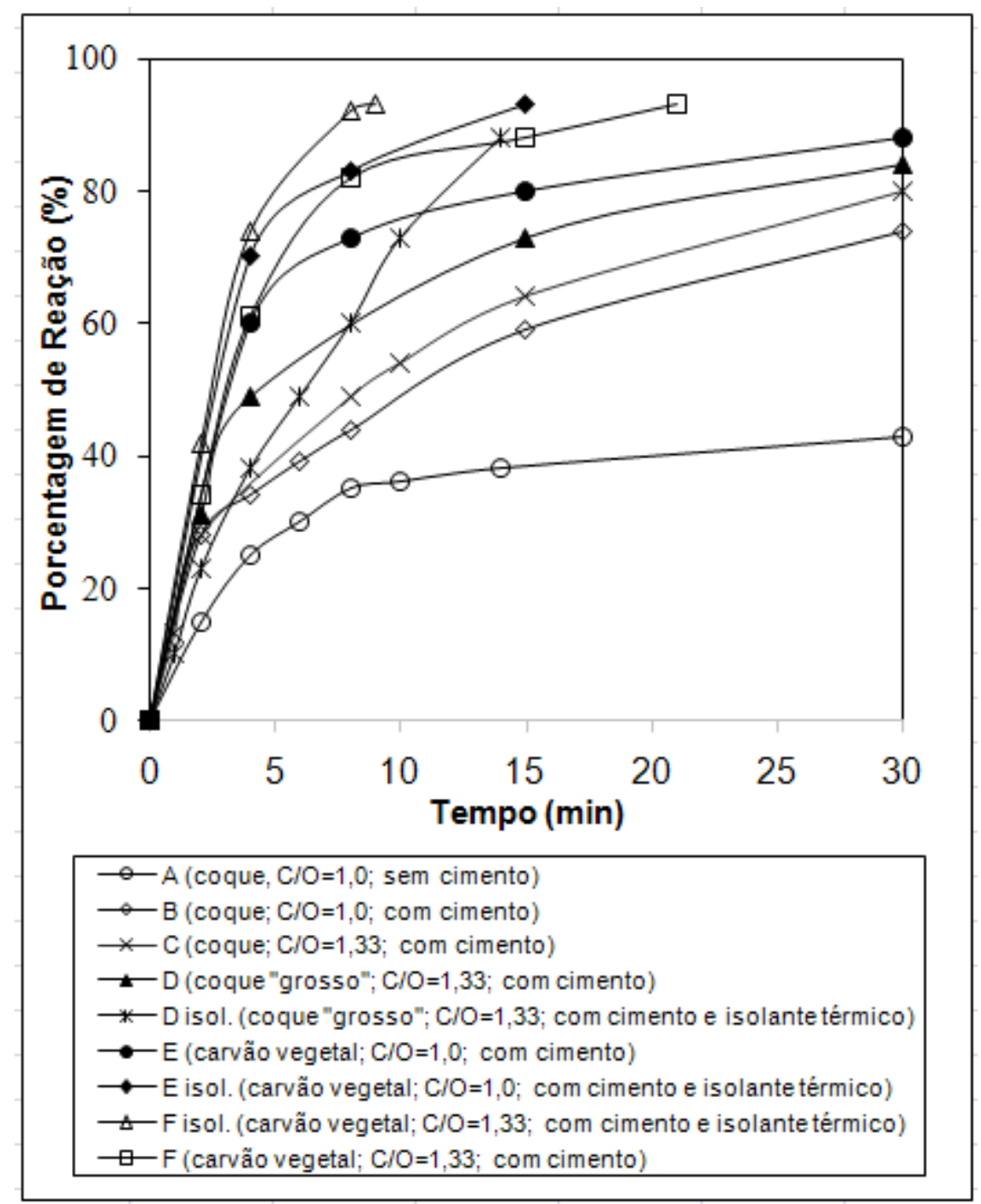

Figura 19 - Porcentagem de reação em função do tempo e tipo de pelota quando as pelotas são submetidas ao aquecimento por micro-ondas ${ }^{16,46}$

De uma maneira geral, as pelotas com aglomerante, uma maior quantidade de redutor, carvão vegetal como redutor e isolamento térmico favoreceram a cinética de redução do minério de ferro.

O trabalho realizado por Nishioka, Maeda e Shimizu ${ }^{52}$ (2002) visou à recuperação dos metais zinco e chumbo de pó residual provenientes do processo de fabricação de aço e ferro através do aquecimento por microondas.

Esta recuperação é realizada convencionalmente por fornos rotativos e contínuos e apresentam alguns problemas como alto consumo de energia, geração enorme de $\mathrm{CO}_{2}$ e alta temperatura dos gases de saída. Os ensaios foram realizados em um forno de micro-ondas doméstico com variação de 
potência de 0 a $1000 \mathrm{~W}$, freqüência de $2.45 \mathrm{GHz}$, atmosfera inerte e controle da temperatura.

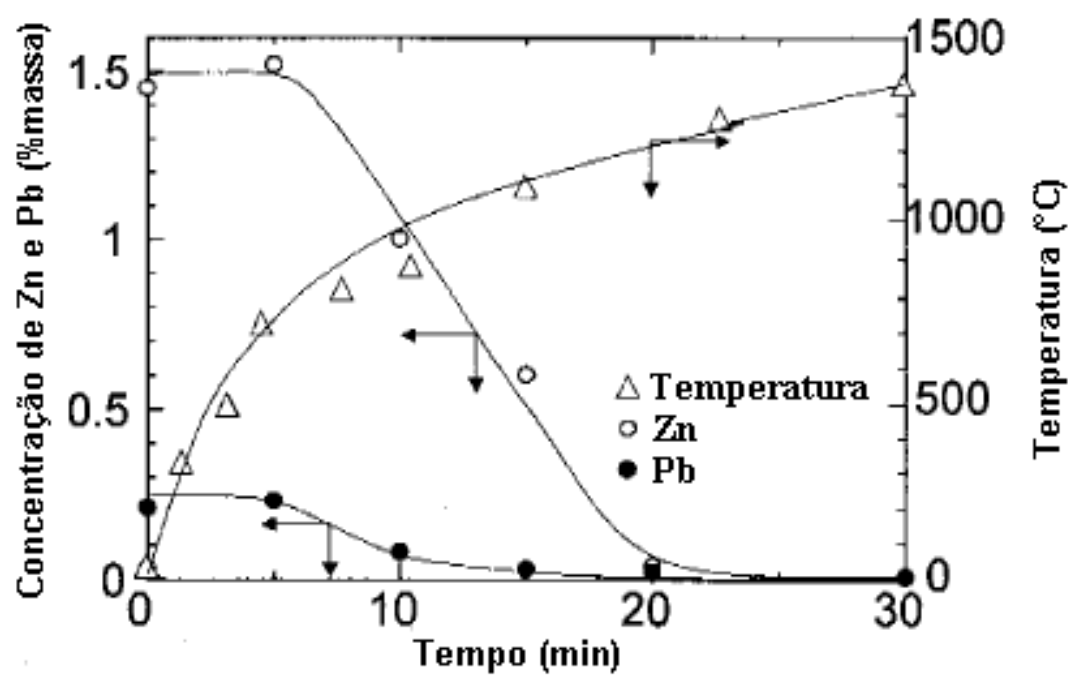

Figura 20 - Mudança de concentração dos metais zinco e chumbo com $1000 \mathrm{~W}$ de energia de micro-ondas ${ }^{52}$

Durante o primeiro estágio de aquecimento, ou seja, 5 minutos, não houve nenhuma alteração na concentração dos metais, pois a redução do $\mathrm{Fe}_{2} \mathrm{O}_{3}$ foi prioritária a redução do $\mathrm{ZnO}$. A variação da concentração de zinco e chumbo começou a ocorrer na faixa de 5 - 10 minutos quando a temperatura da amostra estava entre $900-1000^{\circ} \mathrm{C}$, e em 20 minutos de ensaio recuperou quase $100 \%$ dos metais. Nos estudos com micro-ondas os autores conseguiram recuperar quase $100 \%$ do zinco e do chumbo com 20 minutos de aquecimento por micro-ondas, como mostrado na figura 20.

Ainda no campo de pesquisas sobre a recuperação de metais existentes pós residuais provenientes do processo de fabricação de aço e ferro, Sun, Hwang e Huang ${ }^{53}$ (2008) realizaram testes para validar a possibilidade do tratamento do pó residual de um forno elétrico a arco sob radiação de microondas para produzir ferro e zinco metálico ao invés de óxidos como coprodutos. Este resíduo é composto em sua maior parte por ferrita de zinco, no qual possui alta capacidade de absorver micro-ondas e misturado com carbono se torna muito vantajoso no processo de redução a zinco e ferro metálico com micro-ondas. Três diferentes tipos de carbono foram usados como agentes redutores: coque de petróleo, grafite e coque. A quantidade dos materiais carbonáceos neste estudo foi calculada baseada na quantidade de carbono fixo 
e adotaram-se três variáveis: 10, 15 e $20 \% \mathrm{~m}$. A figura 21 mostra um forno doméstico modificado para este trabalho. Como resultado ferro e zinco metálico relativamente puro foram obtidos em aproximadamente 15 minutos comparada de 4 a 6 horas com o processo Waelz, além de reduzir o consumo de energia.

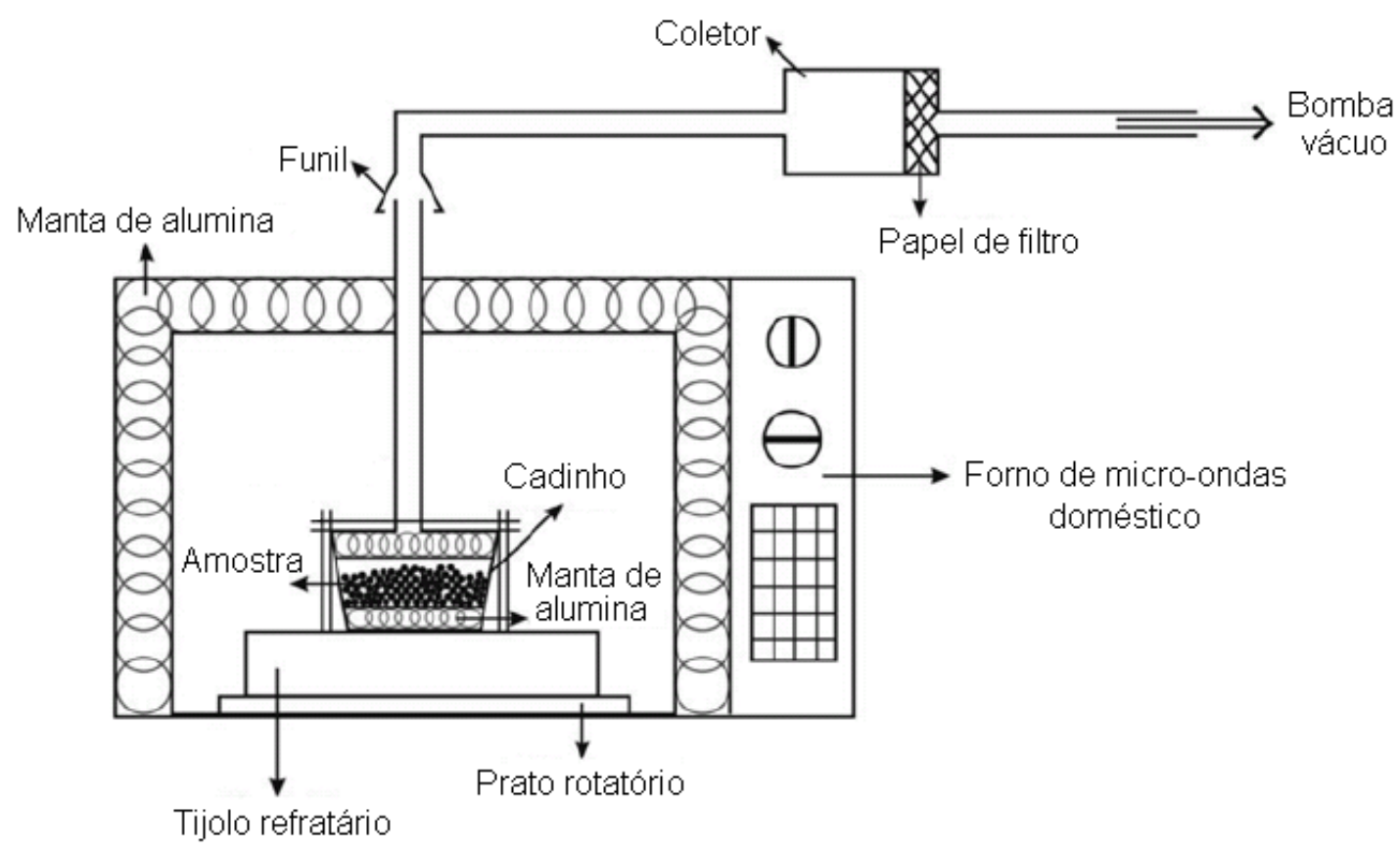

Figura 21 - llustração esquemática de um forno de micro-ondas com cavidade doméstica para recuperação de zinco e ferro metálico de resíduo do forno elétrico a $\operatorname{arco}^{53}$ 


\section{MATERIAIS E MÉTODOS}

\subsection{Materiais}

Os seguintes materiais foram utilizados: minério de ferro de Carajás, finos de coque de petróleo e aglomerante hidroxietil celulose, gás argônio, tarugo e cadinho de fibra cerâmica e cadinho de carbeto de silício.

\subsubsection{Material a ser reduzido por micro-ondas}

\section{Minério de ferro de Carajás}

Para a preparação das pelotas auto-redutoras em estudo, foi utilizado minério de ferro de Carajás para o qual a composição química e análise granulométrica são fornecidas nas tabelas 2 e 3 respectivamente. A análise granulométrica foi realizada conforme a norma ABNT-NBR NM $248^{56}$.

Tabela 2 - Composição química do minério de ferro de Carajás (\% em peso).

\begin{tabular}{ccccccccccc}
\hline $\mathrm{Fe}_{\text {total }}$ & $\mathrm{SiO}_{2}$ & $\mathrm{Al}_{2} \mathrm{O}_{3}$ & $\mathrm{CaO}$ & $\mathrm{MgO}$ & $\mathrm{P}$ & $\mathrm{Mn}$ & $\mathrm{TiO}_{2}$ & $\mathrm{Cr}_{2} \mathrm{O}_{3}$ & $\mathrm{FeO}$ & $\mathrm{SiC}$ \\
\hline 67.65 & 0.67 & 0.61 & 0.03 & 0.06 & 0.029 & 0.0289 & 0.036 & na & - & na \\
\hline
\end{tabular}

Tabela 3 - Análise granulométrica do minério de ferro de Carajás.

\begin{tabular}{cccc}
\hline Malha & Abertura $(\mu \mathrm{m})$ & \% massa retida & \% massa passante \\
\hline 35 & 420 & 0.00 & 100.0 \\
48 & 300 & 1.39 & 98.61 \\
100 & 149 & 11.93 & 88.06 \\
150 & 106 & 39.35 & 60.65 \\
200 & 74 & 55.06 & 44.94 \\
270 & 53 & 92.94 & 7.06 \\
400 & 38 & 100.0 & 0.00 \\
\hline
\end{tabular}




\section{Coque de petróleo}

A análise imediata do coque de petróleo foi determinada conforme a norma ASTM-D3172-89 ${ }^{57}$ e apresentada na tabela 4. A faixa granulométrica utilizada foi de 300 a $106 \mu \mathrm{m}$.

Tabela 4 - Análise imediata do coque de petróleo (\% em peso).

\begin{tabular}{cccc}
\hline $\mathrm{C}_{\text {Fixo }}$ & Cinzas & Matéria volátil & Enxofre \\
\hline 86.50 & 0.40 & 12.54 & 0.56 \\
\hline
\end{tabular}

\section{Hidroxietil celulose}

As propriedades típicas deste aglomerante são mostradas na tabela 5.

Tabela 5 - Propriedades típicas do hidroxietil celulose.

\begin{tabular}{cc}
\hline Propriedades & Características \\
\hline Aparência & Branco, pó livremente solto \\
Densidade volumétrica $\left(\mathrm{g} / \mathrm{cm}^{3}\right)$ & $0,3-0,6$ \\
Ponto de amolecimento $\left({ }^{\circ} \mathrm{C}\right)$ & 140 \\
Tamanho da partícula & $100 \%<800 \mu \mathrm{m}$ \\
Gravidade específica $20 / 20^{\circ} \mathrm{C}$ & $1,3-1,4$ \\
Matéria volátil $(\% \mathrm{~m})$ & 5 \\
\hline
\end{tabular}

\subsubsection{Gás argônio}

O argônio utilizado para manter o sistema câmara de reação/balança foi o Coogar100 fornecido pela Air Products e possui alto grau de pureza. A vazão adotada para todos os ensaios foi de $0,85 \mathrm{~L} / \mathrm{min}$.

\subsubsection{Base cerâmica/eixo de teflon e cadinho cerâmica/eixo de teflon}

Para posicionar a pelota do centro da câmara de reação foi utilizado um eixo de teflon interligado em sua extremidade superior a um tarugo de fibra cerâmica e/ou cadinho de fibra cerâmica ou ainda em um cadinho de carbeto 
de silício como mostrado na figura 22. As dimensões de ambos são mostradas na figura 23.

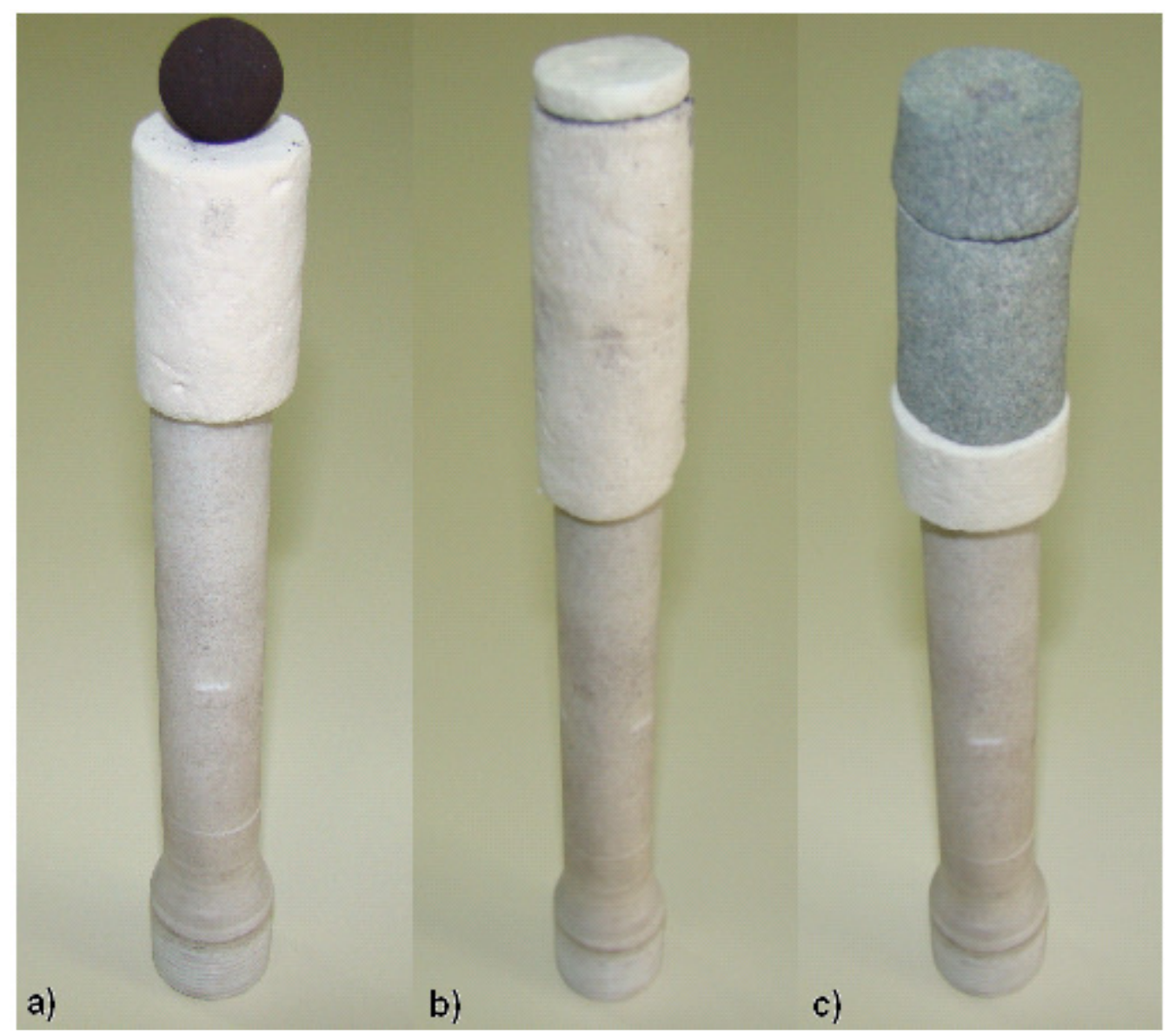

Figura 22 - a) Pelota sem isolação térmica; b) pelota isolada termicamente; c) pelota no interior do cadinho de carbeto de silício

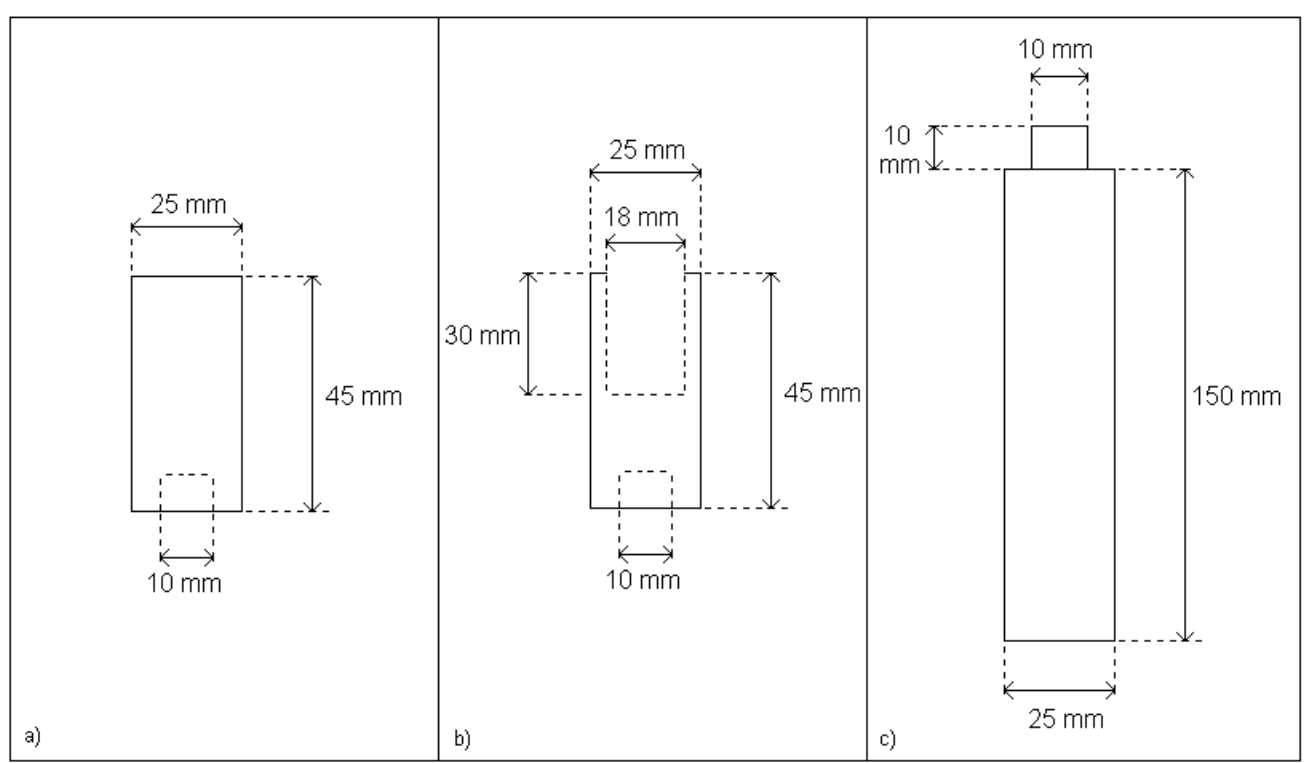

Figura 23 - Dimensões (mm) do a) tarugo de fibra cerâmica; b) do cadinho de fibra cerâmica e/ou carbeto de silício; c) do eixo de teflon 
A fibra cerâmica fabricada pela Morganite Brasil da marca Kaowool, possui um ponto de fusão de $1400^{\circ} \mathrm{C}$.

\subsection{Forno de redução carbotérmica de óxidos metálicos com aquecimento} por micro-ondas

O forno para redução carbotérmica de óxidos metálicos através da irradiação por micro-ondas é mostrado através das figuras 24 e 25.

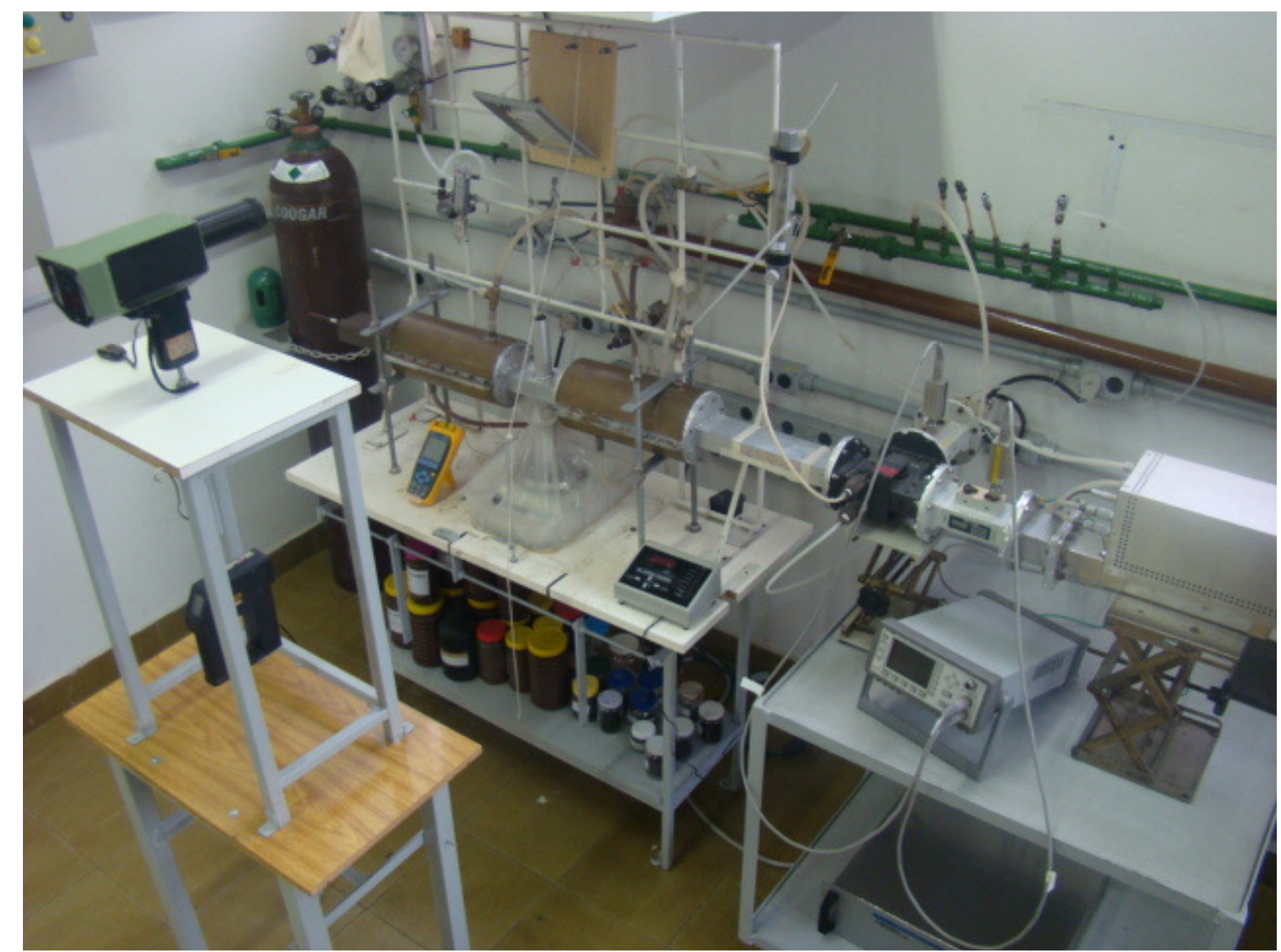

Figura 24 - Forno para redução carbotérmica e aquecimento de materiais por irradiação de micro-ondas 


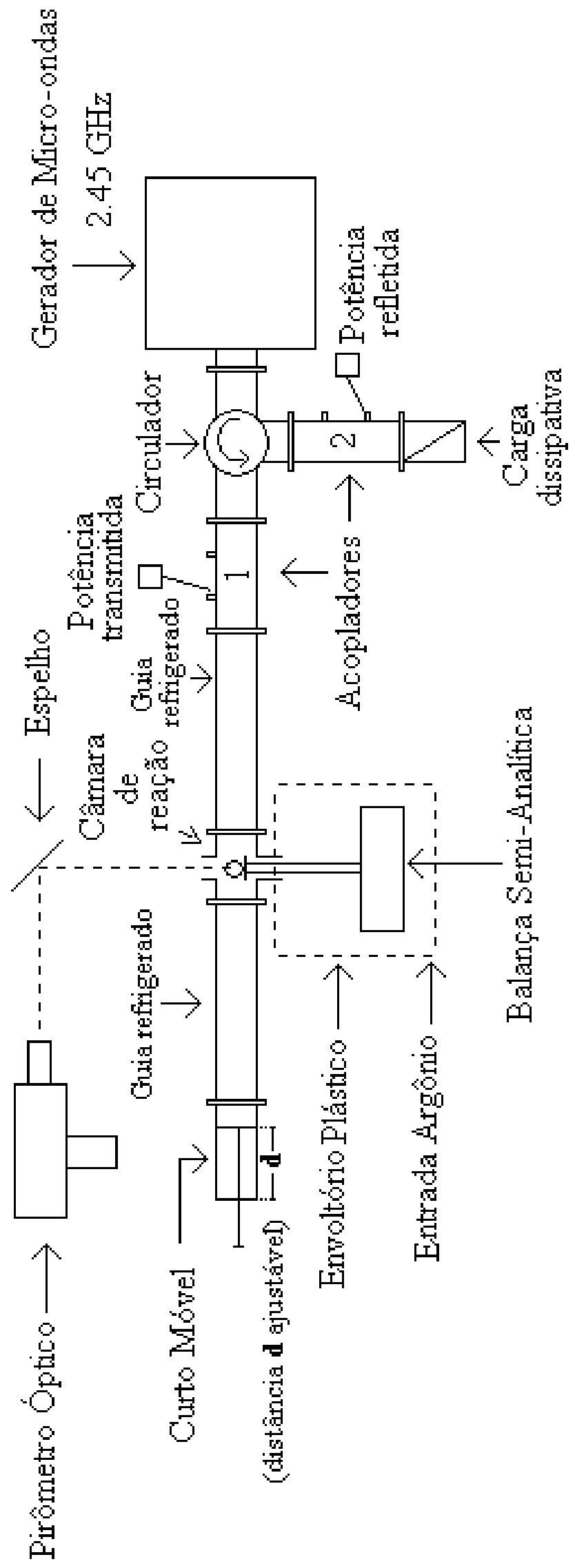

Figura 25 - Diagrama esquemático do forno para redução carbotérmica e aquecimento de materiais por irradiação de micro-ondas 


\subsubsection{Especificação}

O forno tem duas importantes seções, ou seja, das micro-ondas e câmara de redução carbotérmica.

As micro-ondas são geradas através de um gerador de $2.45 \mathrm{GHz}$ de potência regulável até $3000 \mathrm{~W}$. Este gerador é protegido contra o retorno de micro-ondas por um circulador. Este circulador direciona para a seção de teste a potência de saída do gerador e desvia para a carga dissipativa (sem reflexão) a potência refletida. Dois acopladores direcionais que permitem medir a potência de micro-ondas irradiada (a que sai do gerador) e a refletida (a que retorna do forno e é direcionada a carga de dissipação) estão conectados a dois medidores de potência que registram as potências de micro-ondas irradiadas e refletidas ao equipamento. O curto-móvel direciona o máximo campo elétrico ou o máximo campo magnético possível sobre a carga como mostrado pela figura 26. Em termos práticos, permite localizar em dado ponto do guia um determinado valor de campo elétrico e/ou magnético, variando a distância $\mathbf{d}$ entre este ponto e o curto, ou seja, pode-se irradiar uma amostra sempre com um determinado valor de campo elétrico e/ou magnético.

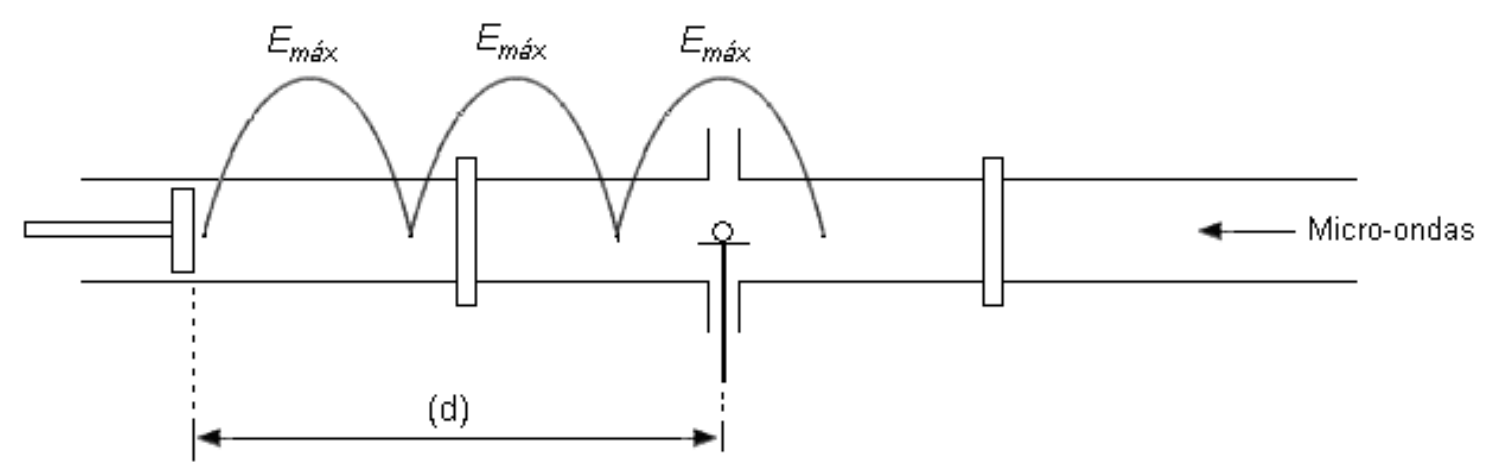

Figura 26 - Representação do campo elétrico em um guia retangular em curto

Os filtros de micro-ondas localizados na parte inferior e superior da câmara de reação asseguram a alimentação da pelota ao interior do reator, ao monitoramento da temperatura na superfície do material e a saída do gás inerte e fumos. Este sistema permite que tanto a balança semi-analítica como o reator esteja em um ambiente inerte. A temperatura no interior da câmara de reação 
pode ser lida através de um pirômetro óptico, por meio de um espelho localizado logo acima do filtro superior. A temperatura dos gases é medida através de um termômetro de fibra óptica localizado na saída do filtro superior. Ao filtro inferior é conectado um envoltório plástico transparente com uma balança semi-analítica em seu interior para monitorar a perda de massa da carga. O envoltório plástico possui entrada para argônio e para o fio de alimentação de energia da balança semi-analítica. Os guias de onda estão envolvidos por trocadores de calor para resfriá-los durante o processo de redução conforme mostrado pela figura 27. Estes trocadores possuem termômetros tanto na entrada como na saída do fluído refrigerante (água). A vazão do argônio e do fluído refrigerante são medidos por rotâmetros. A comunicação e a coleta de dados para um computador foram realizadas por um software.

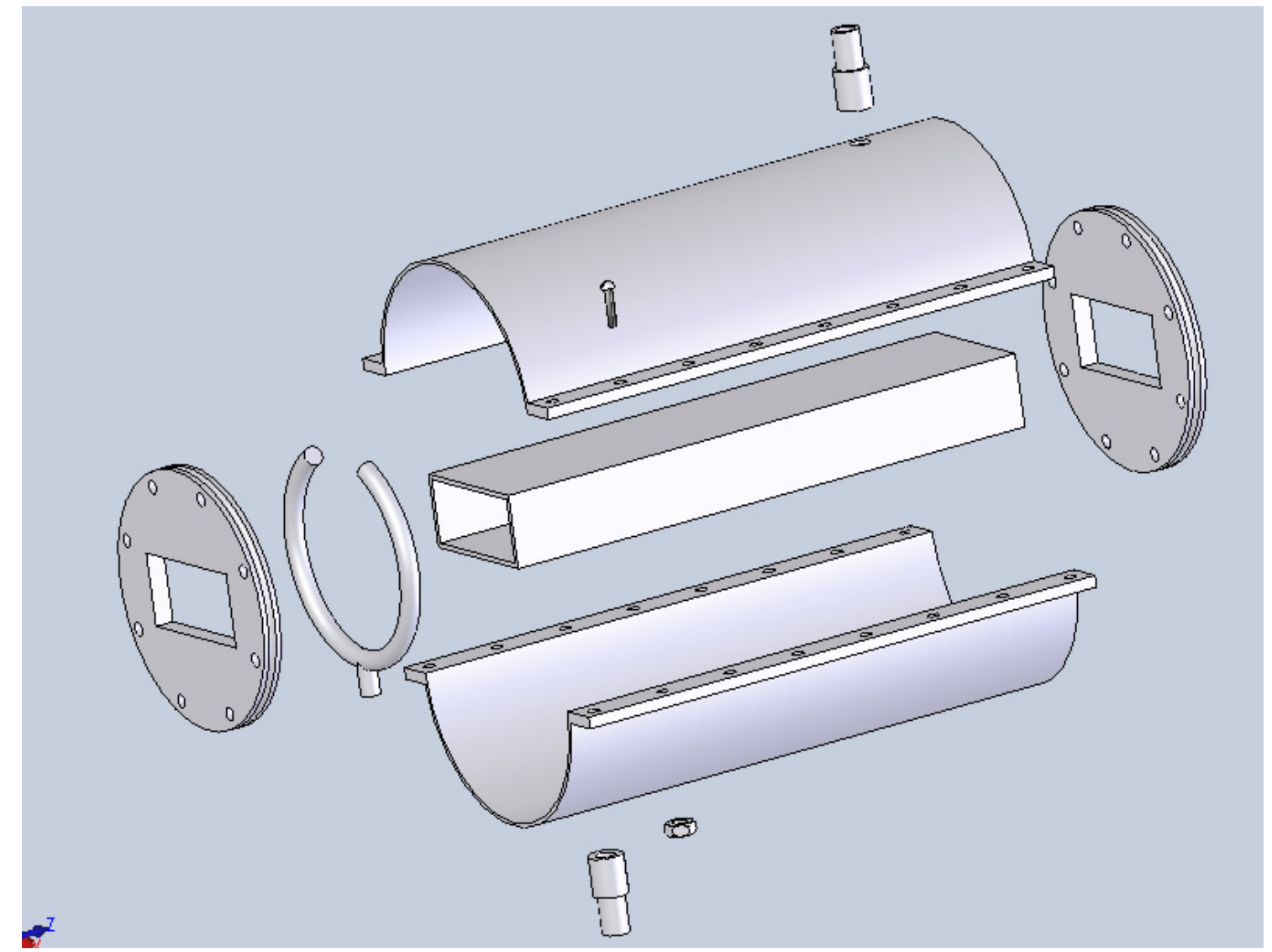

Figura 27 - Representação de um guia retangular envolvido por trocador de calor 


\subsubsection{Determinação das perdas de energia para o equipamento sem amostra}

Perdas de energia para o equipamento sem amostra consistem em toda a energia de micro-ondas absorvida pelo equipamento sem a presença da amostra, ou seja, a energia absorvida em forma de calor pelos trocadores de calor, pelos guias de ondas, reator, gás inerte, cadinhos e dispositivos de micro-ondas como circulador, acoplador e curto móvel. A potência de microondas irradiada menos a potência de micro-ondas refletida é igual à potência de micro-ondas absorvida pelo equipamento.

$$
E_{\text {equip }}=E_{\text {irrsa }}-E_{\text {reflsa }}
$$

Onde:

$E_{\text {equip }}=$ energia de micro-ondas absorvida pelo equipamento durante ensaio com o equipamento sem amostra $(\mathrm{kJ})$;

$E_{\text {irrsa }}=$ energia de micro-ondas irradiada durante 0 ensaio com 0 equipamento sem amostra $(\mathrm{kJ})$;

$E_{r e f f s a}=$ energia de micro-ondas refletida pelo equipamento durante 0 ensaio sem amostra $(\mathrm{kJ})$;

A figura 28 apresenta um esquema diagramático do equipamento. A circulação da água de refrigeração pelos trocadores de calor TC1 e TC2 e do circulador $\mathrm{C} 1$ foi mantida a 0,5 L/min e 1,5 L/min, respectivamente. Também, a vazão entrada do gás argônio seco pela câmara de reação foi mantida a 0,85L/min. A cada 3 minutos as temperaturas dos trocadores de calor TC1 e TC2, do circulador C1 e do gás argônio entrando e saindo do reator foram registrados por termômetros de fibra óptica. Já a temperatura da carcaça externa do reator, bem como a da superfície da base cerâmica e/ou cadinho foram monitoras por termômetro óptico e infravermelho. 


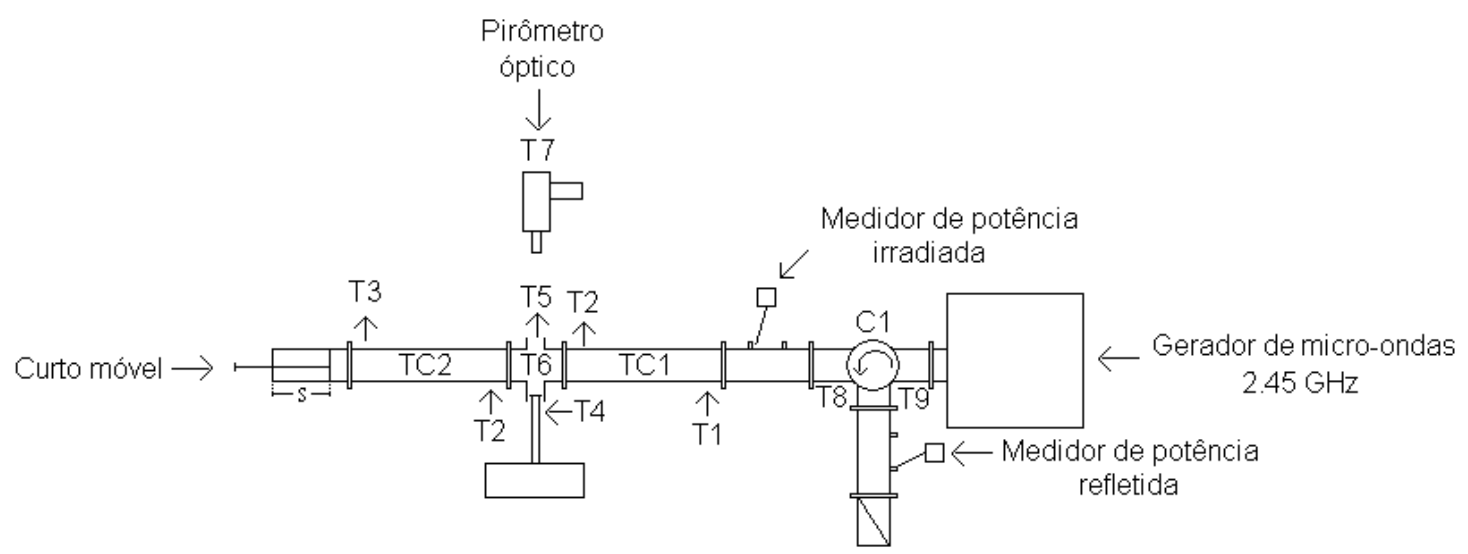

Figura 28 - Esquema diagramático para aferição das perdas para o sistema.

T1 é a temperatura da água de refrigeração na entrada do trocador de calor TC1. T2 e a temperatura da água de refrigeração na saída e na entrada dos trocadores de calor TC1 e TC2, respectivamente. T3 é a temperatura da água de refrigeração na saída do trocador de calor TC2. T4 e T5 são as temperaturas do gás argônio na entrada e na saída da câmara de reação. T6 é a temperatura das paredes externas da câmara de reação. T7 é a temperatura da superfície do tarugo ou do cadinho de fibra cerâmica ou ainda do cadinho de carbeto de silício. T8 e T9 são as temperaturas da água de refrigeração na entrada e saída do circulador C1.

Foram realizados ensaios em triplicata de 60 minutos cada em três níveis de irradiação de micro-ondas; $500 \mathrm{~W}, 1000 \mathrm{~W}$ e $1500 \mathrm{~W}$. As variações das potências foram registradas através de um medidor de potência Agilent E4419B acoplado a um aquisitor de dados. Os apêndices A e B mostram os memoriais de cálculo. 


\subsubsection{Teste de uso do forno para redução carbotérmica de óxidos metálicos}

\subsubsection{Pelotização}

Foram preparadas pelotas de $15 \mathrm{~mm}$ de minério de ferro Carajás e redutor coque de petróleo em proporção estequiométrica com aglomerante hidroxietil celulose a $0,5 \%$.

$O$ processo de pelotização consiste em uma pesagem precisa dos materiais e foram realizadas em uma balança analítica. A homogeneização foi realizada através de um misturador tipo "V" por 1 hora conforme ilustrado na figura 29 e a esta mistura efetuava-se uma pelotização manual onde se adicionava aproximadamente $20 \%$ em água para proporcionar a ligação intergranular dos componentes. Após esta etapa, as pelotas permaneciam por 24 horas secando ao ar e foram transferidas para uma estufa a $110^{\circ} \mathrm{C}$ por mais 24 horas. As pelotas foram resfriadas em dessecador e então sua superfície foi raspada até obter um diâmetro uniforme de $15 \mathrm{~mm}$. Novamente as pelotas foram transferidas para uma a estufa a $110^{\circ} \mathrm{C}$ por 4 horas e armazenadas em um dessecador com sílica gel como dessecante até o ensaio.

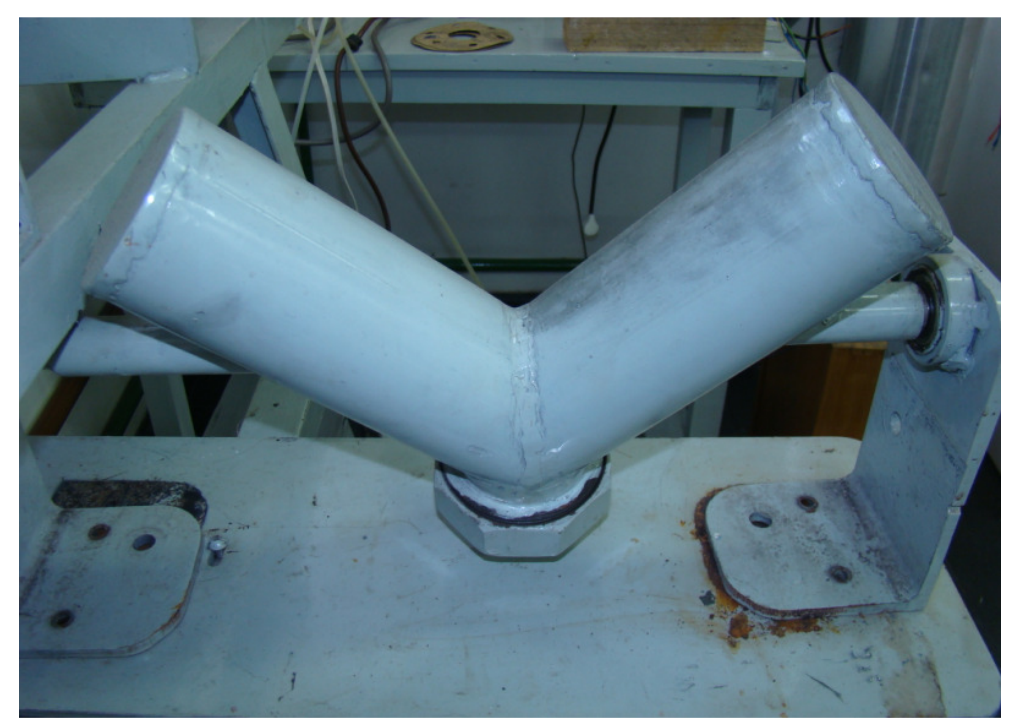

Figura 29 - Misturador tipo V utilizado para a homogeneização da mistura a ser pelotizada 


\subsubsection{Procedimento operacional para redução carbotérmica de óxidos metálicos com e sem isolação e com cadinho de carbeto de silício empregando energia de micro-ondas}

\subsection{Ensaios com uma pelota no máximo campo elétrico}

Uma pelota foi colocada no topo da base cerâmica/teflon para ensaios sem isolação, ou no interior do cadinho de fibra cerâmica para ensaios com isolação ou ainda no interior do cadinho de carbeto de silício conforme ilustrada e especificada anteriormente pelas figuras 22 e 23, respectivamente e inserida no interior do reator através do filtro de micro-ondas localizado na parte superior da câmara de reação. Este conjunto foi apoiado em uma balança semi-analítica para monitorar a perda de massa da pelota. O envoltório plástico usado para manter inerte o ambiente do sistema balança/câmara de reação foi lacrado com presilhas. A posição da pelota no interior do reator deve respeitar a faixa de movimentação do eixo da balança semi-analítica conforme mostrada através da figura 30. A circulação da água de refrigeração pelos trocadores de calor foi mantida a $0,5 \mathrm{~L} / \mathrm{min}$. Também, a vazão do gás argônio seco pelo reator foi mantida a $0,85 \mathrm{~L} / \mathrm{min}$.

A pelota foi irradiada com micro-ondas a $2.45 \mathrm{GHz}$ em $500 \mathrm{~W}, 1000 \mathrm{~W}$ e $1500 \mathrm{~W}$. As potências irradiadas, refletidas e efetivas foram automaticamente registradas por um aquisitor de dados e calculadas conforme a equação 17 para a energia refletida e a equação 18 para a energia efetiva.

$$
E_{r e f l}=E_{i r r}-E_{e f}
$$

Onde:

$E_{r e f l}=$ energia de micro-ondas refletida pelo equipamento durante $\mathrm{o}$ processo de redução carbotérmica $(\mathrm{kJ})$;

$E_{i r r}=$ energia de micro-ondas irradiada durante o processo de redução carbotérmica $(\mathrm{kJ})$; 
$E_{e f}=$ energia de micro-ondas efetivamente utilizada no processo de redução carbotérmica $(\mathrm{kJ})$;

$$
E_{\text {ef }}=E_{\text {irr }}-\left(E_{\text {equip }}+E_{\text {reff }}\right)
$$

Onde:

$E_{e f}=$ energia de micro-ondas efetivamente utilizada no processo de redução carbotérmica $(\mathrm{kJ})$;

$E_{i r r}=$ energia de micro-ondas irradiada durante o processo de redução carbotérmica $(\mathrm{kJ})$;

$E_{\text {equip }}=$ energia de micro-ondas absorvida pelo equipamento durante ensaio com o equipamento sem amostra $(\mathrm{kJ})$;

$E_{\text {refl }}=$ energia de micro-ondas refletida pelo equipamento durante 0 processo de redução carbotérmica $(\mathrm{kJ})$;

O início da reação de redução foi considerado logo que a fonte de microondas foi ligada e o término quando a perda de massa da pelota tornava-se constante, ou quando a pelota reduzida ganhava peso através de sua oxidação ou ainda quando se alcançava 30 minutos de ensaio. A cada 3 minutos as temperaturas dos trocadores de calor, da carcaça externa do reator, da entrada e saída do gás argônio, bem como a da superfície da pelota foram monitoradas. A taxa de redução do minério de ferro é definida como sendo a porcentagem do material reagido e foi determinado pela perda de peso. $O$ cálculo da quantidade de material que reagiu durante cada experimento realizado foi efetuado empregando-se a seguinte equação:

$$
T R=\left(\frac{M_{i}-M_{t}}{M_{i} \times M}\right) \times 100
$$

Onde:

$$
T R=\text { Taxa de redução }(\%)
$$


$M_{i}=$ Peso inicial da amostra $(\mathrm{g})$

$M_{t}=$ Peso no instante t; $(\mathrm{g})$

$M=$ Porcentagem máxima de perda de peso.

A entalpia de reação mais o aquecimento por intervalo de tempo é calculada pela equação 20 .

$$
\Delta H_{\text {reas̆ãotaquecimento }}=\frac{\% T R_{t} \times 9,10 \mathrm{~kJ}}{100}
$$

Onde:

$\Delta H_{\text {reaşão aquecimento }}=$ entalpia de reação + aquecimento no instante $\mathrm{t}(\mathrm{kJ})$;

$\% T R_{t}=$ porcentagem de reação no instante $\mathrm{t}$;

$9,10 \mathrm{~kJ}=$ energia necessária para aquecer a $1000^{\circ} \mathrm{C}$ e reduzir uma pelota de $3,5 \mathrm{~g}$ de minério de ferro com coque de petróleo na proporção estequiométrica conforme anexo $A$;

As perdas de calor da massa reagente para o meio ambiente é calculado através da equação 21 .

$$
E_{p p r}=E_{e f}-\Delta H_{\text {reaşäotaquecimento }}
$$

Onde:

$E_{p p r}=$ energia de micro-ondas perdida por radiação térmica da pelota $(\mathrm{kJ})$;

$E_{e f}=$ energia de micro-ondas efetivamente utilizada no processo de redução carbotérmica $(\mathrm{kJ})$;

$\Delta H_{\text {reação+aquecimento }}=$ entalpia de reação + aquecimento $(\mathrm{kJ})$.

A pelota reduzida foi resfriada até a temperatura ambiente mantendo o fluxo de gás argônio no reator para evitar a reoxidação. 


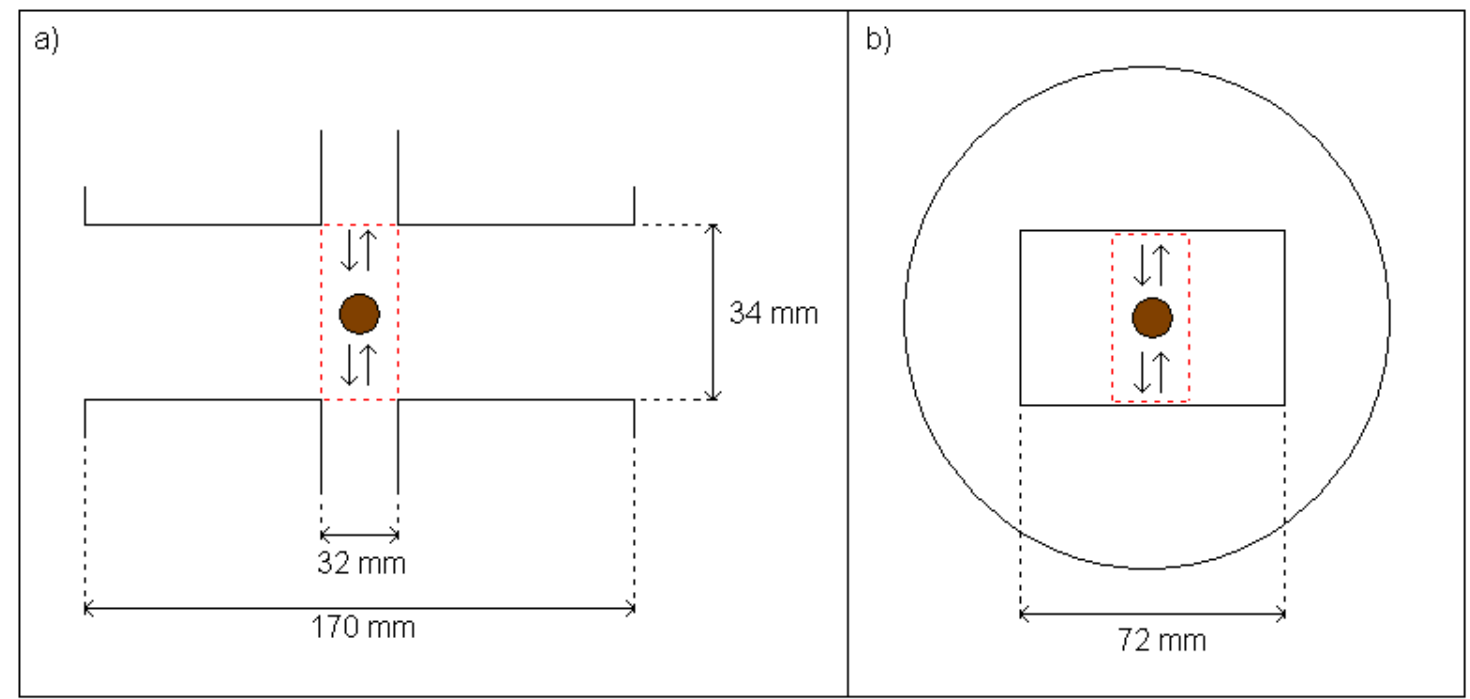

Figura 30 - Posição da pelota respeitando a faixa de movimentação (tracejado vermelho) do eixo da balança semi-analítica no interior da câmara de reação. a) Vista frontal. b) Vista lateral

\subsection{Ensaios com uma pelota no máximo campo magnético}

Uma pelota foi colocada no topo da base cerâmica/teflon para ensaios sem isolação térmica seguindo procedimento de operação análogo ao realizado com o máximo campo elétrico (vide 3.2.3.2.1). A pelota foi irradiada com micro-ondas a $1000 \mathrm{~W}$, em triplicata.

\subsection{Ensaios com duas pelotas no máximo campo elétrico}

Duas pelotas foram colocadas no interior do cadinho de fibra cerâmica para ensaios com isolação térmica seguindo procedimento de operação análogo ao realizado para uma pelota (vide 3.2.3.2.1). As pelotas foram irradiadas com micro-ondas a $1000 \mathrm{~W}$, em triplicata. 


\subsection{Forno de redução carbotérmica de óxidos metálicos com aquecimento por resistência elétrica}

As experiências que utilizaram como fonte de energia a resistência elétrica foram processadas em um forno de resistência, que atinge uma máxima temperatura de $1500^{\circ} \mathrm{C}$ através de $7200 \mathrm{~W}$ de potência. O esquema deste equipamento está mostrado pela figura 31 e ilustrado pela figura 32.

A figura 31 mostra: 1) balança semi-analítica; 2) suporte de fixação do forno; 3) fio de Ni-Cr; 4a e 4b) entrada e saída de água de refrigeração, respectivamente; $5 a$ e 5b) entrada e saída de gás argônio, respectivamente; 6 ) amostra; 7) termopar; 8) forno de resistência.

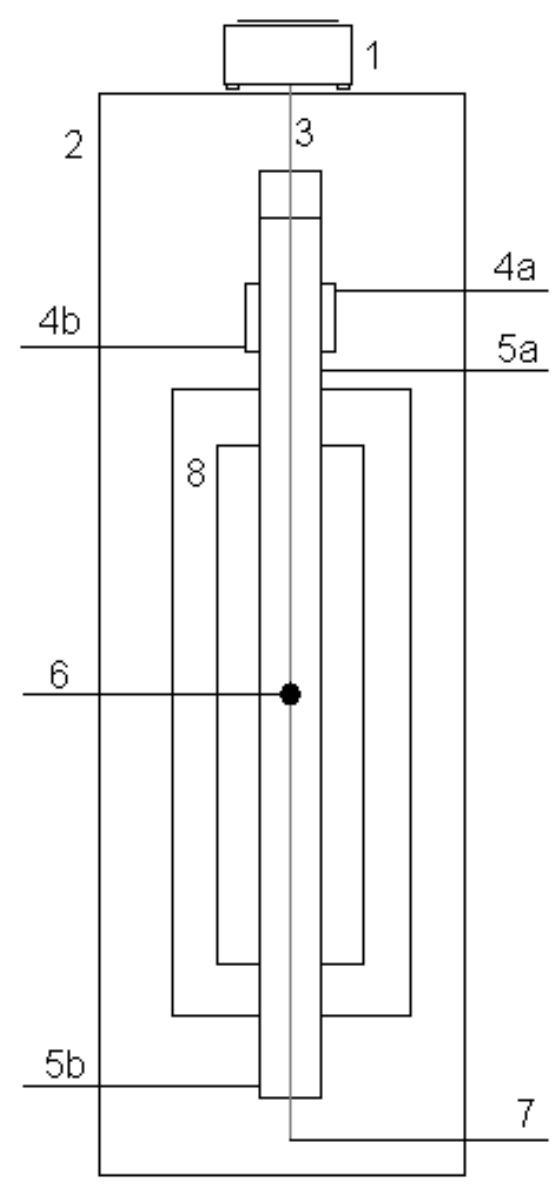

Figura 31 - Esquema do forno de resistência utilizado nos ensaios termogravimétricos. 


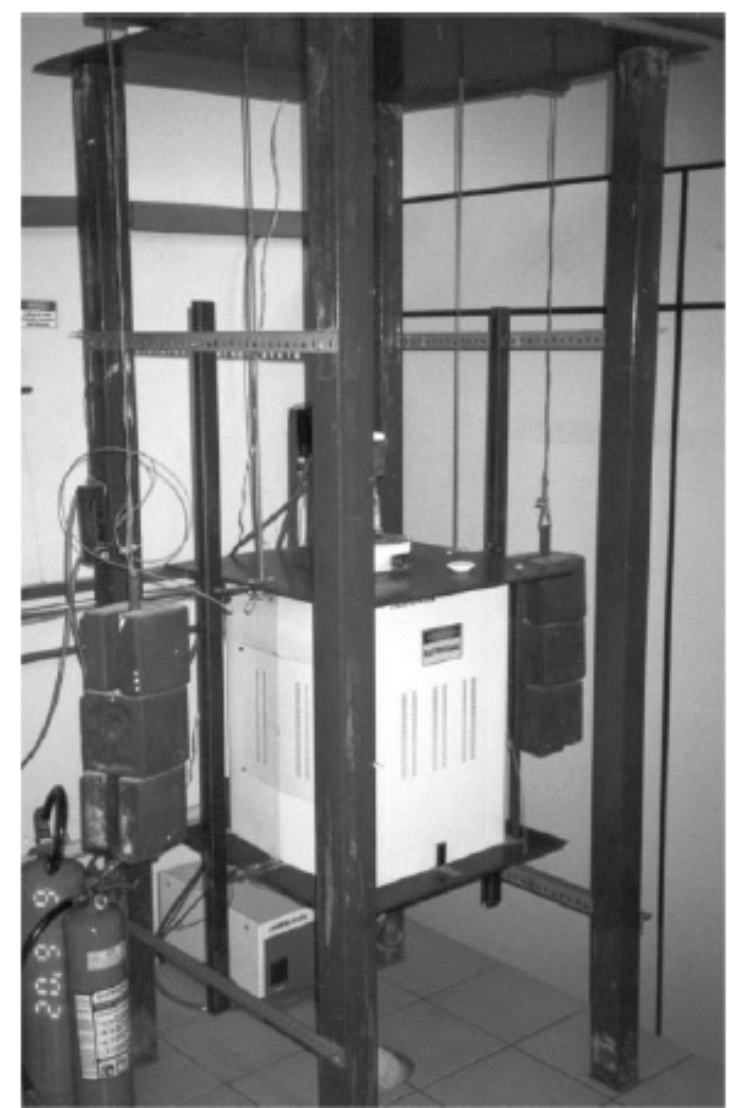

Figura 32 - Ilustração do forno de resistência utilizado nos ensaios termogravimétricos.

Uma pelota foi submetida à análise termogravimétrica no equipamento mostrado pelas figuras 31 e 32 . O forno possui um tubo de alumina no centro de sua cavidade é aquecido por resistências elétricas. Através de um fio de Ni$\mathrm{Cr}$ interligado com uma balança semi-analítica localizada na parte superior de sua plataforma de sustentação, uma pelota é suspendida e posicionada na zona quente do tubo de reação por onde circula gás argônio. A temperatura é medida através de um termopar tipo K. A taxa de reação é calculada através da equação 19. 


\section{RESULTADOS E DISCUSSÃO}

\subsection{Quantificação da energia absorvida pelo equipamento sem amostra}

\subsubsection{Com tarugo ou cadinho de fibra cerâmica}

O gráfico 1 apresenta resultados da evolução da perda de energia de micro-ondas para o equipamento sem amostra e com a presença do tarugo ou cadinho de fibra cerâmica usado nos ensaios de redução carbotérmica.

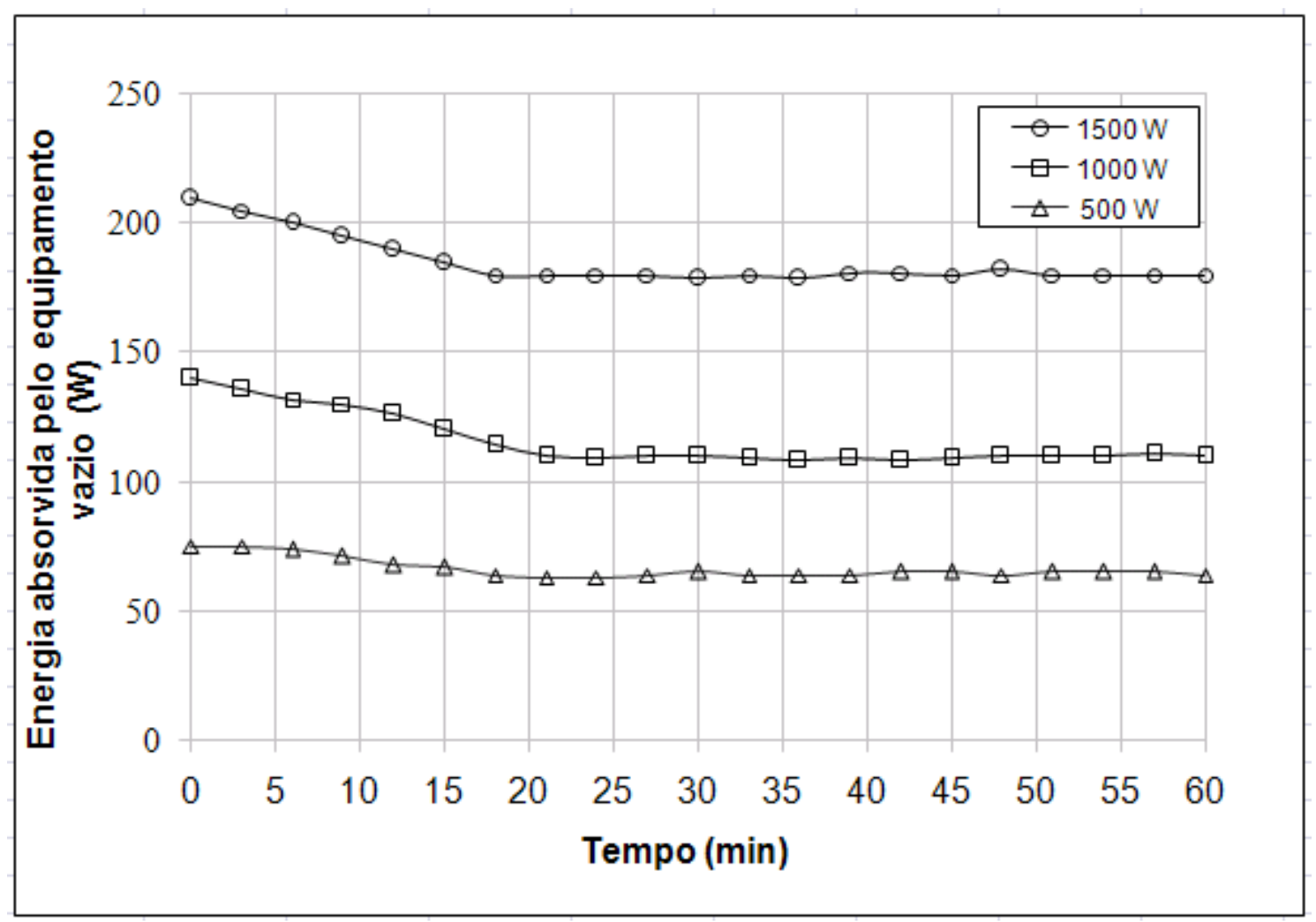

Gráfico 1 - Perfil da evolução da energia de micro-ondas absorvida pelo equipamento sem amostra e com cadinho ou tarugo de fibra cerâmica (W)

Observa-se um período de indução, entre o início e 20 minutos, no qual acontece o aquecimento do equipamento vazio. Após este período de inicialização, o registro da variação de energia não apresenta variação 
significativa, tornando-se praticamente constante. A energia média absorvida pelo equipamento vazio é quantificada através da equação 16.

A tabela 6 mostra a energia média absorvida pelo sistema, sem amostra, nos três níveis de potência de micro-ondas, em triplicata e valores registrados por 30 minutos após a estabilização do equipamento.

Tabela 6 - Energia média de micro-ondas irradiada, refletida e absorvida pelo equipamento sem amostra e com a presença do tarugo ou cadinho de fibra cerâmica

\begin{tabular}{ccc}
$\begin{array}{c}\text { Energia irradiada de } \\
\text { micro-ondas (W) }\end{array}$ & $\begin{array}{c}\text { Energia média refletida } \\
\text { pelo equipamento sem } \\
\text { amostra (W) }\end{array}$ & $\begin{array}{c}\text { Energia média } \\
\text { absorvida pelo } \\
\text { equipamento sem } \\
\text { amostra (W) }\end{array}$ \\
\hline 500 & 435 & 65 \\
1000 & 890 & 110 \\
1500 & 1325 & 175 \\
\hline
\end{tabular}

Os resultados das perdas de energia para os trocadores de calor, câmara de reação, gás argônio, circulador, cadinho e/ou tarugo de fibra cerâmica são mostrados na tabela 7 .

Tabela 7 - Balanço de energia absorvida pelo equipamento sem amostra e com a presença do tarugo ou cadinho de fibra cerâmica

\begin{tabular}{ccccc}
\hline Energia de micro-ondas & \multirow{2}{*}{ 1800 segundos } & $\mathbf{5 0 0} \mathbf{~ W}$ & $\mathbf{1 0 0 0} \mathbf{~ W}$ & $\mathbf{1 5 0 0 ~ \mathbf { ~ }}$ \\
\cline { 3 - 5 } & $\mathbf{9 0 0} \mathbf{~ k J}$ & $\mathbf{1 8 0 0} \mathbf{~ k J}$ & $\mathbf{2 7 0 0} \mathbf{~ k J}$ \\
\hline & Trocador de calor 1 & 29,51 & 38,96 & 62,80 \\
& Trocador de calor 2 & 33,29 & 53,98 & 57,16 \\
Energia absorvida pelo & Câmara de reação & 3,33 & 5,21 & 5,91 \\
equipamento $(\mathrm{kJ})$ & Argônio & 0,02 & 0,08 & 0,17 \\
& Circulador & 49,44 & 88,58 & 131,83 \\
& Cadinho ou tarugo & 0,12 & 0,25 & 0,42 \\
\hline Energia refletida pelo & Diferença & 1,29 & 10,94 & 56,71 \\
equipamento $(\mathrm{kJ})$ & & 783,0 & 1602,0 & 2385,0 \\
\hline
\end{tabular}

Houve perdas insignificantes tanto para o cadinho ou tarugo de fibra cerâmica como para o gás argônio. Pode-se afirmar que as perdas para este material cerâmico tanto na forma de tarugo como na forma de cadinho são as mesmas e, portanto a tabela 6 mostra o resultado que se deve extrair nos ensaios de redução carbotérmica utilizando o equipamento ora descrito com e sem isolante térmico. 


\subsubsection{Com cadinho de carbeto de silício}

O gráfico 2 apresenta resultados da evolução da perda de energia de micro-ondas, na forma de calor, para o equipamento sem amostra e com cadinho de carbeto de silício usado nos ensaios de redução carbotérmica.

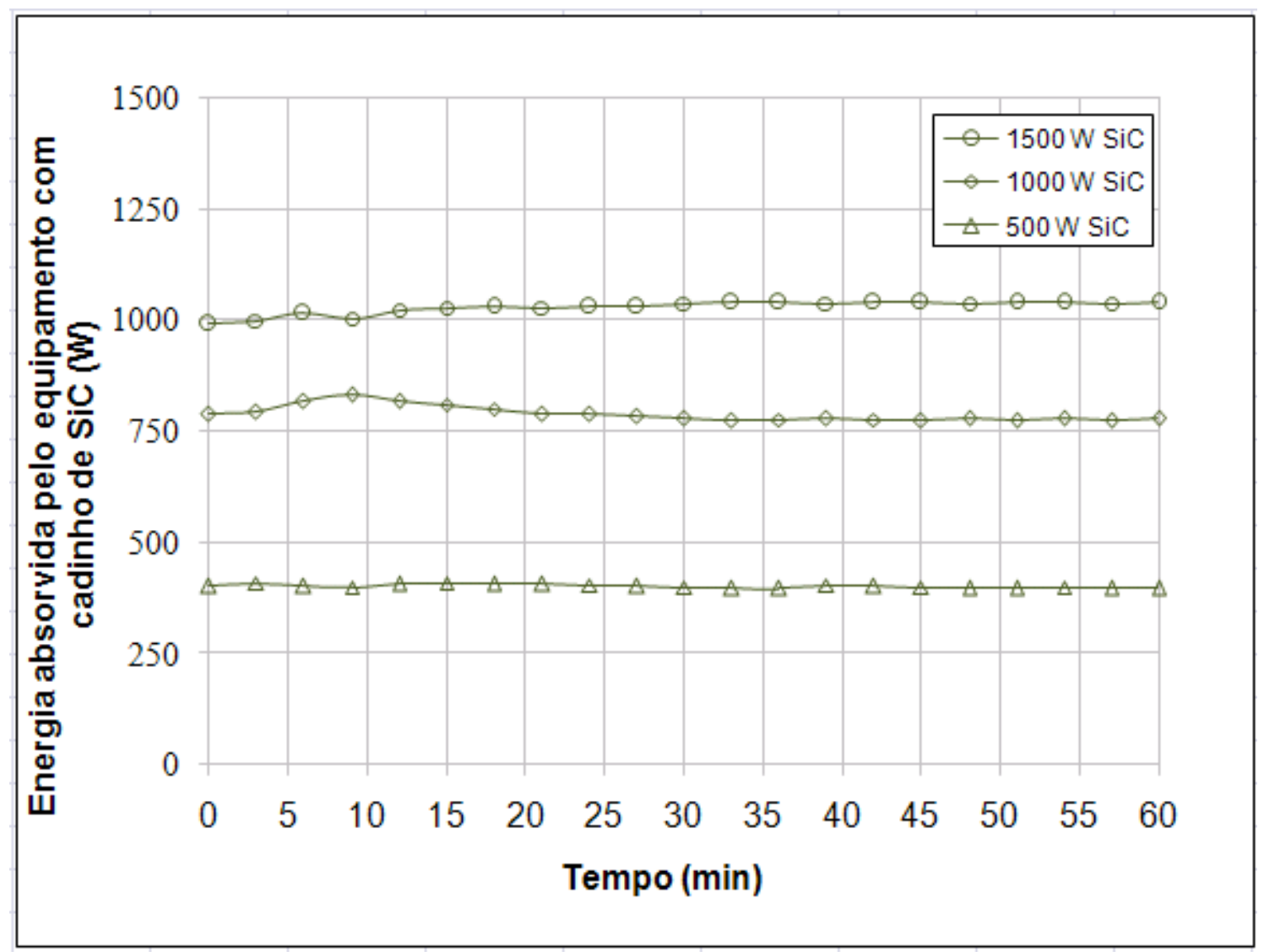

Gráfico 2 - Perfil da evolução da energia de micro-ondas absorvida pelo equipamento sem amostra e com cadinho de carbeto de silício (W)

Após um período no qual acontece o aquecimento do equipamento o registro da variação de energia não apresenta variação significativa, tornandose praticamente constante após 30 minutos de irradiação de micro-ondas. A energia média absorvida pelo equipamento é quantificada através da equação 16.

A tabela 8 mostra a energia absorvida pelo sistema, sem pelota, com cadinho de carbeto de silício, nos três níveis de potência de micro-ondas em ensaios em triplicata e valores registrados por 30 minutos após a estabilização do equipamento. 
Tabela 8 - Energia média de micro-ondas irradiada, refletida e absorvida pelo equipamento sem amostra e com a presença do cadinho de carbeto de silício

\begin{tabular}{ccc}
\hline $\begin{array}{c}\text { Energia irradiada de } \\
\text { micro-ondas (W) }\end{array}$ & $\begin{array}{c}\text { Energia média refletida } \\
\text { pelo equipamento sem } \\
\text { amostra (W) }\end{array}$ & $\begin{array}{c}\text { Energia média } \\
\text { absorvida pelo } \\
\text { equipamento sem } \\
\text { amostra (W) }\end{array}$ \\
\hline 500 & 110 & 390 \\
1000 & 245 & 755 \\
1500 & 472 & 1028 \\
\hline
\end{tabular}

O gráfico 3 mostra a evolução do perfil de temperatura encontrado na superfície externa do cadinho de carbeto de silício sem pelota no seu interior nos três níveis de potência de micro-ondas irradiada.

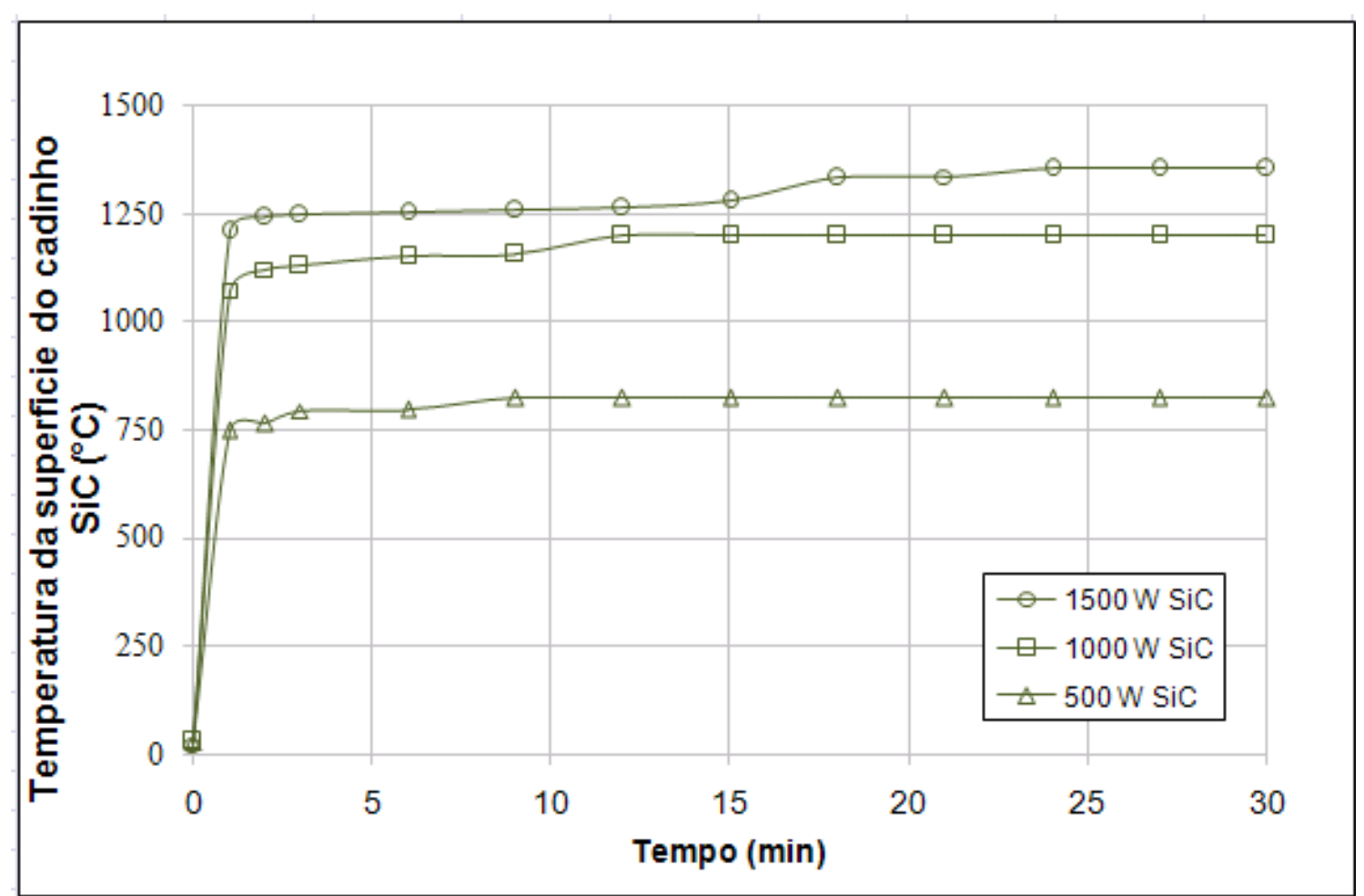

Gráfico 3 - Temperatura da superfície do cadinho de SiC em função do tempo de exposição a três níveis de potências às micro-ondas

As perdas de energia para os trocadores de calor, câmara de reação, gás argônio e circulador são mostrados na tabela 9. 
Tabela 9 - Balanço de energia absorvida pelo equipamento sem amostra e com a presença do cadinho de carbeto de silício

\begin{tabular}{ccccc}
\hline Energia de micro-ondas & \multirow{2}{*}{1800 segundos } & $\mathbf{5 0 0} \mathbf{~ W}$ & $\mathbf{1 0 0 0} \mathbf{~ W}$ & $\mathbf{1 5 0 0} \mathbf{~ W}$ \\
\cline { 3 - 5 } irradiada & & $\mathbf{9 0 0} \mathbf{~ J J}$ & $\mathbf{1 8 0 0} \mathbf{~ J J}$ & $\mathbf{2 7 0 0} \mathbf{~ k J}$ \\
\hline & Trocador de calor 1 & 143,84 & 298,31 & 408,21 \\
& Trocador de calor 2 & 154,49 & 298,31 & 386,23 \\
Energia absorvida pelo & Câmara de reação & 22,07 & 42,56 & 59,90 \\
equipamento $(\mathrm{kJ})$ & Argônio & 4,63 & 6,75 & 8,64 \\
& Circulador & 37,93 & 58,80 & 91,04 \\
& Diferença & 339,04 & 654,27 & 896,38 \\
\hline Energia refletida pelo & & 198,00 & 441,0 & 849,6 \\
equipamento $(\mathrm{kJ})$ & & & &
\end{tabular}

\subsection{Redução carbotérmica com micro-ondas}

\subsubsection{Ensaios com uma pelota no máximo campo elétrico}

Neste item são apresentados e discutidos os principais resultados encontrados para a redução carbotérmica de uma pelota auto-redutora na proporção estequiométrica com irradiação por micro-ondas em três níveis de potência com e sem isolação térmica e em cadinho de carbeto de silício.

A cada lote de ensaios o equipamento foi ligado por 20 minutos nas condições de trabalho sem amostra para estabilizar as perdas térmicas para o sistema. 


\subsubsection{Sem isolante térmico}

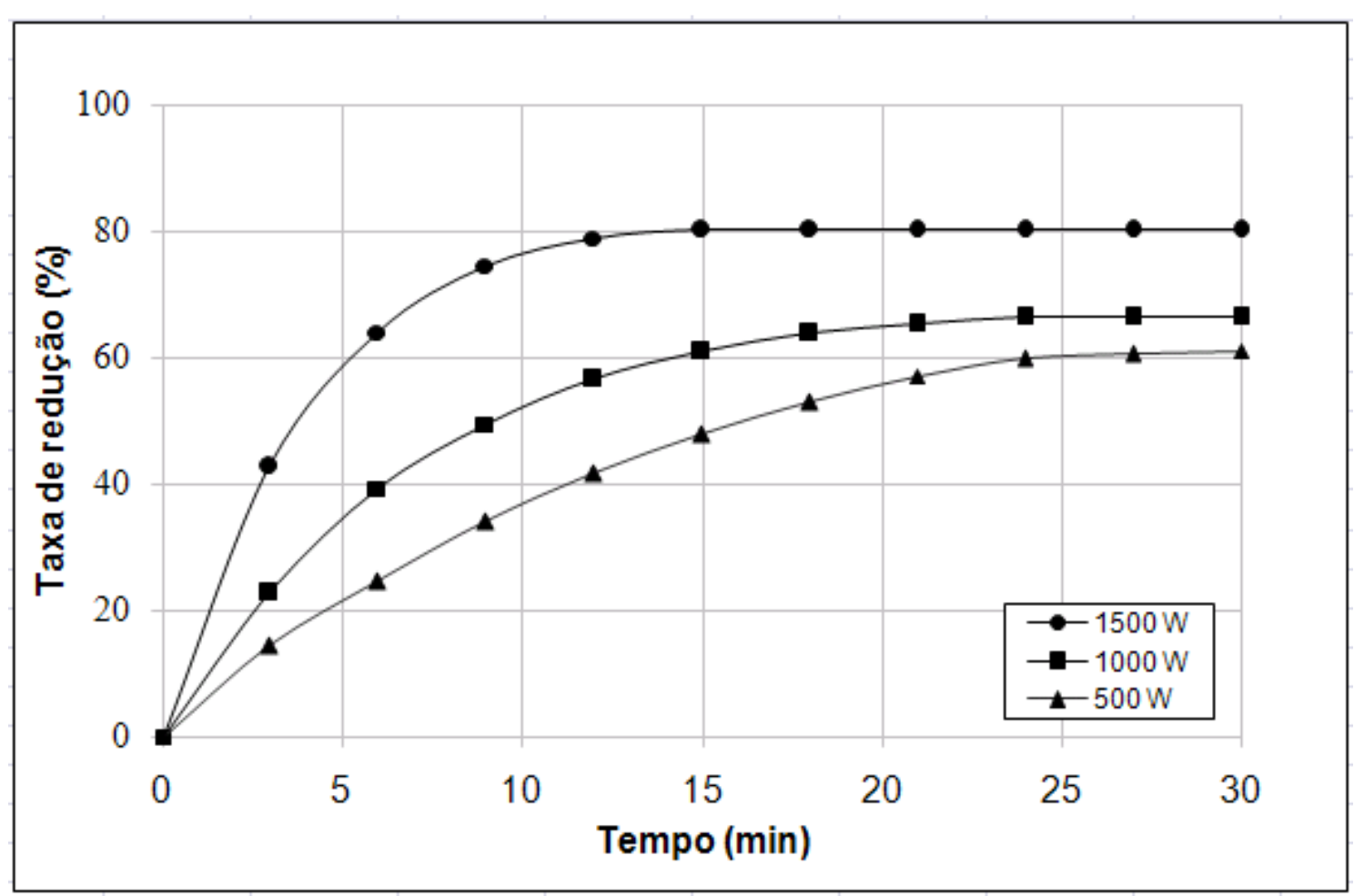

Gráfico 4 - Taxa de redução em função do tempo de exposição a três níveis de potências às micro-ondas para uma pelota na proporção estequiométrica entre minério de ferro de Carajás e coque de petróleo sem isolação térmica

O gráfico 4 apresenta a porcentagem de reação em função do tempo de exposição à irradiação por micro-ondas sem isolação térmica calculada através da equação 19.

Nas curvas de redução apresentadas pelo gráfico 4 observa-se melhor resultado para com a pelota irradiada a $1500 \mathrm{~W}$. Após 15 minutos de reação, $80 \%$ da taxa de redução foi obtida enquanto que para os testes realizados a $1000 \mathrm{~W}$ e $500 \mathrm{~W}$ alcançaram $66 \%$ e $60 \%$ de redução respectivamente.

O gráfico 5 mostra a evolução do perfil de temperatura encontrado nas amostras durante o processo de redução enquanto que o gráfico 6 mostra a evolução da energia de micro-ondas refletida durante a redução carbotérmica calculada através da equação 17. 


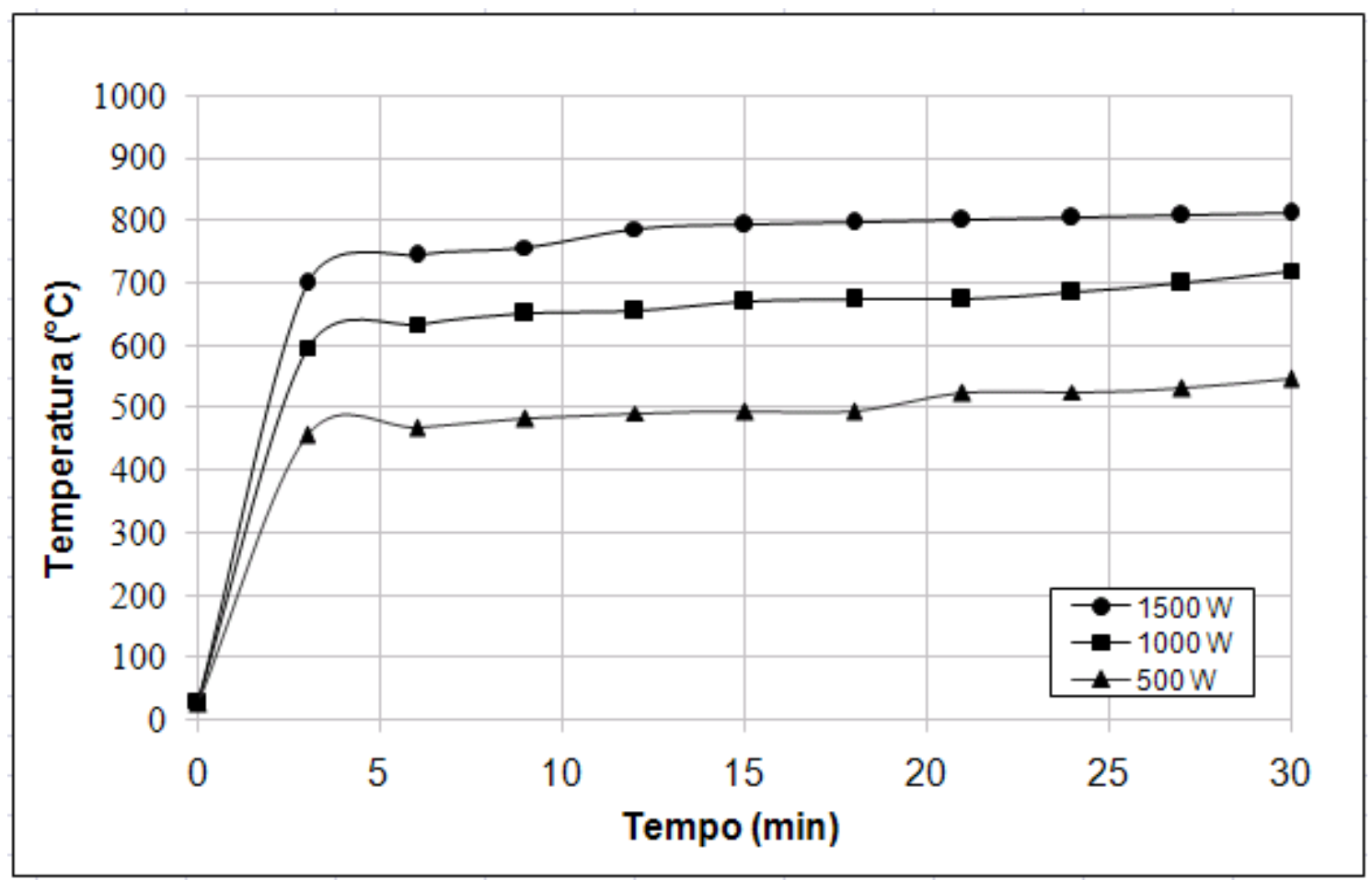

Gráfico 5 - Temperatura da superfície da pelota em função do tempo de exposição a três níveis de potências às micro-ondas para uma pelota na proporção estequiométrica entre minério de ferro de Carajás e coque de petróleo sem isolação térmica

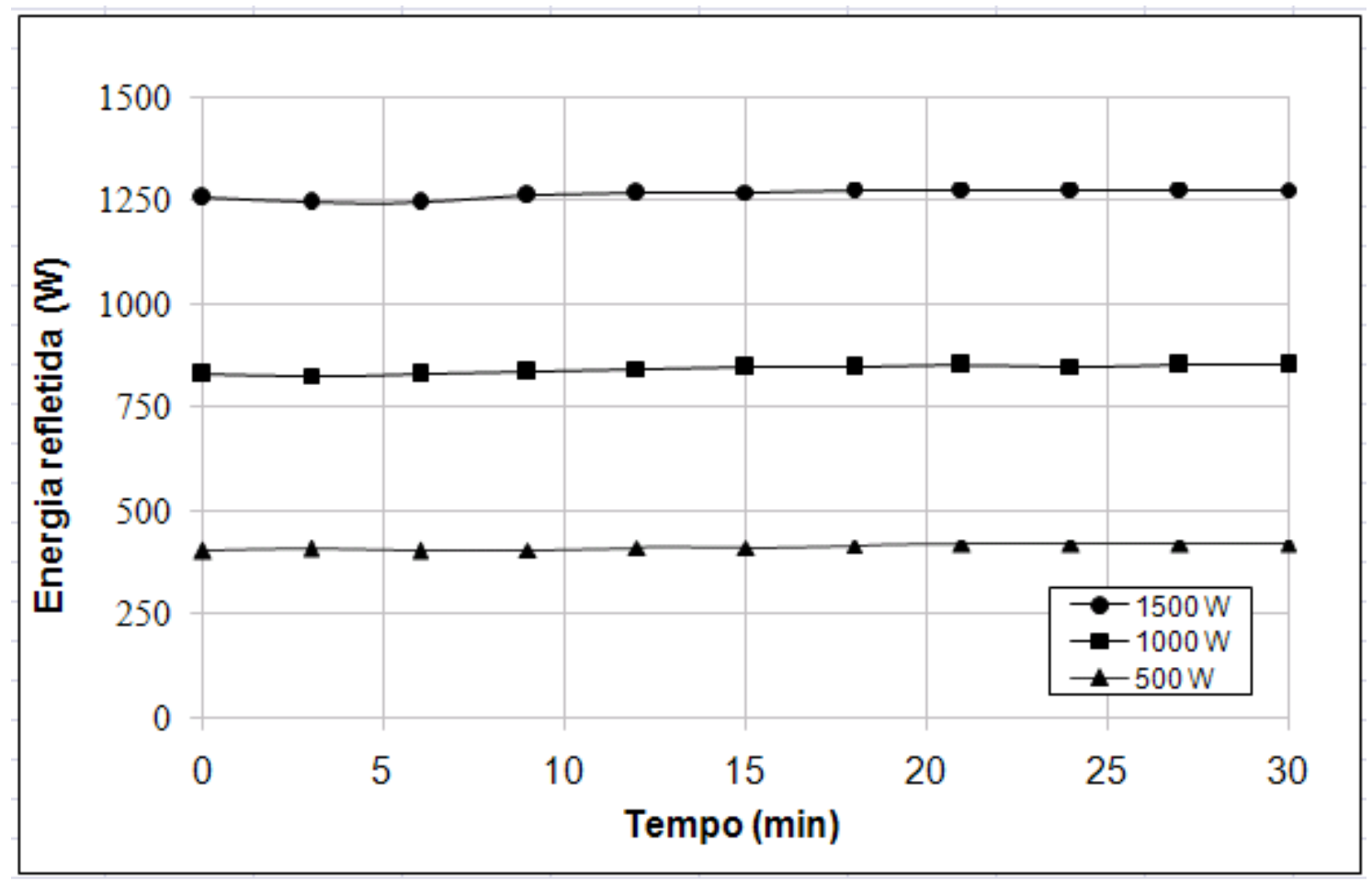

Gráfico 6 - Perfil da evolução da energia de micro-ondas refletida (W) na redução carbotérmica de uma pelota sem isolação térmica 
O gráfico 7 apresenta o perfil da evolução da energia de micro-ondas utilizada na redução carbotérmica de uma pelota sem isolação calculada através da equação 18.

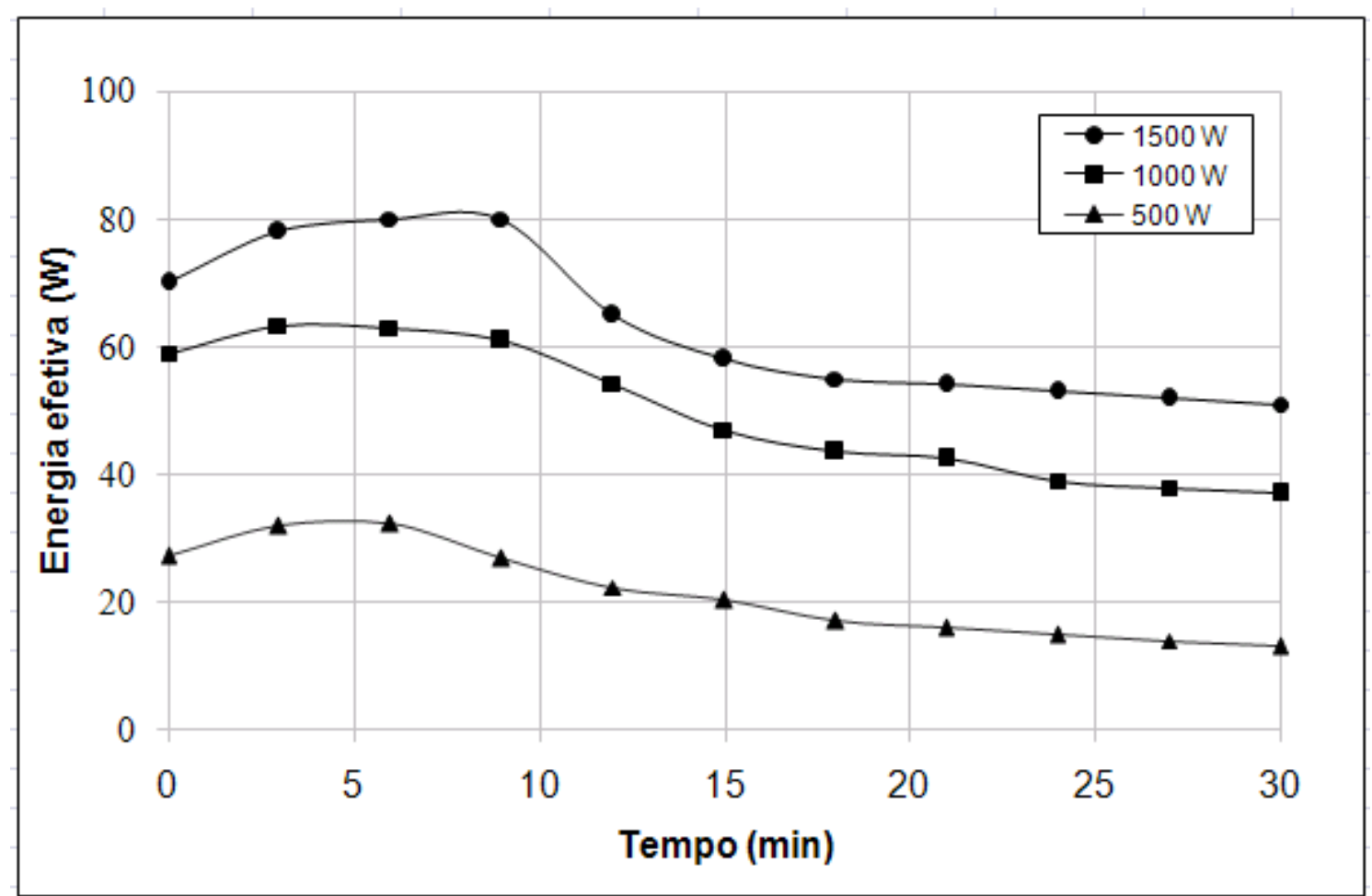

Gráfico 7 - Perfil da evolução da energia de micro-ondas efetiva (W) na redução carbotérmica de uma pelota sem isolação térmica

As tabelas 10, 11 e 12 apresentam a quantificação de energia nos ensaios de redução carbotérmica com uma pelota na proporção estequiométrica sem isolação térmica no período de 30 minutos a $500 \mathrm{~W}, 1000$ W e $1500 \mathrm{~W}$ de energia de micro-ondas irradiada, respectivamente. 
Tabela 10 - Balanço de energia para ensaios de redução carbotérmica com $500 \mathrm{~W}$ de energia de micro-ondas irradiada em uma pelota sem isolação térmica

\begin{tabular}{|c|c|c|c|c|c|}
\hline \multicolumn{2}{|c|}{ ENTRADA } & \multicolumn{4}{|c|}{ SAÍDA } \\
\hline \multirow[b]{2}{*}{$\begin{array}{l}\text { Tempo } \\
\text { (min) }\end{array}$} & \multirow[b]{2}{*}{$\begin{array}{c}\text { Energia } \\
\text { irradiada } \\
\text { (kJ) }\end{array}$} & \multirow[b]{2}{*}{$\begin{array}{c}\text { Energia } \\
\text { absorvida } \\
\text { pelo } \\
\text { equipamento } \\
\text { sem amostra } \\
\text { (kJ) }\end{array}$} & \multirow[b]{2}{*}{$\begin{array}{l}\text { Energia } \\
\text { refletida (kJ) }\end{array}$} & \multicolumn{2}{|c|}{ Energia efetiva (kJ) } \\
\hline & & & & $\begin{array}{l}\text { Entalpia de } \\
\text { reação (kJ) }\end{array}$ & $\begin{array}{c}\text { Perdas } \\
\text { térmicas } \\
\text { por } \\
\text { radiação } \\
\text { (kJ) }\end{array}$ \\
\hline 0 a 3 & 90 & 11,7 & 72,54 & 1,30 & 4,46 \\
\hline 3 a 6 & 90 & 11,7 & 72,48 & 0,93 & 4,89 \\
\hline 6 a 9 & 90 & 11,7 & 73,44 & 0,86 & 4,00 \\
\hline 9 a 12 & 90 & 11,7 & 74,28 & 0,69 & 3,33 \\
\hline 12 a 15 & 90 & 11,7 & 74,64 & 0,57 & 3,09 \\
\hline 15 a 18 & 90 & 11,7 & 75,24 & 0,47 & 2,59 \\
\hline 18 a 21 & 90 & 11,7 & 75,42 & 0,37 & 2,51 \\
\hline 21 a 24 & 90 & 11,7 & 75,60 & 0,24 & 2,46 \\
\hline 24 a 27 & 90 & 11,7 & 75,78 & 0,07 & 2,45 \\
\hline 27 a 30 & 90 & 11,7 & 75,96 & 0,05 & 2,29 \\
\hline \multirow{2}{*}{ TOTAL } & \multirow{2}{*}{900} & 117 & 745,38 & 5,56 & 32,06 \\
\hline & & \multicolumn{4}{|c|}{900} \\
\hline
\end{tabular}

Tabela 11 - Balanço de energia para ensaios de redução carbotérmica com $1000 \mathrm{~W}$ de energia de micro-ondas irradiada em uma pelota sem isolação térmica

\begin{tabular}{|c|c|c|c|c|c|}
\hline \multicolumn{2}{|c|}{ ENTRADA } & \multicolumn{4}{|c|}{ SAÍDA } \\
\hline \multirow[b]{2}{*}{$\begin{array}{l}\text { Tempo } \\
\text { (min) }\end{array}$} & \multirow[b]{2}{*}{$\begin{array}{c}\text { Energia } \\
\text { irradiada } \\
\quad \text { (kJ) }\end{array}$} & \multirow[b]{2}{*}{$\begin{array}{c}\text { Energia } \\
\text { absorvida } \\
\text { pelo } \\
\text { equipamento } \\
\text { sem amostra } \\
\text { (kJ) }\end{array}$} & \multirow[b]{2}{*}{$\begin{array}{l}\text { Energia } \\
\text { refletida (kJ) }\end{array}$} & \multicolumn{2}{|c|}{ Energia efetiva (kJ) } \\
\hline & & & & $\begin{array}{l}\text { Entalpia de } \\
\text { reação (kJ) }\end{array}$ & $\begin{array}{c}\text { Perdas } \\
\text { térmicas } \\
\text { por } \\
\text { radiação } \\
(\mathbf{k J})\end{array}$ \\
\hline 0 a 3 & 180 & 19,8 & 149,58 & 2,05 & 8,57 \\
\hline 3 a 6 & 180 & 19,8 & 148,80 & 1,52 & 9,88 \\
\hline 6 a 9 & 180 & 19,8 & 148,86 & 0,92 & 10,42 \\
\hline 9 a 12 & 180 & 19,8 & 149,22 & 0,65 & 10,33 \\
\hline 12 a 15 & 180 & 19,8 & 150,42 & 0,39 & 9,39 \\
\hline 15 a 18 & 180 & 19,8 & 151,74 & 0,26 & 8,20 \\
\hline 18 a 21 & 180 & 19,8 & 152,34 & 0,14 & 7,72 \\
\hline 21 a 24 & 180 & 19,8 & 152,55 & 0,10 & 7,55 \\
\hline 24 a 27 & 180 & 19,8 & 153,18 & 0,00 & 7,02 \\
\hline 27 a 30 & 180 & 19,8 & 153,36 & 0,00 & 6,84 \\
\hline \multirow{2}{*}{ TOTAL } & \multirow{2}{*}{1800} & 198 & 1510,05 & 6,04 & 85,91 \\
\hline & & \multicolumn{4}{|c|}{1800} \\
\hline
\end{tabular}


Tabela 12 - Balanço de energia para ensaios de redução carbotérmica com $1500 \mathrm{~W}$ de energia de micro-ondas irradiada em uma pelota sem isolação térmica

\begin{tabular}{|c|c|c|c|c|c|}
\hline \multicolumn{2}{|c|}{ ENTRADA } & \multicolumn{4}{|c|}{ SAÍDA } \\
\hline \multirow[b]{2}{*}{$\begin{array}{c}\text { Tempo } \\
\text { (min) }\end{array}$} & \multirow[b]{2}{*}{$\begin{array}{c}\text { Energia } \\
\text { irradiada } \\
(\mathbf{k J})\end{array}$} & \multirow[b]{2}{*}{$\begin{array}{c}\text { Energia } \\
\text { absorvida } \\
\text { pelo } \\
\text { equipamento } \\
\text { sem amostra } \\
\text { (kJ) }\end{array}$} & \multirow[b]{2}{*}{$\begin{array}{l}\text { Energia } \\
\text { refletida (kJ) }\end{array}$} & \multicolumn{2}{|c|}{ Energia efetiva (kJ) } \\
\hline & & & & $\begin{array}{l}\text { Entalpia de } \\
\text { reação (kJ) }\end{array}$ & $\begin{array}{c}\text { Perdas } \\
\text { térmicas } \\
\text { por } \\
\text { radiação } \\
\text { (kJ) }\end{array}$ \\
\hline 0 a 3 & 270 & 31,5 & 225,90 & 3,88 & 8,72 \\
\hline 3 a 6 & 270 & 31,5 & 224,46 & 1,94 & 12,10 \\
\hline 6 a 9 & 270 & 31,5 & 224,10 & 0,95 & 13,45 \\
\hline 9 a 12 & 270 & 31,5 & 224,10 & 0,40 & 14,00 \\
\hline 12 a 15 & 270 & 31,5 & 226,80 & 0,11 & 11,59 \\
\hline 15 a 18 & 270 & 31,5 & 228,06 & 0,00 & 10,44 \\
\hline 18 a 21 & 270 & 31,5 & 228,60 & 0,00 & 9,90 \\
\hline 21 a 24 & 270 & 31,5 & 228,78 & 0,00 & 9,72 \\
\hline 24 a 27 & 270 & 31,5 & 228,96 & 0,00 & 9,54 \\
\hline 27 a 30 & 270 & 31,5 & 229,14 & 0,00 & 9,36 \\
\hline \multirow{2}{*}{ TOTAL } & \multirow{2}{*}{2700} & 315 & 2268,90 & 7,29 & 108,81 \\
\hline & & \multicolumn{4}{|c|}{2700} \\
\hline
\end{tabular}

Comparando os gráficos 4 e 7 percebe-se que a absorção de energia de micro-ondas no processo de redução carbotérmica varia a cada nível de potência irradiada. Quanto maior for à energia utilizada maior será a taxa de redução e menor o tempo de processamento. As taxas de redução apresentadas no gráfico 4 mostram que após o período de redução, o registro de variação de massa apresenta que não há mais variação de massa significativa, o que indica o término da reação de redução do minério podendo ser visualizado através de um patamar. Observa-se ainda que, em se mantendo o fornecimento de energia de micro-ondas o período de queda da absorção de energia mostrado pelo gráfico 7 está relacionado com as mudanças de etapas da amostra, ou seja, a variação da constante dielétrica. Ainda, se percebe que não há completa redução carbotérmica em nenhum dos três níveis de potência. Isto se deve provavelmente a dois fatores: a perda de calor da massa reagente para o meio ambiente, calculado empiricamente através da equação 21 e a baixas temperaturas como mostrado pelo gráfico 5 .

Um problema comum encontrado nos ensaios de redução carbotérmica com micro-ondas sem isolação térmica era a formação de arcos voltaicos na superfície da pelota devido à formação de partículas metálicas, trincas, etc. e até mesmo em seu interior. Quando tal fenômeno ocorria o ensaio era 
interrompido por medida de precaução para não danificar o equipamento como mostrado pelas figuras 33 e 34 .

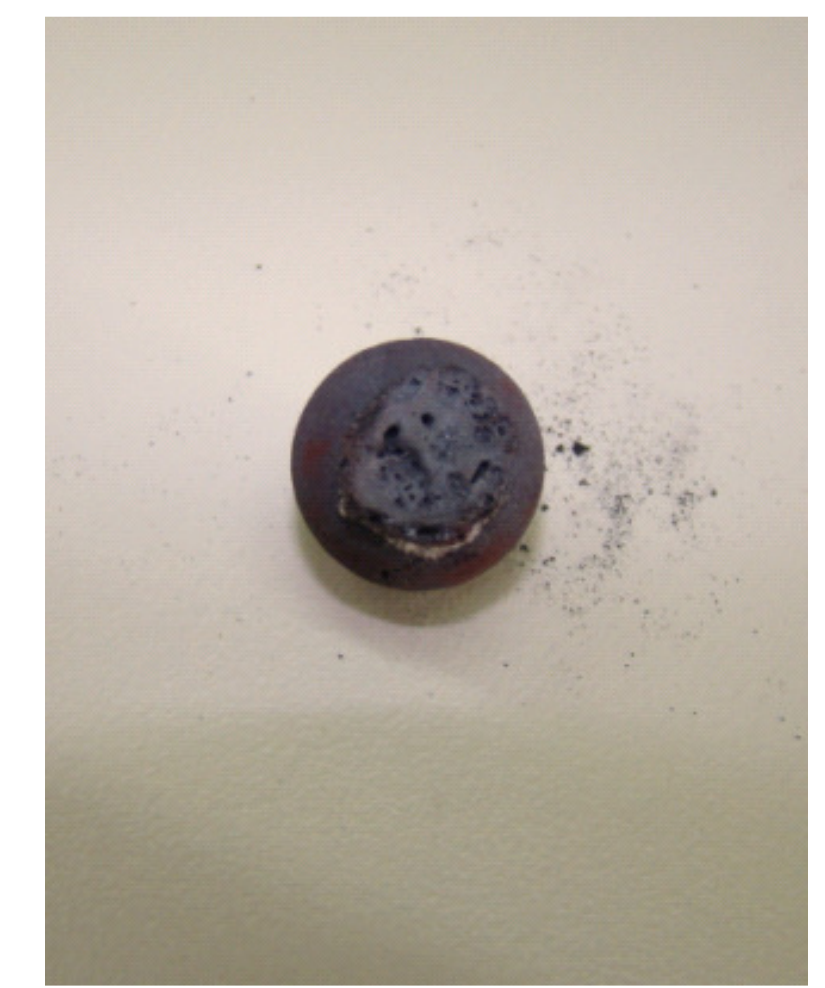

Figura 33 - Pelota após a formação de arco voltaico em sua superfície

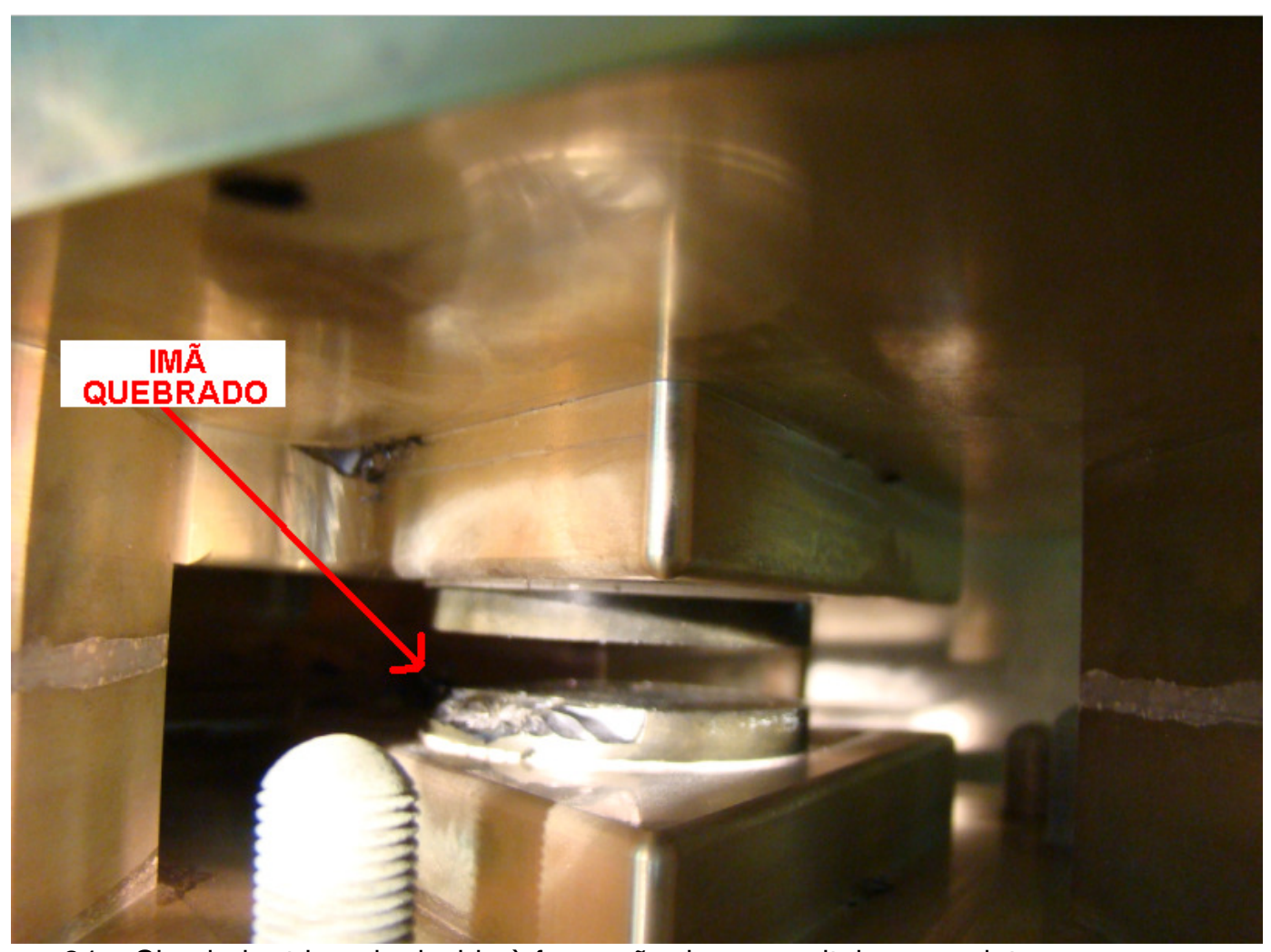

Figura 34 - Circulador trincado devido à formação de arco voltaico na pelota 


\subsubsection{Com isolante térmico}

O gráfico 8 apresenta a porcentagem de reação em função do tempo de exposição à irradiação por micro-ondas com isolação térmica calculada através da equação 19.

Nas curvas de redução apresentadas pelo gráfico 8 observa-se melhor resultado para com a pelota irradiada a $1500 \mathrm{~W}$, sendo que após 12 minutos de reação, $100 \%$ da taxa de redução foi obtida enquanto que para os testes realizados a $1000 \mathrm{~W}$ e $500 \mathrm{~W}$ foi alcançado $74 \%$ e $63 \%$ de redução respectivamente. A temperatura não foi possível medir devido à pelota estar inserida no interior do cadinho de material cerâmico com tampa.

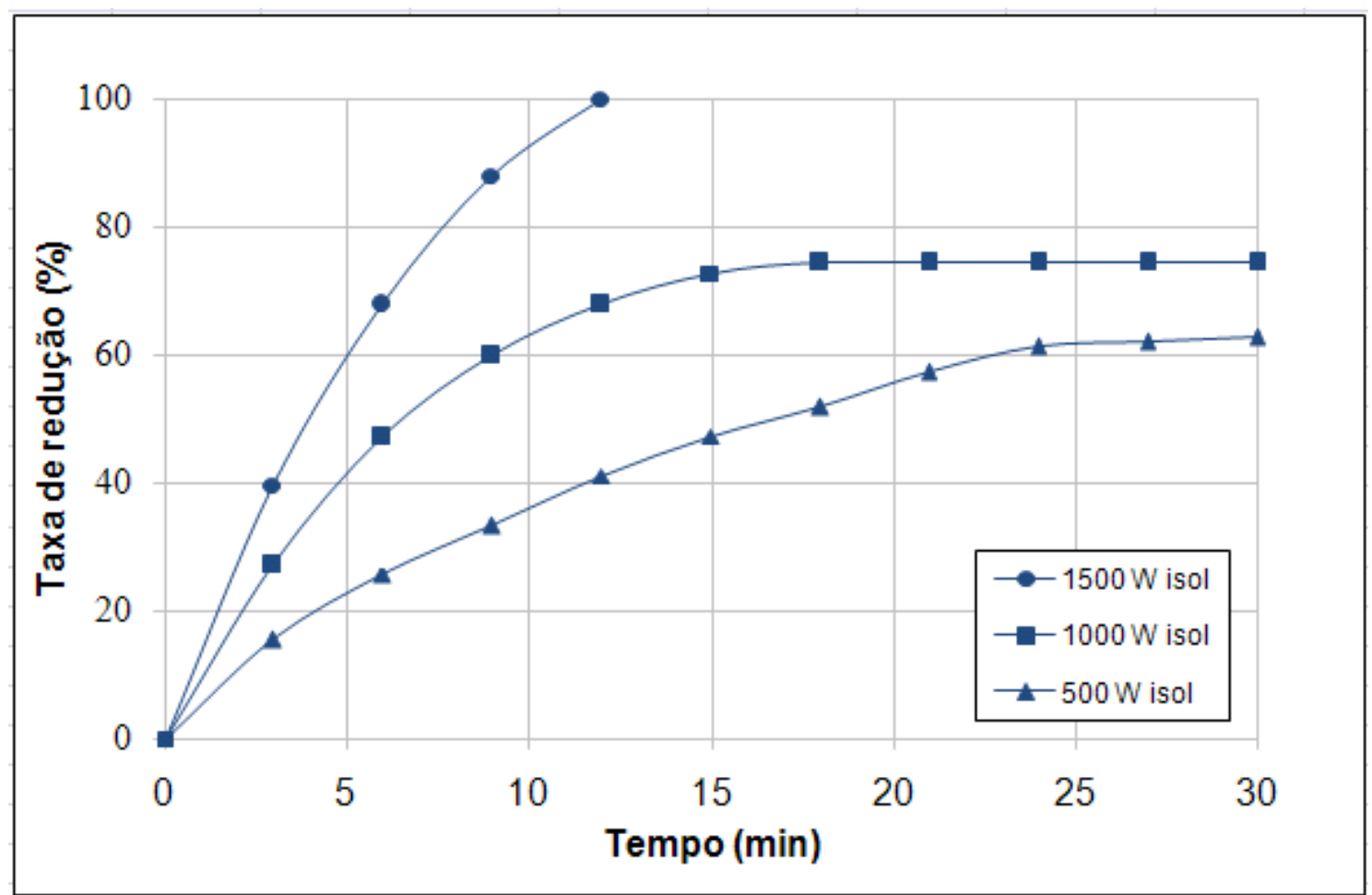

Gráfico 8 - Taxa de redução em função do tempo de exposição a três níveis de potências às micro-ondas para uma pelota na proporção estequiométrica entre minério de ferro de Carajás e coque de petróleo com isolação térmica

O gráfico 9 mostra a evolução da energia de micro-ondas refletida durante a redução carbotérmica calculada através da equação 17. 


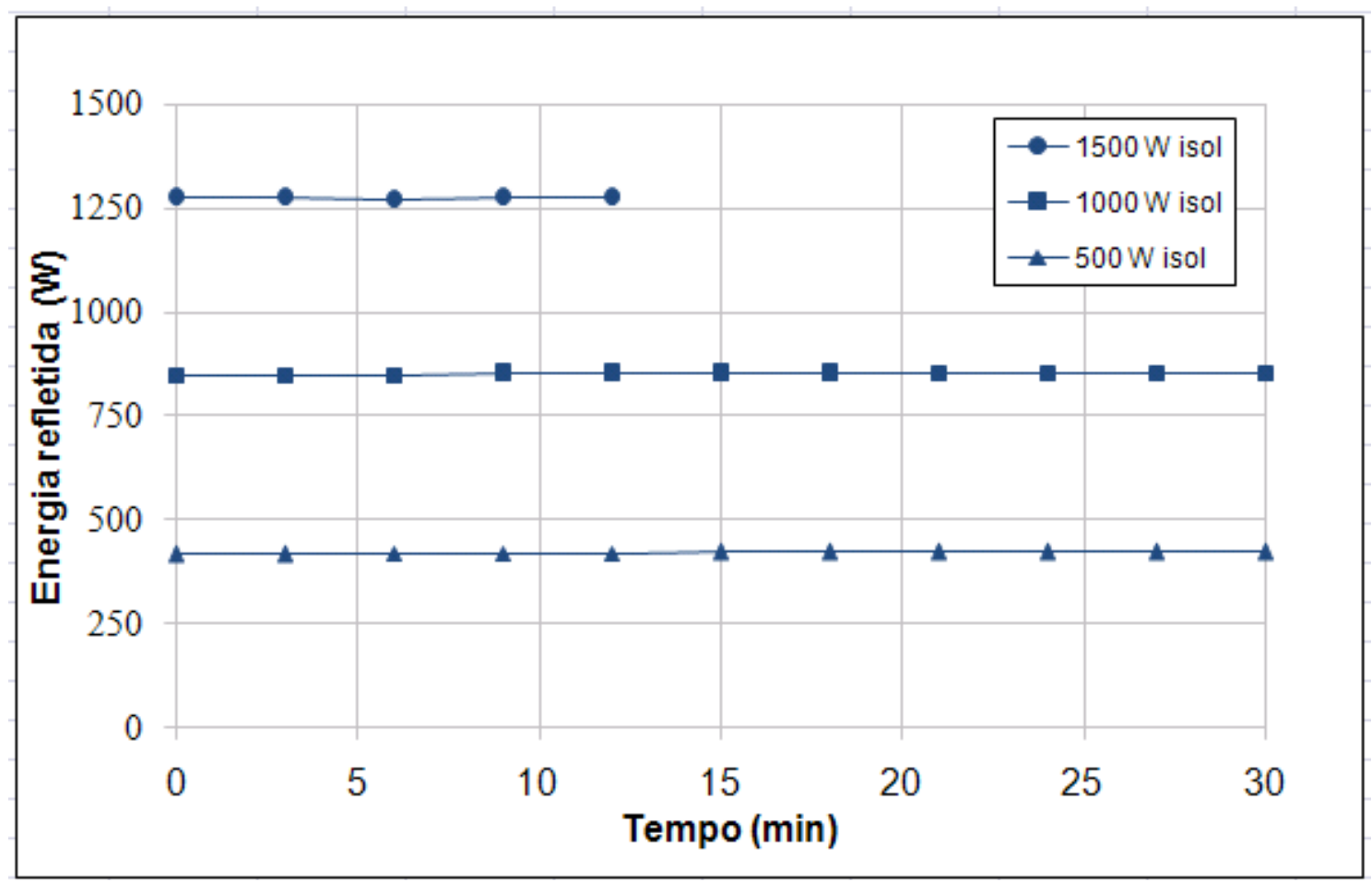

Gráfico 9 - Perfil da evolução de energia de micro-ondas refletida (W) na redução carbotérmica de uma pelota com isolação térmica

O gráfico 10 apresenta o perfil da evolução da energia de micro-ondas efetiva na redução carbotérmica de uma pelota com isolação calculada através da equação 18.

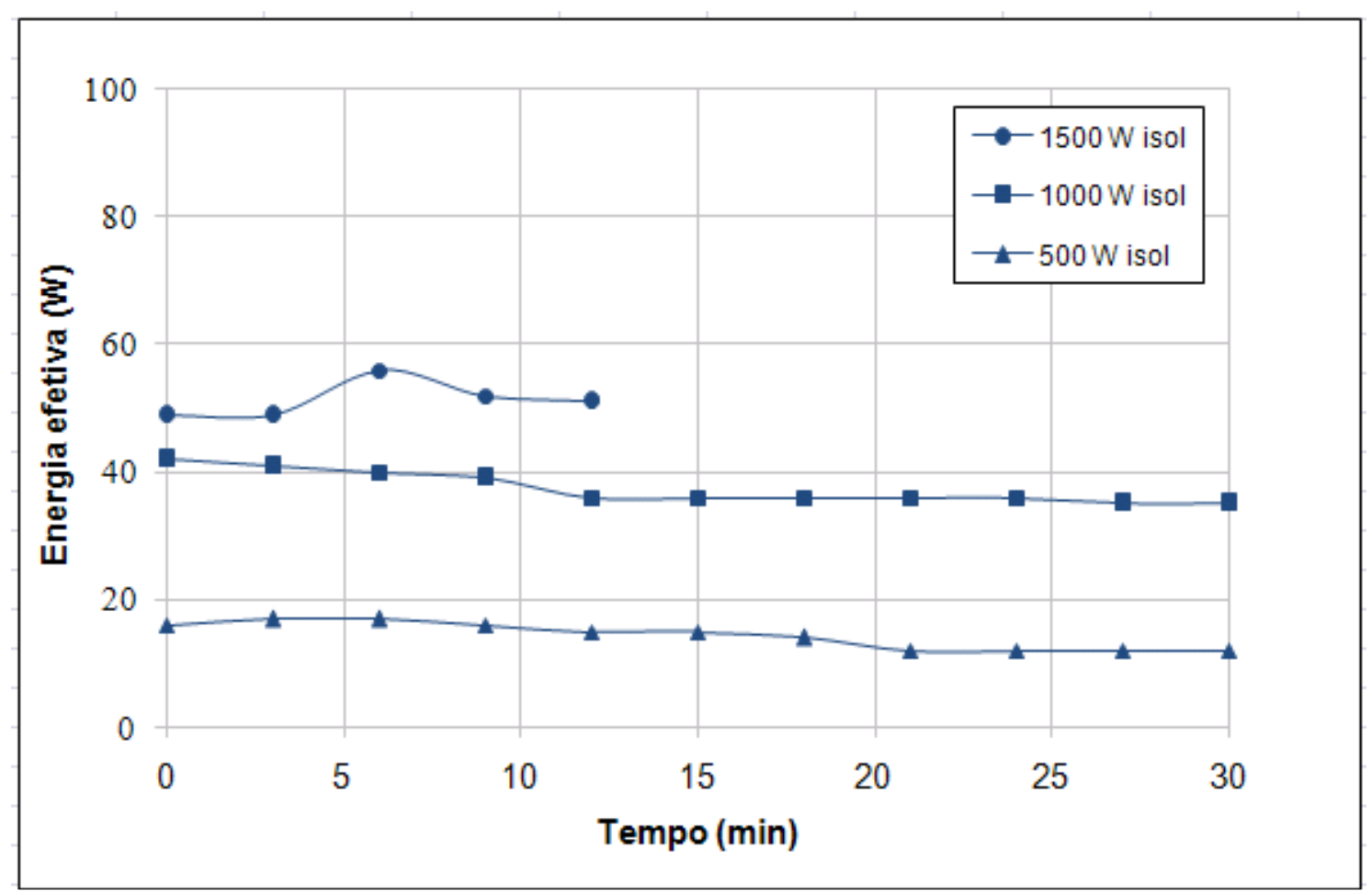

Gráfico 10 - Perfil da evolução da energia de micro-ondas efetiva (W) na redução carbotérmica de uma pelota com isolação térmica 
As tabelas 13, 14 e 15 apresentam a quantificação de energia dos ensaios de redução carbotérmica com uma pelota na proporção estequiométrica com isolação térmica a $500 \mathrm{~W}, 1000 \mathrm{~W}$ e $1500 \mathrm{~W}$ de energia de micro-ondas irradiada, respectivamente.

Tabela 13 - Balanço de energia para ensaios de redução carbotérmica com $500 \mathrm{~W}$ de energia de micro-ondas irradiada em uma pelota com isolação térmica

\begin{tabular}{|c|c|c|c|c|c|}
\hline \multicolumn{2}{|c|}{ ENTRADA } & \multicolumn{4}{|c|}{ SAÍDA } \\
\hline \multirow[b]{2}{*}{$\begin{array}{c}\text { Tempo } \\
(\min )\end{array}$} & \multirow[b]{2}{*}{$\begin{array}{c}\text { Energia } \\
\text { irradiada } \\
\text { (kJ) }\end{array}$} & \multirow[b]{2}{*}{$\begin{array}{c}\text { Energia } \\
\text { absorvida } \\
\text { pelo } \\
\text { equipamento } \\
\text { sem amostra } \\
(\mathrm{kJ})\end{array}$} & \multirow[b]{2}{*}{$\begin{array}{c}\text { Energia } \\
\text { refletida }(k J)\end{array}$} & \multicolumn{2}{|c|}{ Energia efetiva (kJ) } \\
\hline & & & & $\begin{array}{l}\text { Entalpia } \\
\text { de reação } \\
(\mathrm{kJ})\end{array}$ & $\begin{array}{l}\text { Perdas } \\
\text { térmicas } \\
\text { por } \\
\text { radiação } \\
\text { (kJ) }\end{array}$ \\
\hline 0 a 3 & 90 & 11,7 & 75,42 & 1,41 & 1,47 \\
\hline 3 a 6 & 90 & 11,7 & 75,24 & 0,92 & 2,14 \\
\hline 6 a 9 & 90 & 11,7 & 75,24 & 0,70 & 2,36 \\
\hline 9 a 12 & 90 & 11,7 & 75,42 & 0,71 & 2,17 \\
\hline 12 a 15 & 90 & 11,7 & 75,60 & 0,56 & 2,14 \\
\hline 15 a 18 & 90 & 11,7 & 75,60 & 0,42 & 2,28 \\
\hline 18 a 21 & 90 & 11,7 & 75,78 & 0,49 & 2,03 \\
\hline 21 a 24 & 90 & 11,7 & 76,14 & 0,35 & 1,81 \\
\hline 24 a 27 & 90 & 11,7 & 76,14 & 0,07 & 2,09 \\
\hline 27 a 30 & 90 & 11,7 & 76,14 & 0,07 & 2,09 \\
\hline \multirow{2}{*}{ TOTAL } & \multirow{2}{*}{900} & 117 & 756,72 & 5,71 & 20,57 \\
\hline & & \multicolumn{4}{|c|}{900} \\
\hline
\end{tabular}


Tabela 14 - Balanço de energia para ensaios de redução carbotérmica com $1000 \mathrm{~W}$ de energia de micro-ondas irradiada em uma pelota com isolação térmica

\begin{tabular}{|c|c|c|c|c|c|}
\hline \multicolumn{2}{|c|}{ ENTRADA } & \multicolumn{4}{|c|}{ SAÍDA } \\
\hline \multirow[b]{2}{*}{$\begin{array}{c}\text { Tempo } \\
(\min )\end{array}$} & \multirow[b]{2}{*}{$\begin{array}{c}\text { Energia } \\
\text { irradiada } \\
\quad(\mathrm{kJ})\end{array}$} & \multirow[b]{2}{*}{$\begin{array}{c}\text { Energia } \\
\text { absorvida } \\
\text { pelo } \\
\text { equipamento } \\
\text { sem amostra } \\
(k J)\end{array}$} & \multirow[b]{2}{*}{$\begin{array}{c}\text { Energia } \\
\text { refletida }(k \mathrm{~J})\end{array}$} & \multicolumn{2}{|c|}{ Energia efetiva (kJ) } \\
\hline & & & & $\begin{array}{l}\text { Entalpia } \\
\text { de reação } \\
(\mathrm{kJ})\end{array}$ & $\begin{array}{c}\text { Perdas } \\
\text { térmicas } \\
\text { por } \\
\text { radiação } \\
(\mathbf{k J})\end{array}$ \\
\hline 0 a 3 & 180 & 19,8 & 152,64 & 2,47 & 5,09 \\
\hline 3 a 6 & 180 & 19,8 & 152,82 & 1,82 & 5,56 \\
\hline 6 a 9 & 180 & 19,8 & 153,00 & 1,16 & 6,04 \\
\hline 9 a 12 & 180 & 19,8 & 153,18 & 0,73 & 6,29 \\
\hline 12 a 15 & 180 & 19,8 & 153,72 & 0,44 & 6,04 \\
\hline 15 a 18 & 180 & 19,8 & 153,72 & 0,14 & 6,34 \\
\hline 18 a 21 & 180 & 19,8 & 153,72 & 0,00 & 6,48 \\
\hline 21 a 24 & 180 & 19,8 & 153,72 & 0,00 & 6,48 \\
\hline 24 a 27 & 180 & 19,8 & 153,72 & 0,00 & 6,48 \\
\hline 27 a 30 & 180 & 19,8 & 153,90 & 0,00 & 6,30 \\
\hline \multirow{2}{*}{ TOTAL } & \multirow{2}{*}{1800} & 198 & 1534,14 & 6,75 & 61,11 \\
\hline & & \multicolumn{4}{|c|}{1800} \\
\hline
\end{tabular}

Tabela 15 - Balanço de energia para ensaios de redução carbotérmica com $1500 \mathrm{~W}$ de energia de micro-ondas irradiada em uma pelota com isolação térmica

\begin{tabular}{|c|c|c|c|c|c|}
\hline \multicolumn{2}{|c|}{ ENTRADA } & \multicolumn{4}{|c|}{ SAÍDA } \\
\hline \multirow[b]{2}{*}{$\begin{array}{c}\text { Tempo } \\
\text { (min) }\end{array}$} & \multirow[b]{2}{*}{$\begin{array}{c}\text { Energia } \\
\text { irradiada } \\
\text { (kJ) }\end{array}$} & \multirow[b]{2}{*}{$\begin{array}{c}\text { Energia } \\
\text { absorvida } \\
\text { pelo } \\
\text { equipamento } \\
\text { sem amostra } \\
\text { (kJ) }\end{array}$} & \multirow[b]{2}{*}{$\begin{array}{c}\text { Energia } \\
\text { refletida (kJ) }\end{array}$} & \multicolumn{2}{|c|}{ Energia efetiva (kJ) } \\
\hline & & & & $\begin{array}{l}\text { Entalpia } \\
\text { de reação } \\
\text { (kJ) }\end{array}$ & $\begin{array}{c}\text { Perdas } \\
\text { térmicas } \\
\text { por } \\
\text { radiação } \\
\text { (kJ) }\end{array}$ \\
\hline 0 a 3 & 270 & 31,5 & 229,68 & 3,60 & 5,22 \\
\hline 3 a 6 & 270 & 31,5 & 229,68 & 2,57 & 6,25 \\
\hline 6 a 9 & 270 & 31,5 & 228,42 & 1,84 & 8,24 \\
\hline 9 a 12 & 270 & 31,5 & 229,14 & 1,09 & 8,27 \\
\hline \multirow{2}{*}{ TOTAL } & \multirow{2}{*}{1080} & 126 & 916,92 & 9,10 & 27,98 \\
\hline & & \multicolumn{4}{|c|}{1080} \\
\hline
\end{tabular}

Como é sabido, os cadinhos foram preparados com fibra cerâmica transparente as micro-ondas. Com este material, o número de arcos voltaicos que ocorrem durante a redução foi diminuído significantemente, mas não totalmente eliminados. Vários cadinhos fundiram devido ainda aos arcos voltaicos e também algumas vezes ao ferro fundido indicando que a temperatura nestes casos era superior a $1400^{\circ} \mathrm{C}$, ou seja, superior ao ponto de 
fusão da fibra cerâmica. A figura 35 mostra um cadinho de fibra cerâmica fundido.

Figura 35 - Cadinho de fibra cerâmica fundido

\subsubsection{Com cadinho de carbeto de silício}

O gráfico 11 apresenta a porcentagem de reação em função do tempo de uma pelota no interior de um cadinho de carbeto de silício exposto à irradiação de três níveis de potência de microondas calculada através da equação 19. 


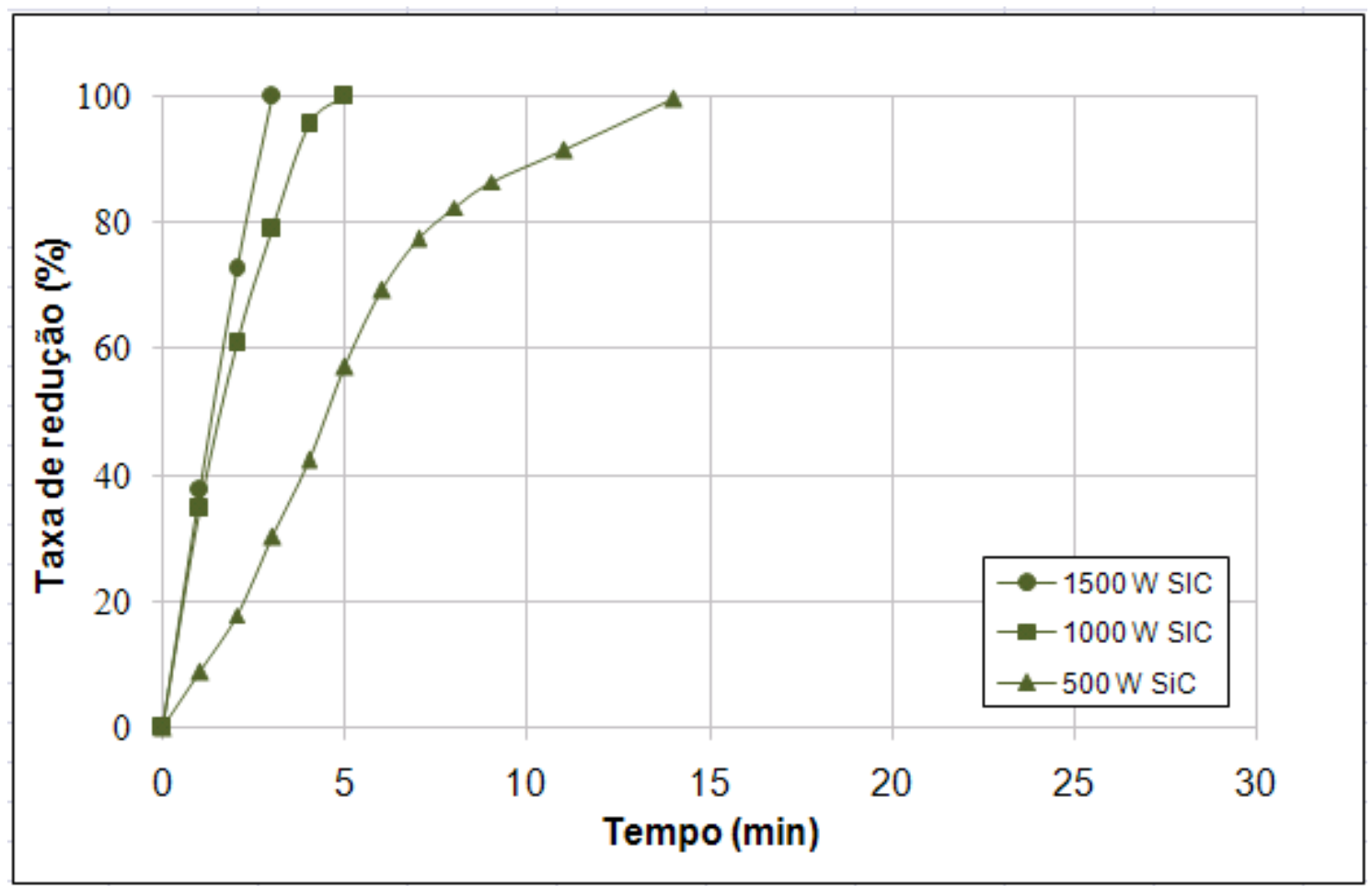

Gráfico 11 - Taxa de redução em função do tempo de exposição a três níveis de potências às micro-ondas para uma pelota na proporção estequiométrica entre minério de ferro de Carajás e coque de petróleo em um cadinho de carbeto de silício

Nas curvas de redução apresentadas pelo gráfico 11 observa-se que a 1500 W e 1000 W a taxas de redução atingem 100\% em 3 e 5 minutos respectivamente. Com $500 \mathrm{~W}$ irradiado atingiu-se 100\% de redução em 14 minutos. Nestes ensaios a pelota também estava no interior de um cadinho com tampa como nos ensaios realizados com cadinho de isolante cerâmico, portanto não foi possível medir a temperatura da pelota.

O gráfico 12 mostra a evolução da energia de micro-ondas refletida durante a redução carbotérmica com cadinho de carbeto de silício calculada através da equação 17. 


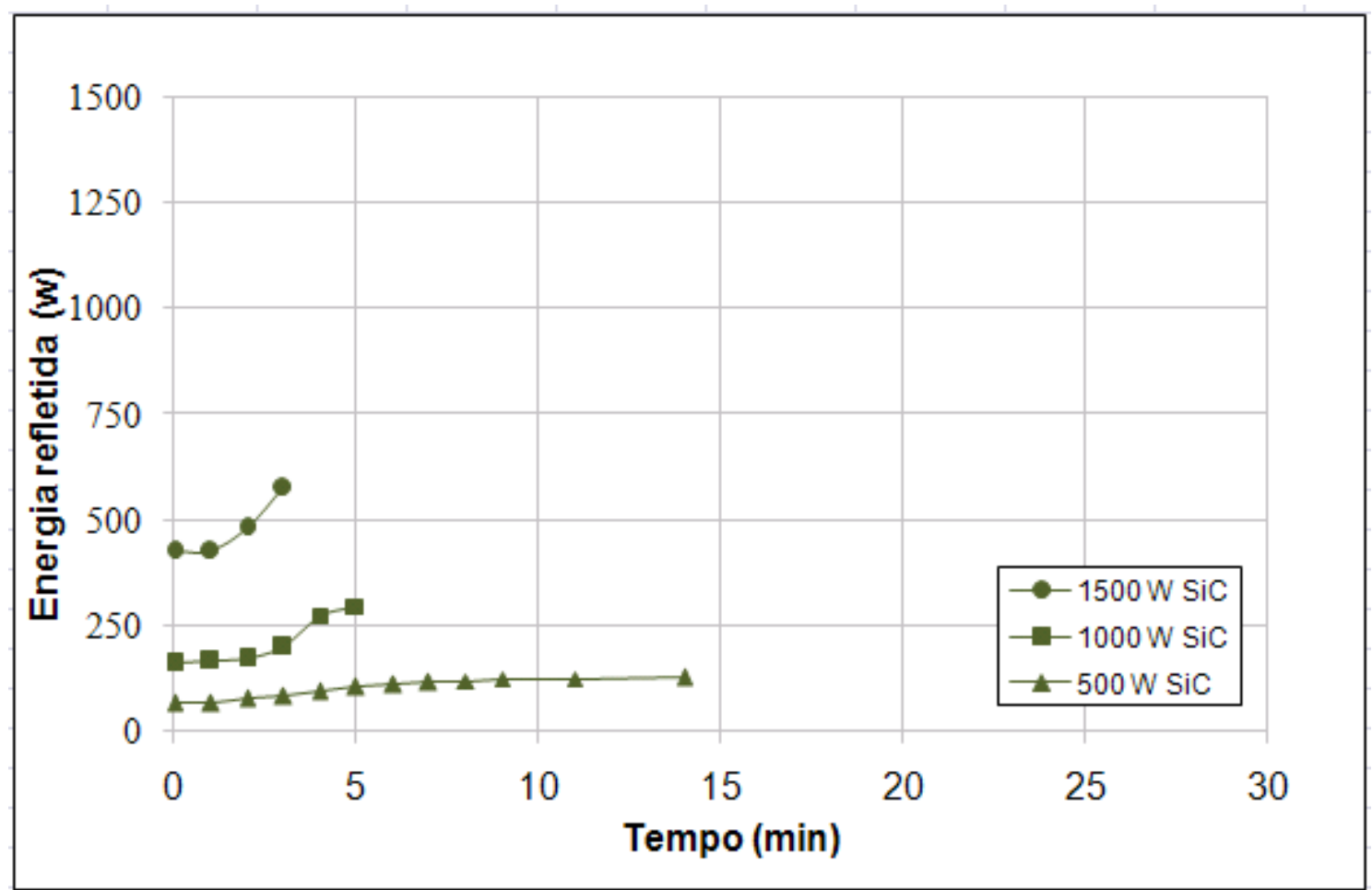

Gráfico 12 - Perfil da evolução de energia de micro-ondas refletida (W) na redução carbotérmica de uma pelota com cadinho de carbeto de silício

Não foi possível determinar as energias efetivas na pelota no interior do cadinho de carbeto de silício nos três níveis de potência de micro-ondas irradiada, pois nos ensaios o equipamento não estava previamente estabilizado termicamente como realizado nas reduções carbotérmicas com e sem isolante térmico, ou seja, os ensaios iniciaram com o equipamento frio. Isto impossibilitou o uso da equação 18, pois a energia absorvida pelo equipamento sem amostra e com cadinho de carbeto de silício mostrados através do item 4.1.2 só é válida quando o equipamento atinge equilíbrio térmico. Nota-se através dos gráficos 2 e 3 que para estabilizar o equipamento com o cadinho de carbeto de silício se faz necessário pelo menos 20 minutos de irradiação de micro-ondas até que todos os dispositivos do equipamento atinjam a faixa de equilíbrio térmico. Este período de aquecimento inicial é muito instável gerando valores imprecisos impossibilitando a quantificação da energia efetivamente imposta à pelota. Este empecilho foi gerado devido a não possibilidade de manipular o cadinho de carbeto de silício em altas temperaturas como mostrado pela figura 36 . 


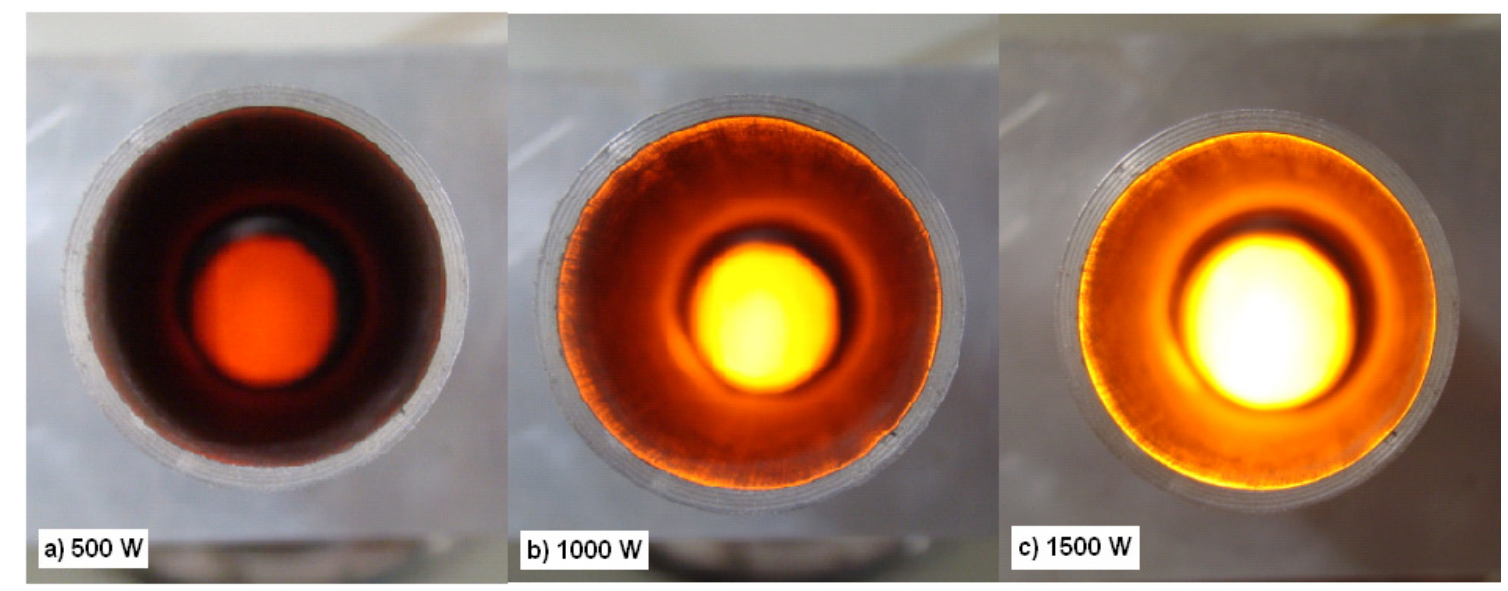

Figura 36 - Vista superior do interior da câmara de reação com o cadinho de carbeto de silício com tampa e sem pelota sob os três níveis de irradiação de micro-ondas

\subsubsection{Ensaios com uma pelota no máximo campo magnético}

Neste item são apresentados e discutidos os principais resultados encontrados para a redução carbotérmica de uma pelota auto-redutora na proporção estequiométrica com irradiação por micro-ondas de $1000 \mathrm{~W}$ no máximo campo magnético e sem isolação térmica.

O equipamento foi ligado por 20 minutos nas condições de trabalho sem amostra para estabilizar as perdas térmicas para o sistema.

O gráfico 13 apresenta a porcentagem de reação em função do tempo de exposição à irradiação por micro-ondas sem isolação térmica calculada através da equação 19.

Na curva de redução apresentada pelo gráfico 13 observa-se que após 15 minutos de reação, $68 \%$ da taxa de redução foi obtida podendo ser visualizado por um patamar. 


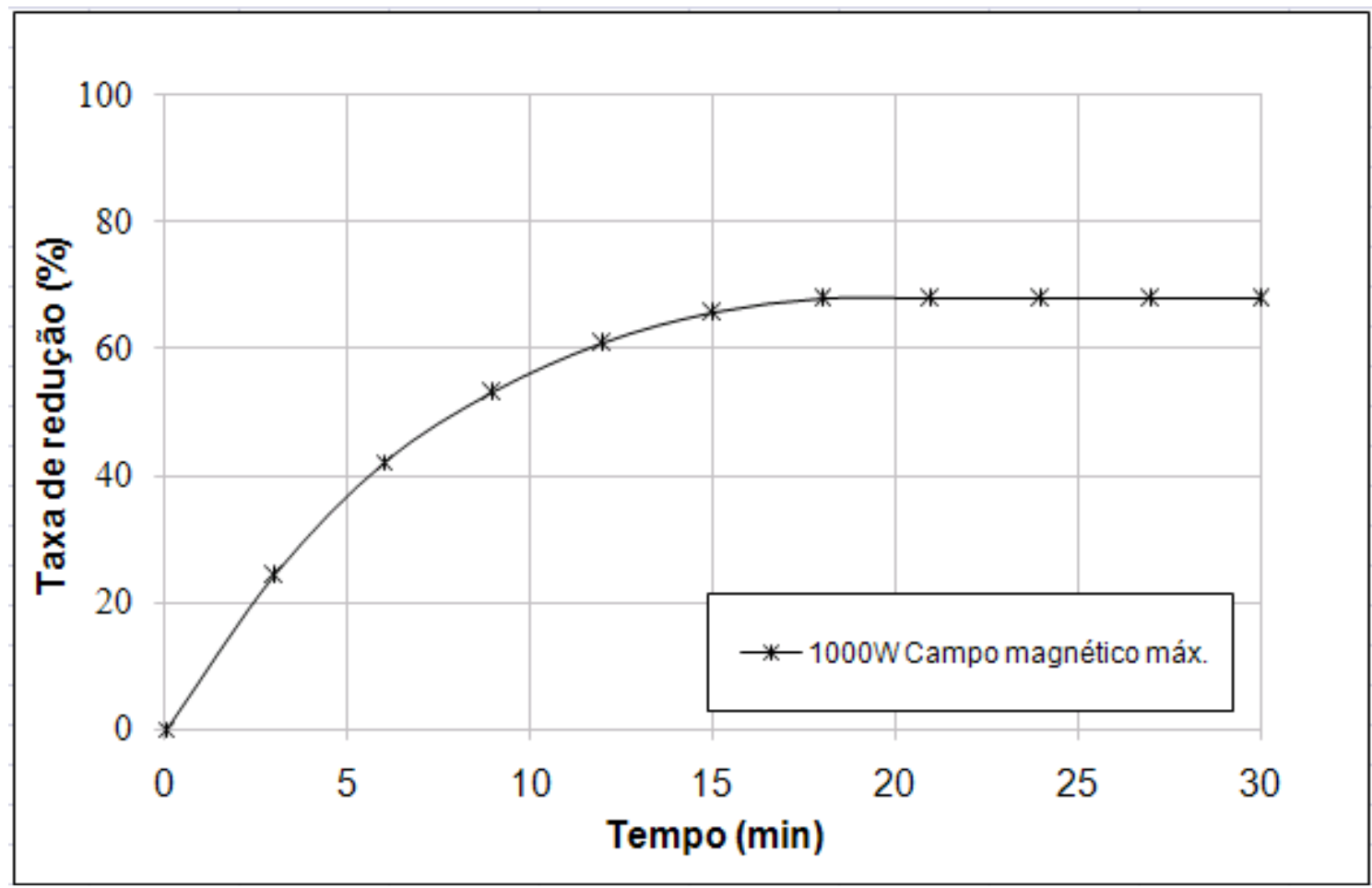

Gráfico 13 - Taxa de redução em função do tempo de exposição a $1000 \mathrm{~W}$ de micro-ondas para uma pelota na proporção estequiométrica entre minério de ferro de Carajás e coque de petróleo sem isolação térmica no máximo campo magnético

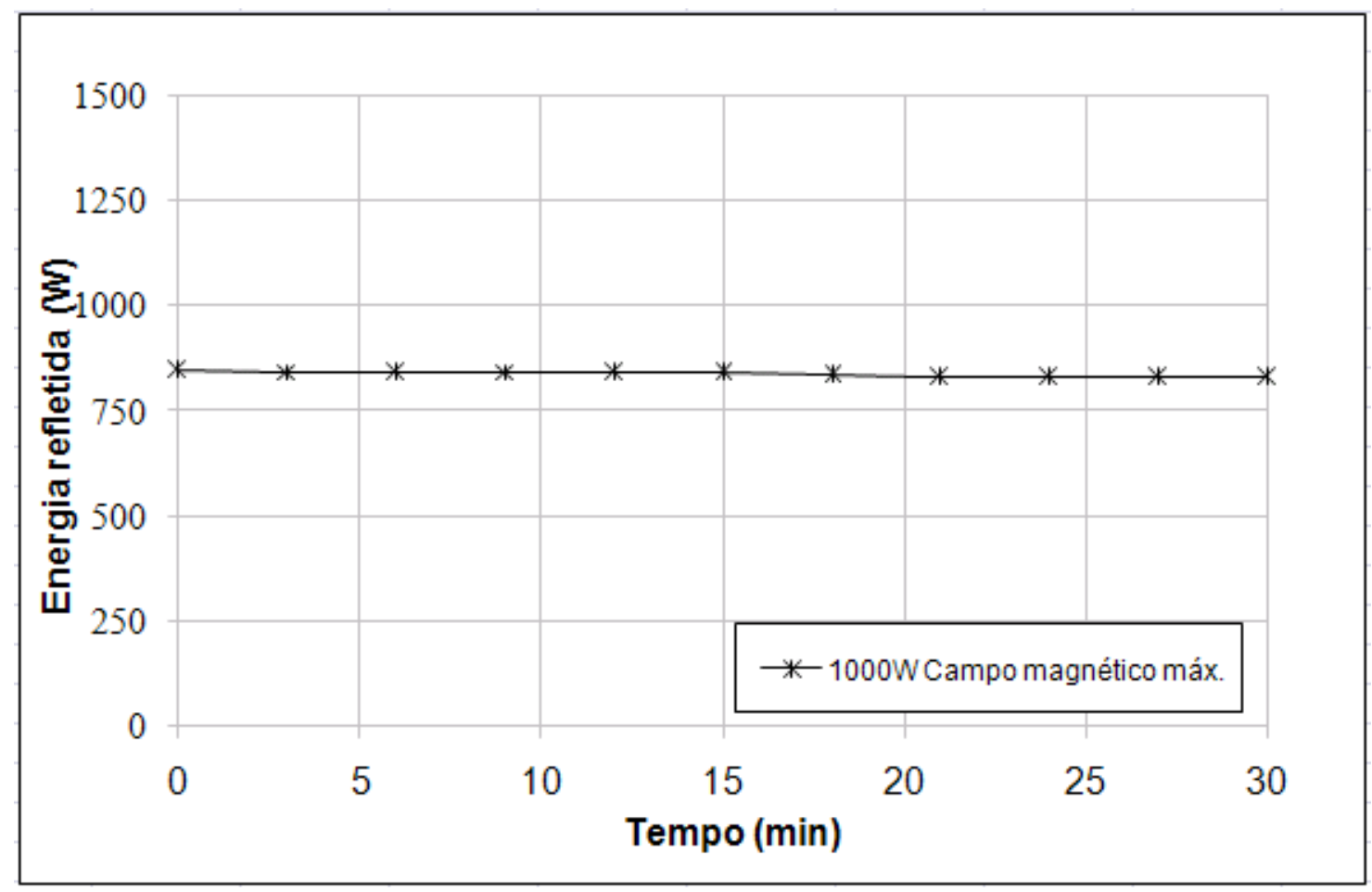

Gráfico 14 - Perfil da evolução da energia de micro-ondas refletida (W) na redução carbotérmica de uma pelota sem isolação térmica no máximo campo magnético 
O gráfico 14 mostra a evolução da energia de micro-ondas refletida durante a redução carbotérmica no máximo campo magnético calculado através da equação 17.

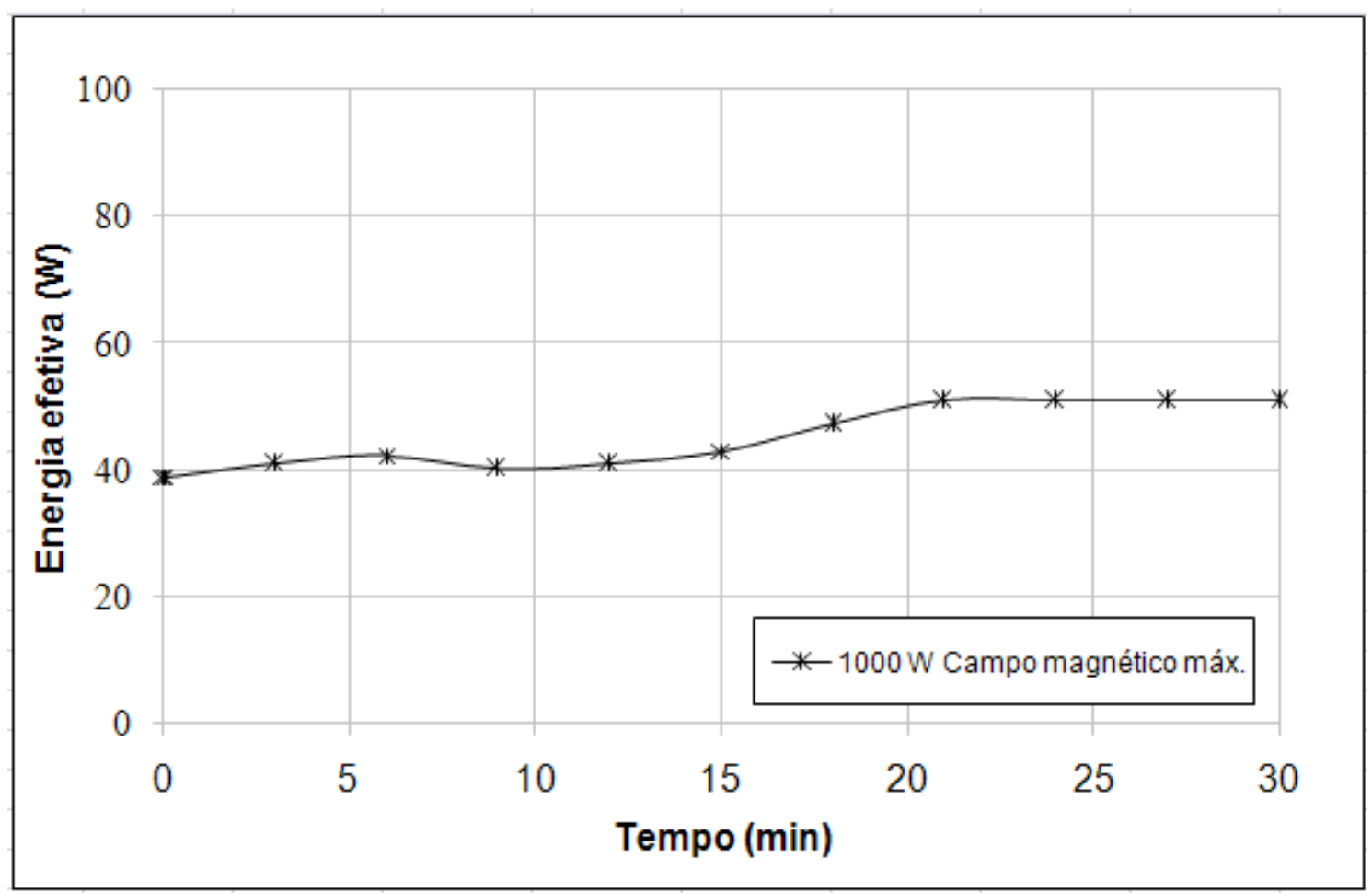

Gráfico 15 - Perfil da evolução da energia de micro-ondas efetiva (W) na redução carbotérmica de uma pelota sem isolação térmica no máximo campo magnético

O gráfico 15 apresenta o perfil da evolução da energia de micro-ondas utilizada na redução carbotérmica de uma pelota sem isolação calculada através da equação 18. Após 15 minutos de ensaio a pelota começa a absorver mais energia de micro-ondas no campo magnético, favorecida pelas mudanças de etapas que ocorrem durante o ensaio como, por exemplo, a formação de partículas metálicas, como apresentado através do trabalho realizado por Cheng, Roy e Agrawal ${ }^{40}$ (2002).

A tabela 16 apresenta a quantificação de energia nos ensaios de redução carbotérmica com uma pelota na proporção estequiométrica sem isolação térmica no período de 30 minutos a $1000 \mathrm{~W}$ de energia de microondas irradiada no máximo campo magnético. 
Tabela 16 - Balanço de energia para ensaios de redução carbotérmica com $1000 \mathrm{~W}$ de energia de micro-ondas no máximo campo magnético irradiada em uma pelota sem isolação térmica

\begin{tabular}{|c|c|c|c|c|c|}
\hline \multicolumn{2}{|c|}{ ENTRADA } & \multicolumn{4}{|c|}{ SAÍDA } \\
\hline \multirow[b]{2}{*}{$\begin{array}{c}\text { Tempo } \\
(\mathrm{min})\end{array}$} & \multirow[b]{2}{*}{$\begin{array}{c}\text { Energia } \\
\text { irradiada } \\
\text { (kJ) }\end{array}$} & \multirow[b]{2}{*}{$\begin{array}{c}\text { Energia } \\
\text { absorvida } \\
\text { pelo } \\
\text { equipamento } \\
\text { sem amostra } \\
\text { (kJ) }\end{array}$} & \multirow[b]{2}{*}{$\begin{array}{c}\text { Energia } \\
\text { refletida (kJ) }\end{array}$} & \multicolumn{2}{|c|}{ Energia efetiva (kJ) } \\
\hline & & & & $\begin{array}{l}\text { Entalpia de } \\
\text { reação (kJ) }\end{array}$ & $\begin{array}{l}\text { Perdas } \\
\text { térmicas } \\
\text { por } \\
\text { radiação } \\
\text { (kJ) }\end{array}$ \\
\hline 0 a 3 & 180 & 19,8 & 152,82 & 2,21 & 5,17 \\
\hline 3 a 6 & 180 & 19,8 & 152,58 & 1,62 & 6,00 \\
\hline 6 a 9 & 180 & 19,8 & 152,94 & 1,00 & 6,26 \\
\hline 9 a 12 & 180 & 19,8 & 152,82 & 0,70 & 6,68 \\
\hline 12 a 15 & 180 & 19,8 & 152,46 & 0,43 & 7,31 \\
\hline 15 a 18 & 180 & 19,8 & 151,68 & 0,22 & 8,30 \\
\hline 18 a 21 & 180 & 19,8 & 151,02 & 0,00 & 9,18 \\
\hline 21 a 24 & 180 & 19,8 & 151,02 & 0,00 & 9,18 \\
\hline 24 a 27 & 180 & 19,8 & 151,02 & 0,00 & 9,18 \\
\hline 27 a 30 & 180 & 19,8 & 151,02 & 0,00 & 9,18 \\
\hline \multirow{2}{*}{ TOTAL } & \multirow{2}{*}{1800} & 198 & 1519,38 & 6,17 & 76,45 \\
\hline & & \multicolumn{4}{|c|}{1800} \\
\hline
\end{tabular}

\subsubsection{Ensaios com duas pelotas no máximo campo elétrico}

Neste item são apresentados e discutidos os principais resultados encontrados para a redução carbotérmica de duas pelotas auto-redutoras na proporção estequiométrica com irradiação por micro-ondas de $1000 \mathrm{~W}$ no máximo campo elétrico e com isolação térmica.

O equipamento foi ligado por 20 minutos nas condições de trabalho sem amostra para estabilizar as perdas térmicas para o sistema.

O gráfico 16 apresenta a porcentagem de reação em função do tempo de exposição à irradiação por micro-ondas com isolação térmica calculada através da equação 19.

$\mathrm{Na}$ curva de redução apresentada pelo gráfico 16 observa-se que após 18 minutos de reação, $88,5 \%$ da taxa de redução foi obtida podendo ser visualizado por um patamar. 


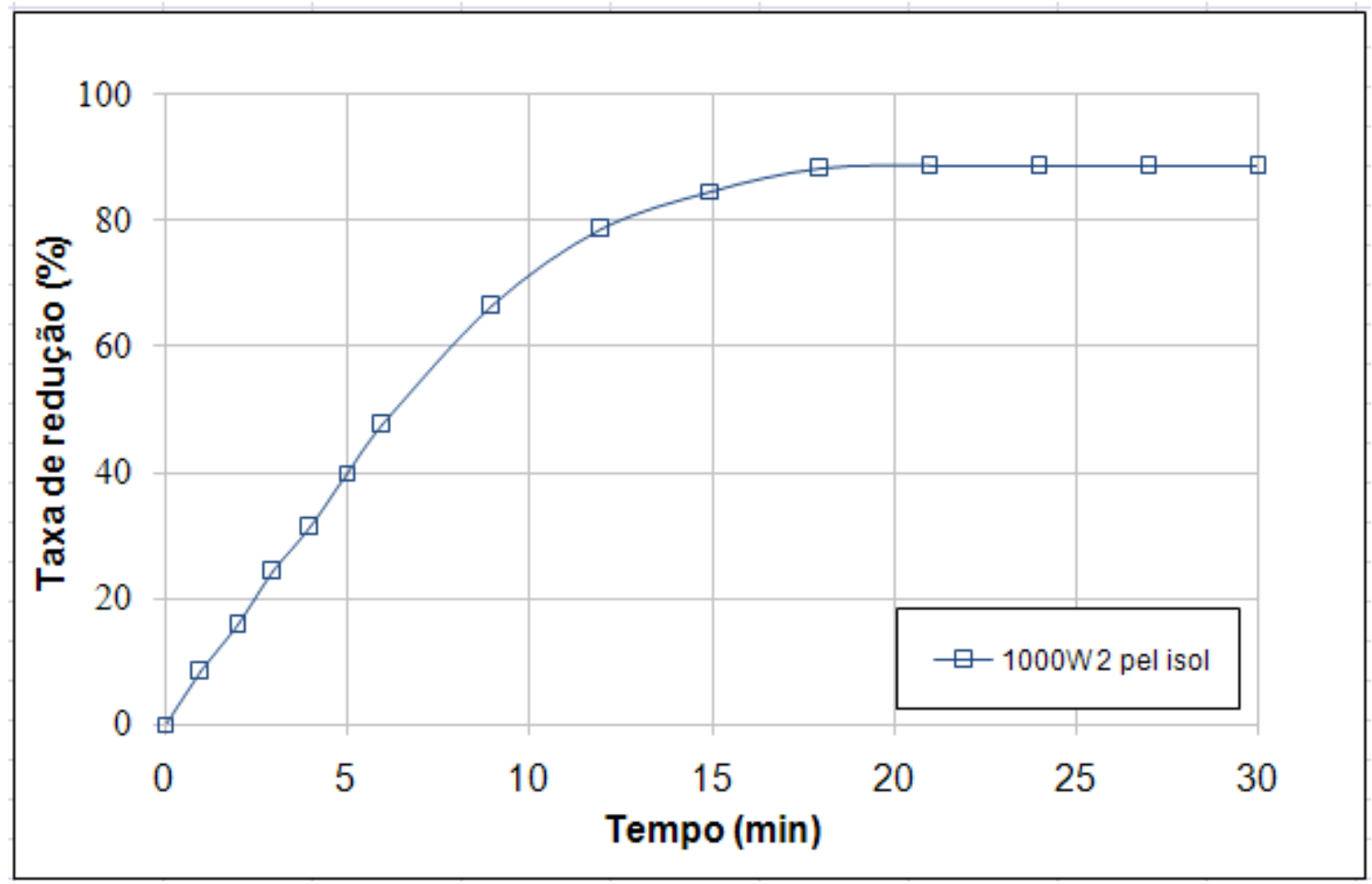

Gráfico 16 - Taxa de redução em função do tempo de exposição a $1000 \mathrm{~W}$ de micro-ondas para duas pelotas na proporção estequiométrica entre minério de ferro de Carajás e coque de petróleo com isolação térmica

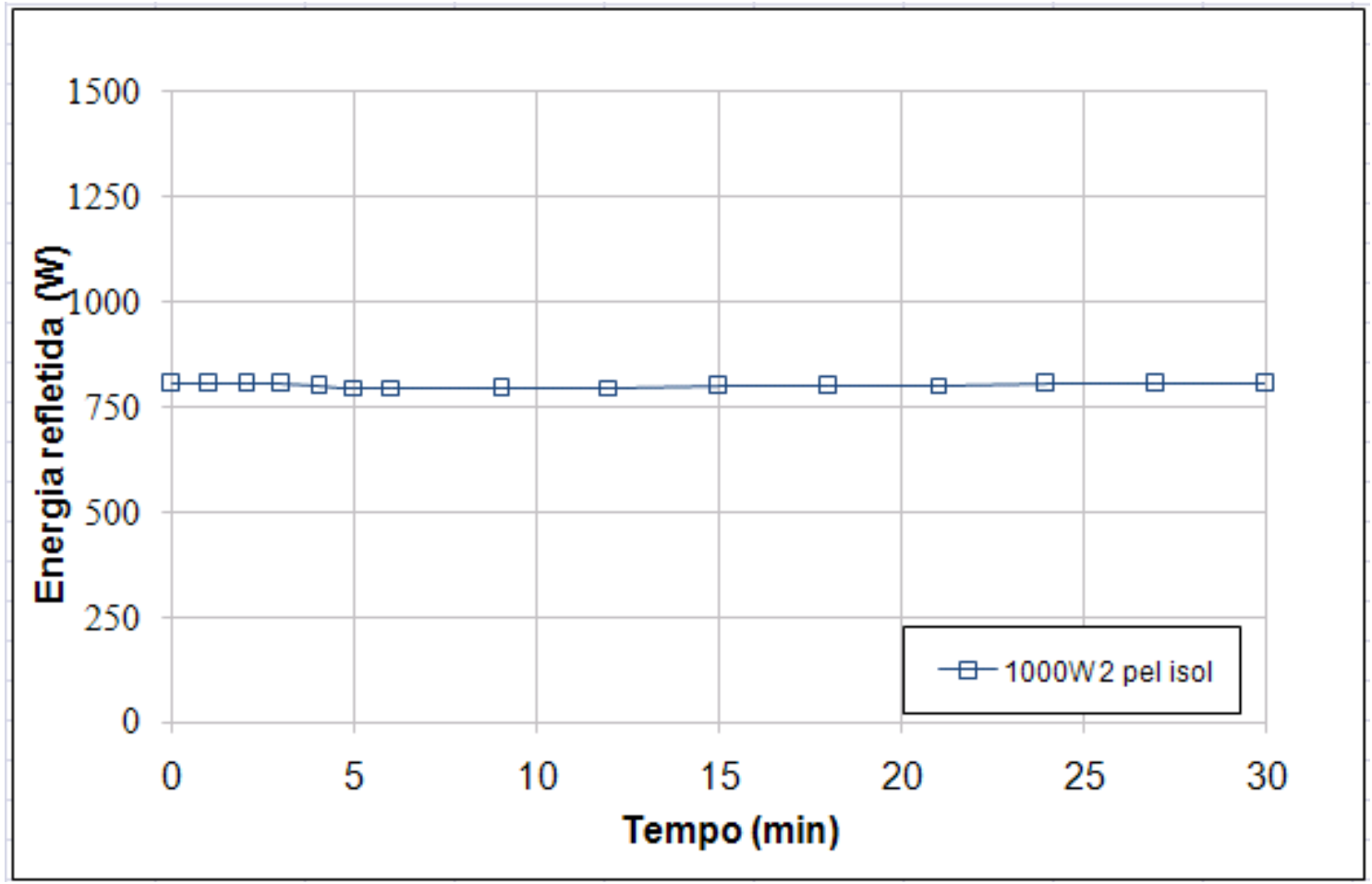

Gráfico 17 - Perfil da evolução da energia de micro-ondas refletida (W) na redução carbotérmica de duas pelotas com isolação térmica 
O gráfico 17 mostra a evolução da energia de micro-ondas refletida durante a redução carbotérmica de duas pelotas no máximo campo elétrico calculado através da equação 17.

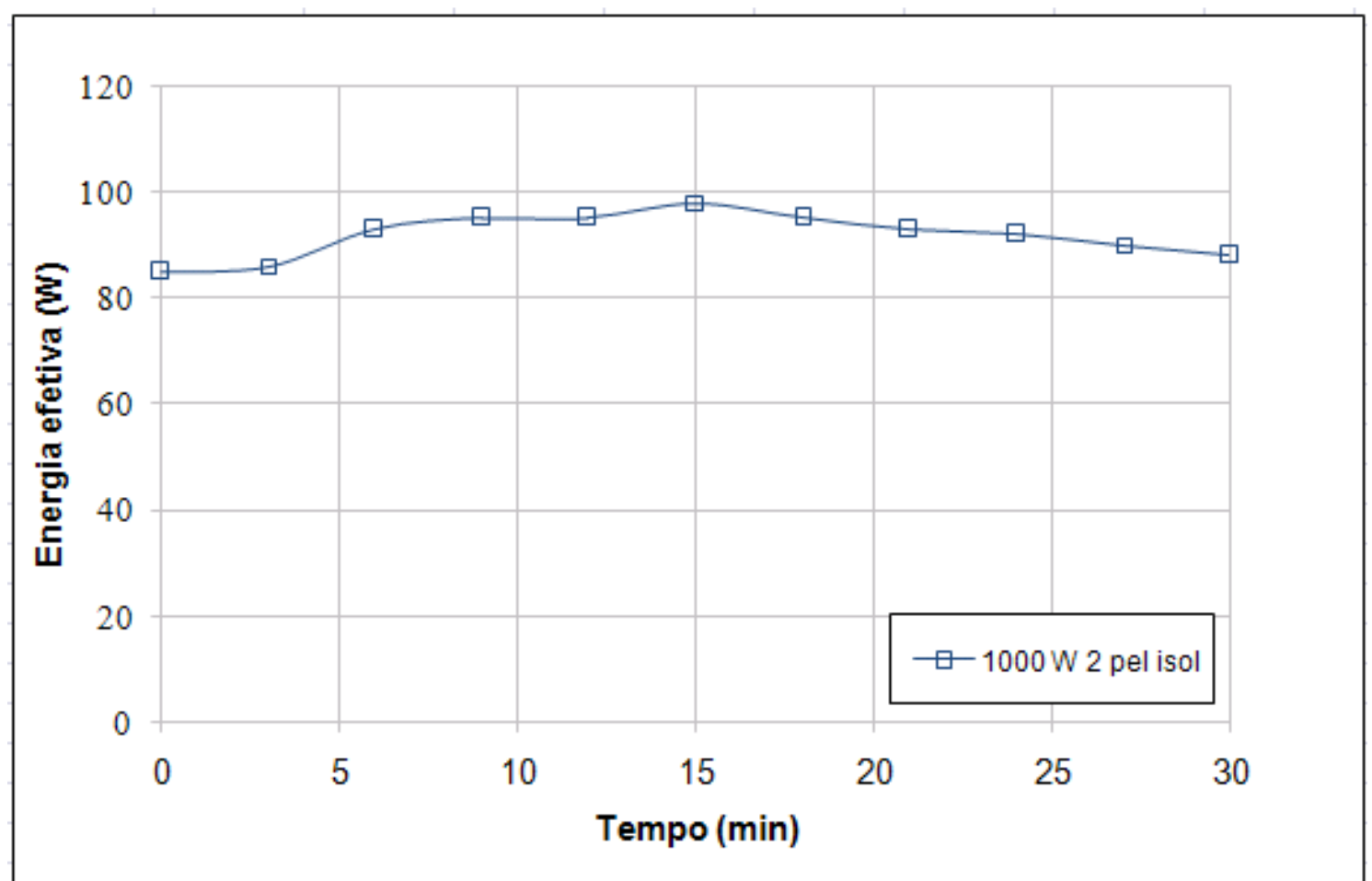

Gráfico 18 - Perfil da evolução da energia de micro-ondas efetiva (W) na redução carbotérmica de duas pelotas com isolação térmica

O gráfico 18 apresenta o perfil da evolução da energia de micro-ondas efetiva utilizada na redução carbotérmica de duas pelotas com isolação térmica calculada através da equação 18.

A tabela 17 apresenta a quantificação de energia nos ensaios de redução carbotérmica com duas pelotas na proporção estequiométrica com isolação térmica no período de 30 minutos a $1000 \mathrm{~W}$ de energia de microondas irradiada no máximo campo elétrico. 
Tabela 17 - Balanço de energia para ensaios de redução carbotérmica com $1000 \mathrm{~W}$ de energia de micro-ondas no máximo campo elétrico irradiada em duas pelotas com isolação térmica

\begin{tabular}{|c|c|c|c|c|c|}
\hline \multicolumn{2}{|c|}{ ENTRADA } & \multicolumn{4}{|c|}{ SAÍDA } \\
\hline \multirow[b]{2}{*}{$\begin{array}{c}\text { Tempo } \\
(\min )\end{array}$} & \multirow[b]{2}{*}{$\begin{array}{c}\text { Energia } \\
\text { irradiada } \\
(\mathrm{kJ})\end{array}$} & \multirow[b]{2}{*}{$\begin{array}{c}\text { Energia } \\
\text { absorvida } \\
\text { pelo } \\
\text { equipamento } \\
\text { sem amostra } \\
(\mathrm{kJ})\end{array}$} & \multirow[b]{2}{*}{$\begin{array}{c}\text { Energia } \\
\text { refletida }(\mathbf{k J})\end{array}$} & \multicolumn{2}{|c|}{ Energia efetiva (kJ) } \\
\hline & & & & $\begin{array}{l}\text { Entalpia de } \\
\text { reação (kJ) }\end{array}$ & $\begin{array}{l}\text { Perdas } \\
\text { térmicas } \\
\text { por } \\
\text { radiação } \\
(\mathrm{kJ})\end{array}$ \\
\hline 0 a 3 & 180 & 19,8 & 144,90 & 2,19 & 13,11 \\
\hline 3 a 6 & 180 & 19,8 & 143,10 & 2,11 & 14,99 \\
\hline 6 a 9 & 180 & 19,8 & 142,56 & 1,71 & 15,93 \\
\hline 9 a 12 & 180 & 19,8 & 143,10 & 1,12 & 15,98 \\
\hline 12 a 15 & 180 & 19,8 & 143,46 & 0,56 & 16,18 \\
\hline 15 a 18 & 180 & 19,8 & 143,64 & 0,32 & 16,24 \\
\hline 18 a 21 & 180 & 19,8 & 144,00 & 0,04 & 16,16 \\
\hline 21 a 24 & 180 & 19,8 & 144,36 & 0,00 & 15,84 \\
\hline 24 a 27 & 180 & 19,8 & 144,54 & 0,00 & 15,66 \\
\hline 27 a 30 & 180 & 19,8 & 144,72 & 0,00 & 15,48 \\
\hline \multirow{2}{*}{ TOTAL } & \multirow{2}{*}{1800} & 198 & 1438,38 & 8,06 & 155,56 \\
\hline & & & 180 & & \\
\hline
\end{tabular}

\subsection{Redução carbotérmica em forno de resistência elétrica}

O gráfico 19 apresenta a porcentagem de reação em função do tempo, calculada através da equação 19 , de uma pelota em redução em forno com aquecimento através de resistências elétricas a $1150^{\circ} \mathrm{C}$. Lembrando que para o ensaio termogravimétrico em forno de resistência, a amostra era levada diretamente na temperatura já estabelecida previamente.

A temperatura de $1150^{\circ} \mathrm{C}$ foi escolhida, pois se sabe que, nesta temperatura, a reação de redução de minério de ferro se completa totalmente e que o mecanismo controlador é a reação de Boudouard. 


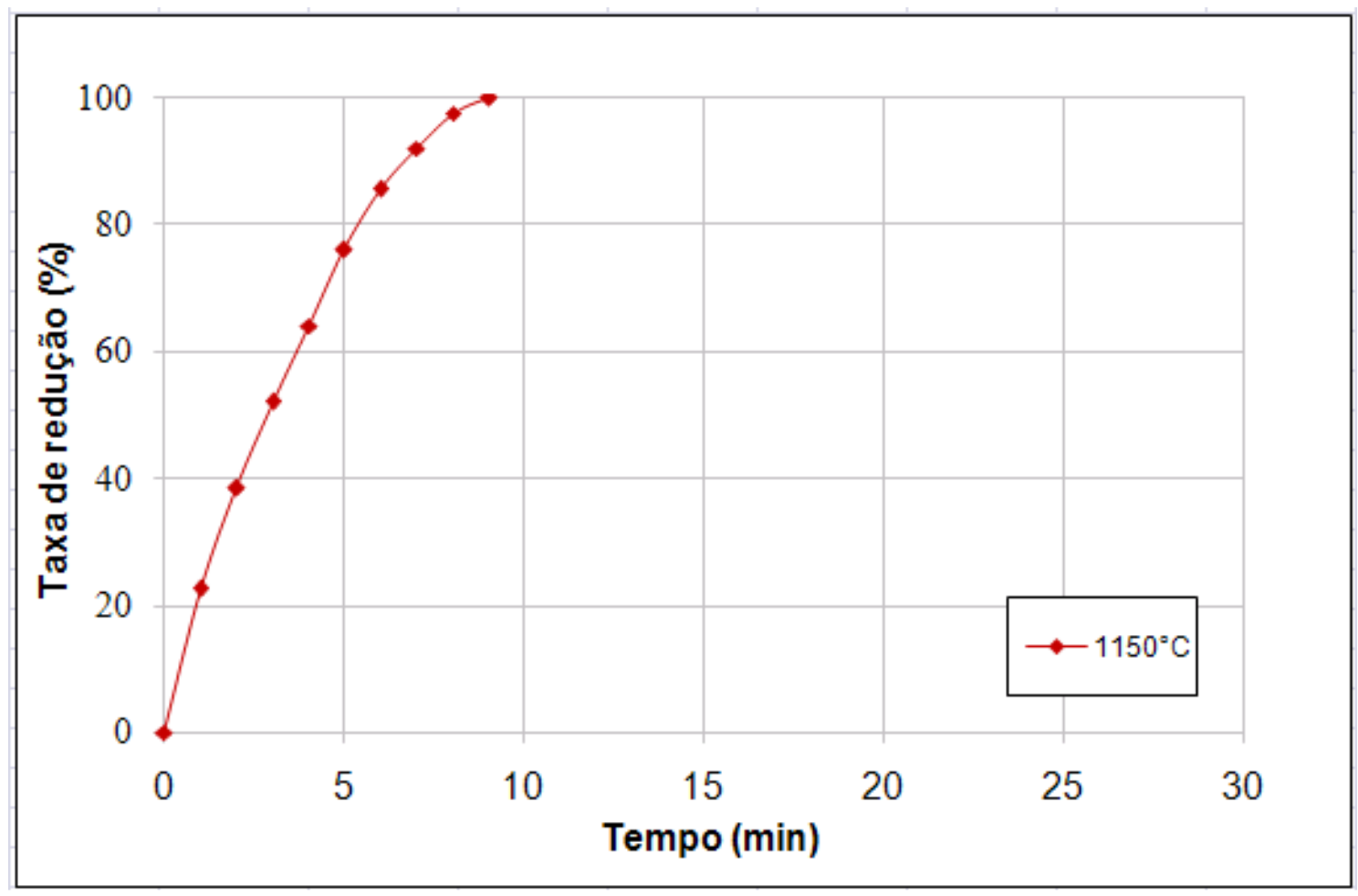

Gráfico 19 - Taxa de redução em função do tempo para uma pelota na proporção estequiométrica entre minério de ferro de Carajás e coque de petróleo, a $1150^{\circ} \mathrm{C}$ em forno de resistência elétrica

\subsection{Análise das variáveis de processo}

\subsubsection{Influência na taxa de redução variando os níveis de energia de micro-ondas irradiadas na pelota no máximo campo elétrico}

A seguir têm-se as comparações dos valores encontrados para as amostras isoladas e não isoladas termicamente e com cadinho de carbeto de silício variando a potência de micro-ondas irradiada.

Os gráficos 20, 21 e 22 apresentam as taxas de redução em função do tempo de exposição a 500 W, 1000 W e 1500 W de potência de micro-ondas irradiada, respectivamente, em uma pelota na proporção estequiométrica entre minério de ferro de Carajás e coque de petróleo isolada e não isolada termicamente e em cadinho de carbeto de silício calculada através da equação 19. 


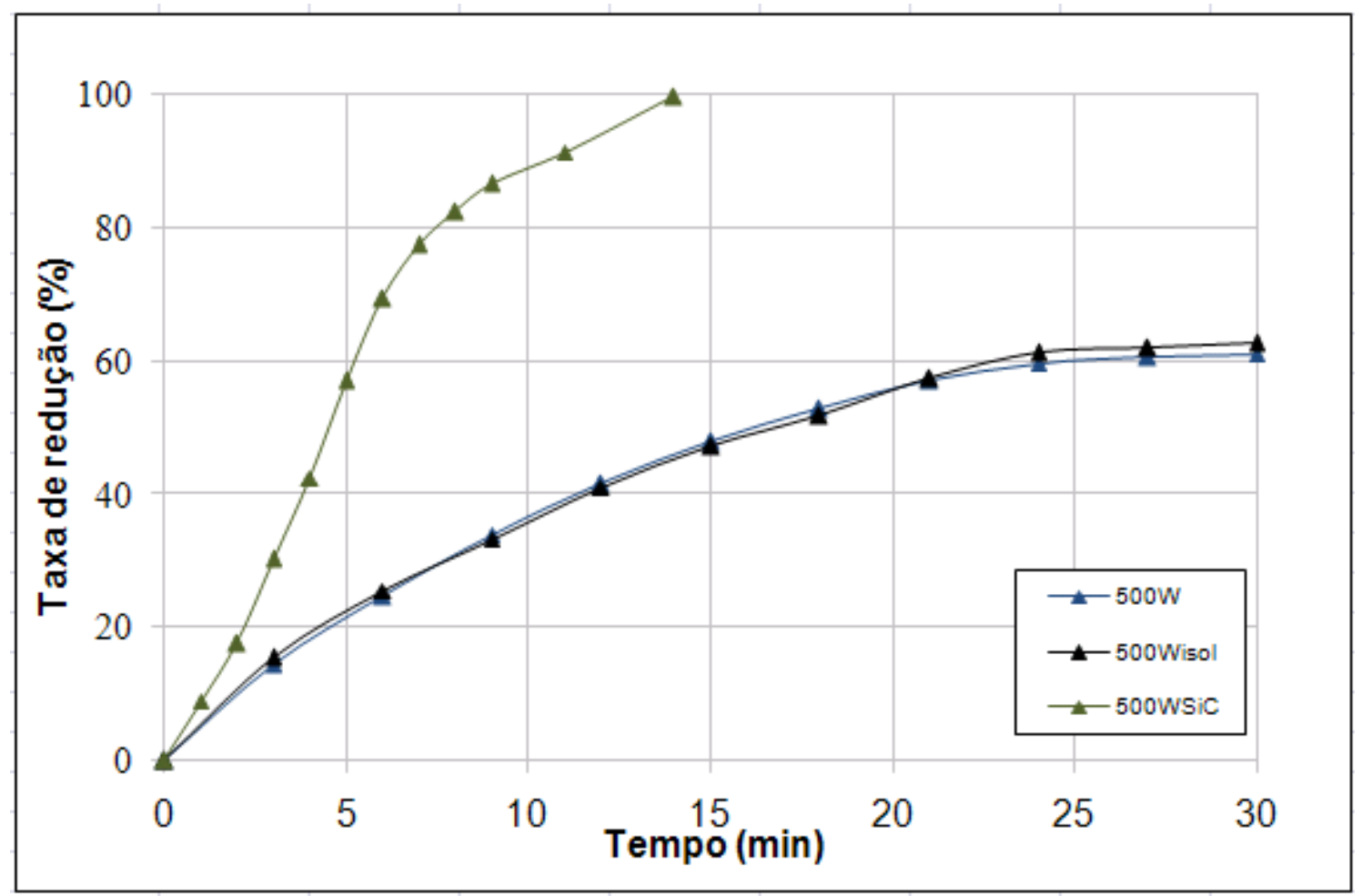

Gráfico 20 - Taxa de redução em função do tempo de exposição a 500 W de potência irradiada de micro-ondas para uma pelota na proporção estequiométrica entre minério de ferro de Carajás e coque de petróleo

O gráfico 20 mostra que taxas de redução para pelotas isoladas e não isoladas termicamente são idênticas. Percebe-se um comportamento linear e com valores de porcentagem de redução próximos a $60 \%$. Tal fato pode ser explicado devido à densidade energética existente na câmara de reação não ser suficiente para se ter uma melhor interação entre o substrato e a energia fornecida. Mesmo a amostra estando isolada termicamente, obtendo assim uma diminuição das perdas por irradiação, e uma diminuição da energia efetiva, a entalpia de reação para a pelota foi à mesma. Resultados melhores foram obtidos utilizando o cadinho de carbeto de silício. Devido este material possuir altas perdas dielétricas frente às ondas eletromagnéticas e, portanto, sendo uma fonte de calor auxiliar, conseguiu uma taxa de redução de $100 \%$ em 14 minutos. 


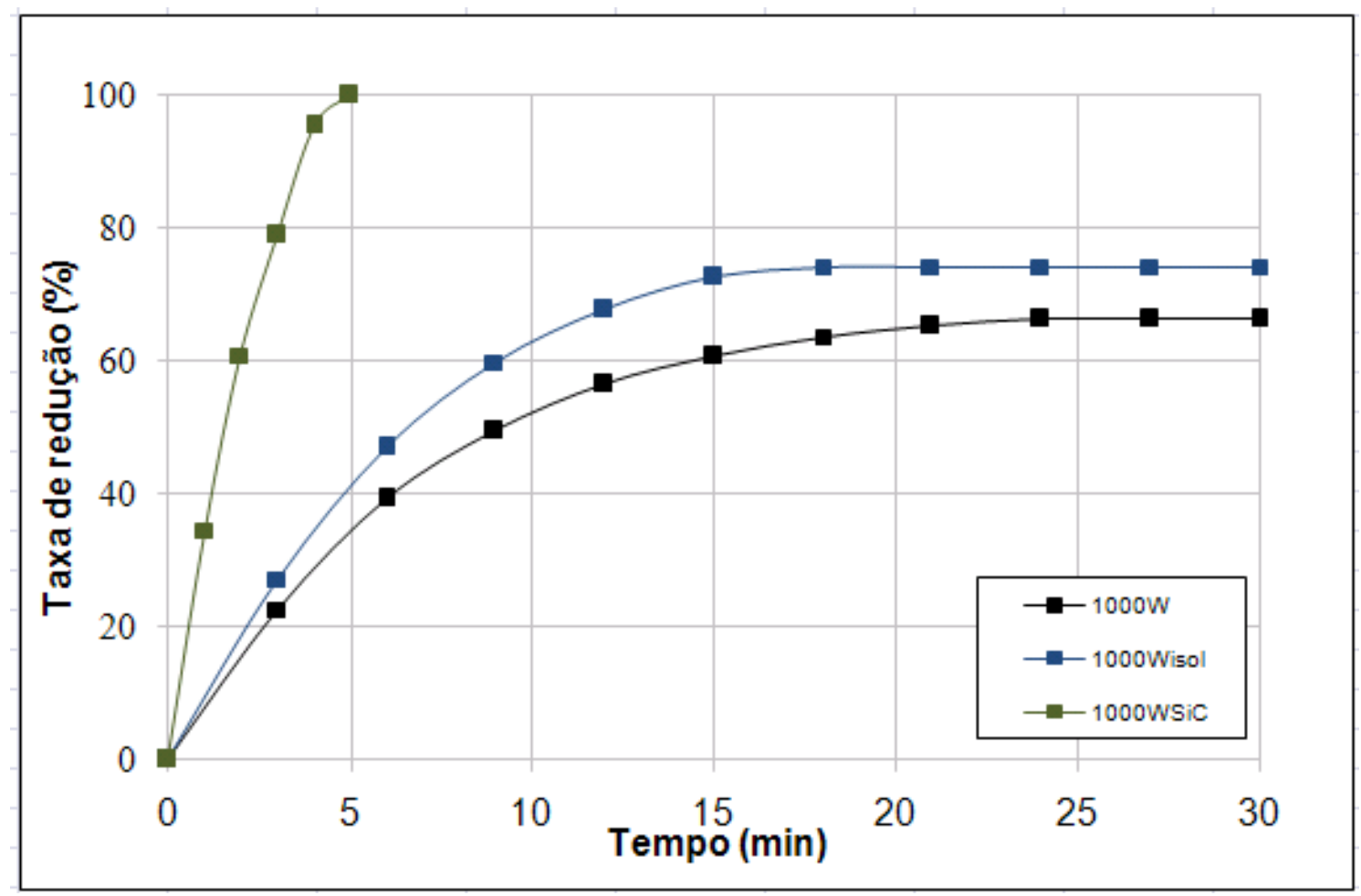

Gráfico 21 - Taxa de redução em função do tempo de exposição a $1000 \mathrm{~W}$ de potência irradiada de micro-ondas para uma pelota na proporção estequiométrica entre minério de ferro de Carajás e coque de petróleo

No gráfico 21, percebe-se também que não ocorreu uma completa redução carbotérmica tanto na amostra isolada como na sem isolação térmica. Mesmo aumentando a densidade energética no interior da câmara de reação através do aumento de energia de micro-ondas irradiada, a taxa de redução teve um ligeiro aumento comparado à taxa de redução a $500 \mathrm{~W}$ que atingiu apenas $66 \%$. Utilizando isolação térmica na pelota neste nível de potência, a taxa de redução teve um ligeiro favorecimento e atingiu $74 \%$ aos 18 minutos de ensaio, mostrando que a isolação térmica neste caso começa a ser mais significante. A taxa de redução utilizando cadinho de carbeto de silício atingiu neste nível de energia 100\% em 5 minutos. 


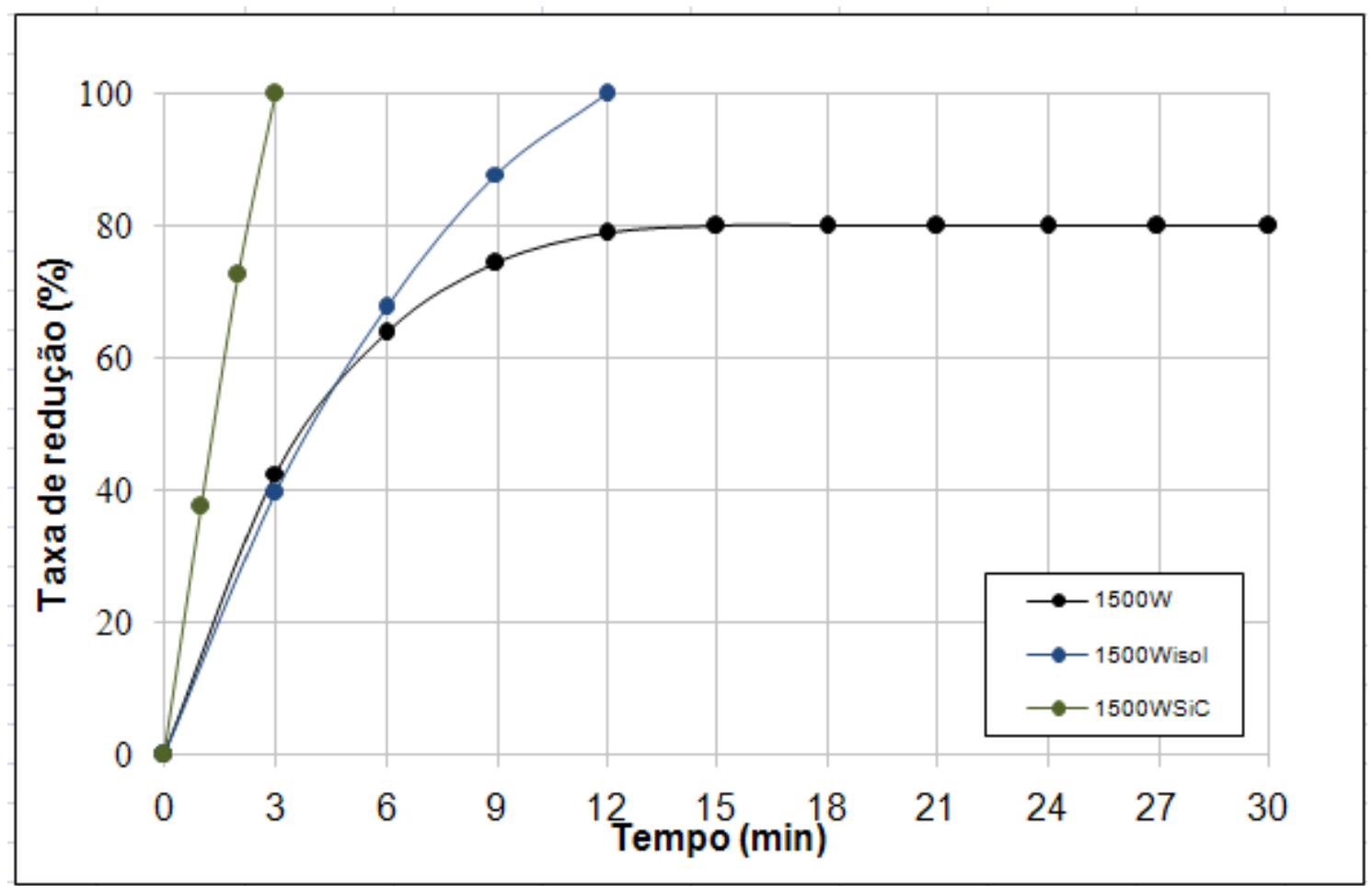

Gráfico 22 - Taxa de redução em função do tempo de exposição a $1500 \mathrm{~W}$ de potência irradiada de micro-ondas para uma pelota na proporção estequiométrica entre minério de ferro de Carajás e coque de petróleo

As taxas de redução apresentadas pelo gráfico 22 mostram que mesmo aumentando a potência de micro-ondas irradiada na amostra sem isolação térmica, ainda não atinge a completa redução. Com isolação térmica a pelota atingiu uma taxa de redução de 100\% em 12 minutos. Resultados melhores novamente foram obtidos utilizando o cadinho de carbeto de silício. A taxa de redução atingiu 100\% em 5 minutos.

\subsubsection{Influência do máximo campo elétrico comparado com o máximo campo magnético}

Estudou-se o comportamento da taxa de redução de uma pelota na proporção estequiométrica, sem isolação térmica, ora no máximo campo elétrico ora no máximo campo magnético com potência de micro-ondas irradiada de $1000 \mathrm{~W}$. Os resultados estão apresentados através dos gráficos 23 e 24. 


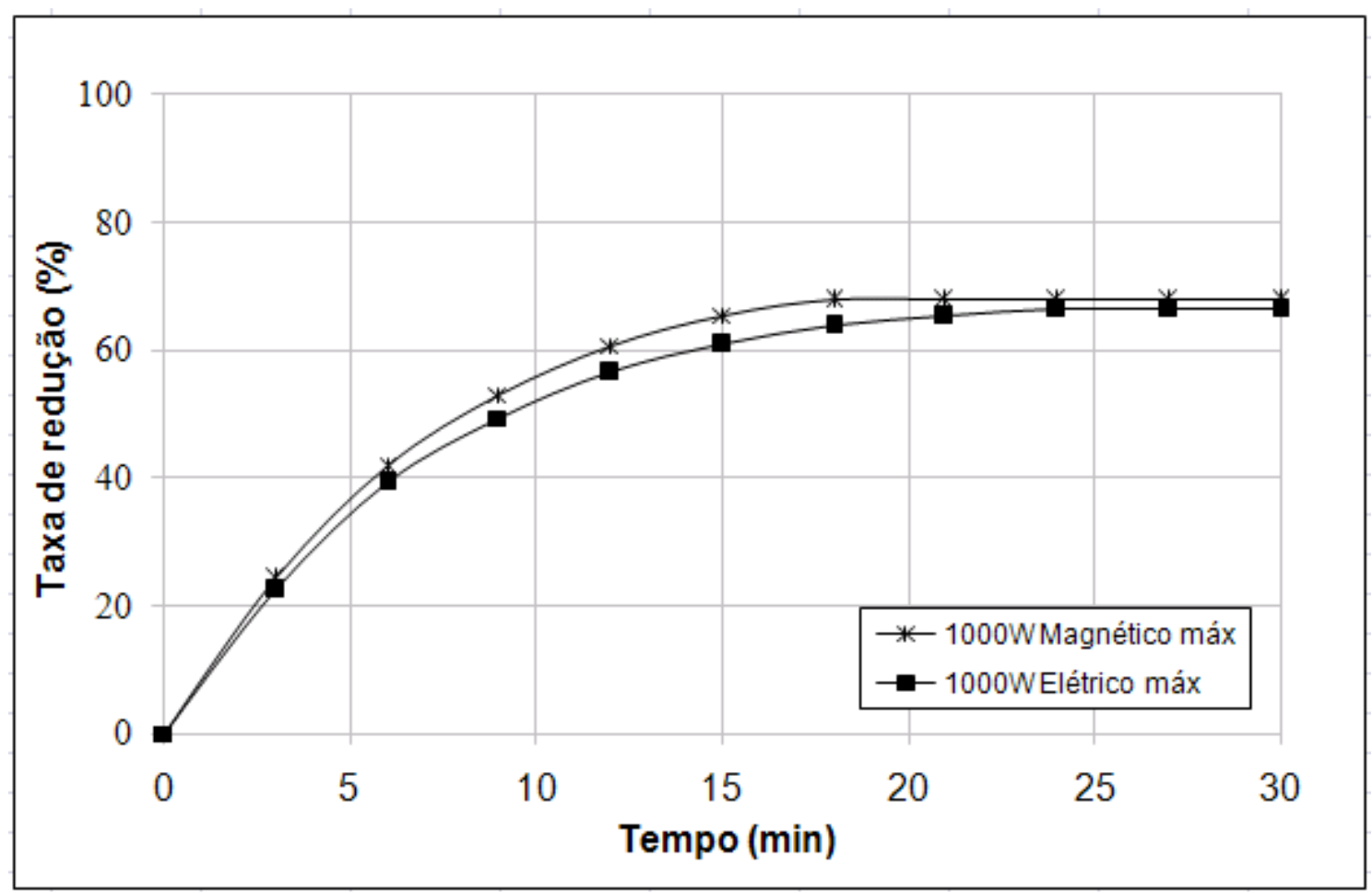

Gráfico 23 - Taxa de redução em função do tempo de exposição a $1000 \mathrm{~W}$ de potência irradiada de micro-ondas no máximo campo elétrico e no máximo campo magnético para uma pelota na proporção estequiométrica entre minério de ferro de Carajás e coque de petróleo

Percebe-se, através do gráfico 23 , que a pelota reduzida no máximo campo magnético apresentou uma pequena melhora no resultado referente à velocidade de reação e no grau final de redução, aproximadamente $66 \%$ contra $68 \%$.

O gráfico 24 mostra que durante a redução carbotérmica, variando o campo de micro-ondas irradiado na pelota, o comportamento da potência refletida é alterado, pois depende do comportamento do corpo submetido à irradiação, ou seja, dependem do comportamento da mistura minério-redutor frente à micro-ondas.

Observa-se que até 6 minutos, a potência refletida para ambos os campos, se mantém praticamente constante, para, a seguir, crescer ligeiramente até 24 minutos, no caso do máximo campo elétrico, e diminuir ligeiramente até 24 minutos, no caso do máximo campo magnético. Aos 16 minutos, ocorre a inversão das potências refletidas, período que coincide com o da admitida redução, ou seja, a taxa de reação praticamente encerrou-se visualizado através de um patamar mostrado pelo gráfico 24 . O decréscimo da potência refletida de micro-ondas no máximo campo magnético indica que o material passou a absorver mais energia que nas fases iniciais deste 
experimento. Pode-se imaginar que corresponda a um período de formação de partículas metálicas na pelota e até a fusão do ferro recém reduzido.

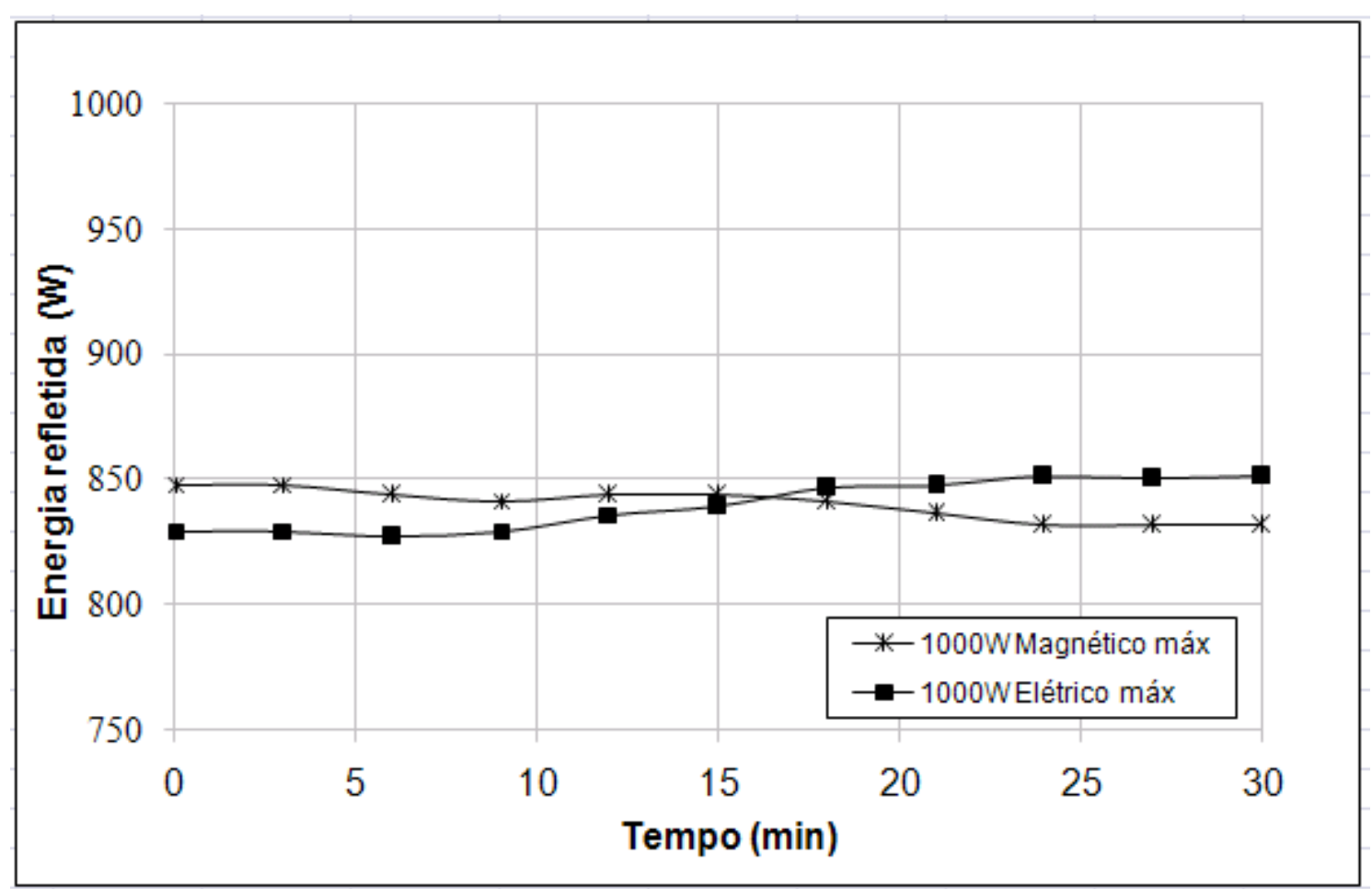

Gráfico 24 - Perfil da evolução da energia de micro-ondas refletida (W) em função do tempo de exposição a $1000 \mathrm{~W}$ de potência de micro-ondas no máximo campo elétrico e no máximo campo magnético na redução carbotérmica de uma pelota sem isolação térmica

\subsubsection{Influência da variação da quantidade de pelotas}

Outro estudo realizado foi referente ao comportamento da taxa de redução entre uma e duas pelotas na proporção estequiométrica, com isolação térmica, no máximo campo elétrico com potência de micro-ondas irradiada de 1000 W. Os resultados estão apresentados através dos gráficos 25, 26 e 27 e pela tabela 18. 


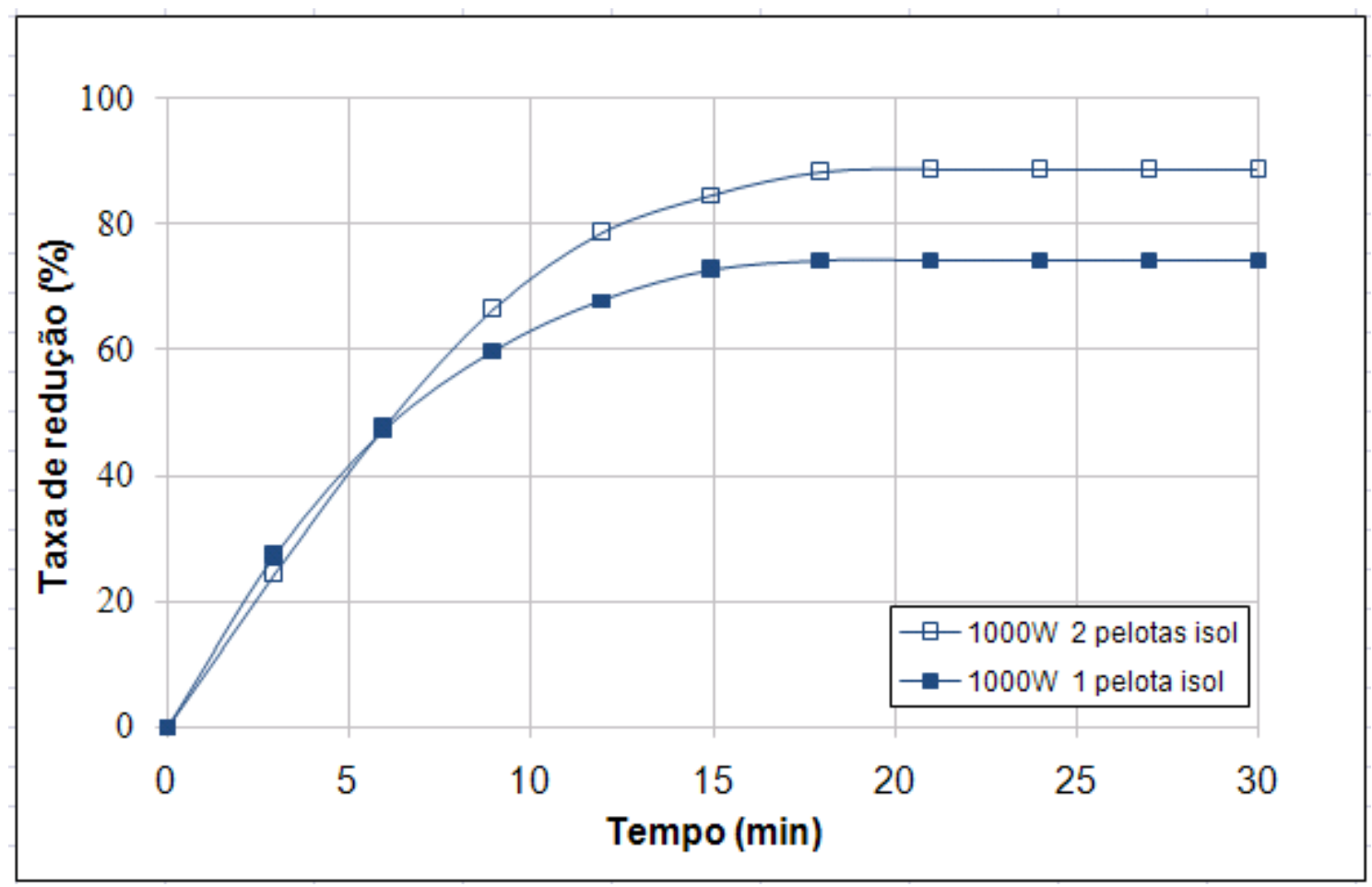

Gráfico 25 - Taxa de redução em função do tempo de exposição a 1000 W de potência irradiada de micro-ondas no máximo campo elétrico para uma e duas pelotas na proporção estequiométrica entre minério de ferro de Carajás e coque de petróleo

Os gráficos 25 e 26 mostram a taxas de redução para uma e duas pelotas isoladas termicamente e a potência de micro-ondas refletida durante os ensaios, respectivamente. Através do gráfico 25 percebe-se um comportamento semelhante na taxa de redução até 6 minutos. Ambas as taxas de redução prosseguem até aproximadamente 18 minutos, aonde atingem um patamar com valores de porcentagem de redução próximos a 88,5\% para os ensaios com duas pelotas e $74 \%$ para ensaios com uma pelota. Tal fato pode ser explicado devido à relação watts-grama $(\mathrm{W} / \mathrm{g})$ mostrado pelo gráfico 27 e pela tabela 18. Quanto maior for esta relação, ou seja, quanto maior a interação entre a energia de micro-ondas com um grama da mistura entre o minério de ferro de Carajás e coque de petróleo na proporção estequiométrica, maior será a taxa de redução. 


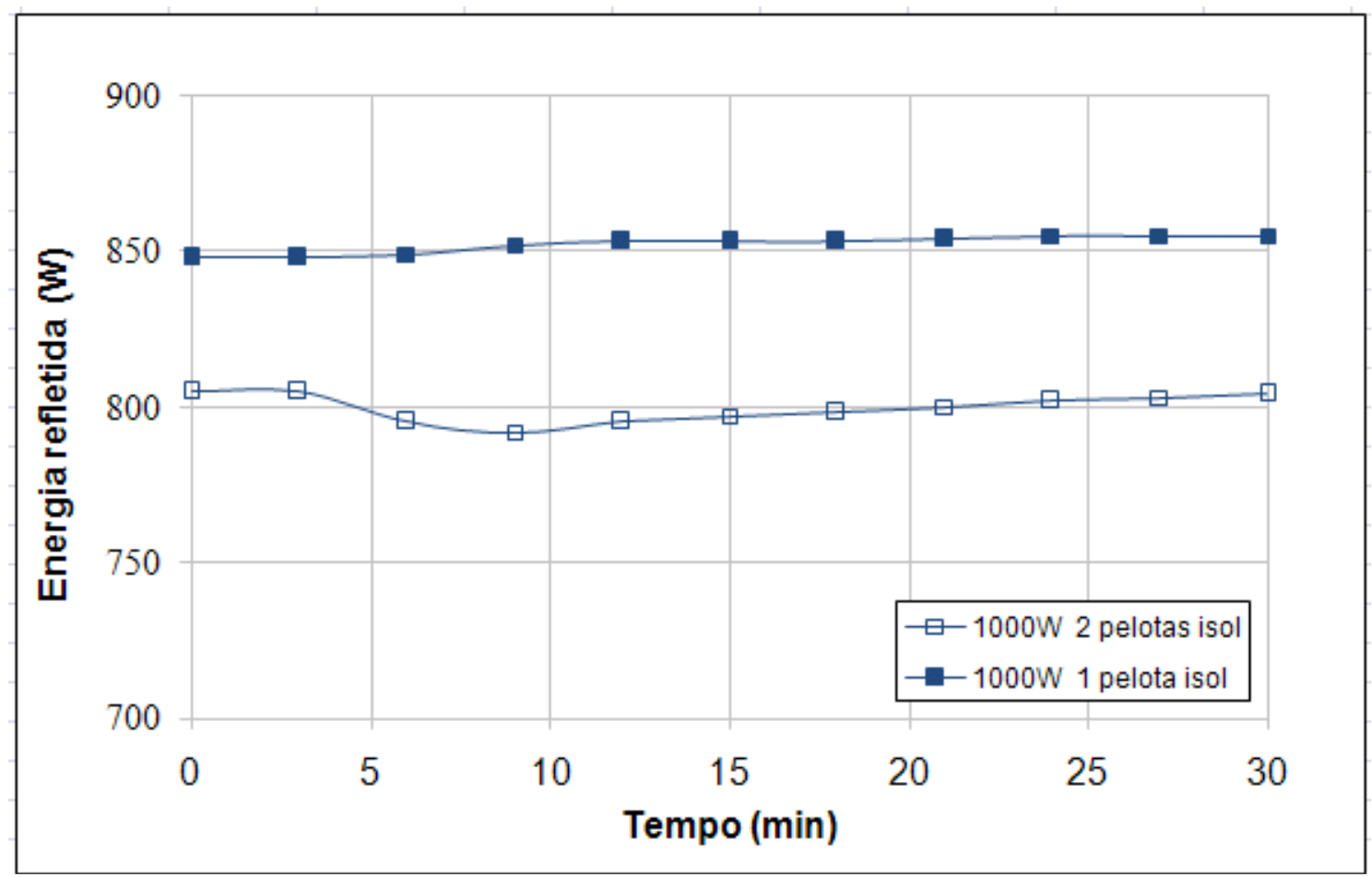

Gráfico 26 - Perfil da evolução da energia de micro-ondas refletida (W) em função do tempo de exposição a $1000 \mathrm{~W}$ de potência de micro-ondas no máximo campo elétrico na redução carbotérmica de uma e duas pelotas com isolação térmica

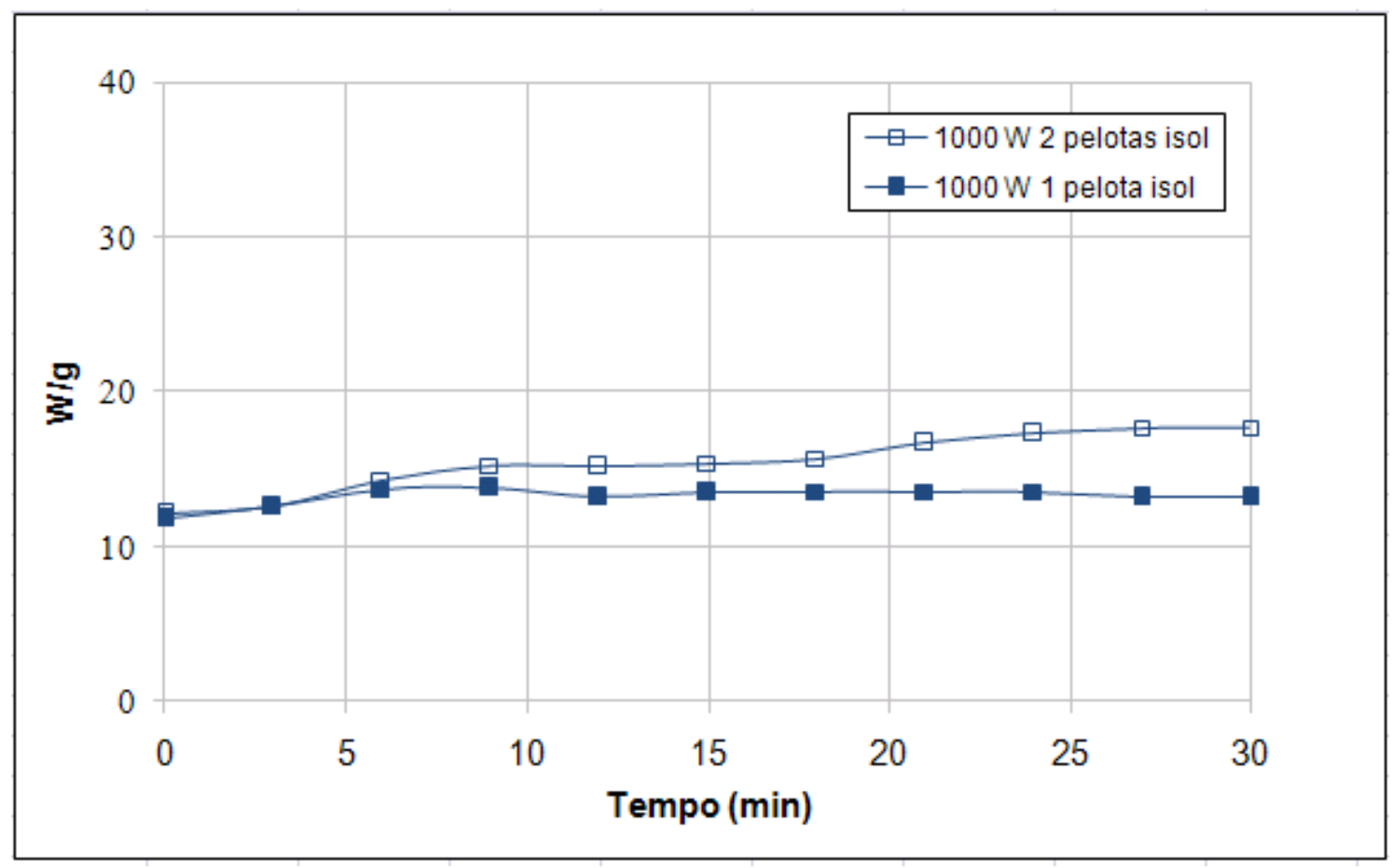

Gráfico 27 - Relação watts/grama em função do tempo de exposição a $1000 \mathrm{~W}$ de potência irradiada de micro-ondas no máximo campo elétrico para uma e duas pelotas na proporção estequiométrica entre minério de ferro de Carajás e coque de petróleo

Nota-se através do gráfico 27 que até 3 minutos, a relação W/g para ambos os ensaios, se mantém constante e praticamente igual, para, a seguir, 
começar a existir diferenças na interação entre o material e a energia de microondas. Esta pequena variação encontrada entre o período de 0 a 6 minutos no gráfico 27 , supostamente explica as taxas de redução praticamente iguais encontradas no mesmo período mostrado pelo gráfico 25 .

Tabela 18 - Relação watts/grama (W/g) para ensaios de redução carbotérmica com $1000 \mathrm{~W}$ de energia de micro-ondas irradiada em uma e duas pelotas com isolação térmica

\begin{tabular}{|c|c|c|c|c|c|c|c|c|}
\hline \multirow[b]{2}{*}{$\begin{array}{c}\text { Tempo } \\
\text { (min) }\end{array}$} & \multicolumn{4}{|c|}{1 pelota } & \multicolumn{4}{|c|}{2 pelotas } \\
\hline & $\begin{array}{c}\text { TR } \\
(\%)\end{array}$ & $\begin{array}{l}\text { VMP } \\
\text { (g) }\end{array}$ & $\begin{array}{l}\text { EE } \\
\text { (W) }\end{array}$ & $W / g$ & $\begin{array}{l}\text { TR } \\
(\%)\end{array}$ & $\begin{array}{c}\text { VMP } \\
\text { (g) }\end{array}$ & $\begin{array}{l}\text { EE } \\
\text { (W) }\end{array}$ & $W / g$ \\
\hline 0 & 0,00 & 3,58 & 0 & 0 & 0 & 7,02 & 0 & 0 \\
\hline 0.017 & 0,80 & 3,57 & 42 & 11,8 & 0,41 & 7,01 & 85 & 12,1 \\
\hline 3 & 27,13 & 3,24 & 41 & 12,7 & 24,09 & 6,43 & 86 & 12,6 \\
\hline 6 & 47,09 & 2,99 & 41 & 13,7 & 47,33 & 5,86 & 95 & 14,3 \\
\hline 9 & 59,86 & 2,83 & 39 & 13,8 & 66,18 & 5,39 & 98 & 15,2 \\
\hline 12 & 67,84 & 2,73 & 36 & 13,2 & 78,43 & 5,09 & 95 & 15,2 \\
\hline 15 & 72,63 & 2,67 & 36 & 13,5 & 84,57 & 4,94 & 93 & 15,4 \\
\hline 18 & 74,22 & 2,65 & 36 & 13,6 & 88,12 & 4,86 & 92 & 15,7 \\
\hline 21 & 74,22 & 2,65 & 36 & 13,6 & 88,56 & 4,84 & 90 & 16,7 \\
\hline 24 & 74,22 & 2,65 & 36 & 13,6 & 88,56 & 4,84 & 88 & 17,3 \\
\hline 27 & 74,22 & 2,65 & 35 & 13,2 & 88,56 & 4,84 & 87 & 17,7 \\
\hline 30 & 74,22 & 2,65 & 35 & 13,2 & 88,56 & 4,84 & 86 & 17,7 \\
\hline
\end{tabular}

TR: Taxa de reação; VMP: Variação da massa da pelota durante o ensaio; EE: Energia efetiva

\subsection{Comparação dos resultados entre aquecimento convencional e por micro-ondas}

O gráfico 28 apresenta a comparação de resultados de taxa de reação de uma pelota em função do tempo obtidos com aquecimento por micro-ondas e com aquecimento em forno de resistência elétrica. Lembrando que para o ensaio termogravimétrico em forno de resistência, a amostra era levada diretamente na temperatura já estabelecida previamente. 


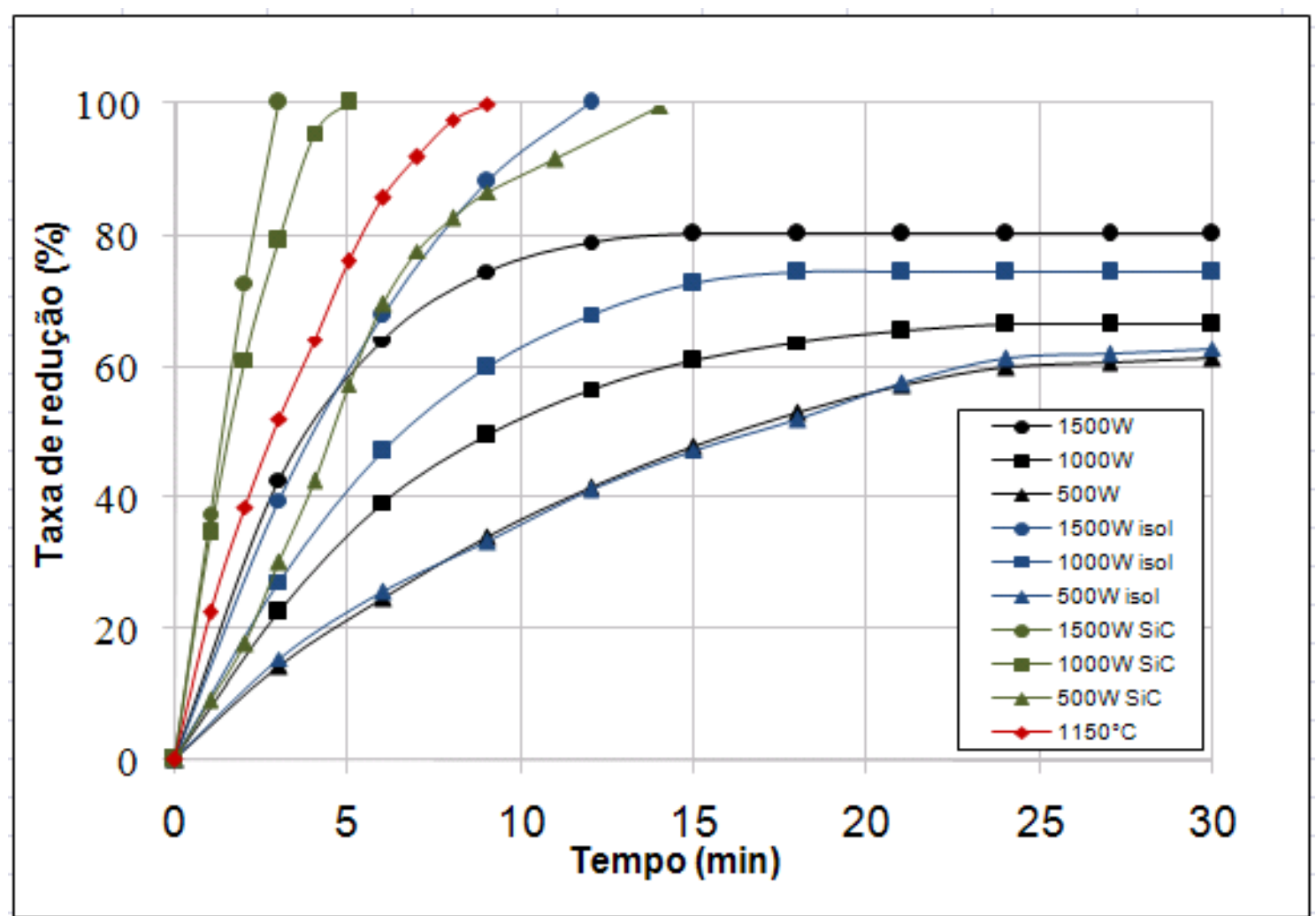

Gráfico 28 - Comparação de resultados de taxa de reação de uma pelota em função do tempo obtidos com aquecimento por micro-ondas e com forno de resistência elétrica

As baixas taxas reação encontradas para amostras sem isolação térmica é devido principalmente às perdas térmicas por radiação para o meio ambiente calculado através da equação 21. Este fenômeno foi identificado visualmente, ao observar a pelota em redução sob irradiação de micro-ondas apresentado pela figura 37. Sua superfície é mais escura que as rachaduras que se abrem. Isto pode ser atribuído a falta de isolação térmica.

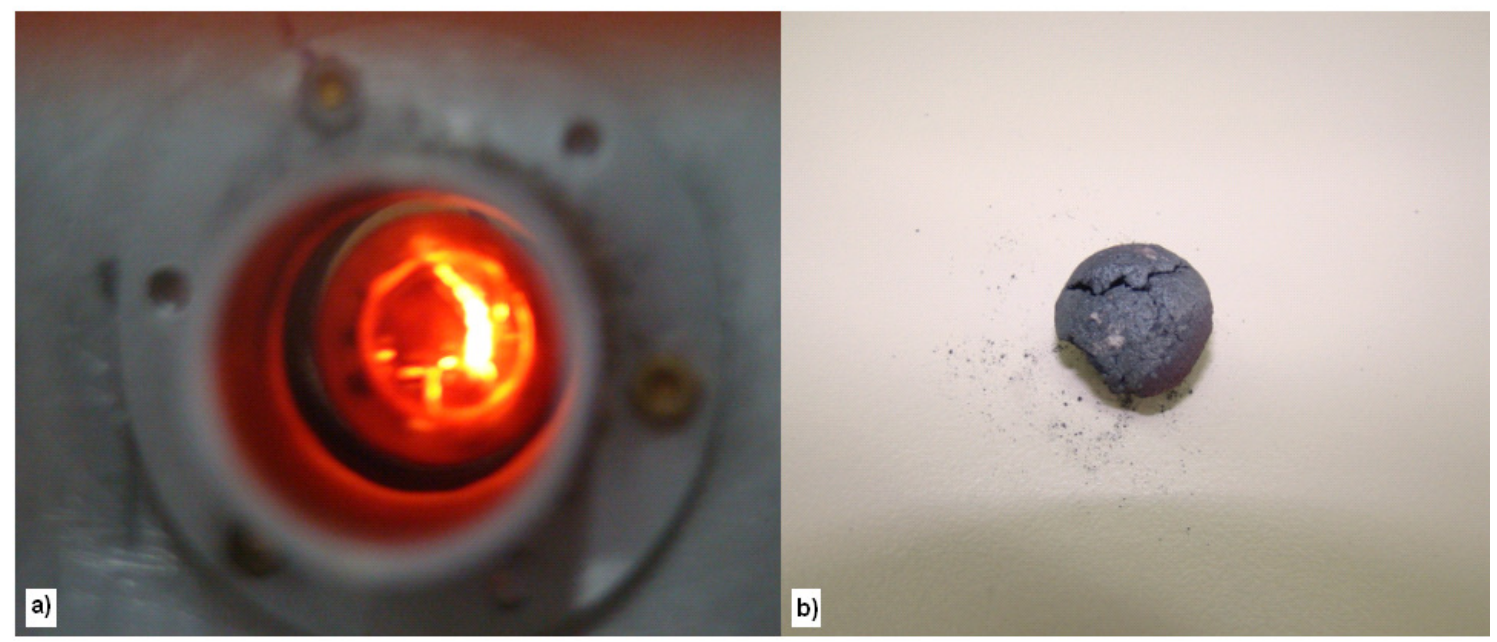

Figura 37 - Pelota sob irradiação a $1500 \mathrm{~W}$ de micro-ondas sem isolação térmica; a) durante o ensaio; b) após o ensaio. 
Os ensaios realizados com isolação térmica mostraram serem eficientes apenas na potência de $1500 \mathrm{~W}$. Neste nível de energia a taxa de reação atingiu 100\% em 12 minutos. Atribui-se esta melhora a eficiência da isolação térmica imposta ao sistema, porém foi constatado que a $500 \mathrm{~W}$ e a $1000 \mathrm{~W}$ de energia de micro-ondas irradiada a taxa de reação não atingiu 100\%. Isto se deve ao isolante térmico não estar corretamente dimensionado para não haver perdas térmicas para o meio ambiente. $O$ tamanho da câmara de reação limitou 0 dimensionamento correto do isolante térmico. A figura 38 mostra uma pelota totalmente reduzida e com partículas de ferro fundido em seu interior.

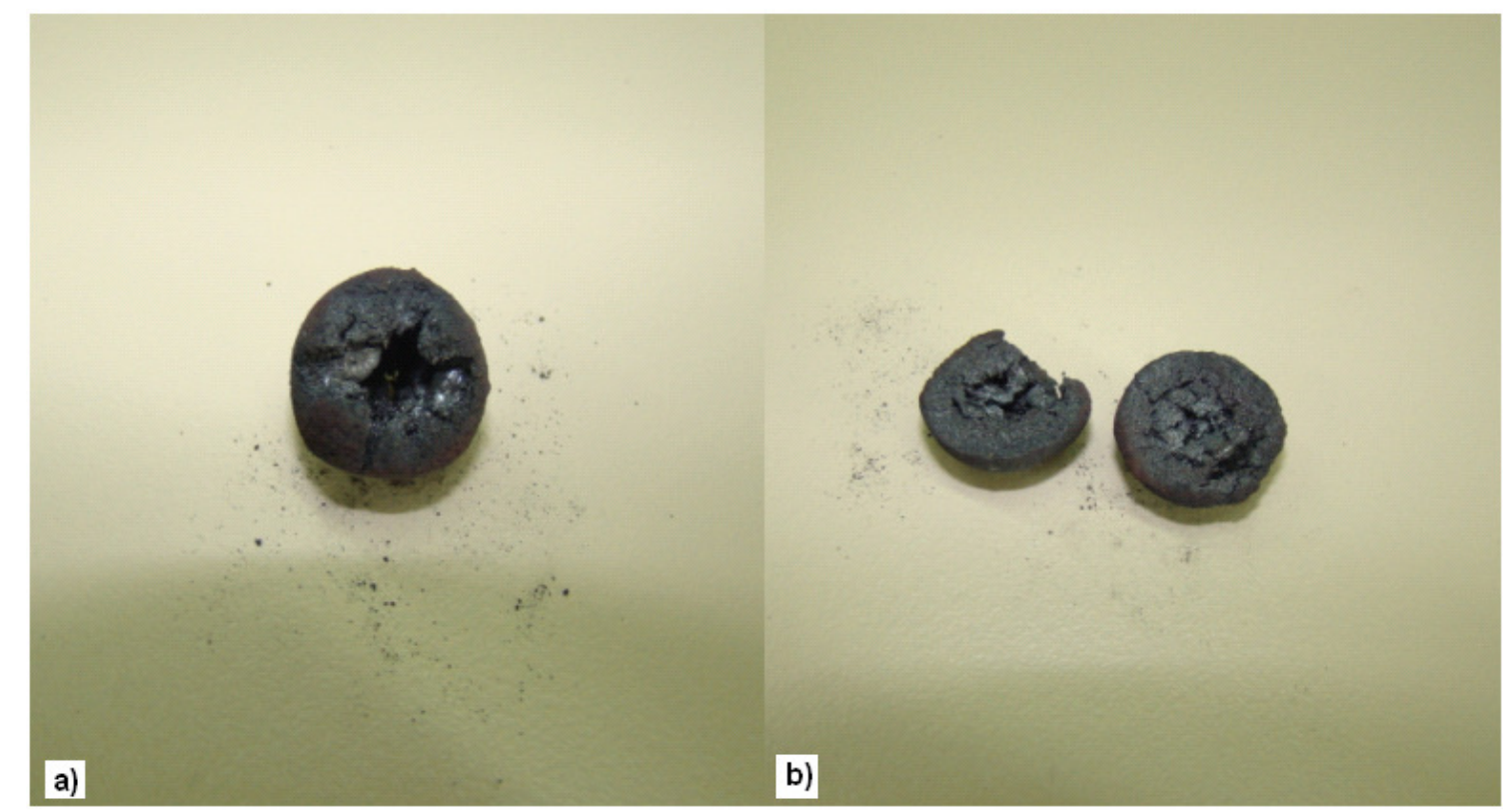

Figura 38 - Pelota reduzida com 1500W de irradiação de micro-ondas com isolação térmica; a) após o ensaio; b) seção transversal

Percebe-se ainda, que os resultados obtidos em que se utilizou o cadinho de carbeto de silício, a $1500 \mathrm{~W}$ e $1000 \mathrm{~W}$ se encontram sempre em valores superiores aos encontrados a $1150^{\circ} \mathrm{C}$ com aquecimento convencional. A presença do carbeto de silício aumentou consideravelmente a velocidade de redução. Isto é comprovado pela temperatura da superfície externa do cadinho mostrado através do gráfico 3 . Nos ensaios a $1000 \mathrm{~W}$ e a $1500 \mathrm{~W}$ de energia de micro-ondas irradiados a temperatura atingiu aproximadamente $1200^{\circ} \mathrm{C} \mathrm{e}$ $1350^{\circ} \mathrm{C}$, respectivamente. Em ambas as situações houve completa redução e fusão do metal formado como mostrado pela figura 39. No caso de $500 \mathrm{~W}$ 
irradiados, percebe-se um comportamento da taxa de redução inferior ao encontrado a $1150^{\circ} \mathrm{C}$, pois a temperatura do cadinho foi em torno de $820^{\circ} \mathrm{C}$.

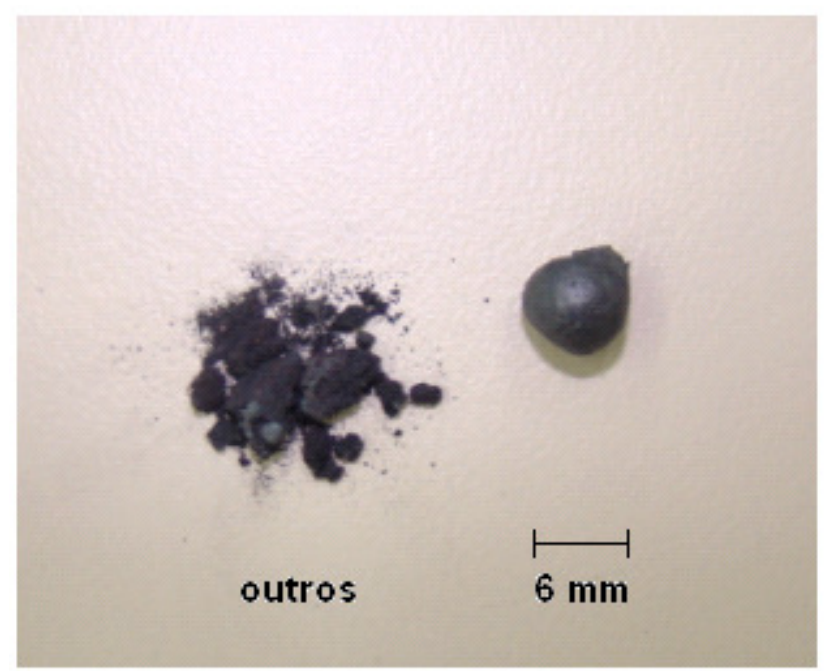

Figura 39 - Gota de ferro gusa produzido nos ensaios com cadinho de carbeto de silício a 1000W e 1500W de irradiação de micro-ondas 


\section{CONCLUSÕES}

1 - O equipamento ora apresentado demonstrou grande facilidade de controle da potência aplicada de micro-ondas e de aquisição de dados, viabilizando assim estudos mais profundos da interação de micro-ondas com o sistema minério-redutor, que não eram viáveis nas adaptações de fornos domésticos citadas na literatura especializada.

2 - Este equipamento abre a oportunidade de uma série de experimentos que levarão a um melhor conhecimento da interação micro-ondas com o sistema minério-redutor por possibilitar a quantificação da energia de micro-ondas colocada em jogo no processo de redução carbotérmica empregando energia de micro-ondas e permitir a fácil reprodutibilidade das condições de ensaio.

3 - Nos ensaios de determinação das perdas de energia para o equipamento sem amostra, observou-se um período inicial de indução, entre o início e 20 minutos, no qual acontece o aquecimento do equipamento vazio. Após este período de inicialização, o registro da variação de energia não apresentou variação significativa. Portanto, se faz necessário uma estabilização das perdas de energia antes de cada lote de ensaios.

4 - O decréscimo da potência efetiva de microondas com o tempo nas experiências com pelotas auto-redutoras indica que o material passou a absorver menos energia que na fase inicial deste experimento. Isto indica que 0 meio irradiado mudou de natureza, ou seja, está relacionado com as mudanças de etapas da amostra como a variação da constante dielétrica e da formação de película metálica, que impossibilita a propagação das micro-ondas pela pelota.

5- Não foi possível determinar as energias efetivas na pelota no interior do cadinho de carbeto de silício nos três níveis de potência de micro-ondas irradiada, pois nos ensaios o equipamento não estava previamente estabilizado termicamente como realizado nas reduções carbotérmicas com e sem isolante 
térmico, ou seja, os ensaios iniciaram com o equipamento frio. Isto ocorreu devido a não possibilidade de manipular o cadinho de carbeto de silício em altas temperaturas.

6 - A medida da temperatura ainda não satisfaz completamente, pois a temperatura observada na superfície da pelota, durante a redução, é menor que no seu interior. Este fenômeno foi identificado visualmente, ao observar a pelota em redução: a sua superfície é mais escura que as rachaduras que se abrem, devido as perdas de calor pela superfície.

7 - Não é possível medir a temperatura da pelota em redução com microondas utilizando cadinho de isolante térmico e/ou de carbeto de silício, pois os mesmos possuíam tampa.

8 - Nos ensaios sem isolação térmica não atingiu-se redução total em nenhum dos três níveis de potência de micro-ondas irradiada. Isto de deve a perda de calor da massa reagente para o meio ambiente e as baixas temperaturas. Isto é comprovado pelos ensaios com isolação térmica, aonde se atingiu $100 \%$ de taxa de reação com $1500 \mathrm{~W}$ de energia de micro-ondas irradiada.

9 - Os ensaios com $500 \mathrm{~W}$ de energia de micro-ondas irradiados com e sem isolação térmica apresentaram uma taxa de reação semelhante. Isto de deve a baixa densidade energética presente na câmara de reação. Portanto, depende do comportamento do corpo submetido aquela quantidade de energia de microondas presente no reator de modo que mesmo diminuindo as perdas de energia da pelota para o meio ambiente com isolação térmica não foi capaz de melhorar a taxa de reação.

10 - Todos os ensaios utilizando o cadinho de carbeto de silício atingiram $100 \%$ de taxa de reação devido o carbeto de silício possuir altas perdas dielétricas frente às ondas eletromagnéticas e, portanto, sendo uma fonte de calor auxiliar. 
11 - Variando o campo de micro-ondas irradiado na pelota durante a redução, o comportamento da potência refletida é alterado, pois depende do comportamento do corpo submetido à irradiação, ou seja, dependem do comportamento da mistura minério-redutor frente à micro-ondas ora no máximo campo elétrico ora no máximo campo magnético.

12 - Aumentando a massa a ser reduzida, ou seja, de uma pelota para duas pelotas, aumentou também a taxa de reação. Tal fato pode ser explicado devido à relação watts-grama $(\mathrm{W} / \mathrm{g})$. Quanto maior for esta relação, ou seja, quanto maior a interação entre a energia de micro-ondas com um grama da mistura entre o minério de ferro de Carajás e coque de petróleo na proporção estequiométrica, maior será a taxa de redução.

13 - O processo de redução carbotérmica de minério de ferro promovida por micro-ondas é viável tecnicamente; é necessário estudos em maior escala para viabilização industrial. 


\section{REFERÊNCIAS}

1 - WU, T. N. Environmental perspectives of microwave applications as remedial alternatives: review. Practice Periodical of Hazardous, Toxic and Radioactive Waste Management. v. 12, n. 2, p. 102-115, 2008.

2 - JONES, D. A. et al. Microwave heating applications in environmental engineering - a review. Resources, Conservation and Recycling. v. 34, n. 2, p. $75-90,2002$.

3 - THOSTENSON, E. T.; CHOU, T. W. Microwave processing - fundamentals and applications. Composites: applied science and manufacturing, part A. v. 30, p. 1055-1071, 1999.

4 - STANDISH, N.; WORNER, H.; KAUL, H. Microwave drying of brown coal agglomerates. International Microwave Power Institute. v. 23, n. 3, p. 171$175,1988$.

5 - WALKIEWICZ, J. W.; McGILL, S. L.; MOYER, L. A. Improved grindability of iron ores using microwave energy. Materials Research Society, Symposium Proceedings. v. 124, p. 297-302, 1988.

6 - LORENSON, C. P. et al. The effect of particle size on microwave heated carbon and the subsequent crystallite growth. Materials Research Society, Symposium Proceedings. v. 269, p. 129-135, 1992.

7 - MORITA, K. et al. Immobilization of ash by microwave melting. Materials Research Society, Symposium Proceedings. v. 269, p. 471-476, 1992.

8 - AMANKWAH, R. K.; PICKLES, C. A.; YEN, W. T. Gold recovery by microwave augmented ashing of waste activated carbon. Minerals Engineering. v. 18, n. 5, p. 517-526, 2005.

9 - USLU, T.; ATALAY, U.; AROL, A. I. Effect of microwave heating on magnetic separation of pyrite. Colloids and Surfaces A: Physicochemical and Engineering Aspects. v. 225, n. 1-3, p. 161-167, 2003. 
10 - OLUBAMBI, P. et al. Influence of microwave heating on the processing and dissolution behavior of low-grade complex sulphide ores. Hydrometallurgy. v. 89, p. 127-135, 2007.

11 - YAN, C.; YOSHIKAWA, N.; TANIGUCHI, S. Microwave heating behavior of blast furnace slag bearing high titanium. ISIJ International. v. 45, n. 9, p. 12321237, 2005.

12 - MATSUI, Y. et al. Analyses on blast furnace raceway formation by microwave reflection gunned through tuyere. ISIJ International. v. 45, n. 10, p. 1432-1438, 2005.

13 - MORITA, K. et al. The heating characteristics of $\mathrm{CaO}-\mathrm{SiO}_{2}-\mathrm{Fe}_{\mathrm{t}} \mathrm{O}$ system slags under microwave irradiation. ISIJ International. v. 41, n. 7, p. 716-721, 2001.

14 - MALMBERG, D. et al. Preliminary microwave measurements on liquids slags. VII International Conference on Molten Slags Fluxes and Salts, The South African Institute of Mining and Metallurgy, 2004, 707p.

15 - PICKLES, C.A. Microwave heating behavior of nickeliferous limonitic laterite ores. Minerals Engineering. v. 17, n. 6, p. 775-784, 2004.

16 - MOURÃO, M. B.; CARVALHO JR., I. P.; TAKANO, C. Carbothermic reduction by microwave heating. ISIJ International. v. 41, p. S27-S30, 2001.

17 - ZHONG, S.; GEOTZMAN, H. E.; BLEIFUSS, R. L. Reduction of iron ore with coal by microwave heating. Minerals and Metallurgical Processing. $p$. 174-178, 1996.

18 - STANDISH, N.; HUANG, W. Microwave application in carbothermic of iron ores. ISIJ International. v. 31, n. 3, p. 241-245, 1991.

19 - GOMEZ, et al. Kinetics of reduction of iron oxides using microwaves as power source. Materials Research Society, Symposium Proceedings. v. 430, p. 423-428, 1996.

20 - HAYASHI, M.; NAGATA, K. Microwave pig-ironmaking. In. $6^{\text {th }}$ JapanBrazil Symposium on Dust Processing-Energy-Environment in Metallurgical Industries. Japan 22-23/11/06. 
21 - SUTTON W. H. Microwave processing of ceramics - An overview. Materials Research Society, Symposium Proceedings. v. 269, p. 3-19, 1992.

22 - NOGUEIRA, A. R. et al. Digestão de amostras assistida por microondas. Métodos de preparo de Amostras: fundamentos sobre preparo de amostras orgânicas e inorgânicas para análise elementar, 2008, 276p.

23 - WHO invented microwaves? The history of the microwave oven. Disponível em: <http://www.gallawa.com/microtech/history.html>. Acesso em: $11 \mathrm{fev}$. 2009.

24 - ERICKSON, C. J. Handbook of electrical heating for industry. New York: IEE, 1995. 629p.

25 - COMMITTEE ON MICROWAVE PROCESSING OF MATERIALS. Microwave processing of materials. Publication NMAB-473. Washington, D.C.: National Academy Press, 1994.

26 - SUTTON W. H. Microwave processing of ceramic materials. Ceramic Bulletin. v. 68, n. 2, p. 376-386, 1989.

27 - HAQUE, K. E. Microwave energy for mineral treatment processes - a brief review. International Journal of Mineral Processing. v. 57, p. 1-24, 1999.

28 - CLARK, D. E.; SUTTON W. H. Microwave processing of ceramic materials. Annu. Rev. Mater. Sci. v.26, p.229-331, 1996.

29 - DECAREAUAND, R. V.; PETERSON, R. A. Microwave processing and engineering. 1986, 42p.

30 - MAYS, S. L. A practical comparrison of moisture measuring systems: Electronic and wood systems. Ligna 2005, Hannover, Alemanha, maio de 2005.

31 - BYKOV, Y. V.; RYBAKOV, K.I.; SEMENOV, V. E. High-temperature microwave processing of materials. Journal of Physics D: Applied Physics. v. 34, p. R55-R75, 2001. 
32 - CLARK, D. E.; FOLZ, D. C.; WEST, J. K. Processing materials with microwave energy. Materials Science and Engineering. v. 287, n. 2, p. 153$158,2000$.

$33-$ METAXAS, A. C. Microwave heating. Power Engineering Journal. v. 5, n. 5, p. 237-247, 1991.

34 - SENISE, J. T. A utilização de microondas em processos de aquecimento na industria da cerâmica. Cerâmica. v. 35, n. 234, p. 95-99, 1989.

35 - KUROKI, T. et al. Effects of $28 \mathrm{GHz} / 2.45 \mathrm{GHz}$ microwave irradiation on the crystallization of blast furnace slag. ISIJ International. v. 47, n. 4, p. 592-595, 2007.

$36-\mathrm{ITOH}, \mathrm{S}$. et al. Application of $28 \mathrm{GHz}$ microwave irradiation to oxidation of ilmenite ore for new rutile extraction process. ISIJ International. v. 47, n. 10, p.1416-1421, 2007.

37 - CHHILLAR, P.; AGRAWAL, D.; ADAIR, J. H. Sintering of molybdenum metal powder using microwave energy. Powder Metallurgy. v. 51, n. 2, p. 182187, 2008.

38 - CHEN, Y. et al. Crack generation in blast furnace slag bearing high titanium by microwave cyclic heating. ISIJ International. v. 47, n. 2, p. 193-196, 2007.

39 - SANO, S. et al. Microwave absorption behavior of iron-alumina mixed powder at elevated temperature. ISIJ International. v. 47, n. 4, p. 588-591, 2007.

40 - CHENG, J.; ROY, R.; AGRAWAL, D. Radically different effects on materials by separated microwave electric and magnetic fields. Mat. Res. Innovat. 2002, 170p.

41 - DANCY, T. E. Solid state reduction of iron ores. The Elliot Symposium on Chemical Process Metallurgy. 1990, 11p.

42 - POVEROMO, J. J. The evolution of ironmaking. 3o IAS Ironmaking Seminar. 2001, 1p. 
43 - ARAÚJO, L. A. de Siderurgia. São Paulo: Lema, 1967. 214p.

$44-$ BALDWIN, B. G. The mechanism of the reduction of iron oxides by solid coke. Journal of the Iron and Steel Institute. v. 179, p. 30-36, 1955.

45 - MOURÃO, M. B.; TAKANO, C. Pelotas auto-redutoras para obtenção de ferro metálico: cinética e processamento. In: 58 CONGRESSO ANUAL DA ASSOCIAÇÃO BRASILEIRA DE METALURGIA E MATERIAIS, 58, São Paulo. Anais... São Paulo: ABM, 2003. p. 15-29.

46 - CARVALHO, I. P. de Estudo da utilização de energia de microondas na redução de minério de ferro por carbono na forma de pelotas autoredutoras. 2001. 100f. Dissertação (Mestrado)-Escola Politécnica, Universidade de São Paulo, São Paulo, 2001.

47 - AGUILAR, J.A.; GOMEZ, I. Microwaves Applied to carbothermic reduction of iron ore pellets. International Microwave Power Institute. p. 67-73, $1997 .$.

48 - NISHIOKA, K. et al. Gasification and reduction behavior of plastics and iron ore mixtures by microwave heating. ISIJ International. v. 47, n. 4, p. 602-607, 2007.

49 - CHO, S.; LEE, J. Metal recovery from stainless steel mill scale by microwave heating. Metals and Materials International. v. 14, n. 2, p. 193196, 2008.

50 - ISHIZAKI, K.; NAGATA, K.; HAYASHI, T. Production of pig iron from magnetite ore-coal composite pellets by microwave heating. ISIJ International. v. 46, n. 10, p. 1403-1409, 2006.

51 - SAIDI, A.; AZARI, K. Carbothermic reduction of zinc oxide concentrate by microwave. Journal of Materials Sciences \& Technology. v. 21, n. 5, p. 724728, 2005.

52 - NISHIOKA, K.; MAEDA, T.; SHIMIZU, M. Dezincing behavior from iron and steelmaking dusts by microwave heating. ISIJ International. v. 42, p. S19-S22, 2002. 
53 - SUN, X.; HWANG, J.Y.; HUANG, X. The microwave processing of electric arc furnace dust. JOM. v. 60, n. 10, p. 35-39, 2008.

54 - STANDISH, N.; WORNER, H. Microwave application in the reduction of metal oxides with carbon. Journal of Microwave Power and Electromagnetic Energy. v. 25, n. 3, p. 177-180, 1996.

55 - STANDISH, N.; PRAMUSANTO. Reduction of microwave irradiated iron particles in CO. ISIJ International. v. 31, n. 1, p. 11-16, 1991.

56 - ASSOCIAÇÃO BRASILEIRA DE NORMAS TÉCNICAS. NM248: Agregados - Determinação da composição granulométrica. Rio de Janeiro, 2003. $6 \mathrm{p}$.

57 - AMERICAN SOCIETY FOR TESTING AND MATERIALS. D 3172-89: Standard Practice for Proximate Analysis of Coal and Coke. 1990. 1p.

58 - KUBASCHEWSKI, O; ALCOCK, C. B. Metallurgical thermochemistry. 5 ed.Oxford: Pergamon, 1979. 449p. 


\section{APÊNDICE A - Memorial de cálculo para as perdas para o equipamento após o período de estabilização térmica sem pelota e com cadinho ou tarugo de fibra cerâmica}

\section{Trocadores de calor 1 e 2 (TC1 e TC2)}

$m_{\mathrm{H}_{2} \mathrm{O}}$ : Vazão de água de refrigeração $=0,5 \mathrm{~L} / \mathrm{min}=500 \mathrm{~g} / \mathrm{min}=1500$ g/3min;

$c p_{\mathrm{H}_{2} \mathrm{O}}$ : Poder calorífico da água $=1,0 \mathrm{cal} / \mathrm{g} \cdot{ }^{\circ} \mathrm{C}$;

T1: Temperatura da água de refrigeração na entrada do trocador de calor TC1 ( $\left.{ }^{\circ} \mathrm{C}\right)$;

T2: Temperatura da água de refrigeração na saída e na entrada dos trocadores de calor TC1 e TC2, respectivamente $\left({ }^{\circ} \mathrm{C}\right)$;

T3: Temperatura da água de refrigeração na saída do trocador de calor TC2 $\left({ }^{\circ} \mathrm{C}\right)$;

$Q_{T C 1}=m_{\mathrm{H}_{2} \mathrm{O}} \times c p_{\mathrm{H}_{2} \mathrm{O}} \times \Delta T:$ energia absorvida pelo trocador de calor $1(\mathrm{~kJ})$;

$Q_{T C 2}=m_{\mathrm{H}_{2} \mathrm{O}} \times c p_{\mathrm{H}_{2} \mathrm{O}} \times \Delta T$ : energia absorvida pelo trocador de calor $2(\mathrm{~kJ})$;

Cal $\times 4,1868 \times 10^{-3}=\mathrm{kJ}$

Tabela 19 - Calor absorvido pelos trocadores de calor 1 e 2 com $500 \mathrm{~W}$ de energia de microondas irradiada após o período de estabilização térmica sem pelota e com cadinho ou tarugo de fibra cerâmica

\begin{tabular}{|c|c|c|c|c|c|c|c|}
\hline$(\min )$ & $m$ & $c p_{\mathrm{H}_{2} \mathrm{O}}$ & T1 & T2 & T3 & $Q_{T C 1}$ & $Q_{T C 2}$ \\
\hline 0 a 3 & 1500 & \multirow{10}{*}{1,0} & 25,0 & 25,4 & 25,8 & 2,51 & 2,51 \\
\hline 3 a 6 & 1500 & & 25,0 & 25,4 & 25,8 & 2,51 & 2,51 \\
\hline 6 a 9 & 1500 & & 25,0 & 25,4 & 25,8 & 2,51 & 2,51 \\
\hline 9 a 12 & 1500 & & 25,0 & 25,5 & 25,9 & 3,14 & 2,51 \\
\hline 12 a 15 & 1500 & & 25,0 & 25,5 & 26,0 & 3,14 & 3,14 \\
\hline 15 a 18 & 1500 & & 25,0 & 25,5 & 26,0 & 3,14 & 3,14 \\
\hline 18 a 21 & 1500 & & 25,0 & 25,5 & 26,1 & 3,14 & 3,77 \\
\hline 21 a 24 & 1500 & & 25,0 & 25,5 & 26,2 & 3,14 & 4,40 \\
\hline 24 a 27 & 1500 & & 25,0 & 25,5 & 26,2 & 3,14 & 4,40 \\
\hline 27 a 30 & 1500 & & 25,0 & 25,5 & 26,2 & 3,14 & 4,40 \\
\hline TOTAL & & & & & & 29,51 & 33,29 \\
\hline
\end{tabular}


Tabela 20 - Calor absorvido pelos trocadores de calor 1 e 2 com $1000 \mathrm{~W}$ de energia de microondas irradiada após o período de estabilização térmica sem pelota e com cadinho ou tarugo de fibra cerâmica

\begin{tabular}{|c|c|c|c|c|c|c|c|}
\hline (min) & $m$ & $c p_{\mathrm{H}_{2} \mathrm{O}}$ & $\mathrm{T} 1\left({ }^{\circ} \mathrm{C}\right)$ & T2 $\left({ }^{\circ} \mathrm{C}\right)$ & T3 $\left({ }^{\circ} \mathrm{C}\right)$ & $Q_{T C 1}$ & $Q_{T C 2}$ \\
\hline 0 a 3 & 1500 & \multirow{10}{*}{1,0} & 25,5 & 26,0 & 26,8 & 3,14 & 5,02 \\
\hline 3 a 6 & 1500 & & 25,5 & 26,0 & 27,0 & 3,14 & 6,28 \\
\hline 6 a 9 & 1500 & & 25,5 & 26,0 & 27,0 & 3,14 & 6,28 \\
\hline 9 a 12 & 1500 & & 25,5 & 26,0 & 27,0 & 3,14 & 6,28 \\
\hline 12 a 15 & 1500 & & 25,5 & 26,2 & 27,0 & 4,40 & 5,02 \\
\hline 15 a 18 & 1500 & & 25,5 & 26,2 & 27,0 & 4,40 & 5,02 \\
\hline 18 a 21 & 1500 & & 25,5 & 26,2 & 27,0 & 4,40 & 5,02 \\
\hline 21 a 24 & 1500 & & 25,5 & 26,2 & 27,0 & 4,40 & 5,02 \\
\hline 24 a 27 & 1500 & & 25,5 & 26,2 & 27,0 & 4,40 & 5,02 \\
\hline 27 a 30 & 1500 & & 25,5 & 26,2 & 27,0 & 4,40 & 5,02 \\
\hline TOTAL & & & & & & 38,96 & 53,98 \\
\hline
\end{tabular}

Tabela 21 - Calor absorvido pelos trocadores de calor 1 e 2 com $1500 \mathrm{~W}$ de energia de microondas irradiada após o período de estabilização térmica sem pelota e com cadinho ou tarugo de fibra cerâmica

\begin{tabular}{|c|c|c|c|c|c|c|c|}
\hline$(\min )$ & $m$ & $c p_{\mathrm{H}_{2} \mathrm{O}}$ & T1 & T2 & T3 & $Q_{T C 1}$ & $Q_{T C 2}$ \\
\hline 0 a 3 & 1500 & \multirow{10}{*}{1,0} & 25,5 & 26,5 & 27,2 & 6,28 & 4,40 \\
\hline 3 a 6 & 1500 & & 25,5 & 26,5 & 27,2 & 6,28 & 4,40 \\
\hline 6 a 9 & 1500 & & 25,5 & 26,5 & 27,2 & 6,28 & 4,40 \\
\hline 9 a 12 & 1500 & & 25,5 & 26,5 & 27,5 & 6,28 & 6,28 \\
\hline 12 a 15 & 1500 & & 25,5 & 26,5 & 27,5 & 6,28 & 6,28 \\
\hline 15 a 18 & 1500 & & 25,5 & 26,5 & 27,5 & 6,28 & 6,28 \\
\hline 18 a 21 & 1500 & & 25,5 & 26,5 & 27,5 & 6,28 & 6,28 \\
\hline 21 a 24 & 1500 & & 25,5 & 26,5 & 27,5 & 6,28 & 6,28 \\
\hline 24 a 27 & 1500 & & 25,5 & 26,5 & 27,5 & 6,28 & 6,28 \\
\hline 27 a 30 & 1500 & & 25,5 & 26,5 & 27,5 & 6,28 & 6,28 \\
\hline TOTAL & & & & & & 62,80 & 57,16 \\
\hline
\end{tabular}

\section{Argônio (Ar)}

$\rho_{A r}:$ Densidade média do argônio $\left(25-125^{\circ} \mathrm{C}\right)=1,425 \mathrm{~g} / \mathrm{L}$

$m_{A r}$ : Vazão do argônio pela câmara de reação $=0,85 \mathrm{~L} / \mathrm{min}=1,21 \mathrm{~g} / \mathrm{min}$ $=3,63 \mathrm{~g} / 3 \mathrm{~min}$;

$c p_{A r}$ : Poder calorífico do argônio $\left(25-125^{\circ} \mathrm{C}\right)=0,1246 \mathrm{cal} / \mathrm{g} .{ }^{\circ} \mathrm{C}$;

T4: Temperatura do argônio na entrada da câmara de reação $\mathrm{RC}\left({ }^{\circ} \mathrm{C}\right)$;

T5: Temperatura do argônio na saída da câmara de reação $\mathrm{RC}\left({ }^{\circ} \mathrm{C}\right)$; 
$Q_{A r}=m_{A r} \times c p_{A r} \times \Delta T$ : energia absorvida argônio (kJ);

Cal $\times 4,1868 \times 10^{-3}=\mathrm{kJ}$

Tabela 22 - Calor absorvido pelo argônio com 500 W de energia de micro-ondas irradiada após o período de estabilização térmica sem pelota e com cadinho ou tarugo de fibra cerâmica

\begin{tabular}{cccccc}
\hline (min) & $m_{A r}$ & $c p_{A r}$ & T4 & T5 & $Q_{A r}$ \\
\hline 0 a 3 & 3,63 & & 27,1 & 28,1 & 0,0019 \\
3 a 6 & 3,63 & & 27,0 & 27,9 & 0,0017 \\
6 a 9 & 3,63 & & 27,0 & 28,1 & 0,0020 \\
9 a 12 & 3,63 & & 27,1 & 28,1 & 0,0019 \\
12 a 15 & 3,63 & 0,1246 & 27,2 & 28,1 & 0,0017 \\
15 a 18 & 3,63 & & 27,2 & 28,1 & 0,0017 \\
18 a 21 & 3,63 & & 27,2 & 28,2 & 0,0019 \\
21 a 24 & 3,63 & 27,0 & 28,3 & 0,0025 \\
24 a 27 & 3,63 & 27,0 & 28,3 & 0,0025 \\
27 a 30 & 3,63 & 27,2 & 28,0 & 0,0015 \\
\hline TOTAL & & & & $\mathbf{0 , 0 2}$ \\
\hline
\end{tabular}

Tabela 23 - Calor absorvido pelo argônio com $1000 \mathrm{~W}$ de energia de micro-ondas irradiada após o período de estabilização térmica sem pelota e com cadinho ou tarugo de fibra cerâmica

\begin{tabular}{cccccc}
\hline ( $\mathbf{m i n})$ & $m_{A r}$ & $c p_{A r}$ & T4 & T5 & $Q_{A r}$ \\
\cline { 1 - 3 } 0 a 3 & 3,63 & & 26,4 & 30,6 & 0,0080 \\
3 a 6 & 3,63 & & 26,3 & 30,3 & 0,0076 \\
6 a 9 & 3,63 & & 26,4 & 31,2 & 0,0091 \\
9 a 12 & 3,63 & & 26,5 & 30,9 & 0,0083 \\
12 a 15 & 3,63 & 0,1246 & 26,5 & 30,5 & 0,0076 \\
15 a 18 & 3,63 & 26,5 & 30,6 & 0,0078 \\
18 a 21 & 3,63 & & 26,6 & 30,6 & 0,0076 \\
21 a 24 & 3,63 & 26,8 & 31,0 & 0,0080 \\
24 a 27 & 3,63 & 26,6 & 30,7 & 0,0078 \\
27 a 30 & 3,63 & 26,7 & 30,0 & 0,0062 \\
\hline TOTAL & & & & $\mathbf{0 , 0 8}$ \\
\hline
\end{tabular}


Tabela 24 - Calor absorvido pelo argônio com 1500 W de energia de micro-ondas irradiada após o período de estabilização térmica sem pelota e com cadinho ou tarugo de fibra cerâmica

\begin{tabular}{|c|c|c|c|c|c|}
\hline$(\min )$ & $m_{A r}$ & $c p_{A r}$ & T4 & T5 & $Q_{A r}$ \\
\hline 0 a 3 & 3,63 & \multirow{10}{*}{0,1246} & 26,2 & 35,1 & 0,0170 \\
\hline 3 a 6 & 3,63 & & 26,3 & 35,6 & 0,0176 \\
\hline 6 a 9 & 3,63 & & 26,3 & 34,8 & 0,0161 \\
\hline 9 a 12 & 3,63 & & 26,4 & 35,4 & 0,0170 \\
\hline 12 a 15 & 3,63 & & 26,5 & 35,0 & 0,0161 \\
\hline 15 a 18 & 3,63 & & 26,4 & 35,2 & 0,0167 \\
\hline 18 a 21 & 3,63 & & 26,7 & 35,3 & 0,0163 \\
\hline 21 a 24 & 3,63 & & 26,7 & 34,4 & 0,0146 \\
\hline 24 a 27 & 3,63 & & 26,7 & 35,8 & 0,0172 \\
\hline 27 a 30 & 3,63 & & 26,7 & 35,8 & 0,0172 \\
\hline TOTAL & & & & & 0,17 \\
\hline
\end{tabular}

\section{Câmara de reação (CR)}

$m_{C R}$ : Massa da câmara de reação $=875,53 \mathrm{~g}$

$c p_{A l}$ : Poder calorífico da chapa de alumínio $\left(25-125^{\circ} \mathrm{C}\right)=0,215 \mathrm{cal} / \mathrm{g} .{ }^{\circ} \mathrm{C}$;

T6: Temperatura média da superfície externa da câmara de reação $\left({ }^{\circ} \mathrm{C}\right)$;

$Q_{C R}=m_{C R} \times c p_{A l} \times \Delta T$ : energia absorvida pela câmara de reação $(\mathrm{kJ})$;

Cal $\times 4,1868 \times 10^{-3}=\mathrm{kJ}$

Tabela 25 - Calor absorvido pela câmara de reação com 500 W de energia de micro-ondas irradiada após o período de estabilização térmica sem pelota e com cadinho ou tarugo de fibra cerâmica

\begin{tabular}{ccccc}
\hline ( $\min )$ & $m_{C R}$ & $c p_{A l}$ & T6 & $Q_{C R}$ \\
\hline 0 & & & 26,0 & - \\
0 a 3 & & 26,5 & 0,39 \\
3 a 6 & & 26,9 & 0,32 \\
6 a 9 & & 27,2 & 0,24 \\
9 a 12 & & 27,5 & 0,24 \\
12 a 15 & & 27,9 & 0,32 \\
15 a 18 & & 28,5 & 0,47 \\
18 a 21 & & 29,6 & 0,87 \\
21 a 24 & & 29,9 & 0,24 \\
24 a 27 & & 30,0 & 0,08 \\
27 a 30 & & 30,2 & 0,16 \\
\hline TOTAL & & & $\mathbf{3 , 3 3}$ \\
\hline
\end{tabular}


Tabela 26 - Calor absorvido pela câmara de reação com $1000 \mathrm{~W}$ de energia de micro-ondas irradiada após o período de estabilização térmica sem pelota e com cadinho ou tarugo de fibra cerâmica

\begin{tabular}{|c|c|c|c|c|}
\hline (min) & $m_{C R}$ & $c p_{A l}$ & T6 & $Q_{C R}$ \\
\hline 0 & \multirow{12}{*}{875,53} & \multirow{12}{*}{0,215} & 27,0 & - \\
\hline 0 a 3 & & & 27,2 & 0,16 \\
\hline 3 a 6 & & & 28,3 & 0,87 \\
\hline 6 a 9 & & & 29,1 & 0,63 \\
\hline 9 a 12 & & & 31,0 & 1,50 \\
\hline 12 a 15 & & & 31,4 & 0,32 \\
\hline 15 a 18 & & & 31,6 & 0,16 \\
\hline 18 a 21 & & & 32,1 & 0,39 \\
\hline 21 a 24 & & & 32,7 & 0,47 \\
\hline 24 a 27 & & & 33,5 & 0,63 \\
\hline 27 a 30 & & & 33,6 & 0,08 \\
\hline TOTAL & & & & 5,21 \\
\hline
\end{tabular}

Tabela 27 - Calor absorvido pela câmara de reação com 1500 W de energia de micro-ondas irradiada após o período de estabilização térmica sem pelota e com cadinho ou tarugo de fibra cerâmica

\begin{tabular}{|c|c|c|c|c|}
\hline (min) & $m_{C R}$ & $c p_{A l}$ & T6 & $Q_{C R}$ \\
\hline 0 & \multirow{12}{*}{875,53} & \multirow{12}{*}{0,215} & 26,1 & - \\
\hline 0 a 3 & & & 26,9 & 0,63 \\
\hline 3 a 6 & & & 27,0 & 0,08 \\
\hline 6 a 9 & & & 28,0 & 0,79 \\
\hline 9 a 12 & & & 29,2 & 0,95 \\
\hline 12 a 15 & & & 29,7 & 0,39 \\
\hline 15 a 18 & & & 30,6 & 0,71 \\
\hline 18 a 21 & & & 31,2 & 0,47 \\
\hline 21 a 24 & & & 32,0 & 0,63 \\
\hline 24 a 27 & & & 32,9 & 0,71 \\
\hline 27 a 30 & & & 33,6 & 0,55 \\
\hline TOTAL & & & & 5,91 \\
\hline
\end{tabular}

\section{Circulador (C1)}

$$
m_{\mathrm{H}_{2} \mathrm{O}}: \text { Vazão de água de refrigeração }=1,64 \mathrm{~L} / \mathrm{min}=1640 \mathrm{~g} / \mathrm{min}=4920
$$

g/3min;

$$
c p_{\mathrm{H}_{2} \mathrm{O}}: \text { Poder calorífico da água }=1,0 \mathrm{cal} / \mathrm{g} .{ }^{\circ} \mathrm{C} ;
$$


T8: Temperatura da água de refrigeração na entrada do circulador $\mathrm{C} 1$ $\left({ }^{\circ} \mathrm{C}\right)$;

T9: Temperatura da água de refrigeração na saída do circulador $\mathrm{C} 1\left({ }^{\circ} \mathrm{C}\right)$;

$Q_{C 1}=m_{\mathrm{H}_{2} \mathrm{O}} \times c p_{\mathrm{H}_{2} \mathrm{O}} \times \Delta T$ : energia absorvida pelo circulador $\mathrm{C} 1(\mathrm{~kJ})$;

Cal $\times 4,1868 \times 10^{-3}=\mathrm{kJ}$

Tabela 28 - Calor absorvido pelo circulador com $500 \mathrm{~W}$ de energia de micro-ondas irradiada após o período de estabilização térmica sem pelota e com cadinho ou tarugo de fibra cerâmica

\begin{tabular}{cccccc}
\hline ( $\mathbf{m i n})$ & $m$ & $c p_{H_{2} O}$ & T8 & T9 & $Q_{T C 1}$ \\
\hline 0 a 3 & 4920 & & 24,65 & 24,90 & 5,15 \\
3 a 6 & 4920 & & 24,55 & 24,85 & 6,18 \\
6 a 9 & 4920 & & 24,60 & 24,80 & 4,12 \\
9 a 12 & 4920 & & 24,55 & 24,85 & 6,18 \\
12 a 15 & 4920 & & 24,65 & 24,85 & 4,12 \\
15 a 18 & 4920 & 1,0 & 24,60 & 24,80 & 4,12 \\
18 a 21 & 4920 & & 24,55 & 24,85 & 6,18 \\
21 a 24 & 4920 & & 24,65 & 24,85 & 4,12 \\
24 a 27 & 4920 & & 24,65 & 24,85 & 4,12 \\
27 a 30 & 4920 & & 24,55 & 24,80 & 5,15 \\
\hline TOTAL & & & & $\mathbf{4 9 , 4 4}$ \\
\hline
\end{tabular}

Tabela 29 - Calor absorvido pelo circulador com $1000 \mathrm{~W}$ de energia de micro-ondas irradiada após o período de estabilização térmica sem pelota e com cadinho ou tarugo de fibra cerâmica

\begin{tabular}{|c|c|c|c|c|c|}
\hline$(\min )$ & $m$ & $c p_{\mathrm{H}_{2} \mathrm{O}}$ & T8 & T9 & $Q_{T C 1}$ \\
\hline 0 a 3 & 4920 & \multirow{10}{*}{1,0} & 29,15 & 29,55 & 8,24 \\
\hline 3 a 6 & 4920 & & 29,15 & 29,55 & 8,24 \\
\hline 6 a 9 & 4920 & & 29,20 & 29,60 & 8,24 \\
\hline 9 a 12 & 4920 & & 29,15 & 29,60 & 9,27 \\
\hline 12 a 15 & 4920 & & 29,15 & 29,55 & 1,30 \\
\hline 15 a 18 & 4920 & & 29,20 & 29,65 & 9,27 \\
\hline 18 a 21 & 4920 & & 29,15 & 29,55 & 8,24 \\
\hline 21 a 24 & 4920 & & 29,15 & 29,60 & 9,27 \\
\hline 24 a 27 & 4920 & & 29,25 & 29,65 & 8,24 \\
\hline 27 a 30 & 4920 & & 29,20 & 29,65 & 9,27 \\
\hline TOTAL & & & & & 88,58 \\
\hline
\end{tabular}


Tabela 30 - Calor absorvido pelo circulador com $1500 \mathrm{~W}$ de energia de micro-ondas irradiada após o período de estabilização térmica sem pelota e com cadinho ou tarugo de fibra cerâmica

\begin{tabular}{|c|c|c|c|c|c|}
\hline$(\min )$ & $m$ & $c p_{\mathrm{H}_{2} \mathrm{O}}$ & T8 & T9 & $Q_{T C 1}$ \\
\hline 0 a 3 & 4920 & \multirow{10}{*}{1,0} & 32,45 & 33,00 & 11,33 \\
\hline 3 a 6 & 4920 & & 32,65 & 33,30 & 13,39 \\
\hline 6 a 9 & 4920 & & 32,75 & 33,40 & 13,39 \\
\hline 9 a 12 & 4920 & & 32,75 & 33,45 & 14,42 \\
\hline 12 a 15 & 4920 & & 32,80 & 33,45 & 13,39 \\
\hline 15 a 18 & 4920 & & 32,45 & 33,00 & 11,33 \\
\hline 18 a 21 & 4920 & & 32,65 & 33,30 & 13,39 \\
\hline 21 a 24 & 4920 & & 32,75 & 33,40 & 13,39 \\
\hline 24 a 27 & 4920 & & 32,75 & 33,45 & 14,42 \\
\hline 27 a 30 & 4920 & & 32,80 & 33,45 & 13,39 \\
\hline TOTAL & & & & & 131,83 \\
\hline
\end{tabular}

\section{Cadinho ou tarugo de fibra cerâmica}

$m_{\text {CTIC }}$ : Massa do cadinho com tampa ou tarugo do isolante térmico cerâmico $= \pm 8,30 \mathrm{~g}$

$c p_{\text {isol }}$ : Poder calorífico do isolante térmico cerâmico $=0,4179 \mathrm{cal} / \mathrm{g} \cdot{ }^{\circ} \mathrm{C}$;

T7: Temperatura média da superfície externa do cadinho ou tarugo de isolante cerâmico $\left({ }^{\circ} \mathrm{C}\right)$;

$Q_{\text {CTIC }}=m_{\text {CTIC }} \times c p_{\text {isol }} \times \Delta T$ : energia absorvida pelo cadinho ou tarugo de isolante cerâmico $(\mathrm{kJ})$;

Cal $\times 4,1868 \times 10^{-3}=\mathrm{kJ}$

Tabela 31 - Calor absorvido pelo cadinho ou tarugo de isolante cerâmico com $500 \mathrm{~W}$ de energia de micro-ondas irradiada após o período de estabilização térmica sem pelota

\begin{tabular}{ccccc}
\hline ( $\mathbf{m i n})$ & $m_{C I C}$ & $c p_{C I C}$ & $\mathbf{T 7}$ & $Q_{C I C}$ \\
\hline 0 & & & 29,0 & - \\
0 a 3 & & 35,0 & 0,09 \\
3 a 6 & & 36,0 & 0,01 \\
6 a 9 & & 36,0 & 0,00 \\
9 a 12 & & 37,0 & 0,01 \\
12 a 15 & & 38,0 & 0,01 \\
15 a 18 & \multirow{2}{*}{0,4179} & 38,0 & 0,00 \\
18 a 21 & & 38,0 & 0,00 \\
21 a 24 & & 38,0 & 0,00 \\
24 a 27 & & 38,0 & 0,00 \\
27 a 30 & & 38,0 & 0,00 \\
\hline TOTAL & & & $\mathbf{0 , 1 2}$ \\
\hline
\end{tabular}


Tabela 32 - Calor absorvido pelo cadinho ou tarugo de isolante cerâmico com 1000 W de energia de micro-ondas irradiada após o período de estabilização térmica sem pelota

\begin{tabular}{|c|c|c|c|c|}
\hline (min) & $m_{C I C}$ & $c p_{C I C}$ & T7 & $Q_{C I C}$ \\
\hline 0 & \multirow{12}{*}{8,30} & \multirow{12}{*}{0,4179} & 26,0 & - \\
\hline 0 a 3 & & & 41,0 & 0,22 \\
\hline 3 a 6 & & & 42,0 & 0,01 \\
\hline 6 a 9 & & & 43,0 & 0,01 \\
\hline 9 a 12 & & & 44,0 & 0,01 \\
\hline 12 a 15 & & & 44,0 & 0,00 \\
\hline 15 a 18 & & & 44,0 & 0,00 \\
\hline 18 a 21 & & & 44,0 & 0,00 \\
\hline 21 a 24 & & & 44,0 & 0,00 \\
\hline 24 a 27 & & & 44,0 & 0,00 \\
\hline 27 a 30 & & & 44,0 & 0,00 \\
\hline TOTAL & & & & 0,25 \\
\hline
\end{tabular}

Tabela 33 - Calor absorvido pelo cadinho ou tarugo de isolante cerâmico com $1500 \mathrm{~W}$ de energia de micro-ondas irradiada após o período de estabilização térmica sem pelota

\begin{tabular}{|c|c|c|c|c|}
\hline (min) & $m_{C I C}$ & $c p_{C I C}$ & T7 & $Q_{C I C}$ \\
\hline 0 & \multirow{12}{*}{8,30} & \multirow{12}{*}{0,4179} & 27,0 & - \\
\hline 0 a 3 & & & 29,0 & 0,03 \\
\hline 3 a 6 & & & 49,0 & 0,29 \\
\hline 6 a 9 & & & 49,0 & 0,00 \\
\hline 9 a 12 & & & 51,0 & 0,03 \\
\hline 12 a 15 & & & 51,0 & 0,00 \\
\hline 15 a 18 & & & 53,0 & 0,03 \\
\hline 18 a 21 & & & 53,0 & 0,00 \\
\hline 21 a 24 & & & 54,0 & 0,01 \\
\hline 24 a 27 & & & 56,0 & 0,03 \\
\hline 27 a 30 & & & 56,0 & 0,00 \\
\hline TOTAL & & & & 0,42 \\
\hline
\end{tabular}




\section{APÊNDICE B - Memorial de cálculo para perdas para o equipamento após o período de estabilização térmica sem pelota e com cadinho de carbeto de silício}

\section{Trocadores de calor 1 e 2 (TC1 e TC2)}

$m_{H_{2} O}$ : Vazão de água de refrigeração $=0,5 \mathrm{~L} / \mathrm{min}=500 \mathrm{~g} / \mathrm{min}=1500$ g/3min;

$c p_{\mathrm{H}_{2} \mathrm{O}}$ : Poder calorífico da água $=1,0 \mathrm{cal} / \mathrm{g} \cdot{ }^{\circ} \mathrm{C}$;

T1: Temperatura da água de refrigeração na entrada do trocador de calor TC1 ( $\left.{ }^{\circ} \mathrm{C}\right)$;

T2: Temperatura da água de refrigeração na saída e na entrada dos trocadores de calor TC1 e TC2, respectivamente $\left({ }^{\circ} \mathrm{C}\right)$;

T3: Temperatura da água de refrigeração na saída do trocador de calor TC2 $\left({ }^{\circ} \mathrm{C}\right)$;

$Q_{T C 1}=m_{\mathrm{H}_{2} \mathrm{O}} \times c p_{\mathrm{H}_{2} \mathrm{O}} \times \Delta T$ : energia absorvida pelo trocador de calor $1(\mathrm{~kJ})$;

$Q_{T C 2}=m_{\mathrm{H}_{2} \mathrm{O}} \times c p_{\mathrm{H}_{2} \mathrm{O}} \times \Delta T$ : energia absorvida pelo trocador de calor $2(\mathrm{~kJ})$;

Cal $\times 4,1868 \times 10^{-3}=\mathrm{kJ}$

Tabela 34 - Calor absorvido pelos trocadores de calor 1 e 2 com $500 \mathrm{~W}$ de energia de microondas irradiada após o período de estabilização térmica sem pelota e com o cadinho de carbeto de silício

\begin{tabular}{|c|c|c|c|c|c|c|c|}
\hline (min) & $m$ & $c p_{\mathrm{H}_{2} \mathrm{O}}$ & $\mathrm{T} 1$ & $\mathrm{~T} 2$ & T3 & $Q_{T C 1}$ & $Q_{T C 2}$ \\
\hline 0 a 3 & 1500 & \multirow{11}{*}{1,0} & 23,8 & 24,0 & 25,0 & 1,26 & 6,28 \\
\hline 3 a 6 & 1500 & & 23,8 & 24,0 & 25,4 & 1,26 & 8,79 \\
\hline 6 a 9 & 1500 & & 23,8 & 25,0 & 26,5 & 7,54 & 9,42 \\
\hline 9 a 12 & 1500 & & 23,8 & 26,0 & 28,0 & 13,82 & 12,56 \\
\hline 12 a 15 & 1500 & & 23,8 & 26,5 & 28,0 & 16,96 & 9,42 \\
\hline 15 a 18 & 1500 & & 23,8 & 27,0 & 29,0 & 20,10 & 12,56 \\
\hline 18 a 21 & 1500 & & 23,8 & 27,0 & 30,0 & 20,10 & 18,84 \\
\hline 21 a 24 & 1500 & & 23,8 & 27,0 & 31,2 & 20,10 & 26,38 \\
\hline 24 a 27 & 1500 & & 23,8 & 27,2 & 31,2 & 21,35 & 25,12 \\
\hline 27 a 30 & 1500 & & 23,8 & 27,2 & 31,2 & 21,35 & 25,12 \\
\hline TOTAL & & & & & & 143,84 & 154,49 \\
\hline
\end{tabular}


Tabela 35 - Calor absorvido pelos trocadores de calor 1 e 2 com $1000 \mathrm{~W}$ de energia de microondas irradiada após o período de estabilização térmica sem pelota e com o cadinho de carbeto de silício

\begin{tabular}{|c|c|c|c|c|c|c|c|}
\hline$(\min )$ & $m$ & $c p_{\mathrm{H}_{2} \mathrm{O}}$ & $\mathrm{T} 1\left({ }^{\circ} \mathrm{C}\right)$ & T2 $\left({ }^{\circ} \mathrm{C}\right)$ & T3 $\left({ }^{\circ} \mathrm{C}\right)$ & $Q_{T C 1}$ & $Q_{T C 2}$ \\
\hline 0 a 3 & 1500 & \multirow{11}{*}{1,0} & 23,8 & 24,0 & 25,5 & 1,26 & 9,42 \\
\hline 3 a 6 & 1500 & & 23,8 & 25,0 & 29,0 & 7,54 & 25,12 \\
\hline 6 a 9 & 1500 & & 23,8 & 27,5 & 31,0 & 23,24 & 21,98 \\
\hline 9 a 12 & 1500 & & 23,8 & 28,5 & 33,0 & 29,52 & 28,26 \\
\hline 12 a 15 & 1500 & & 23,8 & 29,5 & 34,0 & 35,80 & 28,26 \\
\hline 15 a 18 & 1500 & & 23,8 & 30,0 & 35,0 & 38,94 & 31,40 \\
\hline 18 a 21 & 1500 & & 23,8 & 30,0 & 35,5 & 38,94 & 34,54 \\
\hline 21 a 24 & 1500 & & 23,8 & 30,0 & 36,0 & 38,94 & 37,68 \\
\hline 24 a 27 & 1500 & & 23,8 & 30,5 & 37,0 & 42,08 & 40,82 \\
\hline 27 a 30 & 1500 & & 23,8 & 30,5 & 37,0 & 42,08 & 40,82 \\
\hline TOTAL & & & & & & 298,31 & 298,31 \\
\hline
\end{tabular}

Tabela 36 - Calor absorvido pelos trocadores de calor 1 e 2 com $1500 \mathrm{~W}$ de energia de microondas irradiada após o período de estabilização térmica sem pelota e com o cadinho de carbeto de silício

\begin{tabular}{|c|c|c|c|c|c|c|c|}
\hline$(\min )$ & $m$ & $c p_{\mathrm{H}_{2} \mathrm{O}}$ & T1 & T2 & T3 & $Q_{T C 1}$ & $Q_{T C 2}$ \\
\hline 0 a 3 & 1500 & \multirow{10}{*}{1,0} & 23,0 & 23,5 & 28,0 & 3,14 & 28,26 \\
\hline 3 a 6 & 1500 & & 23,0 & 26,0 & 29,0 & 18,84 & 18,84 \\
\hline 6 a 9 & 1500 & & 23,0 & 28,0 & 33,0 & 31,40 & 31,40 \\
\hline 9 a 12 & 1500 & & 23,0 & 29,0 & 35,0 & 37,68 & 37,68 \\
\hline 12 a 15 & 1500 & & 23,0 & 30,0 & 36,0 & 43,96 & 37,68 \\
\hline 15 a 18 & 1500 & & 23,0 & 30,5 & 37,5 & 47,10 & 43,96 \\
\hline 18 a 21 & 1500 & & 23,0 & 32,0 & 39,5 & 56,52 & 47,10 \\
\hline 21 a 24 & 1500 & & 23,0 & 32,0 & 39,5 & 56,52 & 47,10 \\
\hline 24 a 27 & 1500 & & 23,0 & 32,0 & 39,5 & 56,52 & 47,10 \\
\hline 27 a 30 & 1500 & & 23,0 & 32,0 & 39,5 & 56,52 & 47,10 \\
\hline TOTAL & & & & & & 408,21 & 386,23 \\
\hline
\end{tabular}

\section{Argônio (Ar)}

$\rho_{A r}$ : Densidade média do argônio $\left(25-125^{\circ} \mathrm{C}\right)=1,425 \mathrm{~g} / \mathrm{L}$

$m_{A r}$ : Vazão do argônio pela câmara de reação $=0,85 \mathrm{~L} / \mathrm{min}=1,21 \mathrm{~g} / \mathrm{min}$

$=3,63 \mathrm{~g} / 3 \mathrm{~min}$;

$c p_{A r}$ : Poder calorífico do argônio $\left(25-125^{\circ} \mathrm{C}\right)=0,1246 \mathrm{cal} / \mathrm{g} .{ }^{\circ} \mathrm{C}$;

T4: Temperatura do argônio na entrada da câmara de reação, $\mathrm{RC}\left({ }^{\circ} \mathrm{C}\right)$;

T5: Temperatura do argônio na saída da câmara de reação, $\mathrm{RC}\left({ }^{\circ} \mathrm{C}\right)$;

$Q_{A r}=m_{A r} \times c p_{A r} \times \Delta T$ : energia absorvida argônio (kJ); 
Cal $\times 4,1868 \times 10^{-3}=\mathrm{kJ}$

Tabela 37 - Calor absorvido pelo argônio com 500 W de energia de micro-ondas irradiada após o período de estabilização térmica sem pelota e com o cadinho de carbeto de silício

\begin{tabular}{cccccc}
\hline (min) & $m_{A r}$ & $c p_{A r}$ & T4 & T5 & $Q_{A r}$ \\
\hline 0 a 3 & 3,63 & & 26,0 & 80,5 & 0,12 \\
3 a 6 & 3,63 & & 25,6 & 226,0 & 0,45 \\
6 a 9 & 3,63 & & 25,4 & 235,0 & 0,47 \\
9 a 12 & 3,63 & & 25,7 & 245,0 & 0,49 \\
12 a 15 & 3,63 & \multirow{2}{*}{0,1246} & 25,8 & 259,0 & 0,52 \\
15 a 18 & 3,63 & & 25,7 & 256,0 & 0,51 \\
18 a 21 & 3,63 & & 25,6 & 260,0 & 0,52 \\
21 a 24 & 3,63 & & 25,7 & 257,0 & 0,52 \\
24 a 27 & 3,63 & 26,1 & 257,0 & 0,52 \\
27 a 30 & 3,63 & & 26,0 & 258,0 & 0,52 \\
\hline TOTAL & & & & $\mathbf{4 , 6 3}$ \\
\hline
\end{tabular}

Tabela 38 - Calor absorvido pelo argônio com 1000 W de energia de micro-ondas irradiada após o período de estabilização térmica sem pelota e com o cadinho de carbeto de silício

\begin{tabular}{cccccc}
\hline ( $\mathbf{m i n})$ & $m_{A r}$ & $c p_{A r}$ & T4 & T5 & $Q_{A r}$ \\
\hline 0 a 3 & 3,63 & & 26,2 & 223,0 & 0,44 \\
3 a 6 & 3,63 & & 25,2 & 261,0 & 0,53 \\
6 a 9 & 3,63 & & 24,1 & 264,0 & 0,53 \\
9 a 12 & 3,63 & & 23,9 & 275,0 & 0,56 \\
12 a 15 & 3,63 & \multirow{2}{*}{0,1246} & 23,7 & 374,0 & 0,78 \\
15 a 18 & 3,63 & & 23,4 & 375,0 & 0,78 \\
18 a 21 & 3,63 & & 24,1 & 375,0 & 0,78 \\
21 a 24 & 3,63 & & 24,2 & 375,0 & 0,78 \\
24 a 27 & 3,63 & & 24,0 & 375,0 & 0,78 \\
27 a 30 & 3,63 & & 23,9 & 375,0 & 0,78 \\
\hline TOTAL & & & & $\mathbf{6 , 7 5}$ \\
\hline
\end{tabular}

Tabela 39 - Calor absorvido pelo argônio com $1500 \mathrm{~W}$ de energia de micro-ondas irradiada após o período de estabilização térmica sem pelota e com o cadinho de carbeto de silício

\begin{tabular}{cccccc}
\hline ( $\mathbf{m i n})$ & $m_{A r}$ & $c p_{A r}$ & T4 & T5 & $Q_{A r}$ \\
\hline 0 a 3 & 3,63 & & 21,5 & 280,0 & 0,58 \\
3 a 6 & 3,63 & & 21,6 & 411,0 & 0,87 \\
6 a 9 & 3,63 & & 21,6 & 438,0 & 0,93 \\
9 a 12 & 3,63 & & 21,3 & 431,0 & 0,91 \\
12 a 15 & 3,63 & 0,1246 & 21,6 & 427,0 & 0,90 \\
15 a 18 & 3,63 & & 21,4 & 422,0 & 0,89 \\
18 a 21 & 3,63 & & 21,5 & 421,0 & 0,89 \\
21 a 24 & 3,63 & & 21,7 & 420,0 & 0,89 \\
24 a 27 & 3,63 & & 21,6 & 421,0 & 0,89 \\
27 a 30 & 3,63 & & 21,4 & 419,0 & 0,89 \\
\hline TOTAL & & & & $\mathbf{8 , 6 4}$ \\
\hline
\end{tabular}




\section{Câmara de reação (CR)}

$m_{C R}$ : Massa da câmara de reação $=875,53 \mathrm{~g}$

$c p_{A l}$ : Poder calorífico da chapa de alumínio $\left(25-125^{\circ} \mathrm{C}\right)=0,215 \mathrm{cal} / \mathrm{g} .{ }^{\circ} \mathrm{C}$;

T6: Temperatura média da superfície externa da câmara de reação $\left({ }^{\circ} \mathrm{C}\right)$;

$Q_{C R}=m_{C R} \times c p_{A l} \times \Delta T$ : energia absorvida pela câmara de reação (kJ);

Cal $\times 4,1868 \times 10^{-3}=\mathrm{kJ}$

Tabela 40 - Calor absorvido pela câmara de reação com 500 W de energia de micro-ondas irradiada após o período de estabilização térmica sem pelota e com o cadinho de carbeto de silício

\begin{tabular}{|c|c|c|c|c|}
\hline$(\min )$ & $m_{C R}$ & $c p_{A l}$ & T6 & $Q_{C R}$ \\
\hline 0 & & & 27,0 & - \\
\hline 0 a 3 & & & 28,0 & 0,79 \\
\hline 3 a 6 & & & 29,0 & 0,79 \\
\hline 6 a 9 & & & 31,0 & 1,58 \\
\hline 9 a 12 & & & 32,0 & 0,79 \\
\hline 12 a 15 & 87552 & & 33,0 & 0,79 \\
\hline 15 a 18 & 010,50 & 0,215 & 35,0 & 1,58 \\
\hline 18 a 21 & & & 36,0 & 0,79 \\
\hline 21 a 24 & & & 46,0 & 7,88 \\
\hline 24 a 27 & & & 51,0 & 3,94 \\
\hline 27 a 30 & & & 55,0 & 3,15 \\
\hline TOTAL & & & & 22,07 \\
\hline
\end{tabular}

Tabela 41 - Calor absorvido pela câmara de reação com $1000 \mathrm{~W}$ de energia de micro-ondas irradiada após o período de estabilização térmica sem pelota e com o cadinho de carbeto de silício

\begin{tabular}{ccccc}
\hline ( $\mathbf{m i n})$ & $m_{C R}$ & $c p_{A l}$ & T6 & $Q_{C R}$ \\
\hline 0 & & & 31,0 & - \\
0 a 3 & & 33,0 & 1,58 \\
3 a 6 & & & 65,0 & 25,22 \\
6 a 9 & & 66,0 & 0,79 \\
9 a 12 & & 67,0 & 0,79 \\
12 a 15 & & & 08,0 & 0,79 \\
15 a 18 & \multirow{2}{*}{0,215} & 69,0 & 0,79 \\
18 a 21 & & & 72,0 & 2,36 \\
21 a 24 & & 77,0 & 3,94 \\
24 a 27 & & 79,0 & 1,58 \\
27 a 30 & & 85,0 & 4,73 \\
\hline TOTAL & & & $\mathbf{4 2 , 5 6}$ \\
\hline
\end{tabular}


Tabela 42 - Calor absorvido pela câmara de reação com $1500 \mathrm{~W}$ de energia de micro-ondas irradiada após o período de estabilização térmica sem pelota e com o cadinho de carbeto de silício

\begin{tabular}{|c|c|c|c|c|}
\hline$(\min )$ & $m_{C R}$ & $c p_{A l}$ & T6 & $Q_{C R}$ \\
\hline 0 & & & 27,0 & - \\
\hline 0 a 3 & & & 50,0 & 18,13 \\
\hline 3 a 6 & & & 58,0 & 6,30 \\
\hline 6 a 9 & & & 65,0 & 5,52 \\
\hline 9 a 12 & & & 81,0 & 12,61 \\
\hline 12 a 15 & 075 & 0215 & 84,0 & 2,36 \\
\hline 15 a 18 & $8 / 3,53$ & 0,215 & 85,0 & 0,79 \\
\hline 18 a 21 & & & 87,0 & 1,58 \\
\hline 21 a 24 & & & 94,0 & 5,52 \\
\hline 24 a 27 & & & 101,0 & 5,52 \\
\hline 27 a 30 & & & 103,0 & 1,58 \\
\hline TOTAL & & & & 59,90 \\
\hline
\end{tabular}

\section{Circulador (C1)}

$m_{\mathrm{H}_{2} \mathrm{O}}:$ Vazão de água de refrigeração $=1,51 \mathrm{~L} / \mathrm{min}=1510 \mathrm{~g} / \mathrm{min}=4530$ g/3min;

$c p_{\mathrm{H}_{2} \mathrm{O}}:$ Poder calorífico da água $=1,0 \mathrm{cal} / \mathrm{g} .{ }^{\circ} \mathrm{C}$;

T8: Temperatura da água de refrigeração na entrada do circulador $\mathrm{C} 1$ $\left({ }^{\circ} \mathrm{C}\right)$;

T9: Temperatura da água de refrigeração na saída do circulador $\mathrm{C} 1\left({ }^{\circ} \mathrm{C}\right)$;

$Q_{C_{1}}=m_{\mathrm{H}_{2} \mathrm{O}} \times c p_{\mathrm{H}_{2} \mathrm{O}} \times \Delta T$ : energia absorvida pelo circulador $\mathrm{C} 1(\mathrm{~kJ})$;

Cal $\times 4,1868 \times 10^{-3}=\mathrm{kJ}$ 
Tabela 43 - Calor absorvido pelo circulador com $500 \mathrm{~W}$ de energia de micro-ondas irradiada após o período de estabilização térmica sem pelota e com o cadinho de carbeto de silício

\begin{tabular}{|c|c|c|c|c|c|}
\hline (min) & $m$ & $c p_{\mathrm{H}_{2} \mathrm{O}}$ & T8 & T9 & $Q_{T C 1}$ \\
\hline 0 a 3 & 4530 & \multirow{10}{*}{1,0} & 21,90 & 22,10 & 3,79 \\
\hline 3 a 6 & 4530 & & 22,10 & 22,30 & 3,79 \\
\hline 6 a 9 & 4530 & & 22,15 & 22,35 & 3,79 \\
\hline 9 a 12 & 4530 & & 22,15 & 22,35 & 3,79 \\
\hline 12 a 15 & 4530 & & 22,15 & 22,35 & 3,79 \\
\hline 15 a 18 & 4530 & & 21,95 & 22,15 & 3,79 \\
\hline 18 a 21 & 4530 & & 22,15 & 22,35 & 3,79 \\
\hline 21 a 24 & 4530 & & 22,15 & 22,35 & 3,79 \\
\hline 24 a 27 & 4530 & & 22,15 & 22,35 & 3,79 \\
\hline 27 a 30 & 4530 & & 22,15 & 22,35 & 3,79 \\
\hline TOTAL & & & & & 37,93 \\
\hline
\end{tabular}

Tabela 44 - Calor absorvido pelo circulador com $1000 \mathrm{~W}$ de energia de micro-ondas irradiada após o período de estabilização térmica sem pelota e com o cadinho de carbeto de silício

\begin{tabular}{cccccc}
\hline (min) & $m$ & $c p_{\mathrm{H}_{2} \mathrm{O}}$ & T8 & T9 & $Q_{T C 1}$ \\
\cline { 1 - 3 } 0 a 3 & 4530 & & 23,80 & 24,15 & 6,64 \\
3 a 6 & 4530 & & 23,90 & 24,20 & 5,69 \\
6 a 9 & 4530 & & 23,90 & 24,20 & 5,69 \\
9 a 12 & 4530 & & 23,90 & 24,20 & 5,69 \\
12 a 15 & 4530 & & 23,95 & 24,25 & 5,69 \\
15 a 18 & 4530 & 1,0 & 23,85 & 24,20 & 6,64 \\
18 a 21 & 4530 & & 23,90 & 24,20 & 5,69 \\
21 a 24 & 4530 & & 23,95 & 24,25 & 5,69 \\
24 a 27 & 4530 & & 23,90 & 24,20 & 5,69 \\
27 a 30 & 4530 & & 23,95 & 24,25 & 5,69 \\
\hline TOTAL & & & & $\mathbf{5 8 , 8 0}$ \\
\hline
\end{tabular}

Tabela 45 - Calor absorvido pelo circulador com $1500 \mathrm{~W}$ de energia de micro-ondas irradiada após o período de estabilização térmica sem pelota e com o cadinho de carbeto de silício

\begin{tabular}{|c|c|c|c|c|c|}
\hline (min) & $m$ & $c p_{\mathrm{H}_{2} \mathrm{O}}$ & T8 & T9 & $Q_{T C 1}$ \\
\hline 0 a 3 & 4530 & \multirow{10}{*}{1,0} & 26,70 & 27,15 & 8,53 \\
\hline 3 a 6 & 4530 & & 26,75 & 27,20 & 8,53 \\
\hline 6 a 9 & 4530 & & 26,80 & 27,25 & 8,53 \\
\hline 9 a 12 & 4530 & & 26,80 & 27,30 & 9,48 \\
\hline 12 a 15 & 4530 & & 26,95 & 27,30 & 6,64 \\
\hline 15 a 18 & 4530 & & 26,90 & 27,45 & 10,43 \\
\hline 18 a 21 & 4530 & & 26,85 & 27,40 & 10,43 \\
\hline 21 a 24 & 4530 & & 26,75 & 27,40 & 12,33 \\
\hline 24 a 27 & 4530 & & 26,80 & 27,30 & 9,48 \\
\hline 27 a 30 & 4530 & & 26,95 & 27,30 & 6,64 \\
\hline TOTAL & & & & & 91,04 \\
\hline
\end{tabular}




\section{APÊNDICE C - Determinação do máximo campo elétrico ou do máximo campo magnético no interior da câmara de reação.}

Materiais:

Fio de cobre, $40 \mathrm{~cm}$ de comprimento e 1,5 mm de diâmetro;

02 rolhas de borracha, $(29 \times 35 \mathrm{~mm})$;

Detector de vazamento de micro-ondas, $2.45 \mathrm{GHz}$, range de 0$100 \mathrm{~mW} / \mathrm{cm}^{2}$.

Procedimento:

Inserir o fio de cobre no interior da câmara de reação, de modo que fique posicionado no centro e sem contato com as paredes metálicas do reator. Para isto, fixe o fio através das rolhas de borracha como mostrado pela figura 40. Irradie em torno de $30 \mathrm{~W}$ para realizar a medição. Meça o vazamento de micro-ondas através do detector de vazamento de micro-ondas. O máximo de campo elétrico (e mínimo de campo magnético) ou vice-versa é obtido ajustando a distância d.

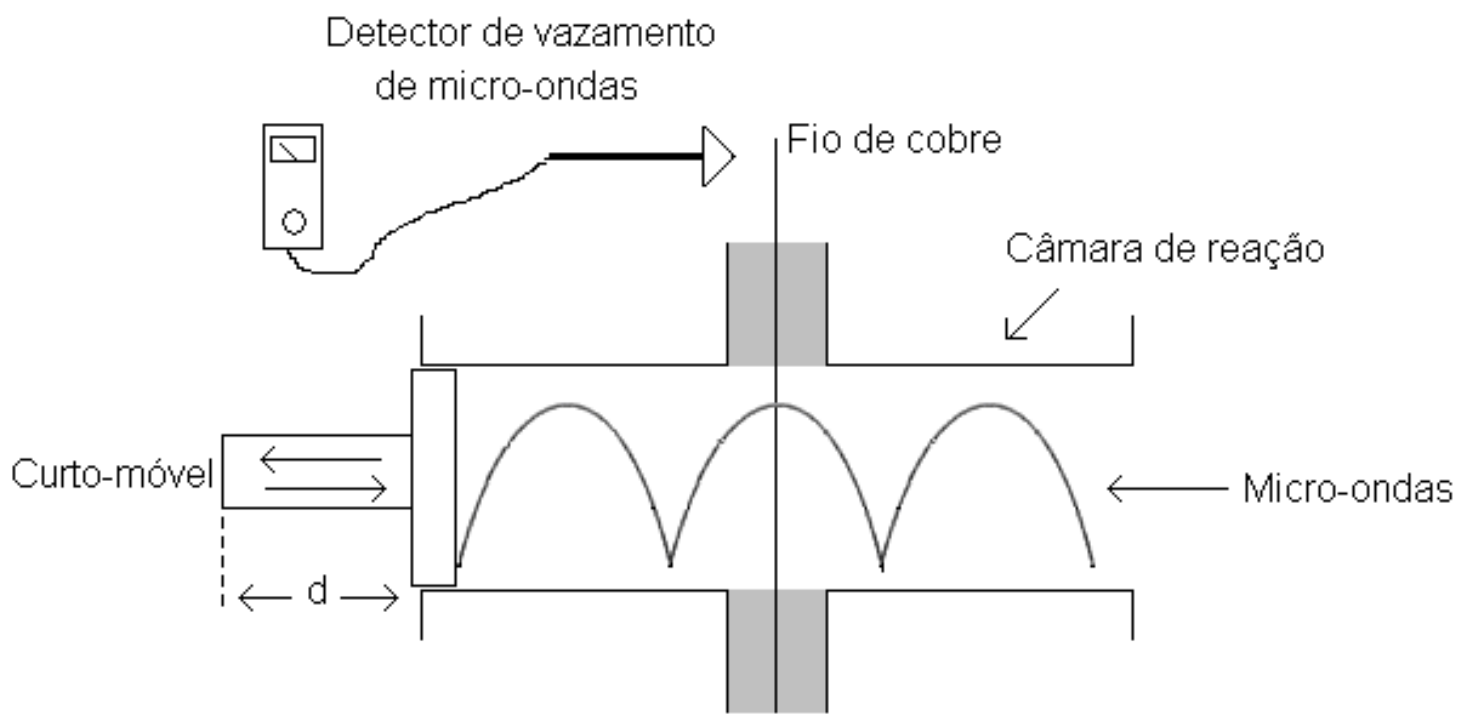

Rolha de borracha

Figura 40 - Esquema diagramático para determinação do máximo campo elétrico ou do máximo campo magnético no interior da câmara de reação. 


\section{ANEXO A - Balanço térmico para aquecer até $1000^{\circ} \mathrm{C}$ e reduzir uma pelota de $3,5 \mathrm{~g}$ com $80,1 \%$ de $\mathrm{Fe}_{2} \mathrm{O}_{3}$ e $19,9 \%$ de redutor}

\section{Dados termodinâmicos}

\begin{tabular}{ccc}
\multicolumn{2}{l}{ Tabela 46-Calores de formação } \\
\hline Substância & $\Delta H_{298}^{0}(\mathrm{kcal} / \mathrm{mol})$ & Ponto de fusão $\left({ }^{\circ} \mathrm{C}\right)$ \\
\hline $\mathrm{Fe}_{0.95} \mathrm{O}$ & 63,2 & 1378 \\
$\mathrm{Fe}_{3} \mathrm{O}_{4}$ & 266,9 & 1594 \\
$\mathrm{Fe}_{2} \mathrm{O}_{3}$ & 196,3 & 1457 \\
$\mathrm{CO}$ & 26,4 & - \\
$\mathrm{CO}$ & 94,05 & - \\
\hline
\end{tabular}

Fonte [58]

Tabela 47 - Capacidade térmica

\begin{tabular}{llc}
\hline & \multicolumn{1}{c}{ Equação } & \multicolumn{1}{c}{$\mathrm{T}(\mathrm{K})$} \\
\hline $\mathrm{Cp} \mathrm{Fe}_{2} \mathrm{O}_{3}(\alpha)$ & $23,49+18,6 \times 10^{-3} \mathrm{~T}-3,55 \times 10^{5} \mathrm{~T}^{-2}$ & $298-950$ \\
$\mathrm{Cp} \mathrm{Fe}_{2} \mathrm{O}_{3}(\beta)$ & 36,0 & $950-1050$ \\
$\mathrm{Cp} \mathrm{Fe}_{2} \mathrm{O}_{3}(\gamma)$ & $31,7+1,76 \times 10^{-3} \mathrm{~T}$ & $1050-1750$ \\
$\mathrm{Cp} \mathrm{C}(\mathrm{g})$ & $4,10+1,02 \times 10^{-3} \mathrm{~T}-2,10 \times 10^{5} \mathrm{~T}^{-2}$ & $298-2300$ \\
\hline
\end{tabular}

Fonte [58]

Tabela 48 - Entalpias de transformação

\begin{tabular}{lcc}
\hline & $\mathrm{T}(\mathrm{K})$ & $\Delta H_{t}(\mathrm{cal} / \mathrm{mol})$ \\
\hline $\mathrm{Fe}(\alpha \rightarrow \gamma)$ & 1184 & 215 \\
$\mathrm{Fe}_{2} \mathrm{O}_{3}$ & 950 & 160 \\
\hline
\end{tabular}

Fonte [58]

Base de cálculo: $100 \mathrm{~kg}$ de mistura contendo $80,1 \%$ de $\mathrm{Fe}_{2} \mathrm{O}_{4}$ e $19,9 \%$ de redutor

\section{Calor de reação}

A partir dos dados da tabela 46 , tem-se:

(2)

$$
\text { Reação }
$$

$$
3 \mathrm{Fe}_{2} \mathrm{O}_{3}+\mathrm{CO} \rightarrow 2 \mathrm{Fe}_{3} \mathrm{O}_{4}+\mathrm{CO}_{2}
$$$$
\mathrm{Fe}_{3} \mathrm{O}_{4}+\mathrm{CO} \rightarrow 3 \mathrm{FeO}+\mathrm{CO}_{2}
$$

$\Delta H_{298}^{0}(\mathrm{cal} / \mathrm{mol})$

$-12550$

9650 


$$
\begin{gathered}
\mathrm{FeO}+\mathrm{CO} \rightarrow \mathrm{Fe}+\mathrm{CO}_{2} \\
\mathrm{CO}_{2}+\mathrm{C} \rightarrow 2 \mathrm{CO}
\end{gathered}
$$$$
-4450
$$

41250

Adotando-se que a reação global $\mathrm{Fe}_{2} \mathrm{O}_{3}+p \mathrm{C} \rightarrow 2 \mathrm{Fe}+w \mathrm{CO}+v \mathrm{CO}_{2}$ sejam consumidos $12 \mathrm{~kg}$ de carbono para reduzir $76,45 \mathrm{~kg}$ de $\mathrm{Fe}_{2} \mathrm{O}_{3}$ presentes na mistura, tem-se:

\begin{tabular}{cc} 
Reação & $(\mathrm{cal} / 100 \mathrm{~kg}$ mistura $)$ \\
$(1)$ & -1.998 .849 \\
$(2)$ & 3.073 .950 \\
$(3)$ & -4.252 .531 \\
$(4)$ & 41.250 .000 \\
\hline TOTAL & 38.072 .561
\end{tabular}

Isto corresponde a $380,72 \mathrm{cal} / \mathrm{g}$ de amostra ou $497,00 \mathrm{cal} / \mathrm{g} \mathrm{Fe} \mathrm{O}_{3}$

\section{$O$ aquecimento da pelota de 25 a $1000^{\circ} \mathrm{C}$}

Usando os dados da tabela 47 e 48 vem:

\section{Aquecimento do $\mathrm{Fe}_{2} \mathrm{O}_{3}$ :}

$$
\begin{aligned}
& \int_{298}^{950}\left(23,49+18,6 \times 10^{-3} T-3,55 \times 10^{5} T^{-2}\right) d T+\int_{950}^{1050}(36,0) d T+\int_{1050}^{1273}\left(31,7+1,76 \times 10^{-3} T\right) d T= \\
= & 33.350,22 \mathrm{cal} / \mathrm{mol}
\end{aligned}
$$

\section{Aquecimento do C:}

$$
\int_{298}^{1273}\left(4,10+1,02 \times 10^{-3} T-2,10 \times 10^{-5} T^{-2}\right) d T=4.238,97 \mathrm{cal} / \mathrm{mol}
$$

Para $1 \mathrm{~g}$ de mistura, tem-se então: 
$\left(\frac{33.350,22}{160} \times 0,801\right)+\left(\frac{4.238,97}{12} \times 0,199\right)=237,22 \mathrm{cal} / \mathrm{g}$ de carbono

Isto corresponde, a $1000^{\circ} \mathrm{C}$, a uma necessidade total de:

$237,22+380,72=617,94$ cal $/ \mathrm{g}$ mistura

O peso médio das pelotas usadas durante os ensaios era de 3,5g. Portanto:

$617,94 \mathrm{cal} / \mathrm{g} \times 3,5 \mathrm{~g}=2.162,79 \mathrm{cal}$

Sendo: Cal $\times 4,1868 \times 10^{-3}=\mathrm{kJ}$

$2.162,79 \mathrm{cal} \times 4,1868 \times 10^{-3}=9,10 \mathrm{~kJ}$ 